University of New Hampshire

University of New Hampshire Scholars' Repository

Spring 2002

\title{
Testing for the significance of induced highway travel demand in metropolitan areas
}

Lawrence Craig Barr

University of New Hampshire, Durham

Follow this and additional works at: https://scholars.unh.edu/dissertation

\section{Recommended Citation}

Barr, Lawrence Craig, "Testing for the significance of induced highway travel demand in metropolitan areas" (2002). Doctoral Dissertations. 58.

https://scholars.unh.edu/dissertation/58

This Dissertation is brought to you for free and open access by the Student Scholarship at University of New Hampshire Scholars' Repository. It has been accepted for inclusion in Doctoral Dissertations by an authorized administrator of University of New Hampshire Scholars' Repository. For more information, please contact Scholarly.Communication@unh.edu. 


\section{INFORMATION TO USERS}

This manuscript has been reproduced from the microfilm master. UMI films the text directly from the original or copy submitted. Thus, some thesis and dissertation copies are in typewriter face, while others may be from any type of computer printer.

The qualty of this reproduction is dependent upon the quality of the copy submittad. Broken or indistinct print, colored or poor quality illustrations and photographs, print bleedthrough, substandard margins, and improper alignment can adversely affect reproduction.

In the unlikely event that the author did not send UMI a complete manuscript and there are missing pages, these will be noted. Also, if unauthorized copyright material had to be removed, a note will indicate the deletion.

Oversize materials (e.g., maps, drawings, charts) are reproduced by sectioning the original, beginning at the upper left-hand comer and continuing from left to right in equal sections with small overlaps.

Pholographs included in the original manuscripl have been reproduced xerographically in this copy. Higher quality $6^{\circ} \times 9^{\circ}$ black and white photographic prints are available for any photographs or illustrations appearing in this copy for an additional charge. Contact UMI directly to order.

ProQuest Information and Leaming 300 North Zeeb Road, Ann Abor, MI 48106-1346 USA 800-521-0600

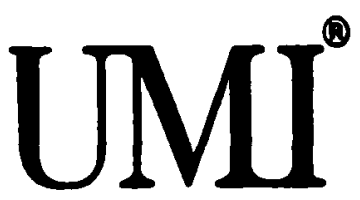




\title{
TESTING FOR THE SIGNIFICANCE OF INDUCED HIGHWAY TRAVEL DEMAND IN METROPOLITAN AREAS
}

\author{
BY \\ LAWRENCE C. BARR \\ Bachelor of Science, University of California at Davis, 1976 \\ Master of Science, The Pennsylvania State University, 1979

\section{DISSERTATION}

Submitted to the University of New Hampshire

in Partial Fulfillment of

the Requirements for the Degree of

Doctor of Philosophy

in

Engineering: Systems Design

May, 2002 
UMI Number: 3045318

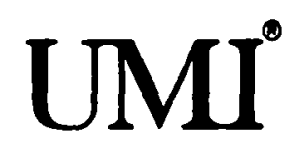

UMI Microform 3045318

Copyright 2002 by ProQuest Information and Learning Company.

All rights reserved. This microform edition is protected against unauthorized copying under Title 17, United States Code.

\section{ProQuest Information and Learning Company 300 North Zeeb Road \\ P.O. Box 1346 \\ Ann Arbor, MI 48106-1346}




\section{Ph.D. DISSERTATION}

This dissertation has been examined and approved.

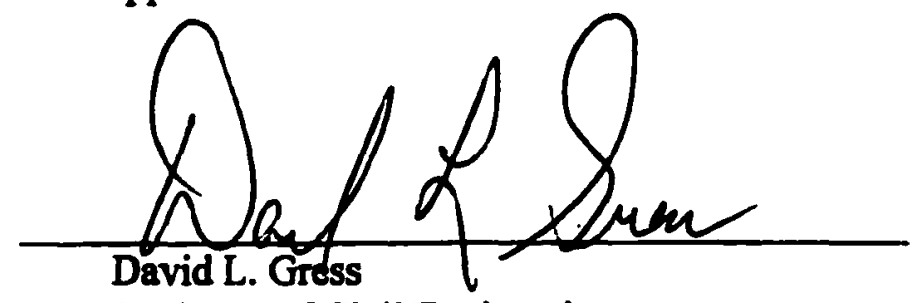

Professor of Civil Engineering

Dissertation Director
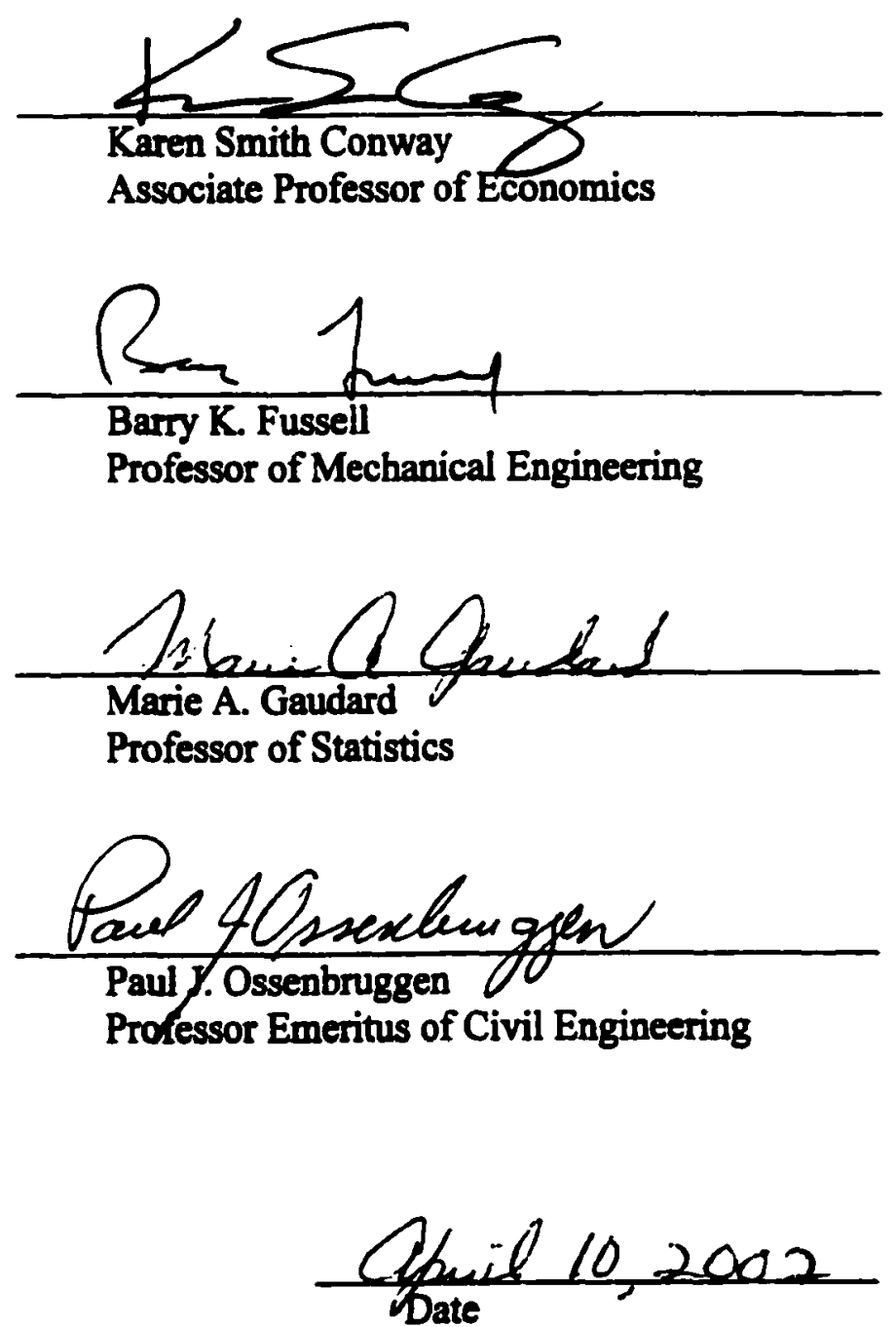


\section{DEDICATION}

To my wife, Donna, whose love and support throughout this ordeal made it all possible 


\section{ACKNOWLEDGMENTS}

This work was sponsored by a research fellowship grant from the Dwight David Eisenhower Transportation Fellowship Program of the National Highway Institute, Federal Highway Administration, U.S. Department of Transportation.

I would like to thank Michael Culp, my technical advisor at the Federal Highway Administration for his professional guidance as well as his friendship throughout this research project. Mike and his wife, Barbara, made a stranger feel very welcome in Washington, DC. I would also like to thank George Dresser of the Texas Transportation Institute and Ken Cervenka and Gustavo Baez of the North Central Texas Council of Governments for providing the Dallas-Fort Worth travel model data used in the beforeand-after case study. I also want to acknowledge Patrick DeCorla-Souza, Brian Gardner, Harry Cohen, and Bob Noland for providing valuable assistance, expert knowledge, and helpful suggestions and feedback that improved the quality of the research.

I wish to express my sincere appreciation to the members of my committee, Professors Marie Gaudard, Karen Conway, Barry Fussell, and David Gress, for their support and guidance and for investing their time and effort to help me through this most challenging and rewarding experience.

Finally, I want to express special thanks to my faculty advisor, mentor, and friend, Paul Ossenbruggen. He made my transition back into academia after a long time away an easy and enjoyable one, and I am deeply grateful for all that I learned from him. 


\section{TABLE OF CONTENTS}

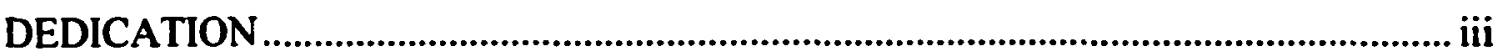

ACKNOWLEDGMENTS .............................................................................................. iv

LIST OF TABLES ...................................................................................................... vi

LIST OF FIGURES …….......................................................................................... vii

ABSTRACT

$\begin{array}{ll}\text { CHAPTER } & \text { PAGE }\end{array}$

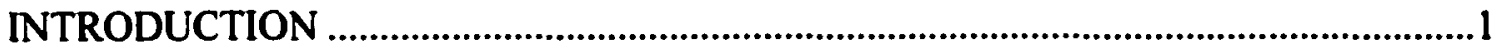

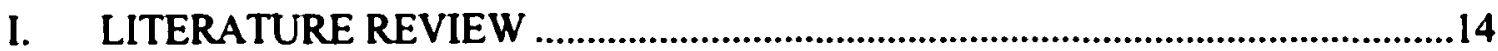

II. NATIONWIDE PERSONAL TRANSPORTATION SURVEY STUDY .................36

Research Objectives.....................................................................................................36

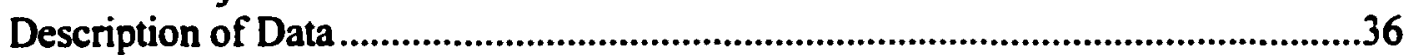

Method of Analysis.........................................................................................................49

Results.....................................................................................................................54

Summary of Major Findings ....................................................................................65

III. BEFORE-AND-AFTER CASE STUDY ANAL YSIS ............................................68

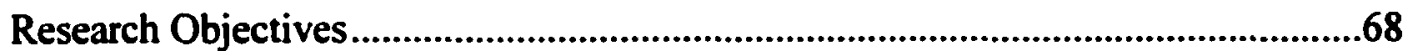

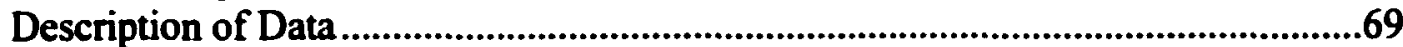

Method of Analysis......................................................................................................105

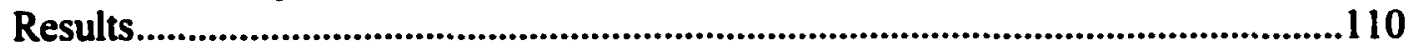

Summary of Major Findings................................................................................126

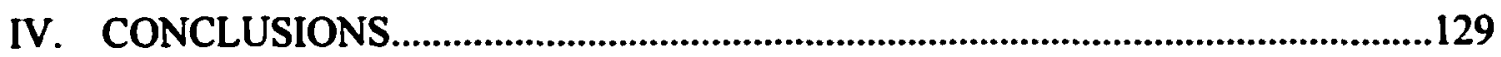

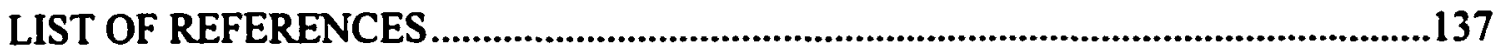

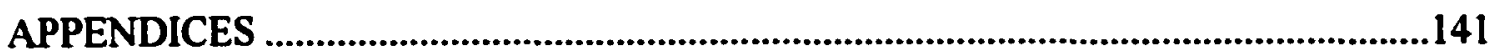




\section{LIST OF TABLES}

PAGE

TABLE 2.1 NPTS Household Variables .........................................................................38

TABLE 2.2 Household Family Income Values................................................................39

TABLE 2.3 Population Density Values.........................................................................40

TABLE 2.4 Median Household Income Values ................................................................40

TABLE 2.5 NPTS Travel Day Variables ............................................................................41

TABLE 2.6 Mean Values of NPTS Variables $(\mathrm{N}=27,409$ households) ........................49

TABLE 2.7 Regression Coefficient Estimates for All Households..................................56

TABLE 2.8 Correlation Matrix of Explanatory Variables ................................................60

TABLE 2.9 1995 NPTS Comparison of Travel Time Elasticities ...................................61

TABLE 3.1 Comparison of Dallas-Fort Worth Travel Behavior

Before vs. After Highway Capacity Additions ...........................................115

TABLE 3.2 Comparison of Dallas-Fort Worth Travel Behavior Inside vs. Outside the Study Area.........................................................116

TABLE 3.3 Regression Analysis of Differences in Travel Behavior Between 1984 and 1995 in Dallas-Fort Worth ........................................125 


\section{LIST OF FIGURES}

PAGE

FIGURE 2.1 Distribution of NPTS Data by Urbanized Area ........................................45

FIGURE 2.2 Public Transportation Availability.........................................................45

FIGURE 2.3 Distribution of Households by Metropolitan Area Population .................46

FIGURE 2.4 Census Tract Population Density Distribution ........................................46

FIGURE 2.5 Household Family Life Cycle Characteristics .............................................47

FIGURE 2.6 Distribution of NPTS Trips by Travel Day................................................48

FIGURE 2.7 Census Tract Population Density of Households Located

in Metropolitan Areas Greater Than One Million ....................................48

FIGURE 3.1 Comparison of 1984 and 1995 DFW Travel Survey Areas......................72

FIGURE 3.2 1984 DFW TAP Zone Area Type ...............................................................74

FIGURE 3.3 1995 DFW TAP Zone Area Type .............................................................75

FIGURE 3.4 1984 DFW TAP Zone Population Distribution .........................................77

FIGURE 3.5 1995 DFW TAP Zone Population Distribution ......................................78

FIGURE 3.6 1984 DFW TAP Zone Population Density Distribution............................79

FIGURE 3.7 1995 DFW TAP Zone Population Density Distribution............................80

FIGURE 3.8 1984 DFW TAP Zone Employment Characteristics .................................81

FIGURE 3.9 1995 DFW TAP Zone Employment Characteristics ................................82

FIGURE 3.10 1984 DFW TAP Zone Employment Density Characteristics...................83

FIGURE 3.11 1995 DFW TAP Zone Employment Density Characteristics...................84

FIGURE 3.12 1984 DFW TAP Zone Household Income Distribution ...........................85

FIGURE 3.13 1995 DFW TAP Zone Household Income Distribution ...........................86

FIGURE 3.141984 DFW Total Trips Produced by Zone ................................................88

FIGURE 3.151995 DFW Total Trips Produced by Zone ……….........................................89

FIGURE 3.16 1984 DFW Total Trips Attracted by Zone...................................................90

FIGURE 3.17 1995 DFW Total Trips Attracted by Zone................................................91

FIGURE 3.18 1984 DFW TAP Zone Trip Productions per Household ...........................92

FIGURE 3.191995 DFW TAP Zone Trip Productions per Household ...........................93

FIGURE 3.20 1984 DFW Total Weekday VMT by Zone .................................................94

FIGURE 3.21 1995 DFW Total Weekday VMT by Zone ...............................................95

FIGURE 3.22 1984 and 1995 Home-Based Work Trips Produced by Zone ..................96

FIGURE 3.23 1984 and 1995 Home-Based Non-Work Trips Produced by Zone..........97

FIGURE $3.24 \quad 1984$ and 1995 Non-Home-Based Trips Produced by Zone.....................98

FIGURE $3.25 \quad 1984$ and 1995 Other Trips Produced by Zone........................................99

FIGURE 3.26 1984 and 1995 Home-Based Work Trips Attracted by Zone ................100

FIGURE 3.27 1984 and 1995 Home-Based Non-Work Trips Attracted by Zone .......101

FIGURE $3.28 \quad 1984$ and 1995 Non-Home-Based Trips Attracted by Zone ..................102

FIGURE 3.29 1984 and 1995 Other Trips Attracted by Zone ........................................103 


\section{LIST OF FIGURES (continued)}

PAGE

FIGURE 3.30 Comparison of DFW TAP Zones Inside vs. Outside the Study Area.

FIGURE 3.31 Analysis of Covariance Sample Output 112

FIGURE 3.32 Schematic of Trip Productions per Household Comparisons 117

FIGURE 3.33 Schematic of Total Trip Production Comparisons. 117

FIGURE 3.34 Schematic of Vehicle-Miles of Travel Comparisons...............................118

FIGURE 3.35 Schematic of Total Trip Attraction Comparisons. 


\title{
ABSTRACT \\ TESTING FOR THE SIGNIFICANCE OF INDUCED HIGHWAY TRAVEL DEMAND IN METROPOLITAN AREAS
}

by

\author{
Lawrence C. Barr
}

University of New Hampshire, May, 2002

The theory of induced growth in vehicle travel hypothesizes that highway improvements which add capacity to a specific corridor or regional transportation network will attract increased levels of vehicle traffic. This relationship of highway capacity to travel demand is an important consideration when evaluating how effective highway expansion alternatives will be in solving transportation problems. Two different but complementary empirical studies were conducted to quantify the effect of highway system improvements on travel behavior. In the first study, I apply ordinary least squares regression models to estimate travel demand elasticities with respect to travel time using travel survey data from the 1995 Nationwide Personal Transportation Survey. This is one of a very few research studies to use disaggregate household-level travel data. Travel time elasticities of -0.3 to -0.5 were found, after accounting for the effects of household size, income, population density, and household employment. These results suggest that capacity additions that reduce travel time by 10 percent will increase vehicle-miles of travel by 3 to 5 percent. My second study investigates geographic differences in travel behavior before and after highway capacity was expanded in the Dallas-Fort Worth metropolitan area. Calibrated travel model data from 1984 and 1995 were used. This 
analysis is unique in that it applies three statistical research designs to quantify the effect of capacity expansion on induced demand for travel using a before-and-after case study approach. The three techniques, namely analysis of covariance, difference-indifferences, and OLS regression on travel changes from 1984 to 1995, produce similar results. After controlling for changes in number of households, income, and population density, total weekday vehicle-miles of travel and daily trip productions were found to increase by approximately 20 percent and 7 percent, respectively, in survey zones that had undergone significant capacity additions versus zones that remained largely unchanged over the 11 -year period. Overall, the results of this research provide evidence that highway capacity improvements generate additional demand for travel. These induced demand effects should not be ignored by transportation planners and policy makers when evaluating highway system investment alternatives. 


\section{INTRODUCTION}

The addition of highway capacity as a transportation improvement strategy has become a controversial issue of interest not only to transportation professionals but to much of the traveling public as well. In particular, a great deal of attention continues to be focused on the traffic-inducing potential of highway expansion. Transportation analysts, environmental groups, and the popular press have all advanced the viewpoint that the level of induced travel demand is so high that adding highway capacity to urban areas will do little to relieve congestion, and any new capacity will be filled as soon as it is built. The issue of induced travel has gained prominence because of its importance for air quality assessment, congestion management, and regional growth planning and management.

The relationship of highway capacity to travel behavior is an important consideration when evaluating how effective highway expansion alternatives will be in solving transportation problems. By reducing the negative consequences of travel in urban areas, such as traffic delays due to congestion, expansion of highway capacity can affect individual decisions about when, where, and how to travel. The primary impact of adding highway capacity is to reduce travel times, and therefore the cost of travel, in the corridor in which the improvement is located.

The theory of induced growth in vehicle travel hypothesizes that highway improvements which add capacity to a specific corridor or a regional transportation network will attract increased levels of vehicle traffic. The underlying principle of 
induced travel is based on the fundamental economic theory of supply and demand (Noland, 1999; Lee et al., 1997). Any increase in highway capacity (supply) in a congested urban transportation network causes a reduction in the travel time component of the generalized cost of travel. This reduction in the cost of travel will result in an increased demand for travel; this increased demand represents the induced travel effect. Note, however, that this effect only considers supply-side changes and assumes no change in underlying demand. In reality, many other confounding and exogenous variables also influence the growing demand for travel. Among these are demographic and socioeconomic factors such as population growth, regional economic growth, employment changes (e.g., increased numbers of women in the workplace), household size and income, and increased automobile ownership. Empirically, it is difficult to isolate these concurrent supply-side and demand-side effects. As Noland points out, this is what causes considerable uncertainty about the magnitude of the induced travel effect, as distinct from the growth effect (Noland, 1999). Furthermore, the growth effect could be caused by changes in highway supply as new land use developments spring up around the newly available capacity in outlying areas of a metropolitan region. Research conducted by Kiefer and Mehndiratta (1998) showed that many of these underlying socioeconomic and demographic changes have contributed significantly to the traffic growth observed over the last few decades. They also argue, however, that contributing factors such as women entering the labor force, reductions in household sizes, and increasing automobile ownership have either stabilized or will soon reach a natural maximum.

It is important to consider the existing levels of service on highway facilities 
when studying the effects of capacity additions. Induced travel is a function of latent or suppressed demand, which in turn is a function of existing congestion levels and travel delays. Roadway improvements that reduce traffic congestion tend to increase total vehicle travel due to the latent demand for travel being released. In other words, travelers who suppress their need or desire to make a trip because severe congestion makes travel so unpleasant or costly (in terms of travel time) may return to the highway when capacity is added and congestion is relieved. Thus, latent demand, which is primarily related to discretionary, non-work trips, is released as people respond to the travel time savings afforded by capacity additions by making trips that were previously foregone.

Conversely, induced travel is not an issue to consider on non-congested highways that present no travel time impediments.

The Transportation Research Board (TRB) documented the results of a study which focused on the effects of investment in highway capacity on air quality and energy use in metropolitan areas (TRB, 1995). The report discussed the following potential effects of highway capacity additions on travel behavior:

- Route Changes: Construction of a new highway or the addition of capacity to an existing highway may increase travel speeds, allowing some automobile users to reduce their travel times by shifting their route to the new or improved facility. Changing routes can result in either shorter or longer distances being traveled.

- Departure Time Changes: Travelers may alter the time of day during which a trip is made in response to congestion levels. When the severity and duration of peak-period congestion are reduced by adding capacity to a 
facility, some of the trips that were previously shifted in time to avoid congestion in peak periods may be shifted back to the peak period.

- Mode Shifts: The possible reduction in travel time due to a capacity improvement may attract auto users who had previously used another mode, such as transit or ridesharing, because the travel time advantage makes the private automobile a more appealing option than other modes of travel. The importance of mode shifts as a source of additional highway use depends on the presence, type, and cost of alternative modes in the corridor where capacity additions are made.

- Destination Changes: Capacity additions can increase the relative attractiveness of some trip destinations by reducing travel times to those destinations. If capacity additions reduce travel times, the time sayed may be spent making longer trips to a farther destination. This effect is more important for discretionary travel such as shopping and recreation than it is for work-related travel since individuals have more flexibility in choosing destinations for discretionary trips. But it must also be recognized that capacity improvements may also influence where individuals choose to live. The substitution of one trip destination for another can either increase or decrease overall highway system use, depending on which destination is closer.

- Additional Trips: New vehicle trips previously foregone because of the difficulty or time required for travel represent latent demand that may be stimulated by the improved level of service created by highway 
improvements. The number of home-to-work trips is unlikely to change significantly. However, capacity additions could influence travel associated with more discretionary activities for which the travel cost might be a substantial portion of the total cost of the activity. In addition, improved travel times may reduce driver incentives to chain trips.

- New Development/Land Use Changes: Highway capacity additions that decrease travel times can improve access to outlying areas of a metropolitan region and make these areas more attractive for future new development. People willing to travel greater distances may choose residential, employment, shopping, or other activity locations that previously had required too much travel time to reach. This may generate new development and longer trips.

The time periods over which these changes in travel behavior occur can be expected to vary. Route changes and changes in travel departure times can be expected to occur soon after a new or expanded highway opens. Mode shifts, changes in trip destinations, and new trips may occur more gradually because they involve more significant changes in travelers' activity patterns. Finally, long-run effects are related to new development and how land use patterns adjust to the improved accessibility created by the newly available capacity and to the resulting spatial allocation of activities.

To understand and quantify the relationship between induced travel and new highway capacity, the term "induced travel" must be clearly defined. In this study, induced travel is defined as any increase in highway system use caused by a highway capacity addition or other transportation system change which results in reduced travel times and/or costs. The primary travel demand variable used to measure the increases in 
highway system use is vehicle-miles of travel (VMT). VMT is a convenient and accurate summary measure that reduces the highly dimensional nature of travel demand (number of trips, the spatial distribution of these trips, the modes and routes chosen to execute these trips) to a single variable. VMT is also a useful indicator of the amount of energy consumed in performing these complex travel patterns since automobile energy use is highly correlated with the total number of vehicle-miles traveled (Miller and Ibrahim, 1998).

Thus, induced travel includes new and longer motor vehicle trips that are made because the highway capacity addition has reduced the cost (primarily the time cost) of travel. Induced travel does not include shifts in the time of day a trip is made because such changes generally do not result in a net increase in highway system use. The primary benefit of a capacity addition that eases congestion and reduces travel times during the peak period is the ability to travel at a preferred time. However, shifts to a preferred peak-period departure time that free up capacity at other times of the day may result in new trips being made at those times that are now less congested. Additional trips as well as mode shifts from transit to private automobile, for example, clearly increase VMT and contribute to induced travel. Route diversion to take advantage of an improved facility can result in either shorter or longer distances being traveled; induced travel includes route shifts that increase net VMT. Finally, if travel speeds are increased, some additional recreational trips or trips to more distant shopping centers are likely to be taken and would certainly represent induced travel. On the other hand, induced travel does not include increases in traffic that occur for reasons not related to highway system supply such as population growth and increased automobile ownership. 
The ongoing debate concerning the ability of major highway capacity additions to reduce traffic congestion and improve air quality in urban areas remains a controversial issue. Supporters of highway expansion argue that building new roads or widening existing roadways will increase average vehicle speeds by eliminating or reducing congestion, thereby promoting greater fuel efficiency, reducing emissions, and improving air quality.

Environmental groups, on the other hand, argue that adding highway capacity in a congested system will increase vehicle use by making automobile travel more desirable and convenient. Specifically, travel behavior in response to improved levels of service include making more trips during traditional peak periods, shifting from transit and higher vehicle occupancies to single occupancy automobile trips, making more individual trips rather than combining trips (trip chaining), and making longer trips or trips that might otherwise have been foregone. Thus, opponents of highway expansion suggest that adding capacity will adversely affect air quality by inducing new demand until the new capacity fills up, ultimately producing levels of congestion comparable to previous conditions but at higher overall traffic volumes (TRB, 1995). In the long run, opponents argue, highway improvements lead to further development of auto-oriented exurban suburbs rather than urban infill by making travel to outlying areas easier and faster. Therefore, overall levels of regional economic growth will increase, making it even more difficult for the region to meet environmental standards.

One of the problems with studying the effects of added capacity is that many of the variables tend to be correlated with each other. For example, income is related to residential choices, and urban population density may be closely related to car ownership 
and household size. In addition, Kitamura (1991) points out that data from 23 cities present strong evidence that more facilities contribute to longer trip distances but that there is a relationship between trip length and population. One problem is that freeway expansion often takes place in areas of urban expansion where the population is increasing, and it is difficult to separate the pure facility effect on induced travel from the growth effect. Thus, quantifying the impact of induced travel demand is complicated by the fact that it is difficult to separate changes in highway use due to socioeconomic and demographic factors such as population growth, rising personal income, increased automobile ownership, regional economic growth, and family life cycle changes, from those caused purely by additions to highway supply.

It is clear that travel in metropolitan areas is influenced by many factors that change over time. Direct observation of the effects of change in individual causal variables becomes extremely difficult, particularly in a dynamic situation where transportation capacity additions and changes in growth and land use patterns are occurring simultaneously. Dunphy (1997) clearly articulates the two conflicting views regarding the relationship between transportation improvements and residential land use development. One view is that plans for new developments are influenced by the plans for highway improvements (i.e., new roads create new residential developments). An alternative opinion is that capacity additions are built in response to public sector expectations concerning anticipated growth in the corridor. Establishing the precise causal relationship between highway capacity and urban travel is a difficult task and creates a serious methodological problem. The issue of causality cannot be completely resolved by a statistical analysis. So, the question of whether highway capacity 
expansion induces additional VMT or whether VMT growth causes additional highway capacity to be built remains unanswered in this study.

The purpose of this research project is to contribute to the understanding of the induced travel phenomenon by providing empirical evidence about the relationship between highway supply and vehicle travel. The approach taken is to design multivariable statistical tests using household travel data to evaluate and quantify the impact that highway improvements have had on travel behavior. It was stated previously that determining the effect of highway capacity additions on induced travel is complicated by the fact that it is difficult to separate changes in highway use caused by socioeconomic and demographic factors from those caused by an increase in highway supply. Furthermore, it is difficult to distinguish new or induced travel from travel that is diverted from other portions of the transportation network or shifted from other times during the day. These adjustments must be taken into account in an overall assessment of the impact of highway capacity additions. An attempt is made to address these issues in this study by applying mathematical models using travel survey and calibrated travel model data that control for changes in travel demand caused by non-system supply factors. Because highway facilities function together as a system, new capacity on any specific facility affects the entire system. So it is important to use regional system data rather than individual facility data to be able to draw meaningful conclusions about the effects of added capacity on travel demand. A region-wide or cross-sectional analysis is also particularly useful to gain insights into longer term equilibrium issues; that is, crosssectional data represent a general long-term equilibrium condition supported by the assumption that people have made all of their travel and land use adjustments in response 
to the levels of service presented by all available transportation alternatives. (Brand, 1991).

Two separate but complementary studies were accomplished in this research project. The first study involved developing travel time elasticities (i.e., the percent change in vehicle-miles of travel proportional to the percent change in travel time) using cross-sectional household travel data from the 1995 Nationwide Personal Transportation Survey (NPTS). It enhances our understanding of induced travel demand because it is one of only a very few analyses to have used disaggregate, household-level travel data. Most previous research studies have investigated the effects of highway capacity additions on induced demand using data aggregated to the county, metropolitan, or state level. Disaggregate data are advantageous since they reflect the travel patterns of individuals, not the average travel patterns of counties, metropolitan areas, or states. Several regression models were estimated to determine demand elasticities with respect to travel time after controlling for the effects of various explanatory variables, including population density, household size, household income, and number of workers per household. The time elasticity of travel demand measures the response of usage of a highway network to changes in its capacity (which subsequently reduce travel time) resulting from investments that extend the network or widen its existing links. A similar study was done by Gorina and Cohen (1998) using data from the 1990 NPTS. My study expands on their work in three important ways. First of all, my analysis is based on more recent data from the 1995 NPTS. At present, data from the 2000 NPTS is not publicly available, so the 1995 NPTS remains the most recent source of nationwide household travel survey data. Second, I include additional explanatory variables in many of the 
models to control for the effects of household employment (number of workers in the household) and the economic status of the census tract in which the household is located. The number of household members employed, in particular, turned out to have significant explanatory power. And finally, I validated the analytical approach of using daily travel speed to determine the impact on annual demand by performing separate analyses based on the average household travel speeds for each day of the week. This will be discussed in detail when the NPTS study results are presented in Chapter II.

The second study accomplished during this project involved a case study analysis in a rapidly growing metropolitan area before and after completion of a substantial expansion of area-wide highway capacity. The analysis is based on the previous work of Michael Smith and George Schoener of the Federal Highway Administration who examined the impact of the construction of Interstate 95 on induced trip making and travel in Providence, Rhode Island (Smith and Schoener, 1978). In their research, the authors were unable to measure the amount of change in travel demand that had occurred in response to the addition of the new interstate highway (though they were able to conclude that a significant increase in VMT had taken place). They state in their concluding remarks that "future research should address the question of how many extra VMT are produced by new highways.... Such a quantification would provide a major breakthrough in the field of highway planning." (Smith and Schoener, 1978, p. 157). Therefore, the major objective of this study was to apply rigorous statistical methods to quantify the differences in travel behavior that occur in response to increases in highway capacity. This study advances the research and adds to the evidence of induced travel since before-and-after case studies of its kind have rarely been found in the literature. 
The analysis employs validated travel model data from the Dallas-Fort Worth, Texas metropolitan area for the years 1984 and 1995 . The focus is not on the expansion of capacity in a single corridor; rather, the aggregation of highway improvements in the entire metropolitan region are considered.

Three analytical designs are employed in the before-and-after study to quantify the amount of change in travel from 1984 to 1995 caused by additions to highway supply. The first is analysis of covariance, a technique that combines elements of analysis of variance (ANOVA) with linear regression to compare travel behavior differences between two categories or groups (e.g., before and after highway expansion) after accounting for the influences of confounding factors such as income and population. A similar technique called difference-in-differences is also used to compare travel demand in a treatment group and a control group before and after highway capacity expansion takes place. Finally, a linear regression model is estimated to determine the effect of additional highway capacity on the observed differences in travel demand between 1984 and 1995. No other research study has quantified changes in travel demand induced by highway improvements, after adjusting for demographic and socioeconomic differences in the models, in a before-and-after case study. The three analytical techniques along with a detailed description of the data used in the study are discussed later in this dissertation. The analyses for both studies are performed using JMP, a statistical analysis software package developed by SAS Institute Inc.

The remainder of the dissertation is organized as follows: Chapter I presents a review of the literature and discusses the results of previous research studies in the area of induced highway travel demand; Chapter II provides the results of the Nationwide 
Personal Transportation Survey analysis, including a detailed description of the data and the analytical methodology used in the study; Chapter III presents the data characteristics, analytical approach, and results of the before-and-after case study analysis; finally, some overall conclusions from the research effort are summarized, and some concluding remarks are made concerning the importance of the induced travel demand issue to the transportation planning process in Chapter IV. Model results for all cases that were analyzed are included as Appendices. 


\section{CHAPTER I}

\section{LITERATURE REVIEW}

The travel forecasting literature contains numerous studies in which the effects of increased highway capacity on travel behavior are investigated. As part of TRB Special Report 245, Expanding Metropolitan Highways: Implications for Air Quality and Energy Use, Cohen (1995) reviewed previous research on the traffic inducing impacts of highway capacity expansions. These studies fall into three general categories: (1) Studies of specific facility improvements; (2) studies that examine the relationship between highway capacity and traffic on an area-wide basis; and (3) studies of the travel behavior of individuals or households that can be used to estimate changes in highway system use. The results of several key research studies in all three categories on the traffic inducing impacts of highway improvements are summarized and discussed in this section.

\section{Facility-Specific Studies}

Facility-specific studies typically involve measurements of traffic levels before and after a roadway expansion project, together with estimates of how traffic would have grown in the absence of the capacity addition. Holder and Stover (1972) studied the traffic generation impacts of eight urban highway projects in Texas, and they identified the following six components of traffic on new highways:

- Traffic diverted from other roads in the network, 
- Traffic shifted from other modes of transportation,

- Traffic growth due to population increases,

- Traffic developed as a result of land use changes,

- Changes in travel behavior resulting from household socioeconomic changes, and

- Induced traffic from new trips made because of added convenience.

For each of the eight highway projects, the authors compared corridor traffic growth after project opening with either regional trends or corridor growth prior to project completion, referring to the difference as "apparent induced traffic." For six of the highway projects that were studied, estimates of apparent induced traffic ranged from 5 to 21 percent. For the other two projects, no evidence of induced traffic was found, a finding the authors attributed to the availability of other routes offering comparable travel times in the project corridors. On the basis of their analysis, Holder and Stover concluded that induced traffic can represent a significant portion of the traffic on a new facility, and, furthermore, that most induced traffic occurs during off-peak hours. In addition, for a substantial amount of induced traffic to occur on a new facility, they concluded that the off-peak travel time must be reduced significantly or that the existing facilities must be congested. While the study conducted by Holder and Stover was an early breakthrough in the identification and classification of the sources of additional traffic on a new or capacity-improved highway, it was severely limited by being only descriptive in nature. Their results were based on observed differences in traffic volume without controlling for any independent variables that contribute to traffic growth such as population growth, auto ownership per capita, employment changes, income growth, and gasoline prices. 
Smith and Schoener (1978) examined the impact of the construction of Interstate 95 on induced trip making and travel in Providence, Rhode Island. Origin-destination travel surveys for the years 1961 (before construction of I-95) and 1971 (after I-95) were used. For each year, the O-D survey data were divided into two groups - samples representing households inside the I-95 corridor and samples representing households outside the corridor. The group outside the corridor, largely unaffected by the new highway, was used as a control group. Thus, if statistically significant differences between the two groups were observed, it could be concluded that the new highway did change travel behavior. For the resulting four groups of households, cross-classification matrices were developed using household size and auto ownership as independent variables; the dependent variables were auto driver trips per household, vehiclekilometers of travel (VKMT) per household, and vehicle-hours of travel (VHT) per household. The authors concluded from their comparison of the resulting matrices that the highway did not increase trips or VHT, but it did increase VKMT.

The study by Smith and Schoener had the advantage of examining the induced travel effects of a major new addition to the urban transportation network. Changes in travel behavior would presumably be more pronounced for such a major capacity expansion than for smaller lane-mile additions on segments of existing highways. Their study, however, was subject to limitations. First, the sample size for the period after construction of $1-95(n=855)$ is extremely small compared to the before period $(n=$ $11,467)$. This may produce the tendency of failing to reject null hypotheses of no change in travel behavior. Second, the method used to test the statistical significance of a change in travel caused by the new highway involved examining the number of significant 
pairwise t-statistics in the before-and-after cross-classification matrices. Thus, while the authors were able to conclude that the new highway resulted in more VKMT, they were unable to determine the amount of change in VKMT. Kitamura (1991) recommended that an analysis of variance should have been used.

Ruiter et al. $(1979,1980)$ used transportation forecasting models to estimate the effects on VMT of two highway projects in California: A new 8-km (5-mile) 8-lane freeway and a 19-km (12-mile) section of freeway that was widened from four lanes to six or eight lanes (depending on the location). Compared with most conventional travel forecasting models, trip generation rates in the Ruiter model were sensitive to travel times. However, land use patterns were fixed, so that changes in VMT associated with longer-term changes in land use patterns were not incorporated in the model. The study found that the new freeway construction project, which provided substantial travel time savings to users in both the peak and off-peak periods, resulted in an increase in the study area VMT. The elasticity of VMT to the capacity increase (i.e., the percent increase in VMT divided by the percent increase in capacity) was 0.4 . The freeway widening project, which provided substantial travel time savings in the peak period only, produced a much different result. In this case, the increase in capacity resulted in a slight decrease in VMT. The primary effect was to shift VMT from off-peak to peak periods, and added VMT from new trips was offset by reduced circuity of travel for existing trips.

Hansen et al. (1993) investigated the traffic effects of adding highway capacity using panel data on changes in travel volume from 1970 to 1990 for 18 major highway segments on which capacity was expanded in California metropolitan areas. For individual highway segments, the elasticities of traffic volume (measured as VMT) with 
respect to highway capacity (measured in lane-miles) were found to increase over time. Estimated elasticities of 0.2 to 0.3 were found during the first four years after the capacity expansion; elasticities increased to 0.3 to 0.4 after 10 years and to between 0.4 and 0.6 after 16 years. Thus, the analysis showed that a capacity expansion did increase traffic on the improved facility and that the effect occurred over an extended period and grew over time. However, the growth in traffic remained less than the capacity added, thereby improving the level of service, throughout the analysis period of nearly 20 years (i.e., a 10 percent increase in lane-miles resulted in a 3 to 4 percent increase in VMT in 10 years and in a 4 to 6 percent VMT increase after 16 years). The authors acknowledged an important limitation of facility-specific studies, namely that only traffic levels on the improved highway segments were analyzed. That is, the VMT estimates refer only to the improved segment itself and do not take into account how other segments are affected. They state that any additional traffic on the improved segment must use other links on the roadway network as well. They conclude that diversions from these links may account for a significant share of the additional traffic on the improved link, particularly if the traffic effect on the improved link is substantial. In my research, I addressed this limitation by doing region-wide analyses. In one study, I used a cross-sectional database of household travel activity covering the entire United States, and in the second study travel model data for the entire Dallas-Fort Worth metropolitan area are analyzed. My analyses do not focus on specific links or highway segments within a transportation network where capacity has been increased.

The Standing Advisory Committee on Trunk Road Assessment (SACTRA) reported the results of a study they conducted for the Department of Transport of the 
United Kingdom to review the evidence for the existence of induced traffic on new or improved roads (SACTRA, 1994). The assessment is based on a review of theory, empirical studies, and transportation models. The studies focused on a review of numerous case studies of major European highway improvement projects as well as on the Department of Transport's own monitoring studies of before-and-after traffic flows for urban and rural trunk road improvements. The results showed that traffic growth on newly expanded road segments exceeded traffic reductions on unimproved segments. This finding provides evidence of induced traffic, that is, of growth in traffic beyond route shifts. However, SACTRA indicated that the studies are not helpful in identifying the relative importance of the components of induced traffic. For example, it is not possible to distinguish among shifts in the time of travel toward the peak period, new travel generated by general economic growth, and new travel attributable to the road improvement itself.

SACTRA also reviewed the evidence for induced traffic using transportation models that allow demand to vary. Predicted estimates of induced traffic from major highway capacity additions in congested urban areas were found to be small when viewed at the network level; the effects were more significant in the corridors directly affected by the road improvements. SACTRA concluded that induced traffic is likely to be greatest when the network is operating close to capacity, when the elasticity of demand with respect to travel cost is high, and when a highway capacity addition causes large changes in travel costs. They also noted that travelers' responses to changes in travel time and cost are likely to be greater in the long run than in the short run (SACTRA, 1994). 
Kroes et al. (1996) presented the results of a before-and-after study conducted in the Netherlands to establish the short-term effects of opening the Zeeburger Tunnel to remove a severe bottleneck in a highly congested network around Amsterdam. An important focus in the study was on measuring changes in time of travel (peak vs. offpeak), route choice, mode choice, destination choice, and trip frequency. In addition, the researchers were interested in determining the extent to which the new road would induce travel, i.e., lead to trips and/or traffic which would not have happened at all if there had been no investment in the road project. Households in an area likely to be affected by the new roadway were surveyed four months before and two months after the opening of the new facility. The authors reported the following results:

- $29 \%$ of auto drivers reported a significant change in their departure times, resulting in a $16 \%$ increase in trips made during the morning peak period (i.e., a return to the preferred time of travel);

- $25 \%$ of drivers changed their route, resulting in changes away from the old bottleneck to the new facility as well as in changes from other routes back to the old bottleneck (i.e., a return to the preferred route);

- Only $1 \%$ to $3 \%$ changed their mode of travel; and

- On a 24-hour basis, the before-and-after study gave no evidence of significant induced trips; parallel studies based on traffic counts showed a net traffic increase of approximately $3 \%$ in the corridor.

On the basis of this evidence, the authors concluded that there was little or no change in mode choice, nor was there significant emergence of new induced trips; however, large shifts in time of travel and route choice were reported, emphasizing the importance of 
changes in the timing and routes of existing trips when a bottleneck is removed to relieve congestion. The authors are careful to note that these are short-term effects that were observed only two months after the new roadway was opened.

\section{Area-wide Studies}

The facility-specific studies discussed in the previous section suffer from the limitation that the demand for travel is evaluated only on the improved highway segment and ignore the effects of the improvement on other adjoining segments of the roadway network. Several researchers have attempted to overcome this shortcoming of the facility-specific studies by investigating the relationship between highway capacity and traffic on an area-wide basis. They have used data for entire metropolitan areas (or large districts within them) to obtain models that predict VMT within these areas as a significant function of transportation system supply. Since they examine large areas rather than individual highway segments or corridors, area-wide studies capture the effects of route diversion and destination shifts better than do facility-specific studies.

Ruiter et al. (1979) summarized the results of several area-wide studies in which estimated elasticities of VMT with respect to various measures of transportation system supply were determined. For most of the transportation supply measures, the elasticities are small, ranging from -0.09 using vehicle miles of transit services as the supply measure to +0.15 using total lane-miles of highway as the supply measure. These results indicate that small changes in area-wide VMT can be expected as the transportation supply measures change. Exceptions to this conclusion were found in two studies which used average highway speed as the supply measure, with estimated elasticities of 
0.58 (A. M. Voorhees \& Associates, Inc., 1971) and 1.76 (Zahavi, 1972) reported.

In addition to the facility-specific study discussed previously, Hansen et al. (1993) and Hansen and Huang (1997) conducted a region-wide analysis in which they compiled data on VMT, lane-miles, population, population density, personal income, and gasoline prices for every urban county in the state of California from 1973 to 1990 . A panel of pooled time series and cross-sectional data was used to estimate relationships between the supply of state highways, measured in lane-miles, and the quantity of traffic, measured in VMT. In one analysis, the authors used the county-level panel data directly. In a second analysis, the county-level data were aggregated to the metropolitan level (e.g., observations from 10 counties in the San Francisco-Oakland-San Jose metropolitan area combined into one observation). Elasticities of VMT with respect to lane-miles were found to be 0.6 to 0.7 (implying that a 10 percent increase in lane-miles would result in a 6 to 7 percent increase in VMT) at the county level and 0.9 at the metropolitan level. Furthermore, the authors concluded that the full impact of region-wide VMT materializes within five years of the change in road supply.

The regression equations developed by Hansen et al. show that population growth, with an elasticity in the range of 0.7 to 0.8 , is a very important contributor to the observed growth in VMT. Rising personal income and declining gasoline prices were also found to be significant factors affecting VMT. They concluded, however, that even when all these factors are accounted for, there has been a sharp increase in the tendency towards vehicle travel over the 18-year study period.

The authors acknowledged an important data limitation in conducting the areawide analysis: whereas VMT data for state highways were available over a sufficient 
period to include significant temporal variation in lane-miles, data for total VMT (including local roads) were available for only five years. Consequently, the primary focus of their research was to determine the impact of changes in state highway lane mileage on state highway VMT. However, expansion of state highways may also have impacts on traffic levels on county highways, local streets, and other non-state arteries. If, for example, state highway expansion diverted traffic from local streets to state highways, the impact of the expansion on total VMT would be less than the impact on state highway VMT. Thus, to account for the possibility that the effect of increases in lane-miles on state highways was simply to divert traffic from non-state roads, the authors conducted some limited analyses using total VMT data. They found no conclusive evidence to suggest that increases in state highway lane-miles affected traffic on other roads, so they tentatively concluded that the traffic increases observed on state highways represented new traffic and not diverted traffic.

Finally, the authors discussed the problem of direction of causality in relating highway capacity increases and VMT. They noted that their analysis "assumes that road supply is the cause and traffic the effect, whereas in fact, traffic levels affect road supply as well" (Hansen et al., 1993). This raises the familiar issue of whether VMT growth is a result of adding road capacity or that road capacity was added in response to or in anticipation of traffic growth which would have occurred anyway. The authors believe that their use of panel data sets attenuates potential distortion arising from the problem of mutual causality. They acknowledge that the causality is bi-directional, but they do not believe that it substantially affects their results.

Interestingly, the results of the facility-specific and area-wide studies conducted 
by Hansen et al. $(1993,1997)$ suggest that the impact of road supply on traffic becomes stronger as the level of aggregation increases. At the individual highway segment level, elasticities of VMT with respect to lane-miles in the 0.3 to 0.4 range were found; regionwide studies indicated elasticities of 0.6 to 0.7 at the county level and 0.9 at the metropolitan level. The authors note that "this pattern implies that much of the traffic induced by a particular capacity expansion project occurs away from the expanded segment." In order to enjoy the improved level of service benefits on the expanded highway, drivers will use other links in the road network to access it. Therefore, while the level of service improves on the expanded link, induced traffic on other links leads to marginal increases in congestion elsewhere in the system.

Noland (1999) used panel data from all 50 U.S. states between the years 1984 and 1996 to estimate relationships between lane mileage and VMT. His analytical approach is similar to the methodology of Hansen and Huang (1997), who used a regression analysis of Califormia data to statistically estimate the impact of new lane-miles on VMT. To isolate the effect of road supply (i.e., lane-miles) on VMT and control for the influences of other factors that drive VMT growth, Noland includes state population, per capita income by state, and the cost per energy unit (million BTUs) of gasoline as independent variables in his models. Separate models are estimated using total VMT and lane-miles for all road types and also by disaggregating the data by individual road type (interstates, arterials, and collectors) and by urban and rural classifications. Furthermore, lagged models are estimated separately where two-year and five-year lagged values (i.e., two years and five years prior to time $t$ ) of lane-miles, in addition to the no-lag case, are included as independent variables. This lag structure reflects the expectation that the 
impact of adding lane-miles on VMT occurs gradually as individuals and households adjust their travel behavior in response to added highway capacity.

The different statistical approaches used by Noland gave a range of values for estimates of the elasticity of VMT with respect to lane-miles. Using the aggregate data for all types of roads, elasticities of 0.2 to 0.3 were found, suggesting that a 10 percent increase in lane-miles leads to a 2 to 3 percent increase in VMT. Disaggregating the data by road type, the author obtained elasticities of approximately 0.5 to 0.8 for interstate highways, 0.2 to 0.7 for arterials, and 0.5 to 0.9 for collector roads. In general, elasticities were higher for the unlagged models than the two-year and five-year lagged cases; for the five-year lag model, in fact, several coefficients were not statistically significantly different from zero suggesting no relationship between lane-miles and VMT. Also, urban roads were found to have a greater relationship to VMT growth than rural roads. This is consistent with the presumption that urban roads are more congested than rural roads and would be currently suppressing some traffic growth if they are congested. Finally, the distributed lag model showed that cumulative long-term elasticities ( 0.7 to 1.0$)$ are larger than short-run elasticities ( 0.2 to 0.5$)$, as would be expected based on previous results obtained by Hansen and Huang (1997).

Overall, the author concluded that his empirical analysis using a cross-sectional time series panel data set found statistically significant relationships between lane-miles and VMT, and, therefore, the hypothesis of induced travel demand cannot be rejected. He noted that "while it is not possible to strictly prove causality with statistical techniques, these results strongly suggest that induced demand effects are real and need to be considered by both planners for specific projects and by policy makers at both the 
regional and national level" (Noland, 1999).

A recent study was conducted by Fulton et al. (2000) to econometrically estimate the relationship between lane miles of roadway capacity and average daily vehicle miles of travel using county level data from the mid-Atlantic states of Maryland, Virginia, and North Carolina as well as for the District of Columbia. Time series data from Virginia and Maryland were available back to 1970 and 1969 , respectively, while data for North Carolina and Washington, D.C. extended back to 1985 and 1984, respectively. Using a modeling approach similar to Hansen and Huang (1997) and Noland (1999), the authors estimated elasticities of VMT with respect to lane miles to be on the order of 0.1 to 0.4 in the short run and 0.5 to 0.8 in the long run, after controlling for population and per capita income.

In addition, Fulton et al. disaggregated the data based upon relative traffic levels (i.e., traffic per lane mile) as a proxy for congestion and also on the basis of population density to examine the effects of induced travel in areas with different levels of congestion. In theory, one would expect higher elasticities in urbanized areas with more initial congestion. However, the authors found no statistically significant differences between coefficients; thus, the results are inconclusive as to whether there are any differences in elasticities due to existing population density and/or congestion effects.

Clearly, recent research has increased the understanding of the induced travel phenomenon by documenting and quantifying the effects of highway capacity expansion on travel behavior. However, the issue of causality and whether the causal relationships between highway supply and urban travel demand are being accurately estimated remains open to considerable debate. None of the studies discussed so far has attempted to adjust 
for potential simultaneity bias in the results. Noland and Cowart (2000) address the issue of causality by using a two-stage least squares or instrumental variable modeling approach to correct for simultaneity bias. Metropolitan level data from 70 urbanized areas across the U.S. from 1982 through 1996 were used in the study. These data were compiled by the Texas Transportation Institute (TTI) and are used for TTI's annual report on traffic congestion. Only the freeway and arterial data for VMT and lane-miles of capacity were used in the analysis; this is consistent with most other studies, both because of the unreliability of VMT data on minor roadways and also because minor roads are thought to have a much smaller role in induced demand.

The authors specified urbanized land area as an instrument for lane-miles of highway capacity because of its high correlation with lane-miles and low correlation with VMT. A two-stage least squares modeling procedure was used. The models were estimated with VMT per capita on freeways and arterials as the dependent variable and lane-miles per capita for each metropolitan area by year as the primary independent variable. The authors control for other variables which affect VMT per capita, including fuel cost, population density of the metropolitan area, and real per capita income by including them as independent variables in their models. The results of the analysis indicated a strong causal relationship between highway capacity (i.e., lane-miles) additions and VMT growth. Furthermore, use of an instrumental variable procedure to correct for simultaneity bias suggested that previous estimates of the induced travel effect were likely biased upward. The effect of lane-mile additions on VMT growth was forecast in this study and found to account for approximately 15 percent of annual VMT growth with substantial variation between metropolitan areas (the induced travel effect 
ranges from a low of 6.4 percent in Fresno, California to a high of 34.3 percent for Louisville, Kentucky). In addition, the impact of lane-mile additions on VMT growth appeared to be greater in urbanized areas with larger percent increases in total capacity.

\section{Travel Time Elasticities}

The studies discussed to this point have measured changes in capacity in terms of lane-miles or vehicle-miles of capacity (i.e., the product of the length of the highway segment in miles and its capacity in vehicles per hour). One advantage of using the changes in lane-miles or vehicle-miles of capacity to represent improvements in capacity is that these measures can often be compiled for a given area directly from highway system inventories maintained by state departments of transportation (Cohen, 1995). However, these measures of highway supply do not consider the context of the capacity addition in estimating induced travel demand. That is, the amount of travel time savings produced by a given change in lane-miles or vehicle-miles of capacity is highly variable, depending on such factors as pre-existing levels of congestion and bottlenecks. For example, widening a congested bridge that is a traffic bottleneck during peak periods could provide large peak-period time savings with a small increase in lane-miles of capacity; conversely, adding lanes to a facility that is not currently congested will have a small effect on travel time, even though the addition may represent a significant increase in lane-miles (TRB, 1995). Therefore, from a theoretical perspective, the use of travel time savings as a measure of supply is preferable to measures such as lane-miles or vehicle-miles of capacity in estimating induced travel demand. Travel time savings are the more direct cause of induced travel; capacity additions cause additional travel only to 
the extent that they reduce the travel time component of the total trip cost by providing time savings.

Several researchers have estimated travel time elasticities (defined as the percentage change in travel between two areas divided by the percentage change in travel time). Domencich et al. (1968) estimated travel time elasticities of -0.82 for automobile work trips and -1.02 for automobile shopping trips. Their analysis used cross-sectional data on inter-zonal travel volumes, times, and costs from the Boston area. These elasticities overstate the magnitude of the system-wide effects of travel time improvements because only part of the observed increase in zone-to-zone travel is composed of completely new trips (i.e., some of the observed increase is from changes in trip destinations). Nevertheless, the elasticities of passenger demand as a function of travel time and cost estimated by Domencich et al. support the important finding that highway supply changes are likely to affect discretionary travel more significantly than work travel.

Burright (1984) estimated the elasticity of vehicle miles with respect to travel time as -0.27 when land use changes are not considered. When travel from changes in land use and household density is taken into account, however, higher elasticities of -0.51 are estimated, providing some evidence that the travel effects of a change in supply increase over time.

Goodwin (1996) examined the empirical evidence from a large number of road improvement projects in Europe to determine the magnitude of induced traffic. The study was based on a comparison of predicted traffic levels using travel forecasting models with actual observed traffic flows on the improved road. The assumption is made 
that the models used to forecast traffic levels on an improved road segment are correct in every respect except for the omission of induced traffic. Then if induced traffic is significant, the forecasts will tend to underestimate actual traffic levels, with the discrepancy being a direct measure of the amount of induced traffic. The study found that when traffic growth due to other factors is forecasted correctly for an average road improvement, the road will experience 10 percent higher traffic than that which was forecasted in the short term and 20 percent higher traffic in the long term. The author suggested that these findings are consistent with VMT elasticities with respect to travel time of -0.5 in the short term and up to -1.0 in the long term. Goodwin also observed that peak-period traffic growth rates on improved roads were particularly high; individual improvement projects with induced traffic at double the 10 to 20 percent level during peak periods was not unusual. He stated that these findings suggest that "when extra capacity is provided, there is a reversal of peak-spreading, consistent with both a suppression effect due to congestion and an induced traffic consequence when that is released" (Goodwin, 1996). Finally, the author discusses the "no induced traffic" hypothesis that any additional traffic on improved roads will be balanced by an approximately equal traffic reduction on the non-improved alternative routes that the road improvements are intended to relieve. The results of his study, however, did not support this hypothesis; increases in traffic observed on improved roads were not, in general, offset by equivalent reductions on the unimproved alternate routes either in the short or long run.

Dowling and Colman (1997) conducted a survey of household travel behavior in the San Francisco and San Diego metropolitan areas to determine if, and to what extent, 
highway capacity expansions increase trip making. The authors utilized a stated preference survey methodology in which respondents were asked to respond to hypothetical changes (both increases and decreases) in travel time of 5 to 15 minutes. The overall result of the survey was that 90 to 95 percent of trips would remain unchanged or would have only schedule changes (i.e., travel at a different time of day when congestion is less) in response to travel time increases and decreases of 15 minutes or less. As expected, the greater the magnitude of the travel time change, the greater was the traveler response. An average travel time savings of five minutes resulted in a three percent increase in daily trips per person, and a 15 minute time savings resulted in a five percent increase in daily trips per person. Interestingly, the results showed that respondents tended to react more strongly to increases in travel time than to decreases. When faced with a travel time increase, travelers would try to adapt by changing route, schedule, mode, or destination for a higher percentage of trips than if they were offered an equal travel time reduction.

Other key results of the research were that: (1) over $35 \%$ of trips made would be unaffected when the travel time increased or decreased by 15 minutes or less when all trip purposes are considered; (2) another $20 \%$ to $40 \%$ of trips would change only to the extent that the respondent would arrive earlier or later at a destination and make no change to the departure time to compensate for the effect of the travel time change; and (3) approximately $10 \%$ to $15 \%$ of trips would be rescheduled to compensate for or take advantage of the travel time change (Dowling and Colman, 1997). The results of this study should be interpreted rather cautiously because they are based on responses to a hypothetical situation. Unlike revealed preference surveys which capture actual 
behavioral responses to real changes, the stated preference approach used in the study by Dowling and Colman does not measure actual decisions. In addition, the surveys were conducted in only two urban areas in Califormia, and the results reflect travel patterns that may not be typical of other urban areas. Nevertheless, the research indicated that an important impact of new highway capacity is to produce temporal shifts in demand (i.e., trips previously made in the off-peak will move to the peak periods). The authors note that this temporal shift will affect the congestion, speed, and emissions estimates produced by travel models and that it reveals a need to develop models that can predict peak spreading and time-of- day of travel.

Heanue (1997) identified several socioeconomic, demographic, and land use factors that cause VMT growth, including: population growth, household characteristics, income, auto ownership, total employment and the increase of women in the workplace, gasoline prices, and population density. He then did an analysis to compare travel growth over time due to these causal factors with the travel growth generated or induced by new highway capacity using the city of Milwaukee, Wisconsin as a case study. Milwaukee was selected because consistent data over time were available and because it has experienced relatively slow population growth compared to other U.S. metropolitan areas. During the period 1963 to 1991 , the population in the Milwaukee metropolitan area grew by only nine percent; however, during the same period, households and employment increased 50 percent, the numbers of registered vehicles and employed women more than doubled, and total VMT growth exceeded 150 percent (Heanue, 1997). To separate travel growth caused or "induced" by transportation system changes from VMT growth resulting from other causal factors (e.g., socioeconomic and land use 
variables), Heanue applied travel demand elasticities developed by previous researchers to the city of Milwaukee. Specifically, he used: (1) a lane-mile elasticity (i.e., percentage change in VMT per percentage change in lane-miles) of 0.9 (Hansen and Huang, 1997); (2) a travel time elasticity of -0.5 in the short term (SACTRA, 1994 and Goodwin, 1996); and (3) a long-term travel time elasticity of -1.0 (SACTRA, 1994 and Goodwin, 1996). Results showed that, depending on the elasticity assumed, the percentage of VMT growth in Milwaukee during the period 1963 to 1991 that could be directly attributed to growth in the capacity of the highway system ranges from 6 to 22 percent. In other words, Heanue conservatively estimated that over 78 percent of the VMT growth in this slowly growing U.S. city was due to socioeconomic and other factors unrelated to highway system supply.

In a recent study, Gorina and Cohen of Cambridge Systematics, Inc. (1998) did an analysis of the effect of highway system speed on household VMT using data from the 1990 Nationwide Personal Transportation Survey. Average highway system speed was calculated for each household using travel day information on the lengths and duration of automobile trips taken by household members. Several regression models were estimated using various combinations of inverse travel speed, population density in which the household is located, household size, household income, and household per capita income as explanatory variables. The coefficient on the inverse travel speed variable could be interpreted as the elasticity of household VMT with respect to travel time since travel time is inversely proportional to travel speed. Results were developed for households stratified by public transportation availability, family life cycle, metropolitan area size, and urbanized area size. Travel time elasticities were found to range from 
-0.269 to -0.584 with a median value of -0.44 .

In this dissertation, I attempt to advance our knowledge of induced travel demand by embarking on two different but complementary studies to quantify the effect of highway system improvements on travel behavior. The first analysis, presented in the following chapter, uses a very rich database of household-level travel patterns to develop demand elasticities with respect to travel time. This analysis is one of a very few to investigate the issue of induced travel demand using disaggregate household-level data. It is very similar to the study done by Gorina and Cohen (1998) that was just discussed, but it extends their work in three significant areas. First of all, my analysis uses a more recent source of data, the 1995 Nationwide Personal Transportation Survey. Secondly, I include two additional independent variables, the number of workers per household and median census tract income, which lend explanatory power to the models. Finally, I validate the analytical approach of measuring the response of annual VMT to changes in average daily household travel speed by doing separate analyses using estimates of travel speed based on each day of the week.

In a second study, presented in Chapter III, I apply a novel modeling approach to a before-and-after case study in a rapidly growing metropolitan area of the United States. This study expands on the work of Smith and Schoener (1978) by applying statistical techniques that attempt to quantify the amount of traffic induced by highway capacity additions after controlling for other factors such as income and population that influence the demand for motor vehicle travel. The primary weakness of Smith and Schoener's research is that the method they used to test the statistical significance of change in travel behavior did not enable them to determine the amount of additional travel caused by the 
highway addition. I address this shortcoming by using three similar analytical designs to quantify the impact of highway capacity additions on induced traffic. 


\section{CHAPTER II}

\section{NATIONWIDE PERSONAL TRANSPORTATION SURVEY STUDY}

\section{Research Objective}

The objective of this study is to utilize a new data source and appropriate analytical techniques to estimate the relationship between highway capacity increases and travel demand. Previous studies discussed in Chapter I typically employed data sets aggregated to the state, county, or metropolitan area level. Recognizing that people - not states, counties, or metropolitan areas - make decisions about how, where, when, and why to travel, this study expands on previous findings and adds to the empirical evidence of induced travel by analyzing disaggregate household-level travel survey data. Disaggregate analysis gives insight into how an individual traveler may respond to highway capacity additions. That is, you need disaggregate level data to analyze individual responses and individual highway improvement projects.

\section{Description of Data}

An analysis was conducted to determine the effect of highway system speed on region-wide VMT using data from the 1995 Nationwide Personal Transportation Survey (NPTS). The NPTS provides comprehensive data on personal travel behavior and transportation patterns in the United States. The survey was conducted over a 14-month period from May 1995 to July 1996. Travel data were collected for all seven days of the 
week, including all holidays; each household reported its travel activity for one day. These data were gathered for all trips, by all modes, for all trip lengths and purposes, and across all areas of the country, both urban and rural. For the 1995 NPTS, 42,033 households were surveyed, and a total of 409,025 individual trips were reported. It should be noted that the NPTS is a cross-sectional survey, meaning that different households are randomly selected for the sample each time the survey is conducted. It is not currently a longitudinal survey, which would involve tracking the same sample households over time.

For this study, raw, non-weighted data were used from three of the six data files in the 1995 NPTS. The Household file provided socioeconomic and demographic data for each household such as household size, income category, education level and employment status of household members, and family life cycle status. In addition, the NPTS Household data file supplied the following information to describe characteristics of the geographic area in which the household is located: population density, median household income, whether or not it is in an urbanized area, metropolitan area size, and availability of public transportation. The NPTS Travel Day file contained detailed information on every trip taken by each household member throughout the day, including length of trip, duration of trip, mode of transportation used, day-of-week of travel, and start time of each trip. Finally, the NPTS Vehicle file provided the annual mileage accrued on every vehicle owned by the household. A description of the variables used in the analysis and a discussion of the steps taken to get the data set into a final workable format are presented in the following paragraphs.

The NPTS Household data file provided the demographic and socioeconomic 
characteristics of each household. Table 2.1 lists the variables that were used in the analysis. For the household family income, median household income in the census tract, and population density variables, non-responsive values (i.e., responses recorded as "Not Ascertained" or "Refused" on the survey) were eliminated from the data set.

The variable HHFAMINC is a categorical parameter with values of 01 to 18.

Each of these values represents a range of actual dollar values into which the household reports its annual family income. To simplify the interpretation of this income parameter in the mathematical analysis, the categorical values 01 to 18 were replaced by a dollar value corresponding to the midpoint of the income range. The income categories and ranges along with the value assigned to the variable for the analysis are shown in Table 2.2. Similarly, the variables HTPPOPDN and HTHINMED are coded in the survey as a single value that represents the midpoint of the range of census tract population density and census tract median household income, respectively. Tables 2.3 and 2.4 show the

Table 2.1. NPTS Household Variables

\begin{tabular}{|c|c|}
\hline Variable & Description \\
\hline HOUSEID & Household identification number \\
BUS_AVL & Bus service available $(01=\mathrm{Yes} ; 02=\mathrm{No})$ \\
URBAN & Located in urbanized area $(01=\mathrm{Yes} ; 02=\mathrm{No})$ \\
MSASIZE & Size of MSA in which household is located \\
LIF_CYC & Family life cycle \\
HHSIZE & Number of persons in household \\
HHFAMINC & Household family income category \\
HTHINMED & Median household income, census tract \\
HTPPOPDN & Population density, census tract \\
WRKCOUNT & Number of workers in household \\
\hline
\end{tabular}


Table 2.2 Household Family Income Values

\begin{tabular}{|c|c|c|}
\hline Value & Range & HHFAMINC \\
\hline 01 & $\$ 0-\$ 4,999$ & 2,500 \\
02 & $\$ 5,000-\$ 9,999$ & 7,500 \\
03 & $\$ 10,000-\$ 14,999$ & 12,500 \\
04 & $\$ 15,000-\$ 19,999$ & 17,500 \\
05 & $\$ 20,000-\$ 24,999$ & 22,500 \\
06 & $\$ 25,000-\$ 29,999$ & 27,500 \\
07 & $\$ 30,000-\$ 34,999$ & 32,500 \\
08 & $\$ 35,000-\$ 39,999$ & 37,500 \\
09 & $\$ 40,000-\$ 44,999$ & 42,500 \\
10 & $\$ 45,000-\$ 49,999$ & 47,500 \\
11 & $\$ 50,000-\$ 54,999$ & 52,500 \\
12 & $\$ 55,000-\$ 59,999$ & 57,500 \\
13 & $\$ 60,000-\$ 64,999$ & 62,500 \\
14 & $\$ 65,000-\$ 69,999$ & 67,500 \\
15 & $\$ 70,000-\$ 74,999$ & 72,500 \\
16 & $\$ 75,000-\$ 79,999$ & 77,500 \\
17 & $\$ \$ 0,000-\$ 99,999$ & 90,000 \\
18 & $\$ 100,000$ or more & 100,000 \\
\hline
\end{tabular}

values assigned to these variables. The numerical values for HTPPOPDN and HTHINMED shown in Tables 2.3 and 2.4 are the values that are coded in the NPTS database. Note that in this study, variable designations HTPPOPDN and HTHINMED have been changed to DENSITY and MEDINC, respectively. This was done to make the variable name more descriptive of the parameter it represents.

The NPTS Travel Day file supplied the data for every trip taken by each household member during the day. The variables from this data file that were used in the analysis are listed in Table 2.5 .

Several steps were required to process the raw data of 409,025 reported trips before obtaining the final data set to be used in the analysis. First of all, individual trips 
Table 2.3. Population Density Values

\begin{tabular}{|c|c|}
\hline Range & DENSITY \\
\hline $0-100$ & 50 \\
$100-500$ & 300 \\
$500-1000$ & 750 \\
$1,000-2,000$ & 1,500 \\
$2,000-4,000$ & 3,000 \\
$4,000-10,000$ & 7,000 \\
$10,000-25,000$ & 17,000 \\
$25,000-999,000$ & 35,000 \\
\hline
\end{tabular}

Table 2.4. Median Household Income Values

\begin{tabular}{|c|c|}
\hline Range & MEDINC \\
\hline$\$ 0-\$ 20,000$ & 15,000 \\
$\$ 20,000-\$ 25,000$ & 22,000 \\
$\$ 25,000-\$ 30,000$ & 27,000 \\
$\$ 30,000-\$ 35,000$ & 32,000 \\
$\$ 35,000-\$ 40,000$ & 37,000 \\
$\$ 40,000-\$ 50,000$ & 45,000 \\
$\$ 50,000-\$ 70,000$ & 60,000 \\
$\$ 70,000-\$ 999,999$ & 80,000 \\
\hline
\end{tabular}

for which the travel time and trip distance were recorded as "Not Ascertained" or "Refused" were eliminated. Then, because this study was concerned with induced auto travel on roadways, only household trips made by privately owned vehicles were considered in the analysis. Thus, all observations for which the TRPTRANS variable indicated that a trip had been made by train, bus, airplane, subway, bicycle, walking, school bus, or taxicab were eliminated. After doing this, nine trips remained in which public transportation was used (PUBTRANS = 01); these observations were deleted. 
Table 2.5. NPTS Travel Day Variables

\begin{tabular}{|c|c|}
\hline Variable & Description \\
\hline HOUSEID & Household identification number \\
PREVREP & Trip also reported by other household member \\
PUBTRANS & Used public transportation $(01=$ Yes; $02=$ No) \\
TRPHHVEH & Used HH vehicle on trip $(01=$ Yes; $02=\mathrm{No})$ \\
TRPTRANS & Mode of transportation code \\
TRVL_MIN & Travel time in minutes \\
TRPMILES & Distance of trip in miles \\
TRAVDAY & Travel day of week \\
STRTTIME & Start time of trip \\
\hline
\end{tabular}

The next step was to eliminate all trips that had been previously reported by another household member (PREVREP $=01$ ). The reason for this is that the travel demand measure of interest in this study is household vehicle miles of travel, not person miles of travel; consequently, trips in which two or more household members traveled together in the same vehicle were counted as a single trip. Although the person provides the demand for travel (i.e., the person, not the vehicle, has a need to travel), traffic planners are concerned with how many additional vehicles are attracted to an improved highway. The majority of research studies discussed in the previous chapter have used vehicle-miles of travel as the dependent variable in their empirical models. Researchers favor VMT as the primary travel demand variable used to measure increases in highway system use because it is a convenient and accurate summary measure that reduces the highly dimensional nature of travel demand (the numbers and destinations of trips as well as the modes and routes chosen to execute these trips) to a single variable. For these reasons, I chose VMT as the response variable for this analysis. Thus, no attempt was made in this analysis to address the obvious societal benefits associated with car pooling and ride sharing. 
Next, and perhaps most important, the average highway system speed for each household was calculated using the reported lengths (TRPMILES) and duration (TRVL_MNN) of automobile trips taken by household members. To do this, the trip data were grouped by household identification number, and the individual trip distances and durations were summed up. Then, the average household travel speed was calculated by simply dividing the total daily travel distance by the total daily travel time and multiplying by the appropriate constant to express the result in miles per hour. It should be noted that, prior to calculating average household travel speed, observations considered to be outliers were omitted. These included all individual trips of less than one block in length as well as all trips whose calculated travel speed was less than 2 mph or greater than $80 \mathrm{mph}$.

Only two variables were used from the NPTS Vehicle file: Household identification number (HOUSEID) and the self-reported annualized VMT (ANNMILES). For households with more than one vehicle, the total combined annual VMT on all vehicles was used in the analysis. And finally, the three NPTS data files were joined to form the master data table by matching household identification numbers. The final data set used in the NPTS analysis consisted of 27,409 households.

The NPTS data are analyzed using ordinary least squares linear regression to determine the elasticity of travel demand with respect to travel time. The dependent variable in the regression model is annual household VMT, and the independent variable used to estimate travel time elasticity is the inverse of the average household daily travel speed which is a function of daily household VMT. Thus, the model specification used in this analysis raises an issue concerning the endogenous nature of travel speed. The 
problem of endogeneity occurs when one of the explanatory variables is jointly determined with the dependent variable so that the model contains a random explanatory variable that is correlated with the stochastic error term. In my regression model, the problem arises from the way in which the travel speed is constructed. Average household travel speed is derived from VMT, and VMT is also used as the dependent variable. Clearly, if either annual VMT or daily VMT were used as both the dependent variable and the basis for travel speed, a condition of perfect endogeneity (also known as division bias) would result. Daily VMT was deliberately not selected as the dependent variable to avoid a perfectly endogenous condition, and annual household travel speed is not available in the NPTS data. The problem in my analysis, then, is mitigated somewhat by using annual household VMT as the response and average daily household travel time (i.e., inverse speed) as the explanatory variable. Nevertheless, these are still weakly related (the correlation coefficient between annual and daily VMT is 0.25 ), and endogeneity must be acknowledged as an issue in the analysis. The consequences of endogeneity on my estimates of travel time elasticities are discussed in the next section of this chapter when the results of the analysis are presented.

It should also be noted that travel speed is not a direct measurement; it is derived from the trip distances and durations reported by each household member for every trip made throughout the day. It can therefore be expected that the travel speed variable is measured with error. It is my feeling that this variable, which is calculated using daily VMT, has less measurement error than annual VMT since people are generally more accurate in their assessment of how far they travel on a daily basis as opposed to a yearly basis. This is especially true for daily trips between home and work that are made 
frequently.

Some key characteristics of the 1995 NPTS data set used in this study are presented in Figures 2.1 through 2.7. Of the 27,409 households included in the final data set, 16,669 (61\%) were located in an urbanized area, as shown in Figure 2.1. The definition of an urbanized area for the 1995 NPTS is based upon the population density of the census block containing the household. A population density of at least 1,000 persons per square mile is considered to be in an urbanized area (URBAN $=01$ ), while a density of less than 1,000 persons per square mile is not in an urbanized area (URBAN = 02). Figure 2.2 indicates that 17,356 households, nearly two-thirds of the total, were located in regions where public transportation is available. Recall that only trips made by privately owned automobile were considered in the study. However, the analysis was done for the data stratified by public transportation availability to determine whether significant differences in automobile driving behavior existed in areas where public transportation was readily available.

Figure 2.3 shows the distribution of households by metropolitan area size. Most of the households in the study were located in large metropolitan areas of one million or more people, and, in fact, over one-third of the households were in metropolitan areas with populations larger than three million. However, only about six percent of the households used in the study were located in very densely populated areas (i.e., census tracts where the population density was 10,000 persons per square mile or greater), as indicated in Figure 2.4.

The distribution of households by family life cycle is shown in Figure 2.5. The largest life cycle group represented; consisting of 39 percent of the total sample, were 


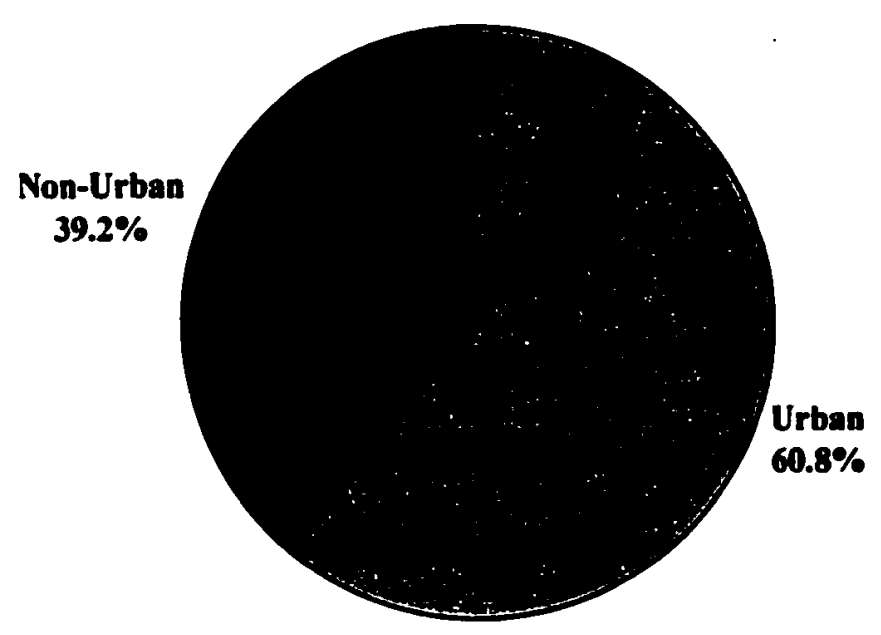

Figure 2.1. Distribution of NPTS Data by Urbanized Area

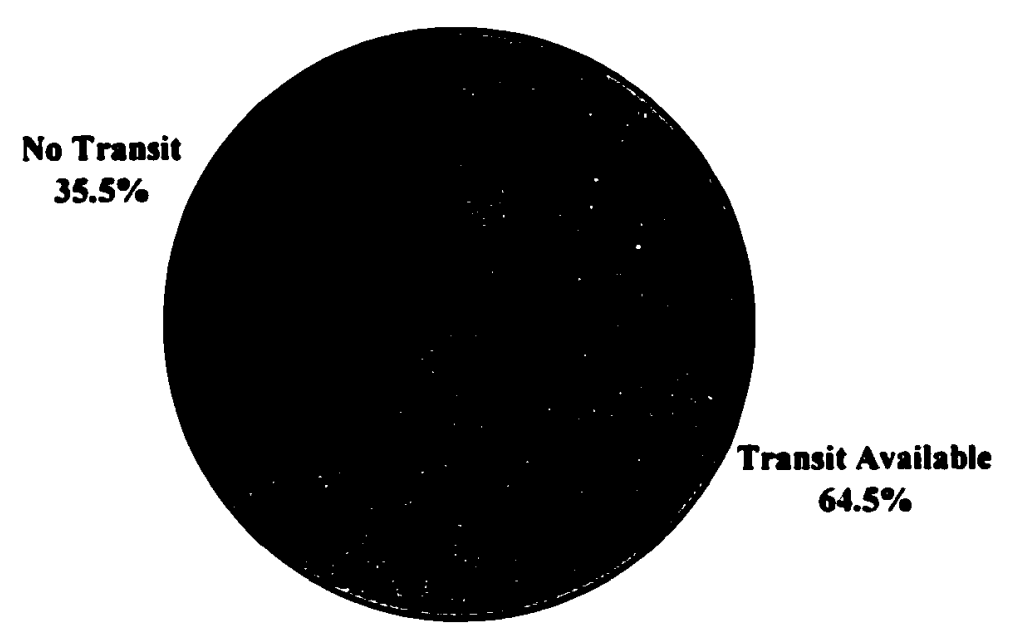

Figure 2.2. Public Transportation Availability 


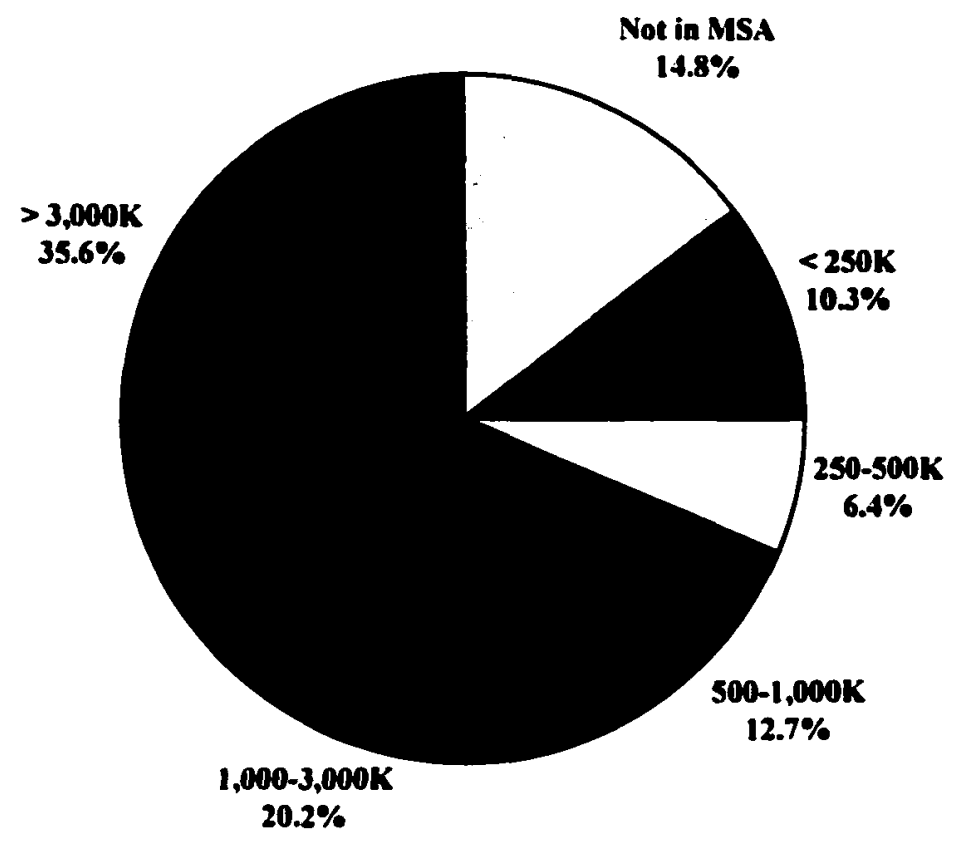

Figure 2.3. Distribution of Households by Metropolitan Area Population

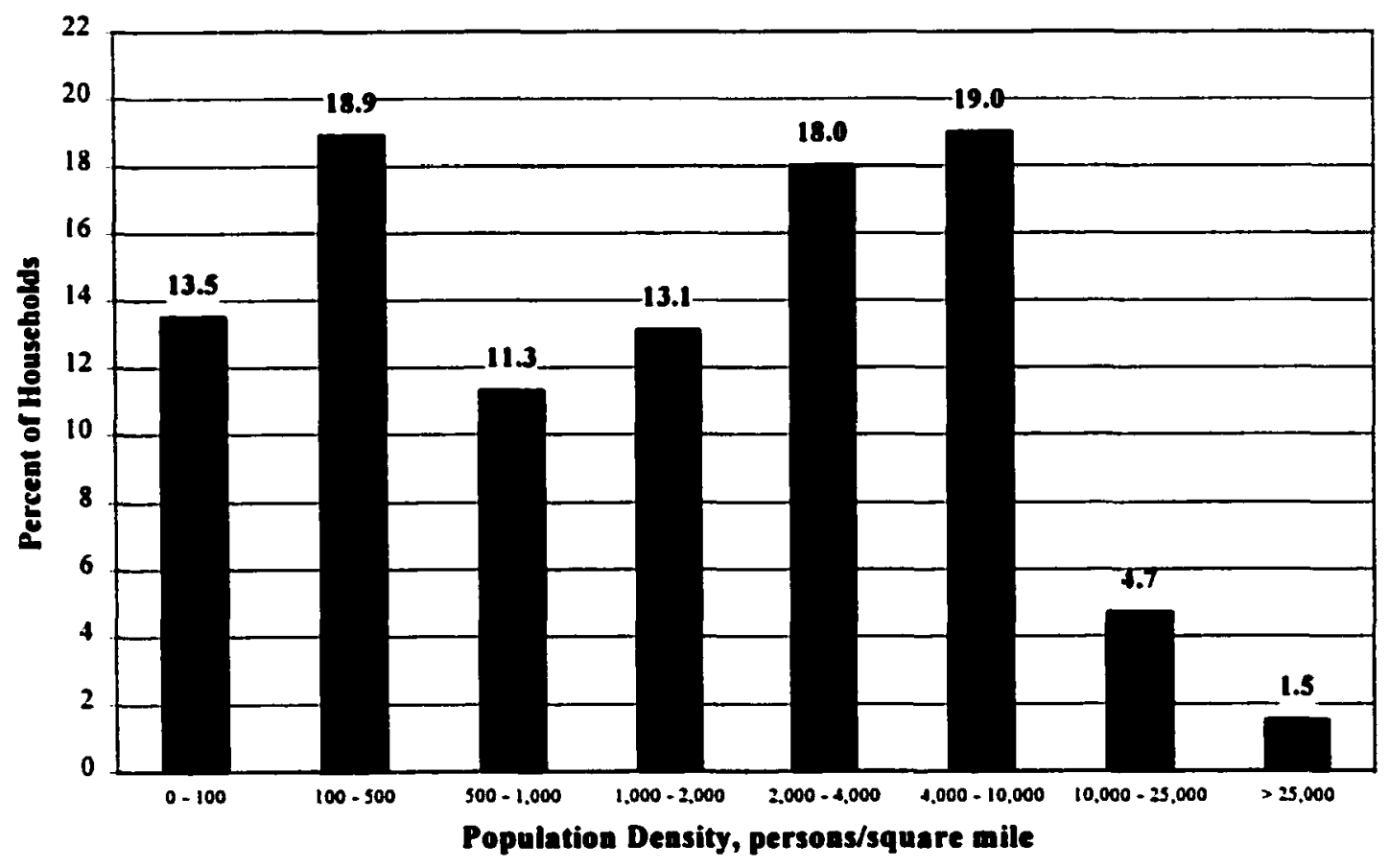

Figure 2.4. Census Tract Population Density Distribution 
families of one or more adults of working age with no children. Figure 2.6 shows that the data are fairly uniformly distributed by day-of-week of travel. And finally, since induced traffic is primarily an issue in urban areas where highways are congested, the data sample was stratified by population density in metropolitan areas of one million or more people. The distribution of these households by population density is illustrated in Figure 2.7.

Table 2.6 shows the mean values of the variables that are used in the statistical models. We can see that the average household consists of nearly three members, half of whom are employed in the workplace, and earns $\$ 45,000$ annually. The households in

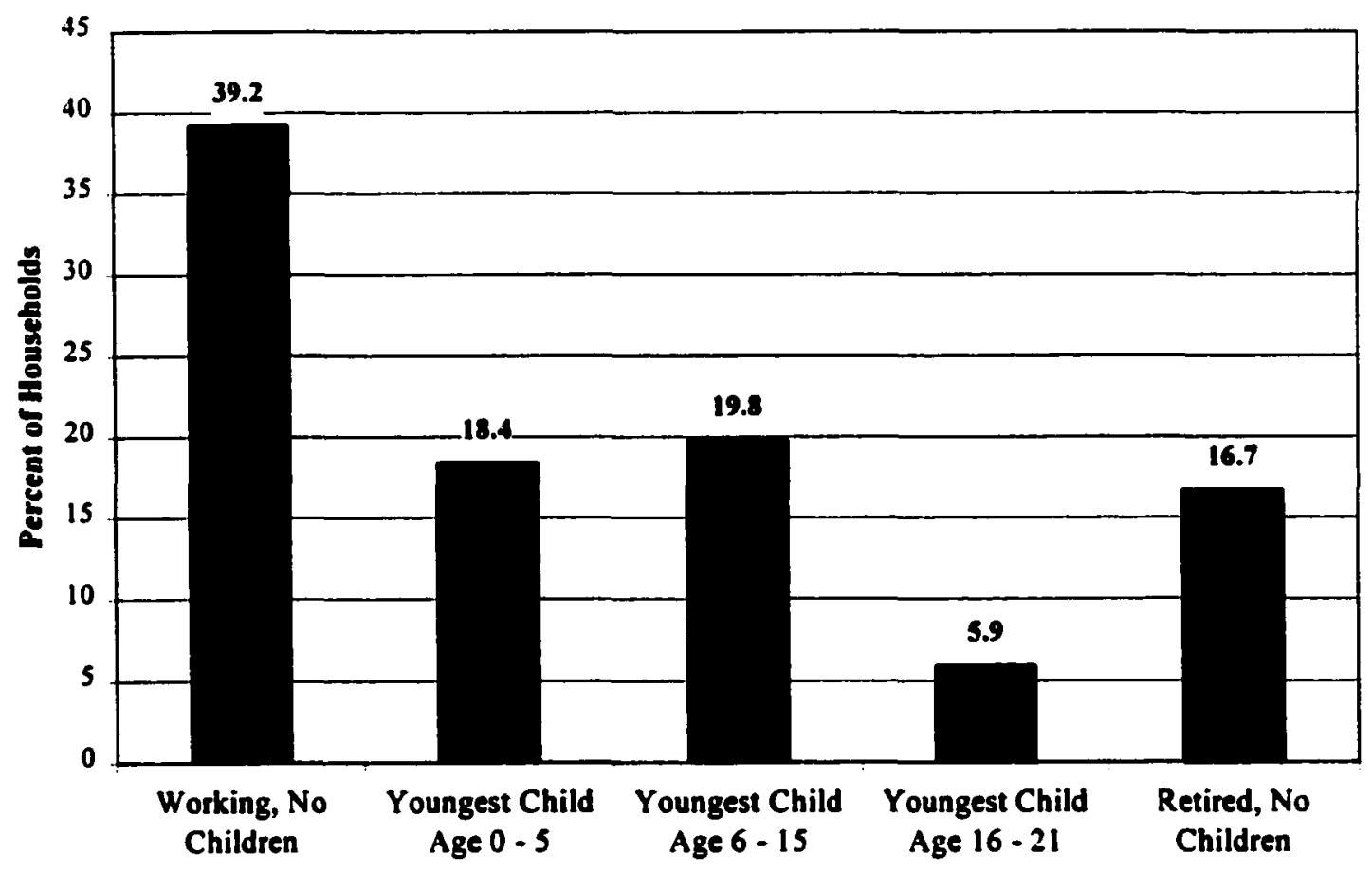

Figure 2.5 Household Family Life Cycle Characteristics 


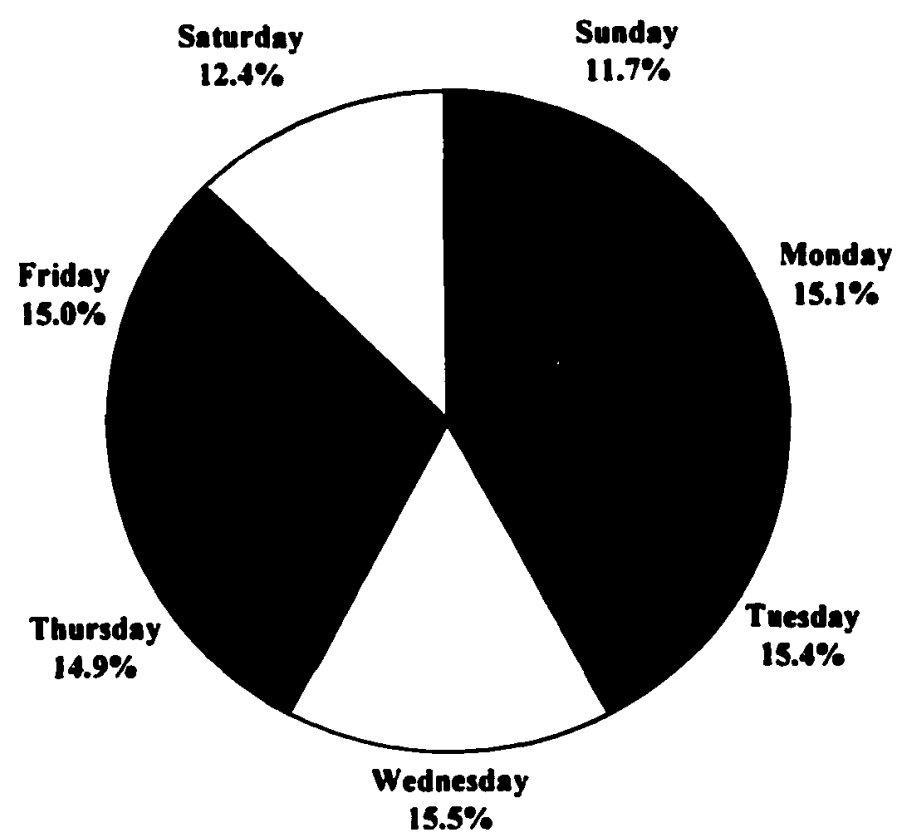

Figure 2.6. Distribution of NPTS Trips by Travel Day

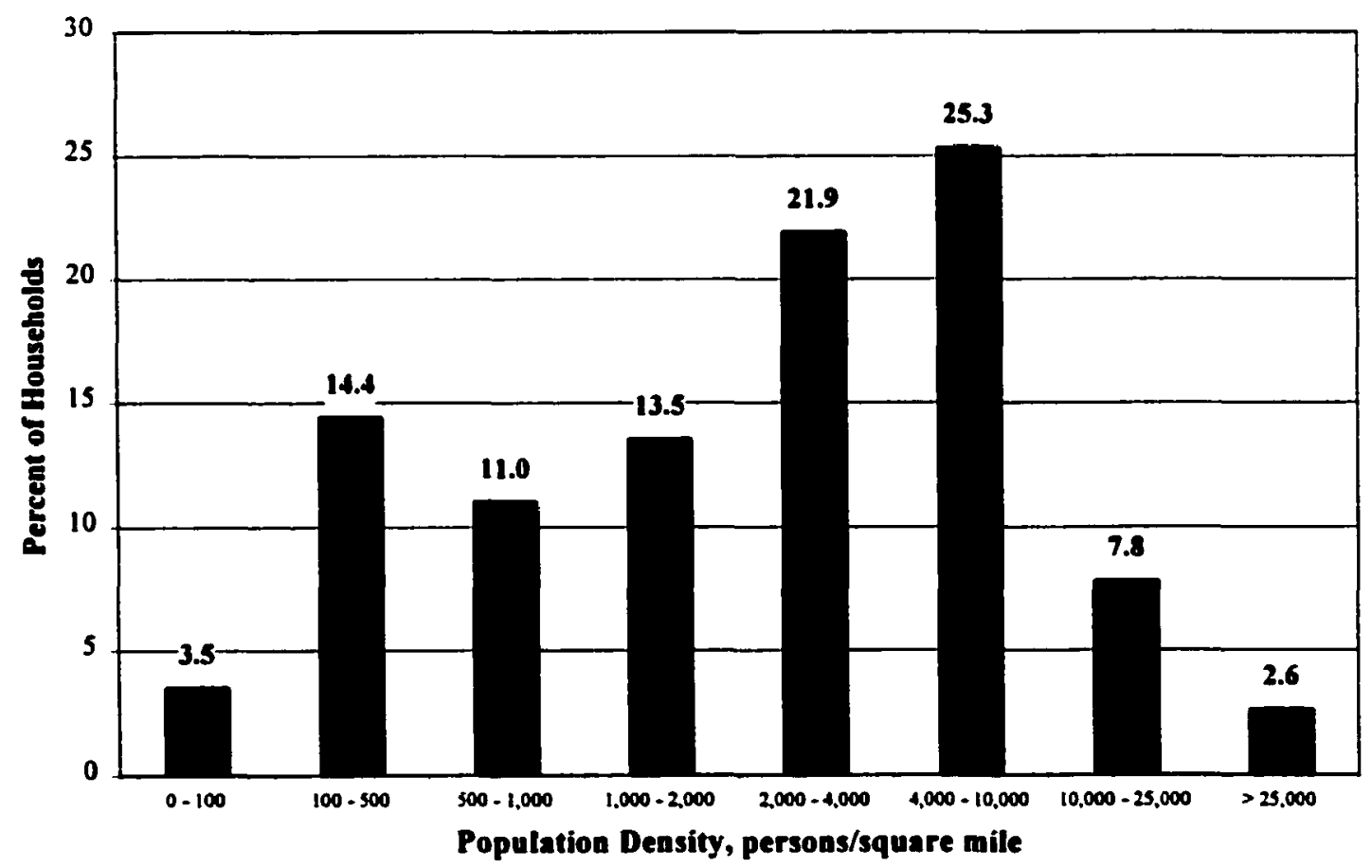

Figure 2.7. Census Tract Population Density of Households Located in Metropolitan Areas Greater Than One Million 
Table 2.6. Mean Values of NPTS Variables ( $N=27,409$ households)

\begin{tabular}{|c|c|c|}
\hline Variable & Description & Mean Value \\
\hline ANNMILES & Annual household VMT, miles & 23,465 \\
\hline SPEED & Average household daily travel speed, $\mathrm{mph}$ & 30.8 \\
\hline NTRIPS & Number of daily trips made by household & 8.99 \\
\hline HHSIZE & Number of persons in household & 2.76 \\
\hline HHFAMINC & Annual household family income, $\mathbf{S}$ & 44,989 \\
\hline HHINC/CAP & Annual per capita income, \$person & 19,238 \\
\hline WRKCOUNT & Number of workers in household & 1.48 \\
\hline DENSITY & Census tract population density, persons/ mi $^{2}$ & 3,537 \\
\hline MEDINC & Median household income (census tract), $\mathbf{S}$ & 40,815 \\
\hline
\end{tabular}

the data set make an average of nine trips per day, and the average travel speed for all these trips is approximately 30 miles per hour. Moreover, the average annual household VMT is 23,465 miles. Note that the income and population density values shown in Table 2.6 are not "true" averages because of the way these variables are coded in the database. As mentioned previously, households report their income within a given range, and the midpoint of this range is assigned as the household family income. Similarly, the population density and median income of the census tract in which the household is located is coded with a single value that is based on the range into which it falls.

\section{Method of Analysis}

To determine the travel time elasticity (i.e., the percentage change in annual household VMT divided by the percentage change in average daily household travel time) from the 1995 NPTS data, several models were estimated using ordinary least squares linear regression. The objective of the regression models is to estimate the 
relationship between VMT and travel time while taking into account various combinations of demographic, socioeconomic, and land use characteristics. This is a region-wide analysis in that it is based on the cross-sectional NPTS data which samples all areas of the U.S. At the same time, however, these can be considered disaggregate statistical models in the sense that each observation in the data set represents the travel behavior of an individual household. It should be emphasized here that the household, not the vehicle, is the unit of observation in the analysis. As an example, consider a twoperson household with two vehicles. If one person drives 15,000 miles annually in her car and the other person drives 10,000 miles in his car during the year, the annual household VMT used as the dependent variable in the analysis for this household is 25,000 miles. The following 15 models were estimated in this study:

1. $\log (V M T)=\alpha_{i}+\beta_{l} \log (I N V S P E E D)+\varepsilon_{i}$

2. $\log (V M T)=\alpha_{i}+\beta_{l} \log (I N V S P E E D)+\beta_{2} \log (D E N S I T Y)+\varepsilon_{i}$

3. $\log (V M T)=\alpha_{i}+\beta_{l} \log (I N V S P E E D)+\beta_{2} H H S I Z E+\varepsilon_{i}$

4. $\log (\mathrm{VMT})=\alpha_{i}+\beta_{l} \log (I N V S P E E D)+\beta_{2} \log (D E N S I T Y)+\beta_{3} H H S I Z E+\varepsilon_{i}$

5. $\log (V M T)=\alpha_{i}+\beta_{1} \log (I N V S P E E D)+\beta_{2} \log (H H F A M I N C)+\beta_{3} H H S I Z E+\varepsilon_{i}$

6. $\log (V M T)=\alpha_{i}+\beta_{1} \log (I N V S P E E D)+\beta_{2} \log (H H I N C / C A P)+\beta_{3} H H S I Z E+\varepsilon_{i}$

7. $\log (V M T)=\alpha_{i}+\beta_{1} \log (I N V S P E E D)+\beta_{2} \log (D E N S I T Y)+\beta_{3} \log (H H I N C / C A P)+$ $\varepsilon_{i}$

8. $\log (V M T)=\alpha_{i}+\beta_{l} \log (I N V S P E E D)+\beta_{2} \log (D E N S I T Y)+\beta_{3} \log (H H I N C / C A P)+$ $\beta_{+} H H S I Z E+\varepsilon$

9. $\log (V M T)=\alpha_{i}+\beta_{l} \log (I N V S P E E D)+\beta_{2} \log (D E N S I T Y)+\beta_{3} \log (H H F A M I N C)+$ $\beta_{+} H H S I Z E+\varepsilon_{i}$

10. $\log (V M T)=\alpha_{i}+\beta_{1} \log (I N V S P E E D)+\beta_{2} \log (D E N S I T Y)+\beta_{3} \log (H H I N C / C A P)+$ $\beta_{4} W R K C O U N T+\varepsilon_{i}$ 
11. $\log (V M T)=\alpha_{i}+\beta_{l} \log (I N V S P E E D)+\beta_{2} \log (D E N S I T Y)+\beta_{3} \log (H H I N C / C A P)+$ $\beta_{\downarrow} H H S I Z E+\beta_{5} W R K C O U N T+\varepsilon_{i}$

12. $\log (V M T)=\alpha_{i}+\beta_{l} \log (I N V S P E E D)+\beta_{2} \log ($ DENSITY $)+\beta_{3} \log (H H F A M I N C)+$ $\beta_{4} H H S I Z E+\beta_{5} W R K C O U N T+\varepsilon_{i}$

13. $\log (V M T)=\alpha_{\mathrm{i}}+\beta_{1} \log (I N V S P E E D)+\beta_{2} \log (D E N S I T Y)+\beta_{3} \log (H H I N C / C A P)+$ $\beta_{4} W R K C O U N T+\beta_{5} \log (M E D I N C)+\varepsilon_{i}$

14. $\log (V M T)=\alpha_{i}+\beta_{1} \log (I N V S P E E D)+\beta_{2} \log (D E N S I T Y)+\beta_{3} \log (H H I N C / C A P)+$ $\beta_{4} H H S I Z E+\beta_{5} W R K C O U N T+\beta_{6} \log (M E D I N C)+\varepsilon_{i}$

15. $\log (V M T)=\alpha_{i}+\beta_{l} \log (I N V S P E E D)+\beta_{2} \log (D E N S I T Y)+\beta_{3} \log (H H F A M I N C)+$ $\beta_{4} H H S I Z E+\beta_{5} W R K C O U N T+\beta_{6} \log (M E D I N C)+\varepsilon_{i}$

The parameters are defined as:

\begin{tabular}{|c|c|c|}
\hline$V M T$ & $=$ & Annual household VMT (miles) \\
\hline$\alpha_{i}$ & $=$ & Constant term \\
\hline INVSPEED & $=$ & $\begin{array}{l}\text { Inverse value of average daily household travel speed } \\
(\mathrm{hr} / \mathrm{mi} \text {.) }\end{array}$ \\
\hline DENSITY & $=$ & $\begin{array}{l}\text { Population density of census tract in which the household is } \\
\text { located (Persons/sq. mi.) }\end{array}$ \\
\hline HHFAMINC & $=$ & Annual household family income (\$) \\
\hline HHINC/CAP & $=$ & $\begin{array}{l}\text { Per capita household family income (i.e., annual household } \\
\text { family income divided by household size, \$) }\end{array}$ \\
\hline HHSIZE & $=$ & Number of members in household \\
\hline WRKCOUNT & $=$ & Number of workers in household \\
\hline MEDINC & $=$ & $\begin{array}{l}\text { Median household income of census tract in which the } \\
\text { household is located (\$) }\end{array}$ \\
\hline$f_{i}$ & $=$ & Stochastic error term \\
\hline
\end{tabular}


The $\beta$ 's are the regression coefficients to be estimated by the models. The models are specified in log-linear form, so the coefficient on INVSPEED can be interpreted directly as the travel time elasticity. Note that the inverse of average daily travel speed is used as the explanatory variable since travel time is inversely proportional to travel speed. Using the inverse or reciprocal of travel speed as the explanatory variable allows speed to have a diminishing effect on travel demand. In other words, as speed increases, the marginal effect on VMT decreases.

Travel time is one component of the generalized cost of travel. Other components of the total trip cost include out-of-pocket costs such as gasoline prices, parking, tolls, etc. The cost of transportation to the individual affects the demand for travel. The theory of induced travel is based in microeconomics; it is essentially a demand response to a reduction in the price of a commodity, in this case the price of vehicle travel. The primary marginal cost of travel is the personal travel time invested to make a given trip. Therefore, when infrastructure changes such as adding capacity to the highway system decreases the travel time of a trip (by increasing travel speeds), and hence its cost, an increase in the demand for travel may be expected. It is because of this economic role that travel time plays in making travel decisions that the relationship of travel time, rather than travel speed, and the demand for travel is examined in this study.

As discussed previously, the model specification used in this analysis raises an issue concerning the endogenous nature of travel speed. Endogenous, or jointly determined, variables have outcome values determined through the joint interaction with other variables within the system. Thus, the problem of endogeneity occurs since one of the explanatory variables, in this case the inverse of travel speed, may be determined 
simultaneously with the dependent variable VMT. Because endogenous variables are correlated with the error or disturbance terms of the equations in which they appear, least squares estimates of the parameters of equations with endogenous independent variables are not only biased, they are also inconsistent. This is known as simultaneous equations or simultaneity bias. Note that consistency refers to the asymptotic properties of an estimator. A sufficient condition for consistency is that the bias and the variance both tend to zero as the sample size increases indefinitely. Thus, a least squares estimate of a parameter is consistent if it is asymptotically unbiased and the variance asymptotically approaches zero. Stated simply, an estimator is consistent if it approaches the true value of the parameter as the sample size gets larger and larger.

Due to the way in which the average household travel speed is constructed, the explanatory variable INVSPEED is correlated with the disturbance term in the linear regression model. In my analysis, then, the problem of endogeneity means that travel time elasticities cannot be consistently estimated by least squares regression of VMT on INVSPEED (i.e., travel time). In this analysis, if daily reported VMT were used as the dependent variable, then the travel speed explanatory variable (INVSPEED) would be completely determined by VMT. Use of annual VMT as the dependent variable avoids the problem of perfect endogeneity. The concern about endogeneity or simultaneity bias is also mitigated by the use of disaggregate household-level data in the analysis; that is, the vehicle miles traveled by individual households should have a minimal influence on average travel speed.

Results were developed for households stratified by:

- Urbanized area, 
- Public transportation availability,

- Family life cycle,

- Metropolitan area size, and

- Census tract population density for households in metropolitan areas of one million or more people.

In addition, separate analyses were done using speed estimates based on the day-of-week of travel. Each household reported the travel activities of every member for one day of the week; thus, comparisons of demand elasticities with respect to travel time were made among weekdays as well as between weekdays and weekend days.

\section{$\underline{\text { Results }}$}

Fifteen regression models were estimated to explore the empirical relationships between average household travel time and vehicle-miles of travel. These models include various combinations of explanatory variables such as population density, household size and income, and number of workers in the household. Growth in VMT is influenced by many factors; the mathematical models developed in this research study provide quantitative estimates of travel time elasticities after controlling for the effects of some of these factors. Furthermore, using the large cross-sectional 1995 NPTS data set in the analysis allows us to predict the effect of travel time on region-wide VMT rather than focusing on a specific corridor. Note, however, that the analysis does not provide a comparison between the short-term and long-term impacts of induced travel, as was done in many previous research studies, since the NPTS travel data were collected within a 14-month period (i.e., it is not a longitudinal survey). 
Estimation results for all 15 models using all 27,409 households in the data set are presented in Table 2.7. The estimated regression coefficient for each independent variable is shown along with the $R$-squared value which describes the amount of variability explained by the model. Travel time elasticities (i.e., the coefficient on the $\log ($ INVSPEED) parameter) range from -0.350 to -0.582 , with an average value of 0.437. The negative sign on the coefficient is expected and simply indicates that demand for travel (measured in VMT) will increase as travel times on the highway system are reduced. The value of the coefficient is interpreted as follows: A 10 percent reduction in average household travel time will result in a 4.37 percent increase in annual household VMT, after accounting for the effects of all other variables included in the model. All the models estimated found highly statistically significant relationships between travel time and VMT, as indicated by the t-statistics in parentheses. A t-statistic absolute value of greater than 1.96 provides evidence of statistical significance at the 5 percent significance level. Therefore, we can conclude that travel time has a significant effect on VMT, after controlling for the effects of population density, household size and income, and number of workers per household. In other words, the results suggest that the hypothesis of induced travel cannot be rejected. However, the results also show that travelers will not spend all the time savings afforded by highway system improvements in additional travel. According to this study, capacity additions that reduce travel time by 10 percent will increase the demand for travel by approximately 3 to 4 percent, after controlling for other factors that affect VMT growth. These results agree very well with those of other studies that were discussed in Chapter I. Other researchers generally found short-run VMT elasticities with respect to lane-miles of capacity to be in the range of 0.2 to 0.6 . And 
Table 2.7. Regression Coeficient Estimates for All Households $(\mathbf{N}=\mathbf{2 7 , 4 0 9 )}$

(t-statistics are shown in parentheses)

\begin{tabular}{|c|c|c|c|c|c|c|c|c|c|c|c|c|c|c|c|}
\hline Model Nember & 1 & 2 & 3 & 4 & 5 & 6 & 7 & 8 & 9 & 10 & 11 & 12 & 13 & 14 & 15 \\
\hline Constent & 7.778 & 8.233 & 7.531 & 7.947 & 3.710 & 3991 & 6.770 & 4.411 & 4.153 & 6.714 & 5.219 & 4.965 & 5.472 & 4.826 & 4.794 \\
\hline $\log ($ IMSPEED $)$ & $\begin{array}{r}-0.582 \\
(-49.97)\end{array}$ & $\begin{array}{r}-0.539 \\
(-44.80)\end{array}$ & $\begin{array}{r}-0.529 \\
(-46.28)\end{array}$ & $\begin{array}{c}-0.491 \\
(-41.58)\end{array}$ & $\begin{array}{c}-0.452 \\
(-40.86)\end{array}$ & $\begin{array}{r}-0.466 \\
(-41.81)\end{array}$ & $\begin{array}{r}-0.516 \\
(-43.08)\end{array}$ & $\begin{array}{c}-0.408 \\
(-35.43)\end{array}$ & $\begin{array}{c}-0.393 \\
(-34.48)\end{array}$ & $\begin{array}{r}-0.382 \\
(-33.07)\end{array}$ & $\begin{array}{c}-0.357 \\
(-31.34)\end{array}$ & $\begin{array}{r}-0.350 \\
(-30.94)\end{array}$ & $\begin{array}{r}-0.378 \\
(-3280)\end{array}$ & $\begin{array}{r}-0.356 \\
(-31.289\end{array}$ & $\begin{array}{r}-0.350 \\
(-30.92)\end{array}$ \\
\hline log(DENSITY) & & $\begin{array}{r}-0.044 \\
(-13,44)\end{array}$ & & $\begin{array}{r}-0.040 \\
(-1253)\end{array}$ & & & $\begin{array}{r}-0.053 \\
(-16.10)\end{array}$ & $\begin{array}{r}-0.058 \\
(-1850)\end{array}$ & $\begin{array}{r}-0.058 \\
(-1873)\end{array}$ & $\begin{array}{r}-0.000 \\
(-19.39)\end{array}$ & $\begin{array}{r}-0.061 \\
(-19.93)\end{array}$ & $\begin{array}{r}-0.060 \\
(-19.96)\end{array}$ & $\begin{array}{r}-0.061 \\
(-19.72)\end{array}$ & $\begin{array}{c}-0.061 \\
(-20.03)\end{array}$ & $\begin{array}{r}-0.061 \\
(-20.00)\end{array}$ \\
\hline $\log ($ HFAMINC) & & & & & $\begin{array}{c}0.399 \\
(50.28)\end{array}$ & & & & $\begin{array}{c}0.415 \\
(5233)\end{array}$ & & & $\begin{array}{r}0.340 \\
(41.46)\end{array}$ & & & $\begin{array}{r}0.335 \\
(3833)\end{array}$ \\
\hline $\log ($ HANCICAP) & & & & & & $\begin{array}{c}0.333 \\
(44.52)\end{array}$ & $\begin{array}{r}0.166 \\
(21.80)\end{array}$ & $\begin{array}{c}0.381 \\
(46.68)\end{array}$ & & $\begin{array}{c}0.173 \\
(2398)\end{array}$ & $\begin{array}{c}0.308 \\
(37.20)\end{array}$ & & $\begin{array}{r}0.153 \\
(20.45)\end{array}$ & $\begin{array}{c}0.298 \\
(33.85)\end{array}$ & \\
\hline HHSIZE & & & $\begin{array}{r}0.153 \\
(37.85)\end{array}$ & $\begin{array}{c}0.151 \\
(37.52)\end{array}$ & $\begin{array}{r}0.109 \\
(27.47)\end{array}$ & $\begin{array}{r}0.245 \\
(55.47)\end{array}$ & & $\begin{array}{c}0.247 \\
(56.29)\end{array}$ & $\begin{array}{c}0.105 \\
(26.54)\end{array}$ & & $\begin{array}{c}0.159 \\
(31.39)\end{array}$ & $\begin{array}{c}0.049 \\
(11.44)\end{array}$ & & $\begin{array}{c}0.155 \\
(29.92)\end{array}$ & $\begin{array}{r}0.049 \\
(11.42)\end{array}$ \\
\hline WPKCOUNT & & & & & & & & & & $\begin{array}{c}0.332 \\
(57.59)\end{array}$ & $\begin{array}{r}0.223 \\
(33.50)\end{array}$ & $\begin{array}{c}0.203 \\
(30.31)\end{array}$ & $\begin{array}{c}0.327 \\
(56.58)\end{array}$ & $\begin{array}{c}0.224 \\
(39.61)\end{array}$ & $\begin{array}{r}0.204 \\
(30.35)\end{array}$ \\
\hline $\log (M E D I N C)$ & & & & & & & & & & & & & $\begin{array}{l}0.138 \\
(9.93)\end{array}$ & $\begin{array}{l}0.048 \\
(3.40)\end{array}$ & $\begin{array}{l}0.001 \\
(1.48)\end{array}$ \\
\hline$R^{2}$ & 0.083 & 0.009 & 0.129 & 0.134 & 0.200 & 0.188 & 0.105 & 0.198 & 0.213 & 0.200 & 0.229 & 0.238 & 0.204 & 0.229 & 0.238 \\
\hline
\end{tabular}


Gorina and Cohen (1998), whose study was very similar to mine, estimated travel time elasticities between -0.27 and -0.58 , with a median value of -0.44 .

Table 2.7 shows that all the explanatory variables, with the possible exception of median household income of the census tract in which the household is located, significantly influence VMT. Income elasticities are in the range of 0.335 to 0.415 , so that a 10 percent increase in household family income can be expected to increase VMT by approximately 3 to 4 percent, all other things being equal. Using per capita rather than absolute household income yields elasticities in the 0.2 to 0.4 range. The interpretation of the coefficients on household size (HHSIZE) and number of workers per household (WRKCOUNT) is slightly different since the variables are actual rather than logarithmic values. Coefficients on household size range from 0.049 to 0.247 . This implies that, accounting for all other factors, each additional family member will increase annual VMT by approximately 5 to 25 percent. Similarly, for every additional worker in the family, VMT can be expected to increase by 20 to 33 percent, taking all other factors in the model into account. These effects will undoubtedly depend on the life cycle characteristics of the family; thus, the data set was stratified by family life cycle, and separate models were estimated for each life cycle stage. These results are presented later in this section. The population density coefficients are negative, implying that, all else being equal, a region with more land area and widely dispersed population will generate more VMT. The coefficients are statistically significant; however, their magnitudes are small. The results show that if the population density of an area doubled (i.e., a 100 percent increase), VMT will be reduced by only 4 to 6 percent.

The R-squared values for these models are fairly low, with the highest value being 
0.238. This means that less than one-quarter of the total variation in annual household vehicle-miles of travel is being explained by the variables in the model. This result merely underscores the statement made earlier that growth in VMT is influenced by many factors; to capture all these effects in a model is not realistic. Moreover, the analysis is based on cross-sectional, individual-level trip data reported in the NPTS Travel Day file, and low R-squared values are not surprising for disaggregate crosssectional data. Because so many factors that affect individual travel decisions (e.g., occupation, number of hours a person works, etc.) have been omitted from the models, the unobserved variation in the individual demand for travel is bound to be high. However, the goal of this analysis was to estimate travel time elasticities and develop an understanding of the relationship between travel time changes and induced VMT growth. It was not intended to develop a tool for predicting VMT increases in a given region or at a specific future point in time. Thus, the emphasis of the study is on the structural analysis rather than the predictive ability of the model.

Another concern when developing mathematical models using multivariable statistical techniques is that many of the independent variables used in the model to explain VMT changes may be strongly related to each other. If two explanatory variables are highly correlated with each other, it is difficult to distinguish their independent effects on the dependent variable, VMT. This problem, known as multicollinearity, is a feature of the data sample and is not attributed to the structural form of the model. Multicollinearity generally inflates the standard errors of the coefficients and results in estimates that, although still unbiased and efficient, lack precision. Several multicollinearity diagnostic measures are available, but a quick way to check for its 
possible existence is to examine the correlation coefficients, which measure the strength of the linear relationships between each pair of explanatory variables. Table 2.8 presents a correlation matrix of the explanatory variables used in the models. The only suspiciously high association is between household income, $\log$ (HHFAMINC), and per capita household income, $\log (\mathrm{HHINCPCAP})$. This does not present a problem since these two variables are not included together in any of the models that were estimated.

As an additional check for the existence of multicollinearity, the Variance Inflation Factors (VIFs) were examined. The VIF, which is determined by regressing each explanatory variable on all the other explanatory variables in the model, shows how the variance of an estimator is inflated by the presence of multicollinearity. A VIF of 10 or greater is indicative of a serious multicollinearity problem. Considering all 15 models that were estimated in this study, the VIFs were found to range from 1.02 to 1.88 . Therefore, it was concluded that none of the regression models suffers from severe multicollinearity.

All 15 regression models were estimated separately for households stratified by: (1) urbanized area; (2) public transportation availability; (3) metropolitan area size; (4) family life cycle; (5) day-of-week of travel; and (6) population density for households in metropolitan areas of one million or more people. A summary table comparing the travel time elasticities obtained from one of the 15 models (Model 12) for every case analyzed is shown in Table 2.9. Complete results for all model runs are presented in Appendix A. A summary of several key results obtained from the study includes the following:

- A broad, general observation from Table 2.9 is that nearly all the estimated 
Table 2.8. Correlation Matrix of Explanatory Variables

\begin{tabular}{|c|c|c|c|c|c|c|c|}
\hline Varioble & log(INVSTIDS) & bg(DINSTY) & bE(HHFAMNO) & log(HANOPCAP) & HAXEe & WRKOOUNT & $\log (\mathrm{MJIN})$ \\
\hline $\log ($ INWSDDD) & 1.0000 & 0.2644 & -0.1637 & -0.0580 & -0.1214 & -0.197 & -0.0571 \\
\hline Iog(DTSTY) & 0.2644 & 1.0000 & 0.0502 & 0.1011 & -0.0638 & -0.0149 & 0.0473 \\
\hline ILE(HAPMNC) & -0.1637 & 0.0502 & 1.0000 & 0.7350 & 0.2362 & 0.3895 & 0.3631 \\
\hline IOE(HANCPCAP) & -0.0580 & 0.1011 & 0.7350 & 1.0000 & -0.4568 & 0.0009 & 0.2753 \\
\hline HWSEe & -0.1214 & -0.0638 & 0.2362 & -0.4568 & 1.0000 & 0.4795 & 0.0742 \\
\hline WRKOOUNT & $-0.19 \pi$ & -0.0149 & 0.3895 & 0.0009 & 0.4795 & 1.0000 & 0.0928 \\
\hline $\log (M T D N C)$ & -0.0571 & 0.0473 & 0.3631 & 0.2753 & 0.0742 & 0.0928 & 1.0000 \\
\hline
\end{tabular}


Table 2.9. 1995 NPTS Comparison of Travel Time Elasticities

Estimated Model:

$$
\begin{aligned}
\log (V M T)= & \alpha+\beta_{1} \log (\text { INVSPEED })+\beta_{2} \log (\text { DENSITY })+\beta_{3} \log (H H F A M I N C)+\beta_{4}(\text { HHSIZE }) \\
& +\beta_{5}(\text { WRKCOUNT })+\varepsilon
\end{aligned}
$$

\begin{tabular}{|c|c|c|c|}
\hline Data Stratification & $\mathbf{N}$ & $\begin{array}{l}\text { Travel Time } \\
\text { Elasticity }\end{array}$ & $\begin{array}{c}\text { Reference } \\
\text { Table }\end{array}$ \\
\hline All Households & 27,409 & -0.350 & 2.7 \\
\hline $\begin{array}{c}\text { Urbanized Area } \\
\text { Urban } \\
\text { Non-UIrban }\end{array}$ & $\begin{array}{l}16,669 \\
10,740\end{array}$ & $\begin{array}{l}-0.360 \\
-0.323\end{array}$ & $\begin{array}{l}\text { A. } 1 \\
\text { A. } 2\end{array}$ \\
\hline $\begin{array}{c}\text { Transit Availability } \\
\text { Available } \\
\text { Not Available }\end{array}$ & $\begin{array}{c}17,356 \\
9,553\end{array}$ & $\begin{array}{l}-0.343 \\
-0.352\end{array}$ & $\begin{array}{l}\text { A.3 } \\
\text { A.t }\end{array}$ \\
\hline $\begin{array}{l}\text { Metropolitan Area Size } \\
\text { Not in MSA } \\
\text { Less than } 250,000 \\
250,000-499.999 \\
500,000-999.999 \\
1,000,000 \cdot 2,999,999 \\
3.000,000 \text { or More }\end{array}$ & $\begin{array}{l}4,052 \\
2,822 \\
1,758 \\
3,487 \\
5,548 \\
9,742\end{array}$ & $\begin{array}{l}-0.375 \\
-0.315 \\
-0.389 \\
-0.309 \\
-0.395 \\
-0.318\end{array}$ & $\begin{array}{l}\text { A.5 } \\
\text { A.6 } \\
\text { A.7 } \\
\text { A.8 } \\
\text { A.9 } \\
\text { A.10 }\end{array}$ \\
\hline $\begin{array}{l}\text { Family Life Cycle } \\
\text { Working, No Children } \\
\text { Youngest Child Age } 0 \text { - } 5 \\
\text { Youngest Child Age } 6 \text { - } 15 \\
\text { Youngest Child Age } 16-21 \\
\text { Retired, No Children }\end{array}$ & $\begin{array}{c}10,735 \\
5,047 \\
5,425 \\
1,621 \\
4,581\end{array}$ & $\begin{array}{l}-0.372 \\
-0.302 \\
-0.362 \\
-0.220 \\
-0.300\end{array}$ & $\begin{array}{l}\text { A.11 } \\
\text { A.12 } \\
\text { A.13 } \\
\text { A.14 } \\
\text { A.15 }\end{array}$ \\
\hline $\begin{array}{l}\text { Day of Week } \\
\text { Sunday } \\
\text { Monday } \\
\text { Tuesday } \\
\text { Wednesday } \\
\text { Thursday } \\
\text { Friday } \\
\text { Saturday }\end{array}$ & $\begin{array}{l}3,207 \\
4,146 \\
4,211 \\
4,262 \\
4,071 \\
4,122 \\
3,390\end{array}$ & $\begin{array}{l}-0.262 \\
-0.329 \\
-0.363 \\
-0.391 \\
-0.376 \\
-0.397 \\
-0.343\end{array}$ & $\begin{array}{l}\text { A. } 16 \\
\text { A. } 17 \\
\text { A. } 18 \\
\text { A.19 } \\
\text { A. } 20 \\
\text { A. } 21 \\
\text { A. } 22\end{array}$ \\
\hline $\begin{array}{l}\text { Population Density in MSA > 1,000,000* } \\
0-100 \text { Persons/Sq. Mi. } \\
100-500 \text { Persons/Sq. Mi. } \\
500-1,000 \text { Persons/Sq. Mi. } \\
1,000-2,000 \text { Persons/Sq. Mi. } \\
2,000-4,000 \text { Persons/Sq. Mi. } \\
4,000-10,000 \text { Persons/Sq. Mi. } \\
10,000-25,000 \text { Persons/Sq. Mi. } \\
\text { Over } 25,000 \text { Persons/Sq. Mi. }\end{array}$ & $\begin{array}{c}537 \\
2,201 \\
1,687 \\
2,064 \\
3,350 \\
3,863 \\
1,192 \\
396\end{array}$ & $\begin{array}{l}-0.136 \\
-0.301 \\
-0.242 \\
-0.374 \\
-0.383 \\
-0.349 \\
-0.418 \\
-0.178\end{array}$ & $\begin{array}{l}\text { A.23 } \\
\text { A.24 } \\
\text { A.25 } \\
\text { A.26 } \\
\text { A.27 } \\
\text { A.28 } \\
\text { A.29 } \\
\text { A.30 }\end{array}$ \\
\hline
\end{tabular}

- Independent variable log(DENSITY) removed from model 
travel time elasticities fall in a very narrow range of -0.3 to -0.4 , after controlling for the effects of population density, household family income, household size, and number of workers per household.

- As expected, the travel time elasticity is higher in urbanized areas than in non-urban areas. This suggests that travel time reductions have a greater impact on induced travel demand in urban areas which suffer from traffic congestion and bottlenecks than in areas where highways are already operating at high levels of service. Also, urban areas have more competing modes to draw induced demand from. To test whether the effect of being located in an urban area on travel time elasticity is statistically significant, I re-estimated Model 12 with the addition of a dummy variable to indicate urban status $(1=$ urbanized area; $0=$ non-urban $)$. Then, a test of whether the coefficient of the interaction of urban status and $\ln$ (INVSPEED) is zero tells us if urban status has a significant effect on travel time elasticity. The results showed that urban status has a marginally significant effect on travel time elasticity ( $t$-statistic $=-1.92 ;$ Prob $>|t|=0.055)$.

- The availability of public transportation has only a very minor effect on travel time elasticities. In fact, when a dummy variable indicating public transit availability was included in the model, the effect of transit availability on travel time elasticity was found to be statistically insignificant. This may be attributed in part to the fact that transit trips were not included in the analysis. Also, dense urban areas with relatively high transit usage as well as smaller cities where public transportation is available but not heavily used were both 
included in the analysis.

- Metropolitan area size appears to have no discernible effect on travel time elasticities. It is interesting to note that households in areas of between a quarter-million and a half-million people as well as households not located in a MSA both have higher elasticities than households in large cities with populations over $3,000,000$.

- Households consisting of one or more adults and no children exhibit the highest travel demand elasticity with respect to time. Also notice in the family life cycle stratification that households with young adult children (ages 16-21) have a very low travel time elasticity after taking into account income, household size, population density, and household employment. This might be partially explained by the relatively low number of data samples for this group. But it is also interesting to note that the effect of income on VMT is significantly greater in this group than in any other group that was analyzed. Income elasticities range from 0.41 to 0.52 for the various models (see Table A.14 in Appendix A). So, for this life cycle group, income appears to be a more important predictor of changes in travel behavior than travel time.

- Separate models were estimated to determine the effect on annual household VMT of the daily household travel speed derived from trips made on each day of the week. I did this to examine the responsiveness of annual travel demand to one day's travel speed. The results shown on Table 2.9 indicate that travel time elasticities using speed estimates for each day of the week are very similar, with the exception of Sunday. Paired t-tests were conducted on the 
travel time elasticity estimates to see if they were statistically significantly different by day-of-week. I found no significant difference in travel time elasticities for any combination of weekday pairs or any combination of a weekday and Saturday. However, elasticities based on average Sunday travel speed turned out to be statistically significantly different from the elasticities based on every other day's travel speed. This finding verifies that, with the exception of Sunday, annual VMT is not sensitive to the day-of-week on which travel speed is based, and it lends credibility to the model specification using daily travel speed as a proxy for overall speed in evaluating the effect on annual travel demand. Furthermore, it suggests that Sunday travel speed is not a good measure of speed for annual demand and should not be used to estimate induced travel effects.

- Stratification of the data by population density in the larger metropolitan areas produces no apparent trends in travel time elasticities. The a priori belief was that the effects of travel time on VMT would be greatest in densely populated areas that experience high levels of congestion, but the results do not generally support this hypothesis. The results for the largest and smallest density groups are unreliable due to the small sample sizes. Tables A.25 and A.32 show that the t-statistics on log(INVSPEED) are small and, in many cases, statistically insignificant.

- Coefficients on the other independent variables in the models (population density, income, per capita income, household size, number of workers per household, and median household income of the census tract) exhibit values 
for all the cases run that are very similar to the values obtained using the entire data set that were presented in Table 2.7.

\section{Summary of Major Findings}

In an effort to add to the growing body of empirical evidence that explains and quantifies the induced travel phenomenon, travel time elasticities were estimated using household-level travel data from the 1995 Nationwide Personal Transportation Survey. Recent literature on the relationship between roadway capacity or travel time and levels of travel appears to be building a consensus on general effects. Short-run elasticities (the change in travel with respect to a change in roadway capacity) of VMT with respect to lane miles on the order of 0.2 to 0.6 and long-run elasticities of 0.6 to 1.0 are commonly found. Also, short-run elasticities of VMT with respect to travel time of -0.2 to -0.6 have been reported by other researchers. The results of my analysis are similar to other studies; short-run elasticities of VMT with respect to travel time of -0.3 to -0.5 are found. Long-run elasticities could not be evaluated since the NPTS data used in the analysis are gathered over a 14-month period. The NPTS is not a longitudinal survey, so no attempt is made to track househcld travel behavior over an extended period of time. Nevertheless, this study showed that the basic hypothesis that additions to roadway capacity which reduce travel time have a significant positive impact on travel (measured here as annual VMT) cannot be rejected. It enhances the state of knowledge about induced travel demand since it is one of the few studies based on disaggregate householdlevel travel data. Furthermore, it is an improvement over Gorina and Cohen's analysis of 1990 NPTS data since it uses the newer 1995 NPTS dataset, it includes additional 
significant explanatory variables in the models, and it estimates separate models using travel speeds for each day of the week.

A large induced travel effect with a VMT elasticity with respect to travel time near -1.0 indicates that nearly all the congestion benefits of highway capacity expansion are lost to increased traffic volume. It could also suggest that there was considerable latent or suppressed travel demand that was released when the cost of driving was lowered. For example, trips that are either made during off-peak hours or foregone altogether because of congestion may be made during preferred peak periods when infrastructure improvements reduce the travel time component of overall travel cost. The smaller induced travel effect determined from my analysis of NPTS data (i.e., elasticities of -0.3 to -0.5 ) tends to suggest that many benefits from highway improvements that reduce travel time are retained over the short run. It may also suggest that no significant latent travel demand is going unfilled.

The type of analysis presented here using average household daily travel speed and VMT data to derive elasticity relationships does not reveal a causal relationship between travel time and VMT growth. The analysis assumes that travel time reductions resulting from highway capacity additions cause a growth in vehicle miles of travel. However, it may also be argued that transportation planners will respond to forecasts of VMT growth by adding capacity. An ideal approach to determining the exogeneity of the relationship between VMT and travel speed is the use of an instrumental variable and a two-stage least squares modeling procedure. This technique is also a remedy for the problem of endogeneity caused by the way in which the travel speed variable is constructed. Because daily VMT is used to calculate travel speed and annual VMT is the 
dependent variable, the independent travel speed variable is jointly determined with the response and is therefore correlated with the error term in the linear regression equation. For the data set analyzed in this study, I was not able to find an adequate instrumental variable for travel speed (i.e., one that is correlated with travel speed but not with VMT). Perhaps a measure of congestion would be useful, but no such variable exists in the NPTS database. I will leave this as an issue to be investigated in a future research study. 


\section{CHAPTER III}

\section{BEFORE-AND-AFTER CASE STUDY ANALYSIS}

\section{Research Objective}

An interesting and direct way to assess the effect of highway capacity on travel behavior is to observe the changes in travel patterns that occur between two points in time in a metropolitan area that has undergone significant highway system improvements. Studies using this before-and-after case study approach are rarely found in the literature. The primary objective of this study is to adapt an analytical approach for evaluating the statistical significance and quantifying the magnitude of observed changes in several measures of travel demand in a metropolitan area after significant increases in highway capacity had taken place. Three similar statistical models are used in the analysis.

Both this study and the previous study presented in Chapter II share a common purpose of estimating relationships between highway capacity and travel demand. However, the data sets and the analytical techniques used in the analysis are distinctly different. The first study uses disaggregate, cross-sectional household travel survey data collected over a 14-month period to estimate the time elasticity of travel demand. Disaggregate data are advantageous since they reflect individual decisions about where, when, why, and how to travel, and cross-sectional data are useful because they capture the travel behavior of many different people who face widely varying highway and transportation situations. However, this approach did not account for the region-specific effects unique to a particular metropolitan area, nor did it evaluate the long-term effects 
of highway capacity on travel demand. The before-and-after case study, on the other hand, uses travel data specific to one metropolitan area from two time periods to measure temporal changes in travel demand. The same groups of households are surveyed although the groups do not necessarily remain static from 1984 to 1995 . In contrast to the NPTS study, the analysis in the before-and-after study is done at the aggregate travel zone level; that is, the travel zone rather than the household is the unit of observation used in the analysis.

\section{Description of Data}

A case study analysis to evaluate differences in travel behavior before and after making extensive additions to highway capacity was performed using travel data from the Dallas-Fort Worth (DFW) metropolitan area. Data files were obtained from the North Central Texas Council of Governments and consisted of output data from their 1984 calibrated travel model and their 1995 validated model. The following data files were provided:

- ArcView shape files containing the 1984 traffic survey zone and transportation analysis process (TAP) zone structures, covering a 3,200square-mile area. TAP zones are aggregations of traffic survey zones; there are 800 TAP zones and 5,691 traffic survey zones in the 1984 data set. The TAP zone is used as the unit of observation in this study.

- ArcView shape files containing the 1995 traffic survey zone and TAP zone structures, which cover an area of 4,980 square miles. The 1995 data have 919 TAP zones and 5,999 traffic survey zones. 
- 1984 and 1995 major thoroughfare links files. These files contain the unique link name code and various link attributes (functional classification, number of lanes, link length, speed limit, etc.) at the traffic survey zone level.

- 1984 and 1995 subarea link and volume files. These files are similar to the major thoroughfare link files, but they are aggregated to the TAP zone level. They contain hourly capacity and assigned weekday volume data for every link in the network.

- 1984 and 1995 major thoroughfare and subarea node files. These files contain the network node numbers, $\mathrm{x}$ and $\mathrm{y}$ coordinates, and corresponding traffic survey zone (for the major thoroughfare file) and TAP zone (for the subarea file) numbers. The $x-y$ coordinates are in NAD27 format with the map units in feet.

- 1984 and 1995 hierarchical zonal data files, containing the zone area in square miles, area type, demographic data (population, number of households, median household income, basic employment, retail employment, and service employment), and travel data (trip productions and attractions by purpose) for every traffic survey zone.

- 1984 and 1995 subarea zone files. These are identical to the hierarchical zonal files but contain the data for each TAP zone.

- 1984 and 1995 street name files, containing the street names of every link in the network along with the names of cross streets at the nodes on the link.

- 1984 and 1995 traffic count data for all links at which 24-hour vehicle counts had been measured. 
There were differences in the traffic survey zone and TAP zone structures between 1984 and 1995. In most cases, the TAP zone boundaries remained unchanged from 1984 to 1995; however, some significant structural changes were observed (a single zone in 1984 being divided into three zones in 1995, for example). Moreover, the TAP zone identification numbers were completely different for the two time periods. By overlaying the two zone structures in ArcView, I established structural equivalency between the 1984 and 1995 TAP zones. I did not develop equivalency tables of traffic survey zones for the two time periods since the process was extremely complex and cumbersome for the large number of zones. Therefore, the data analysis was conducted at the TAP zone level.

Figure 3.1 shows a comparison of the 1984 and 1995 travel survey areas. For reference purposes, the TAP zone structural equivalency between 1984 and 1995 is provided in Appendix B. The following three tables of information are provided in the Appendix:

- Tables B.1 and B.2 present the TAP zone identification numbers corresponding to external stations (i.e., stations located along the outer boundaries of the DFW survey area that have no demographic attributes but are used only for recording external travel into or out of the survey area);

- Table B.2 shows the 1995 TAP zone ID numbers representing zones that were added when the survey area was extended and are therefore not contained in the 1984 data set; and

- Table B.3 provides a complete zone-to-zone comparison by ID number of all other zones between 1984 and 1995. 


\section{Dallas-Ft. Worth TAP Zones 1984/1995 Survey Area Comparison}

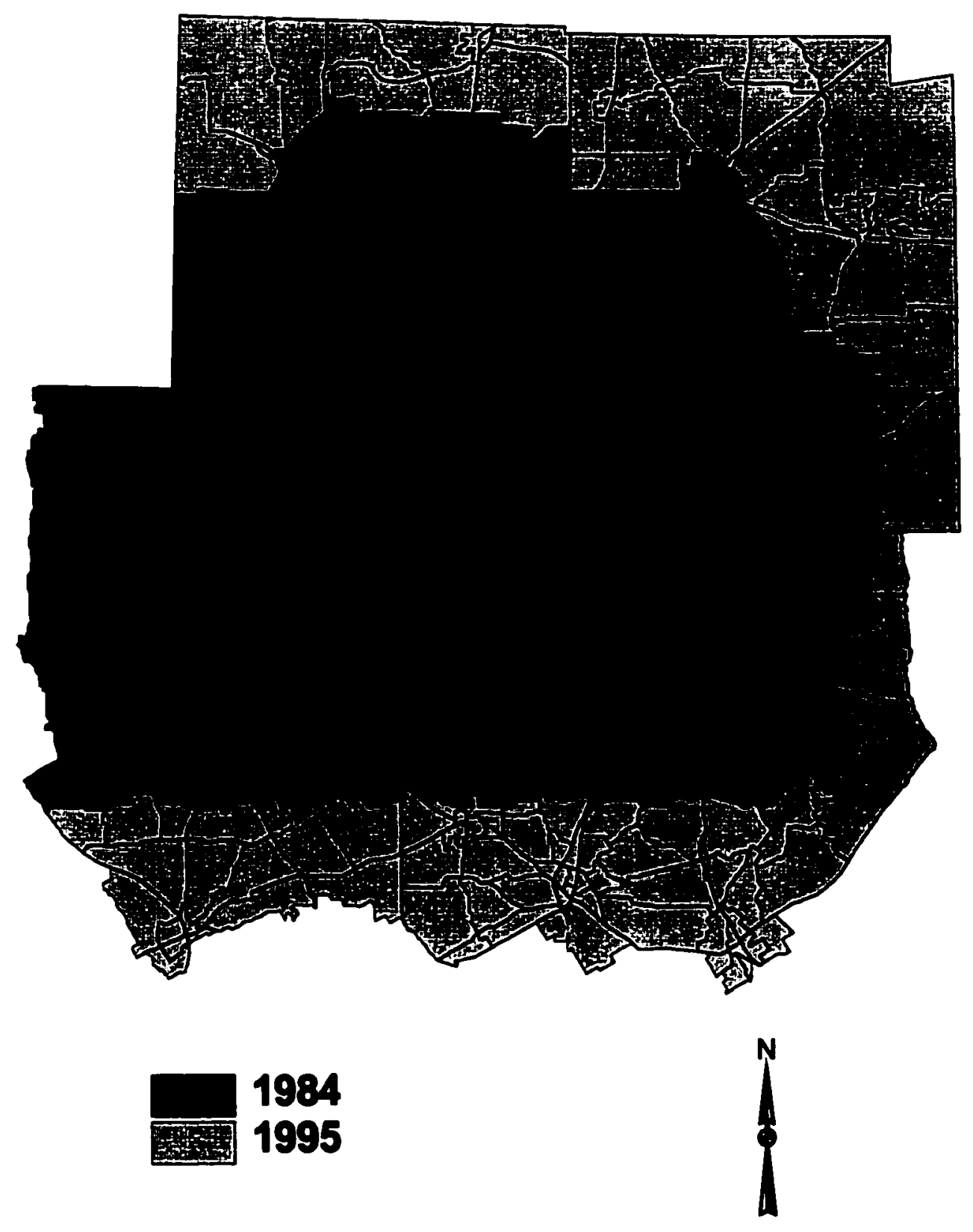

Figure 3.1. Comparison of 1984 and 1995 DFW Travel Survey Areas 
Trip production and attraction data for each TAP zone were obtained directly from the subarea zone files. Total productions/attractions are simply the calculated sum of all productions/attractions by purpose. Trip productions per household are the total number of trips produced in the zone divided by the number of households in the zone. When considering trips produced per household as the dependent variable in the analysis, only zones containing more than 100 households were used. This was done to eliminate obvious outliers and avoid erroneous results. As an example, one TAP zone consisted of one household, yet reported 12,703 non-home-based trip productions; another zone had five households and produced 18,441 non-home-based and 6,609 "other" trips.

Vehicle-miles of travel were determined using the subarea link and volume files. VMT was calculated for each link in the network by multiplying the assigned total weekday volume on the link by the link length. Individual link VMTs were then aggregated up to the TAP zone level, so the total weekday VMT became an attribute of each zone. Finally, all external stations were omitted from the analysis since the "zones" representing external stations contained no road network or demographic attributes.

The important socioeconomic, demographic, and travel distribution patterns of the Dallas-Fort Worth (DFW) metropolitan region in 1984 and 1995 are displayed as ArcView GIS layouts on the pages that follow in this section. Figures 3.2 and 3.3 show the area type for each TAP zone in 1984 and 1995, respectively. The area types are very similar in the two time periods, and they indicate features that are typical of modern American urban areas. Business activity is centered in downtown Dallas and, to the west, downtown Fort Worth. The metropolitan area expands radially outward from the central cities into an outer business district and then into urban, suburban, and exurban 


\section{Dallas-Fort Worth TAP Zones - 1984 Area Type}

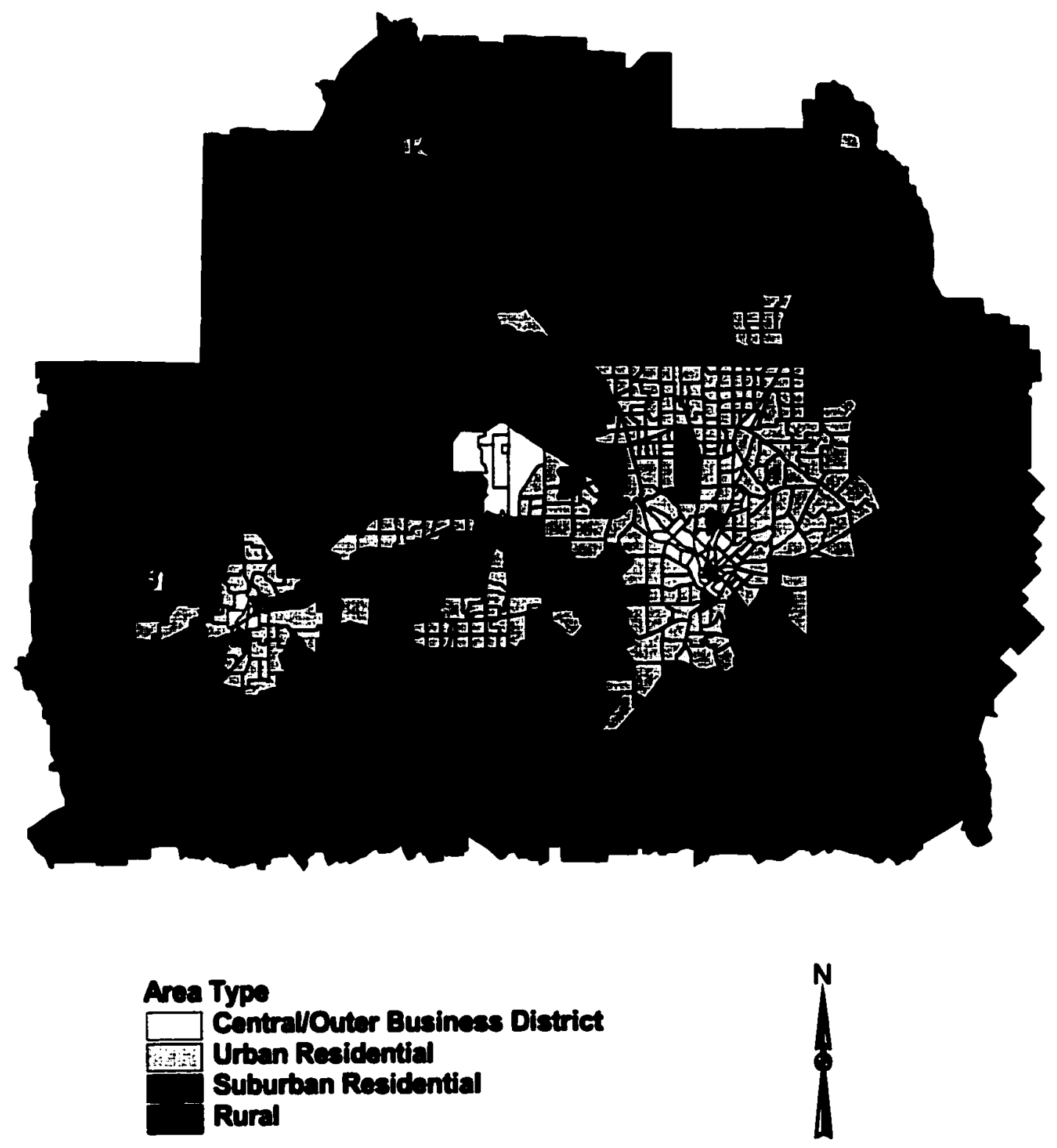

Figure 3.2. 1984 DFW TAP Zone Area Type 


\section{Dallas-Fort Worth TAP Zones - 1995 Area Type}

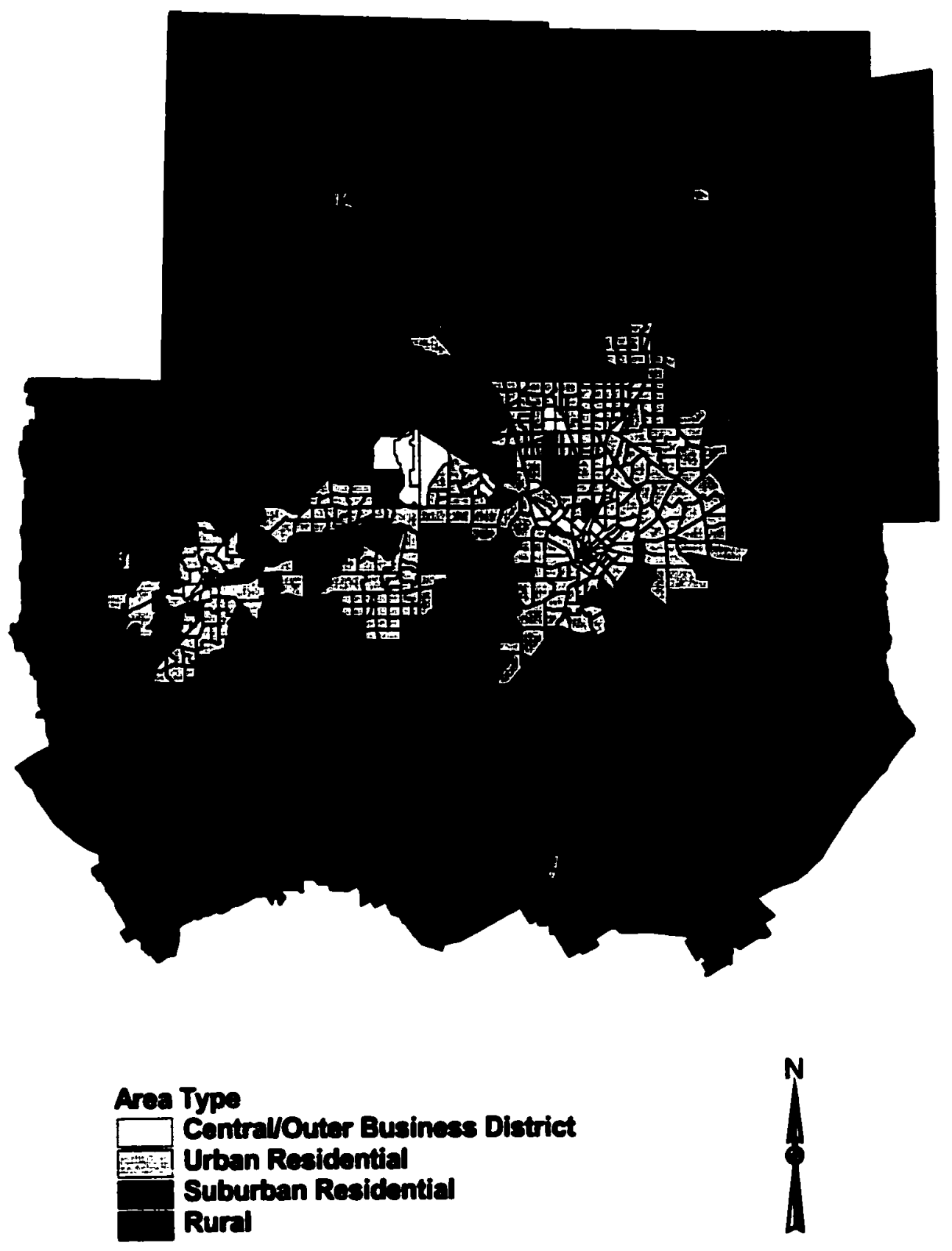

Figure 3.3. 1995 DFW TAP Zone Area Type 
population centers.

The population characteristics and population density distributions for 1984 and 1995 are plotted in Figures 3.4 through 3.7. The distributions for the two years show similar patterns. High-density development is clustered around central Dallas with medium to high densities spreading outward from Dallas in the northeast and southwest directions and also spreading south from downtown Fort Worth. A pocket of fairly high density development is also evident approximately midway between the two cities in Arlington. Another notable feature is large areas of low-density development (i.e., high population and low population density) located in zones at the outer boundaries of the metropolitan area in cities such as Denton and Garland.

The employment and employment density distributions across the DFW metropolitan area in 1984 and 1995, shown in Figures 3.8 through 3.11, are strikingly similar. The very high concentration of jobs in the Dallas central business district, stretching northwest up to DFW International Airport is very evident in both years. Other large employment centers can be seen around the Fort Worth CBD, in Arlington, and also in isolated pockets northwest of Dallas in Denton and east of Dallas in Garland and Richardson.

The distributions of household income in the DFW region for 1984 and 1995 are shown in Figures 3.12 and 3.13, respectively. While there has certainly been overall growth in median household income levels over time, the number of upper and uppermiddle income zones relative to middle and lower income classes appears to have declined, particularly in areas south of the Dallas and Fort Worth city centers. The GIS layouts also indicate a concentration of low-income zones located in and just adjacent to 


\section{Dallas-Fort Worth TAP Zones - 1984 Population}

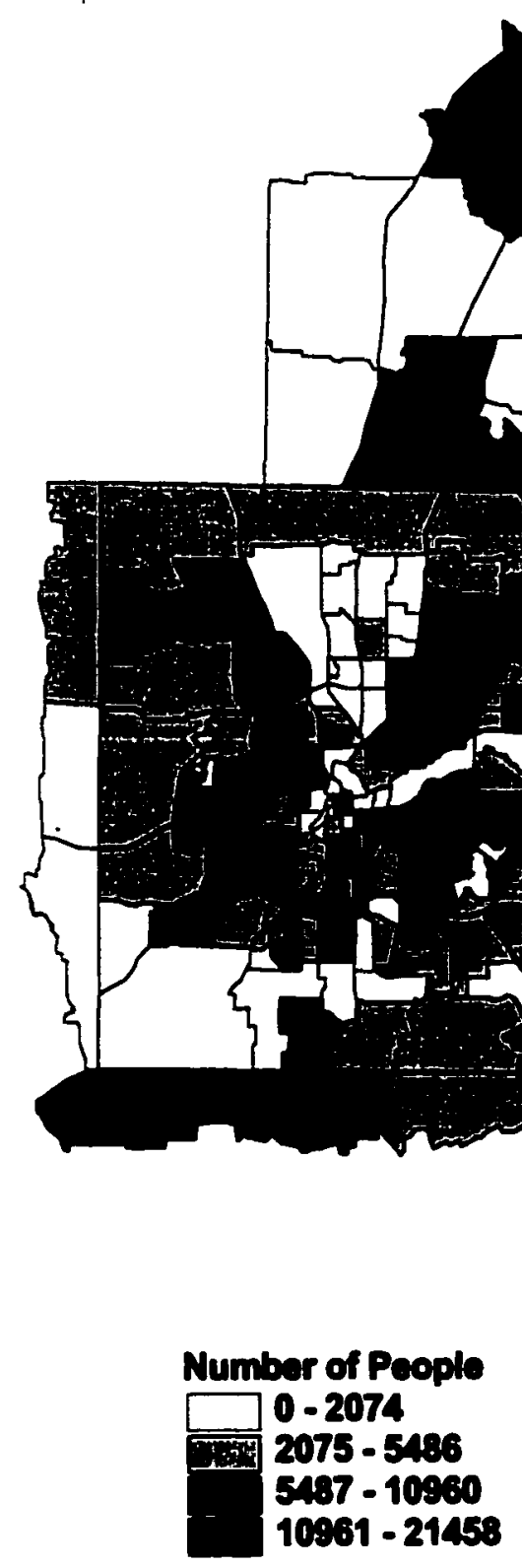

1

Figure 3.4. 1984 DFW TAP Zone Population Distribution 


\section{Dallas-Fort Worth TAP Zones - 1995 Population}

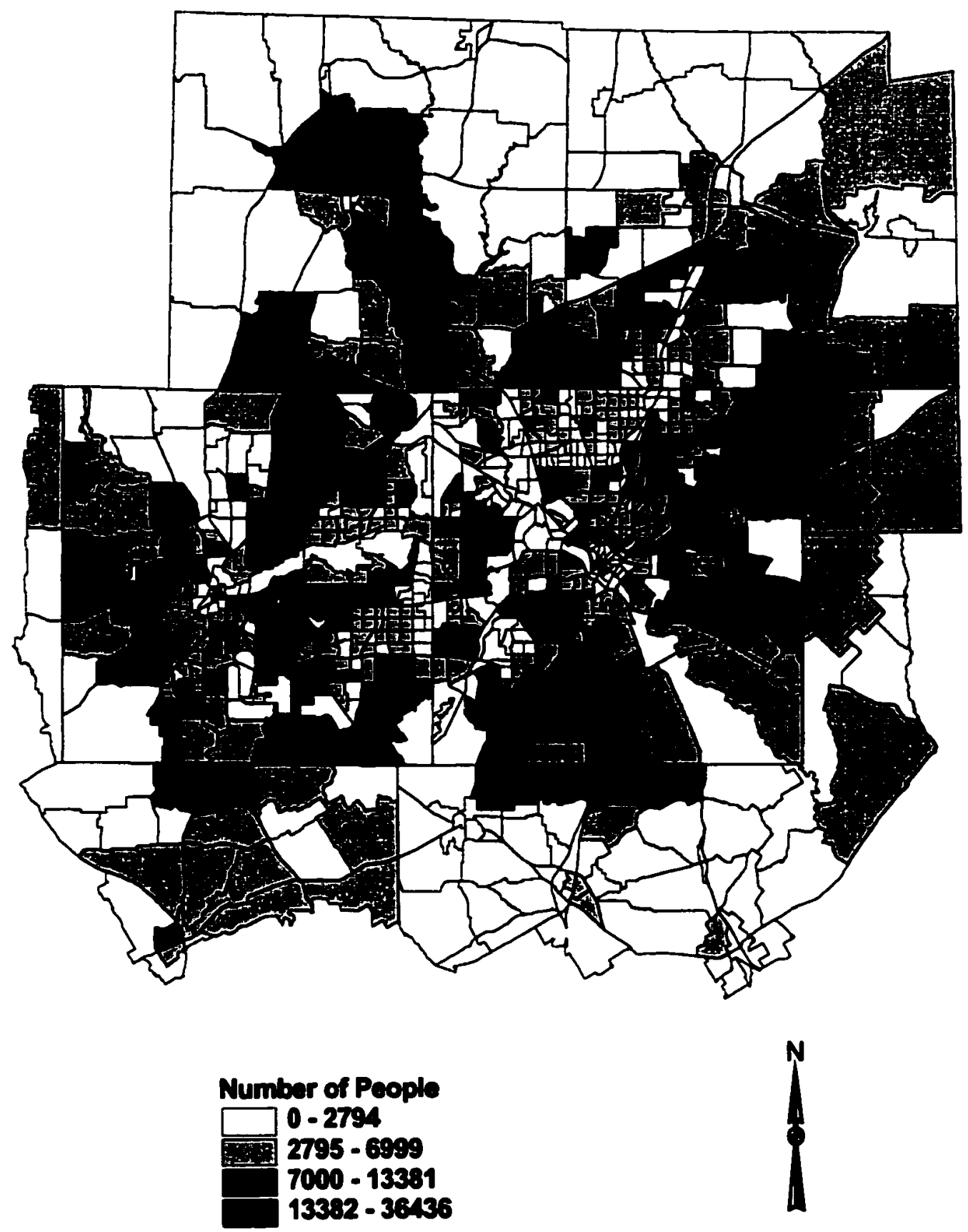

Figure 3.5. 1995 DFW TAP Zone Population Distribution 


\section{Dallas-Fort Worth TAP Zones - 1984 Population Density}

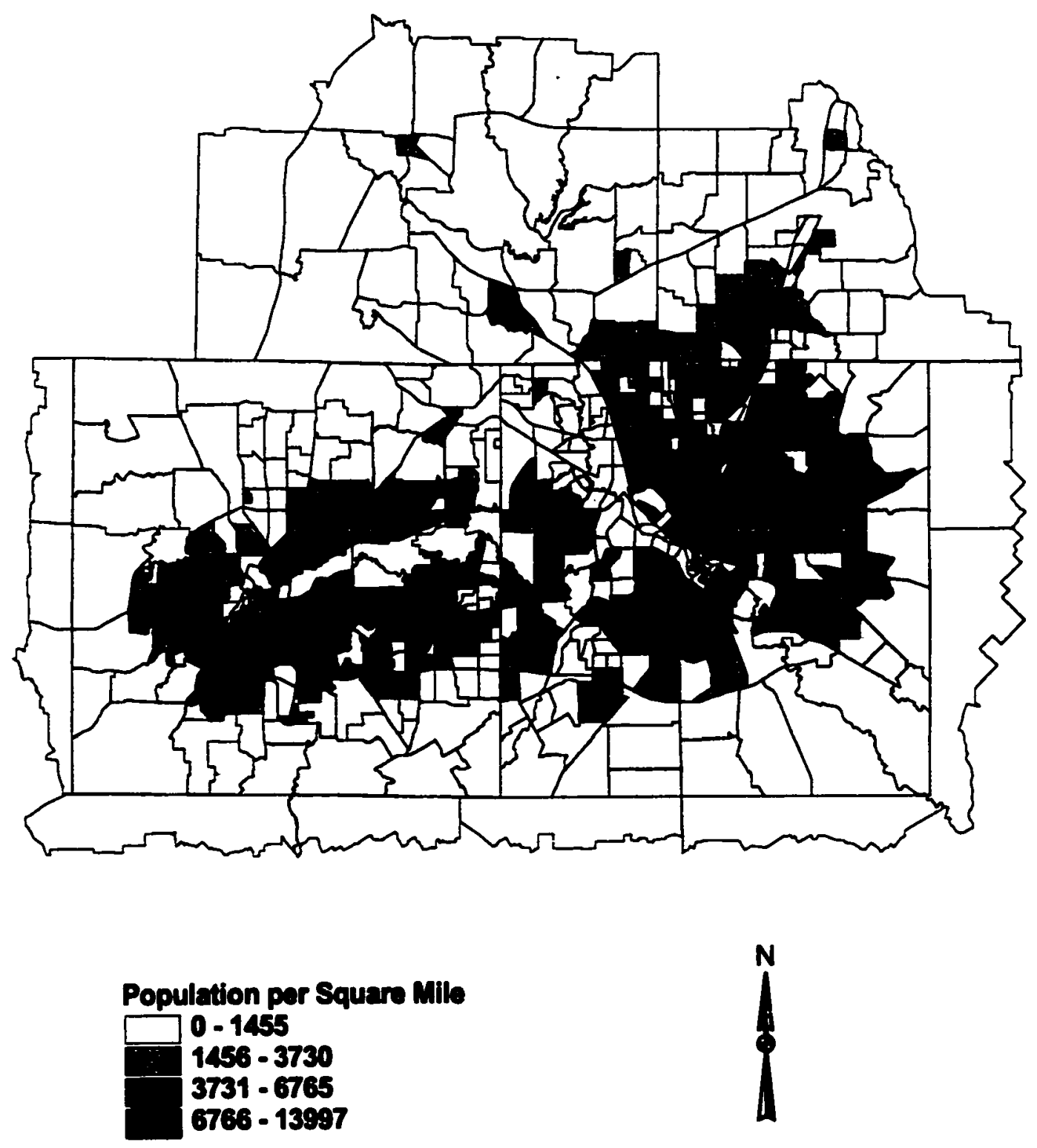

Figure 3.6. 1984 DFW TAP Zone Population Density Distribution 


\section{Dallas-Fort Worth TAP Zones - 1995 Population Density}

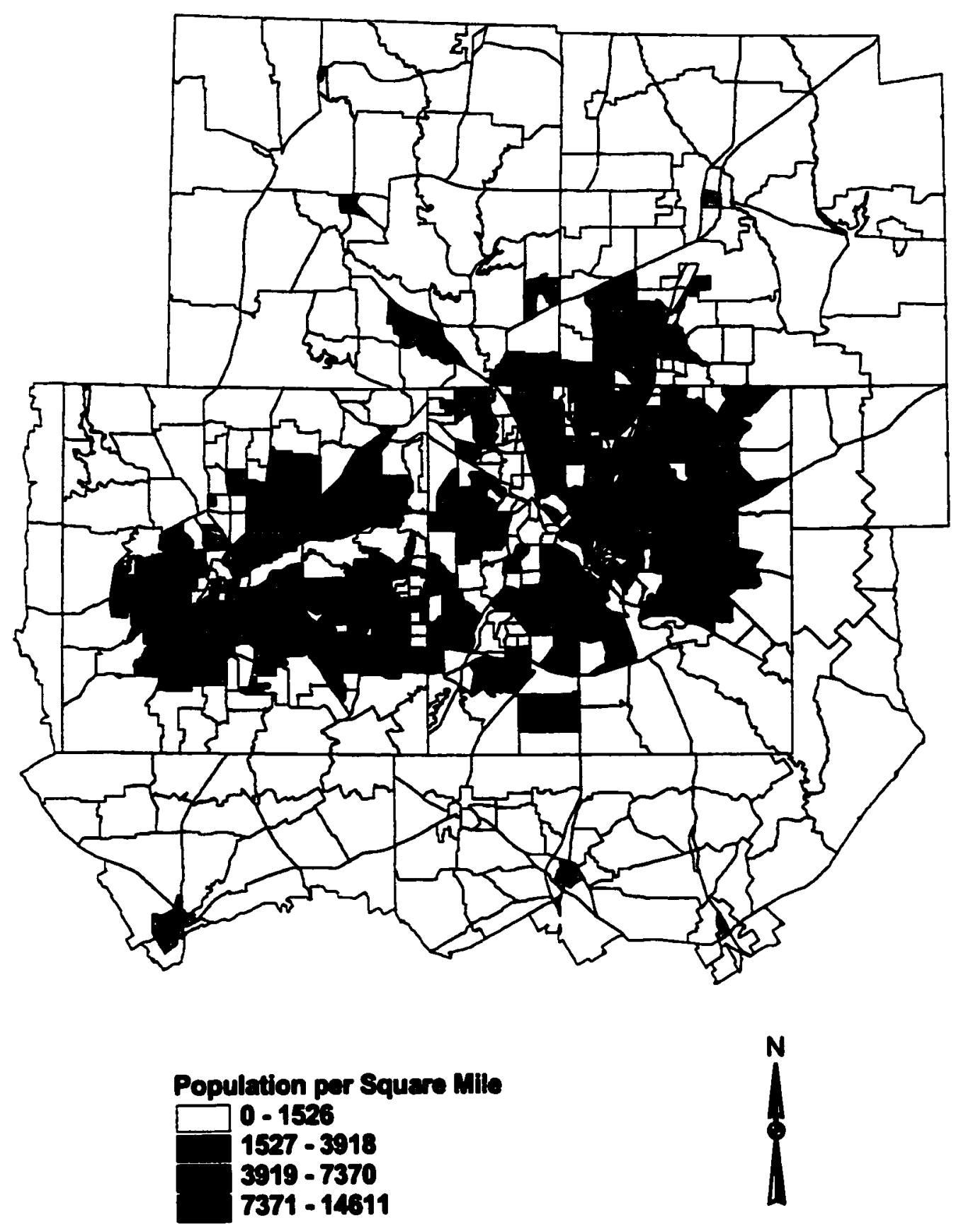

Figure 3.7. 1995 DFW TAP Zone Population Density Distribution 


\section{Dallas-Fort Worth TAP Zones - 1984 Total Employment}

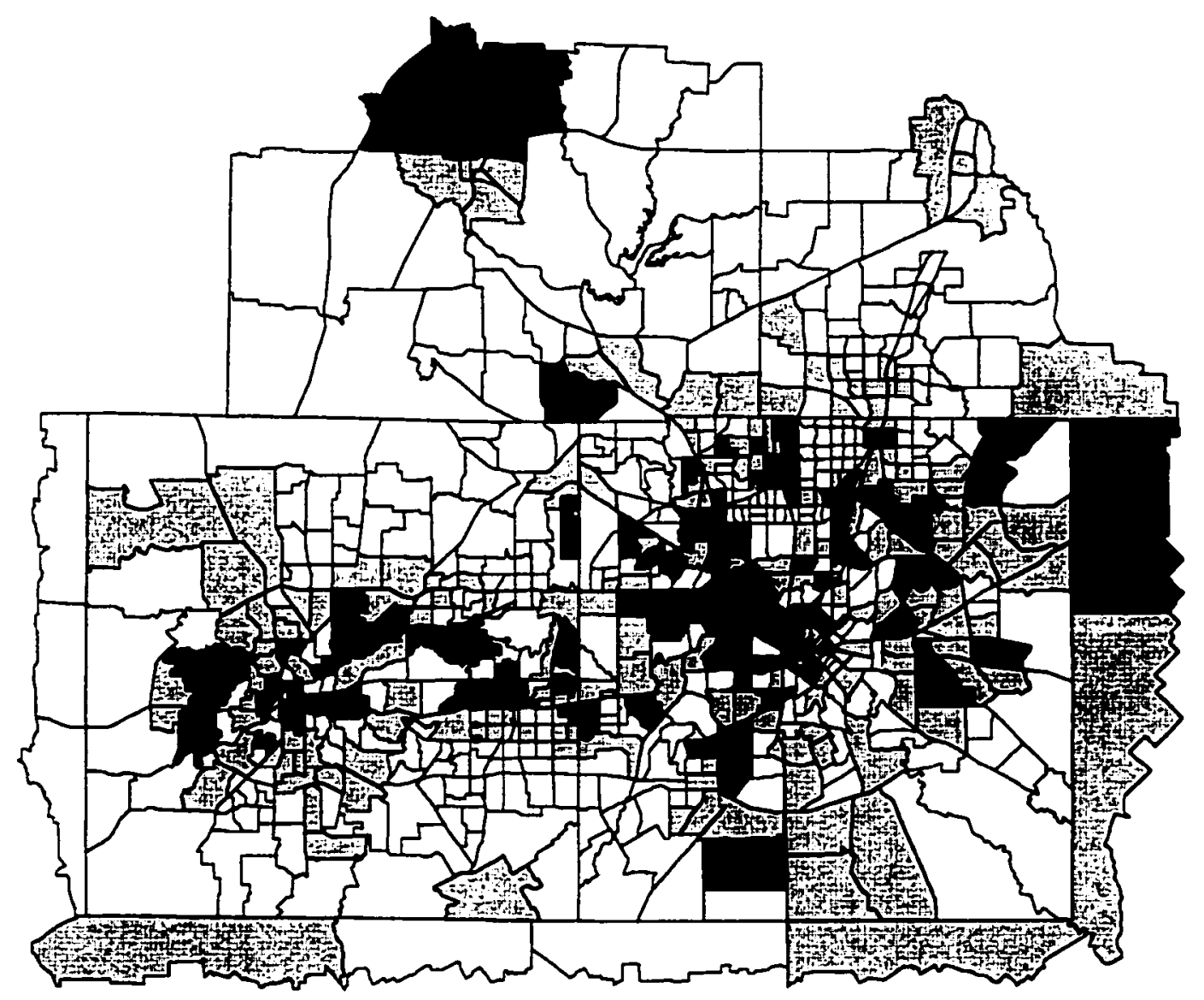

Number of Employses

\begin{tabular}{|l}
\hline \\
\hline \\
$0-1662$ \\
$1663-4412$ \\
$413-9217$ \\
$9218-27683$
\end{tabular}

1

Figure 3.8. 1984 DFW TAP Zone Employment Characteristics 


\section{Dallas-Fort Worth TAP Zones - 1995 Total Employment}

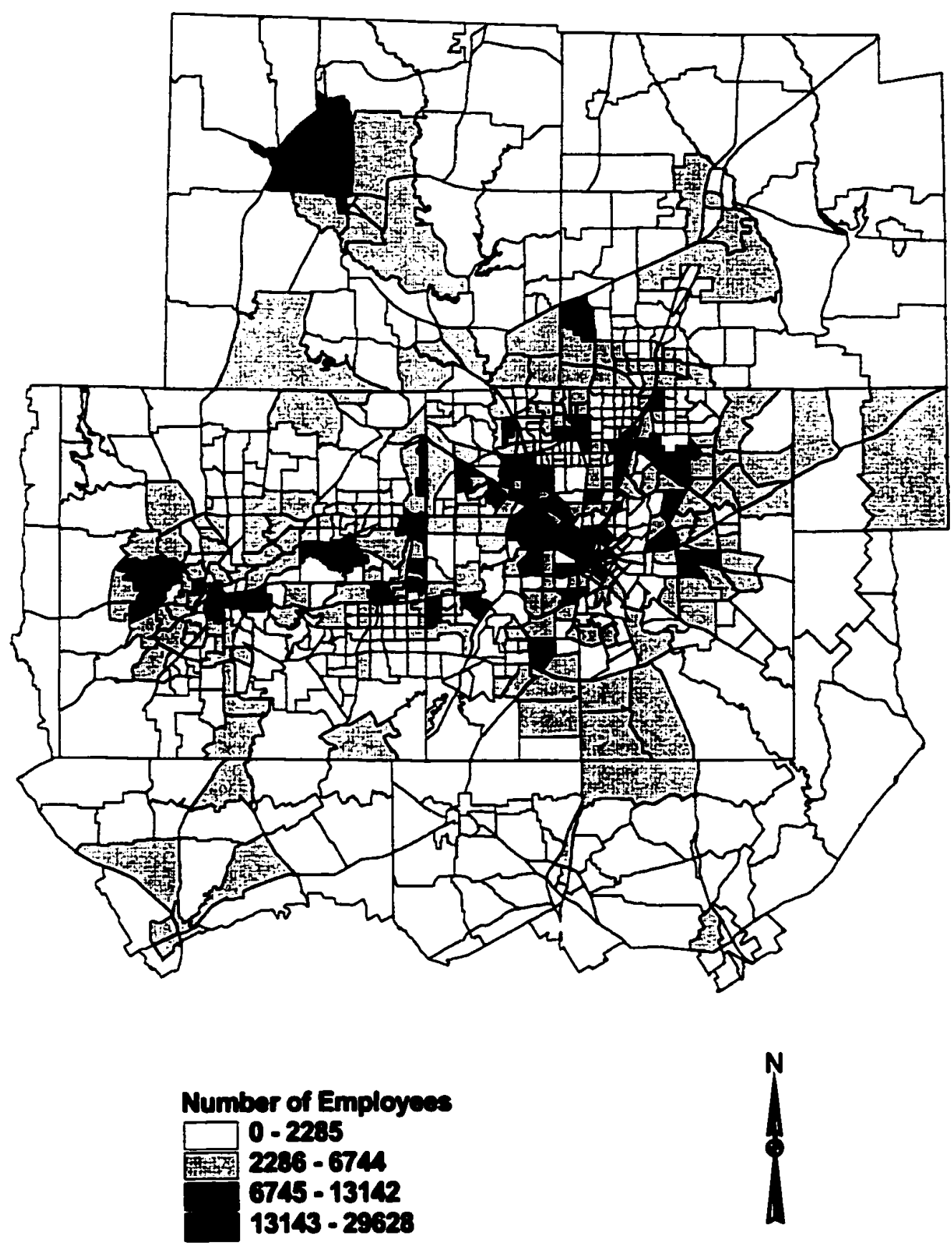

Figure 3.9. 1995 DFW TAP Zone Employment Characteristics 


\section{Dallas-Fort Worth TAP Zones - 1984 Employment Density}

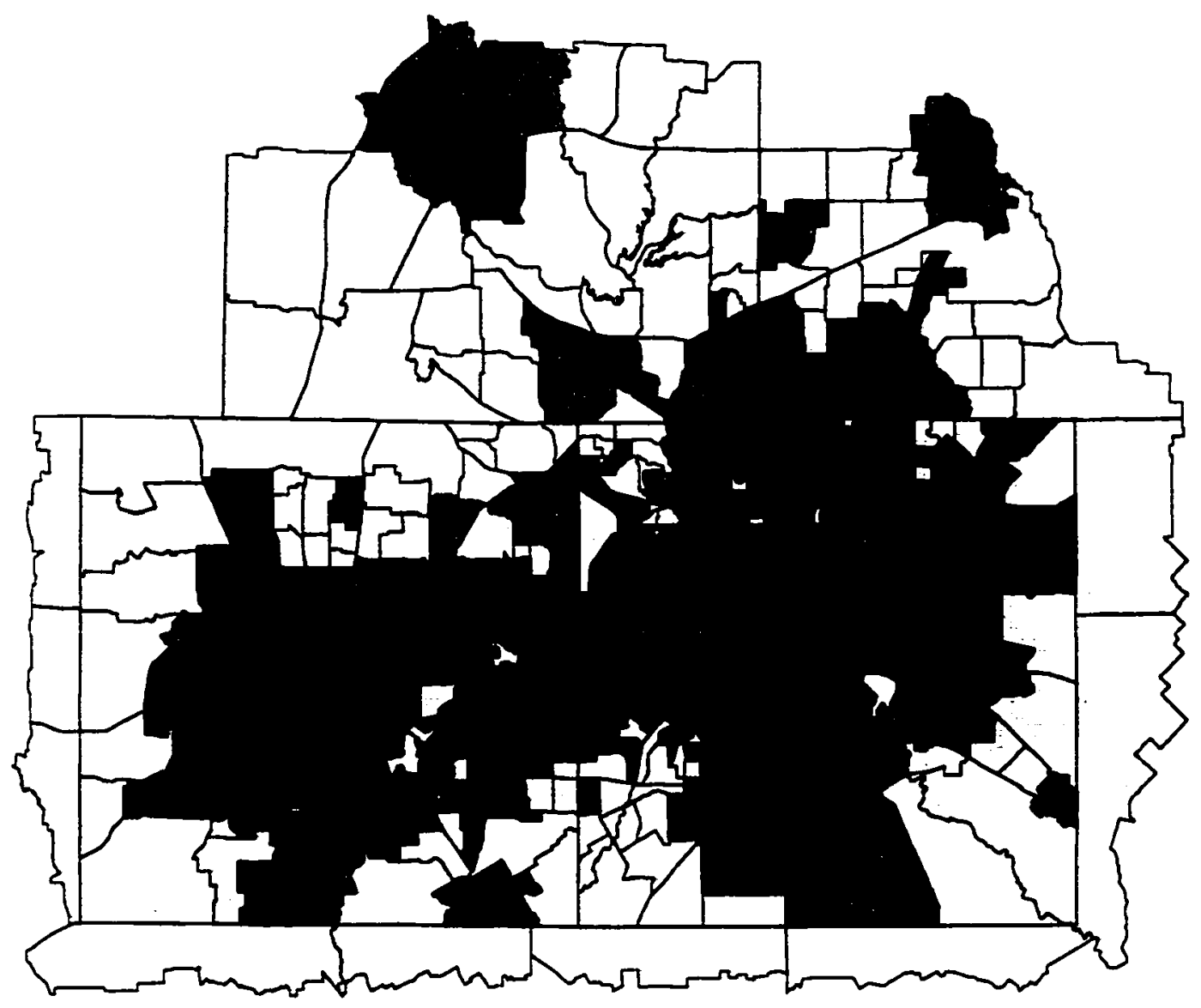

Employees per Square Mile

0.100

$101-645$

$646-2195$

$2196-365043$

1

Figure 3.10. 1984 DFW TAP Zone Employment Density Characteristics 


\section{Dallas-Fort Worth TAP Zones - 1995 Employment Density}

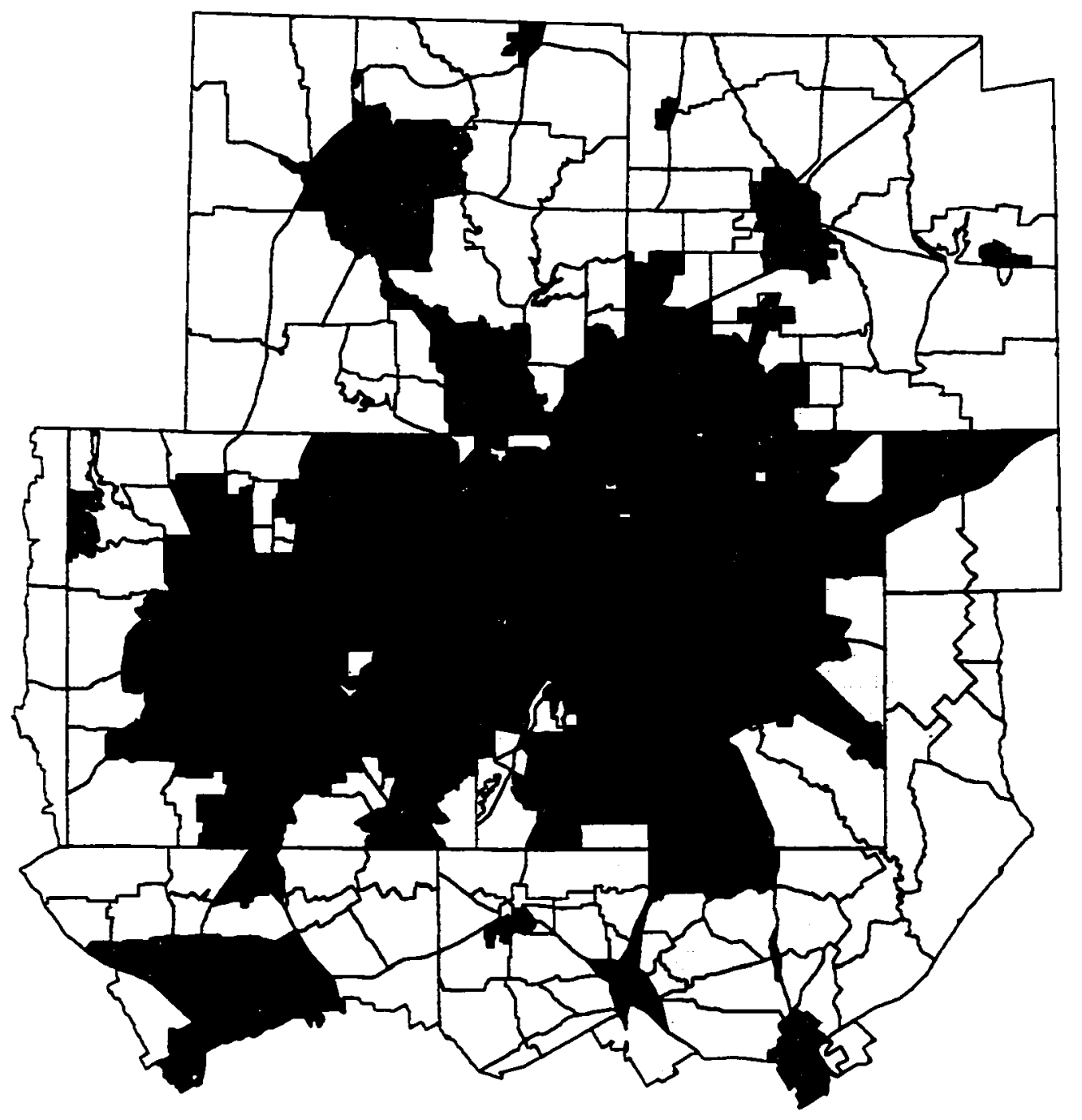

Employees per Square Mile

$0-85$

$89-610$

$611-2095$

$2096-476346$

1

Figure 3.11. 1995 DFW TAP Zone Employment Density Characteristics 


\section{Dallas-Fort Worth TAP Zones - 1984 Median Household Income}

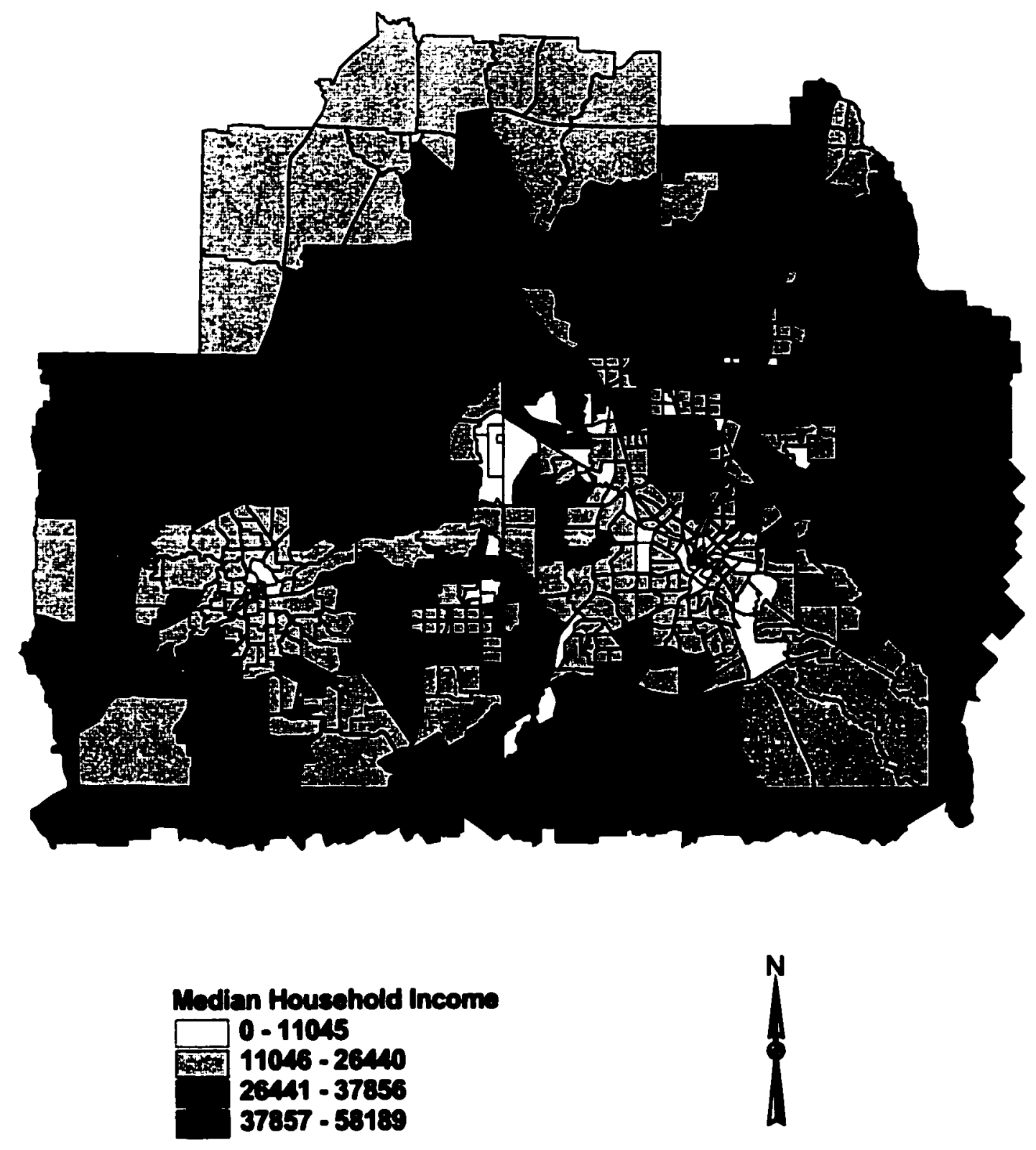

Figure 3.12. 1984 DFW TAP Zone Household Income Distribution 


\section{Dallas-Fort Worth TAP Zones - 1995 Median Household Income}

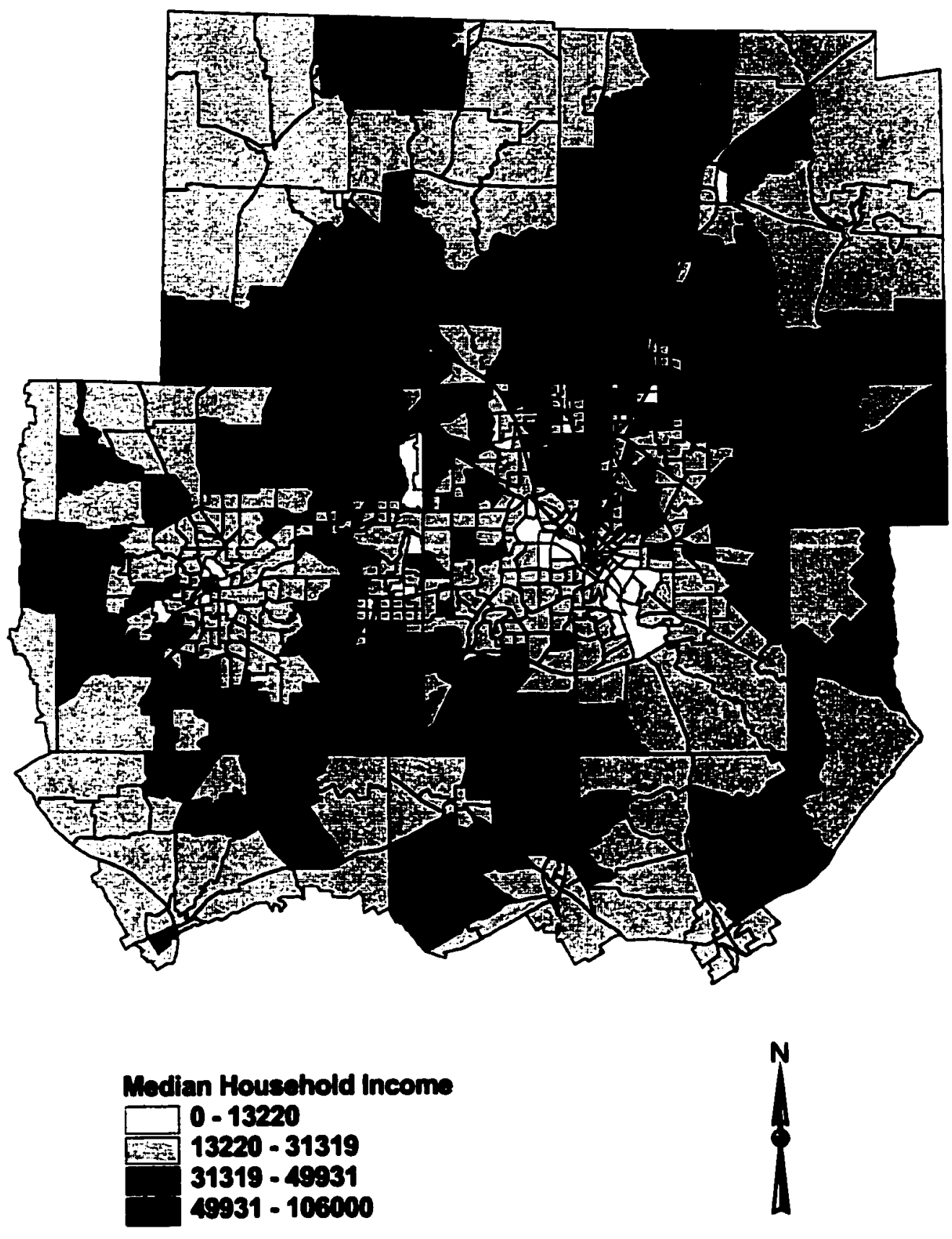

Figure 3.13. 1995 DFW TAP Zone Household Income Distribution 
the central areas of the cities. Within metropolitan Dallas, low-income neighborhoods extend from the northwest corner of the city diagonally to the southeast section, whereas upper-income areas are located predominantly in the northern suburbs. It is also interesting to note that the 1995 outer suburban zones which represent an extension of the survey area from 1984 consist almost entirely of middle and lower-middle income households.

Travel behavior characteristics of the DFW metropolitan area for 1984 and 1995 are presented in Figures 3.14 through 3.29. The measures of travel demand that are shown in these GIS layouts include: Trip productions (Figures 3.14 and 3.15); Trip attractions (Figures 3.16 and 3.17); Trip productions per household (Figures 3.18 and 3.19); and Vehicle-miles of travel (Figures 3.20 and 3.21). In addition, trip productions and attractions by purpose (home-based work, home-based nonwork, nonhome-based, and other trips) are included for information and completeness in Figures 3.22 through 3.29. Some key observations regarding the spatial distribution of travel behavior include:

- Trip productions seem to be reasonably evenly dispersed throughout the region. With the exception of two zones northwest of Dallas and an area east of Dallas that represent the cities of Denton and Richardson, respectively, there are no discernible pockets of high trip-making activity (Figures 3.14 and 3.15). Denton and Richardson produce relatively high numbers of trips for all purposes. In Figure 3.15, it is clear that the majority of the area that was added to the metropolitan area when the survey boundaries were extended in 1995 consists of low trip-producing zones.

- As expected, trip attractions (Figures 3.16 and 3.17) are lowest in the outer 


\section{Dallas-Fort Worth TAP Zones - 1984 Total Trip Productions}

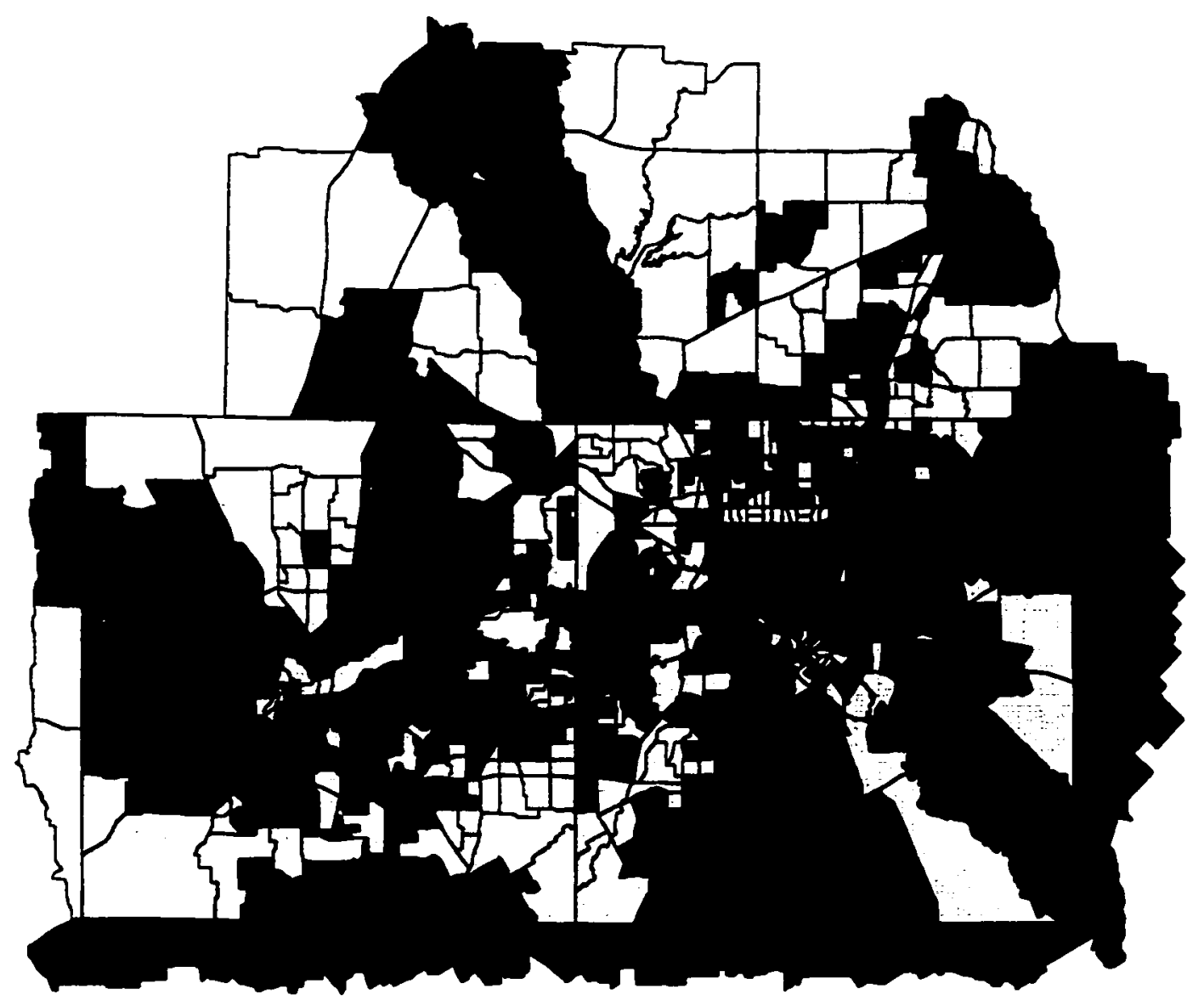

Number of Trips Produced

\begin{tabular}{|l}
\hline 0 - 9003 \\
$8004-20683$ \\
$20684-38204$ \\
38205 - 77187
\end{tabular}

1

Figure 3.14. 1984 DFW Total Trips Produced by Zone 


\section{Dallas-Fort Worth TAP Zones - 1995 Total Trip Productions}

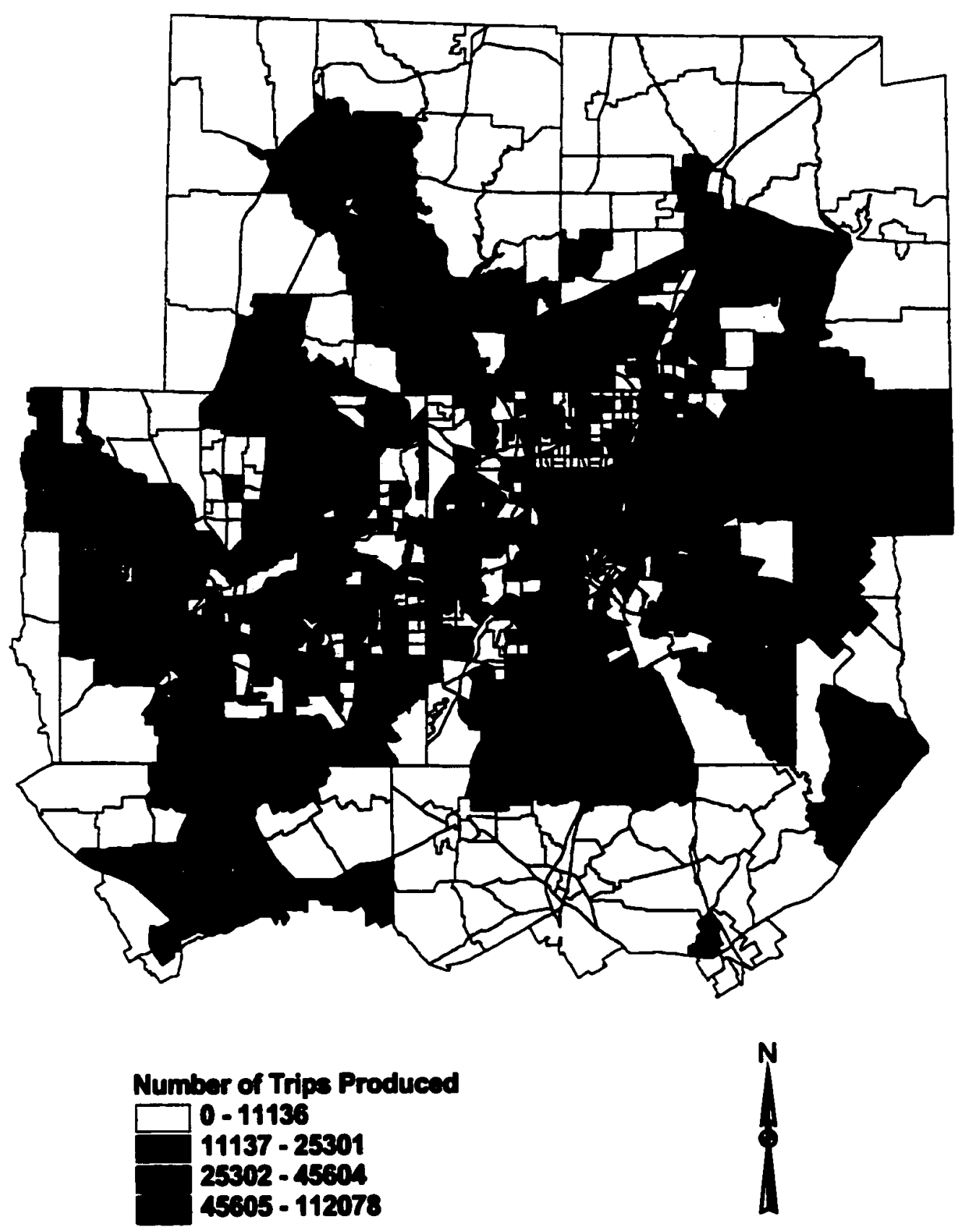

Figure 3.15. 1995 DFW Total Trips Produced by Zone 


\section{Dallas-Fort Worth TAP Zones - 1984 Total Trip Attractions}

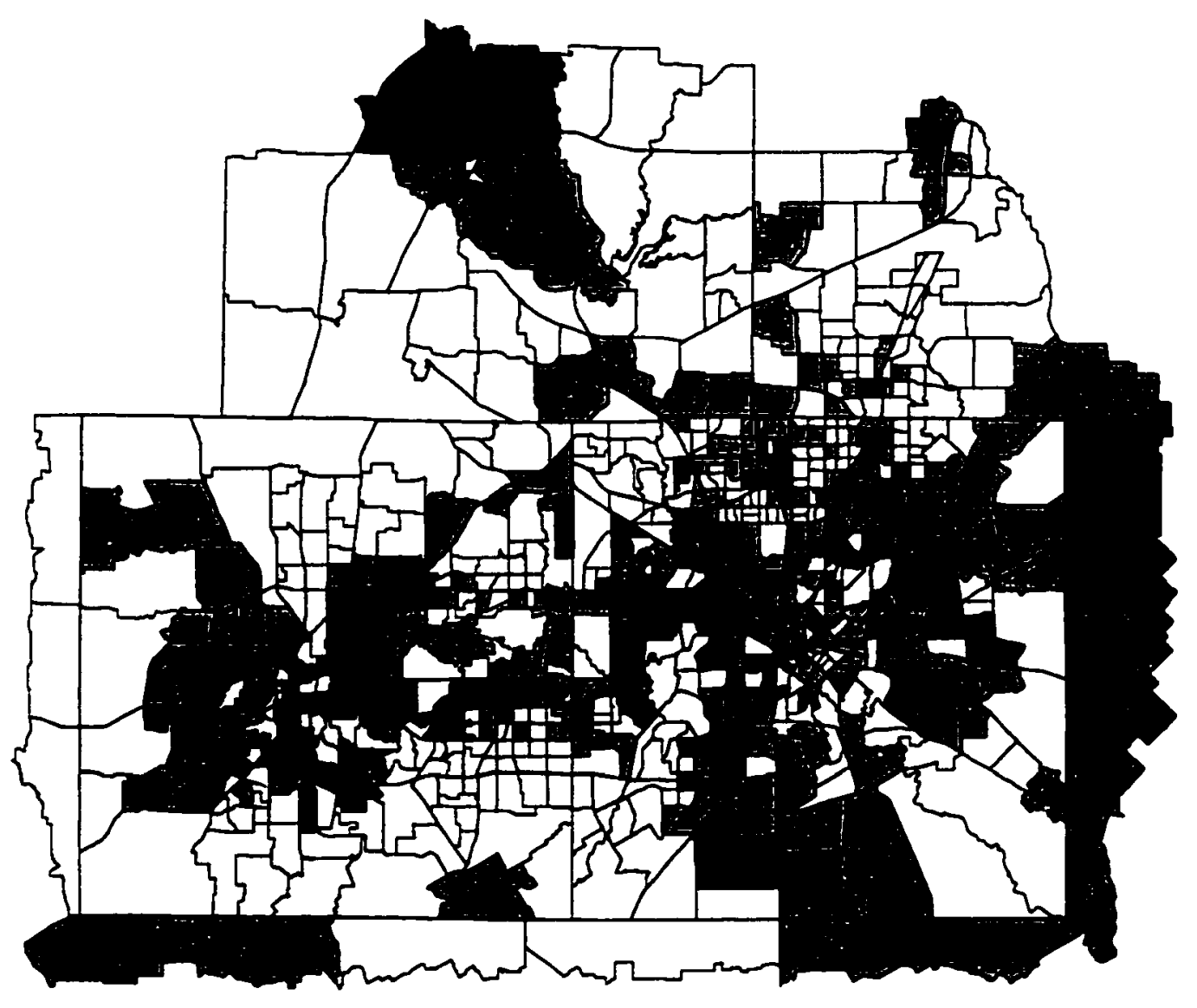

Numbar of Trips Attracted

$\square=-11310$
$11311-28193$
$28194-58125$
58126 - 132921

1

Figure 3.16. 1984 DFW Total Trips Attracted by Zone 


\section{Dallas-Fort Worth TAP Zones - 1995 Total Trip Attractions}

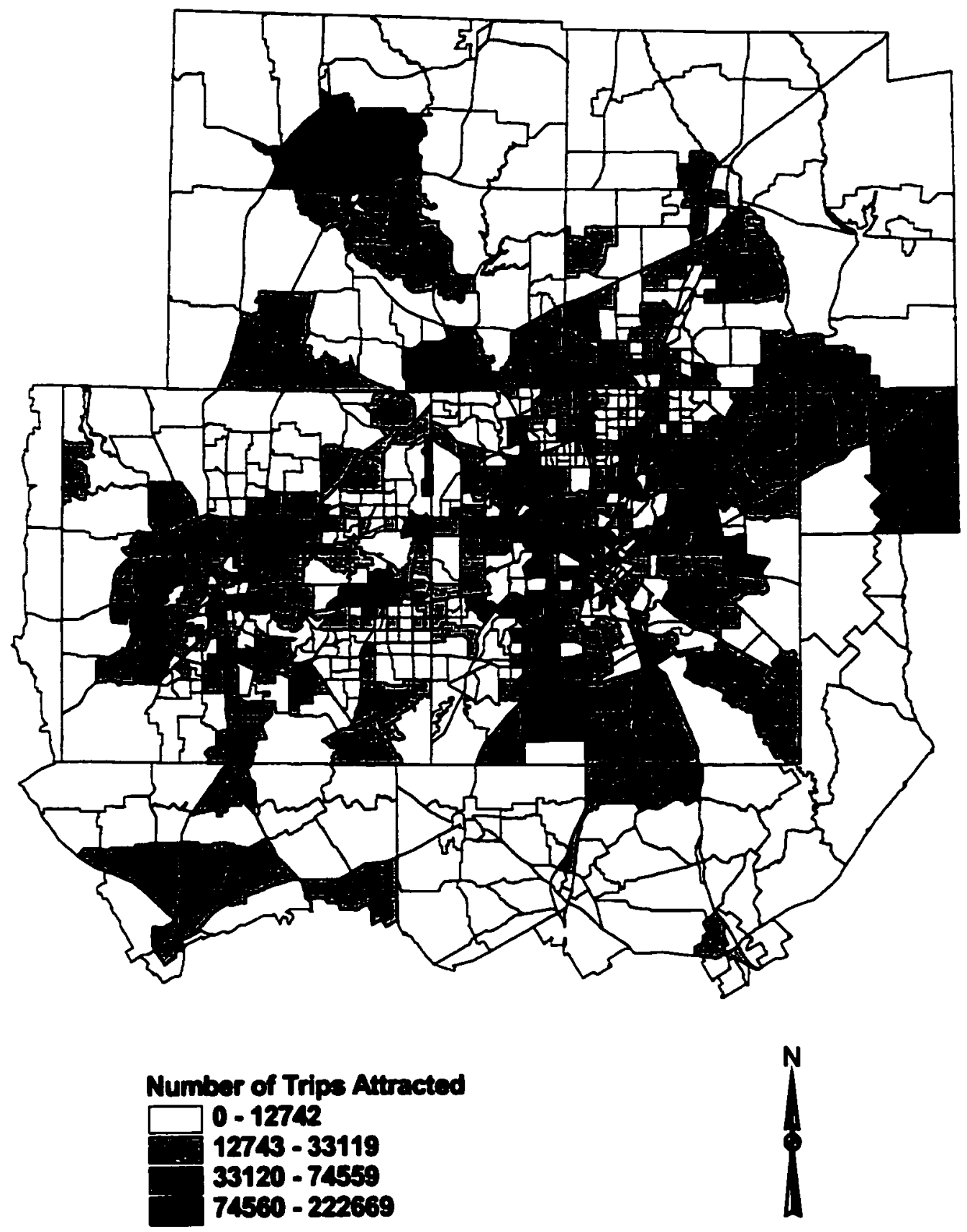

Figure 3.17. 1995 DFW Total Trips Attracted by Zone 


\section{Dallas-Fort Worth TAP Zones - 1984 Trip Productions per Household}

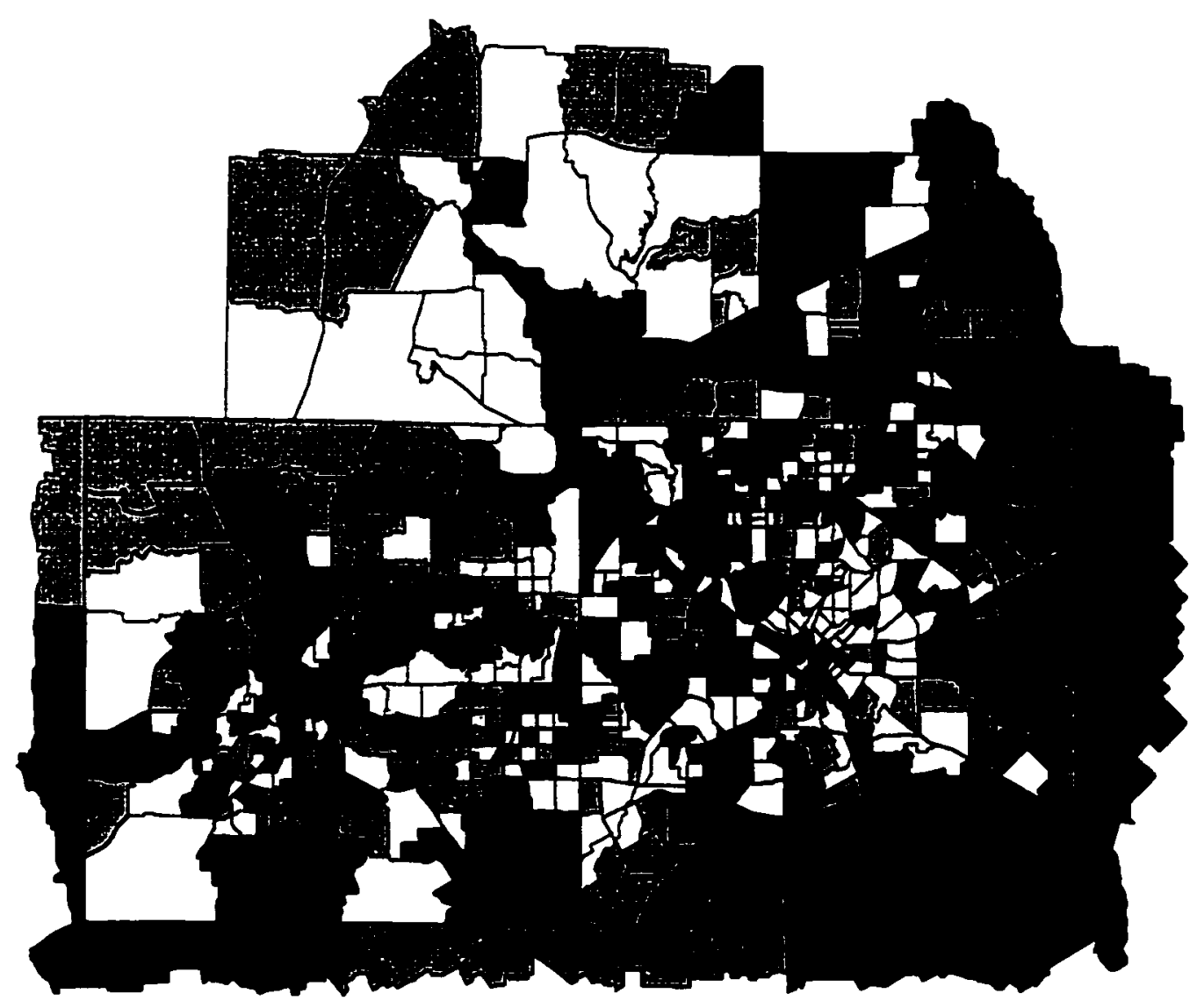

Daily Trips per Houschold

$5.38-8.15$

$8.16-8.78$

$8.79 \cdot 9.70$

$9.71 \cdot 18.00$

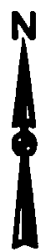

Figure 3.18. 1984 DFW TAP Zone Trip Productions per Household 


\section{Dallas-Fort Worth TAP Zones - 1995 Trip Productions per Household}

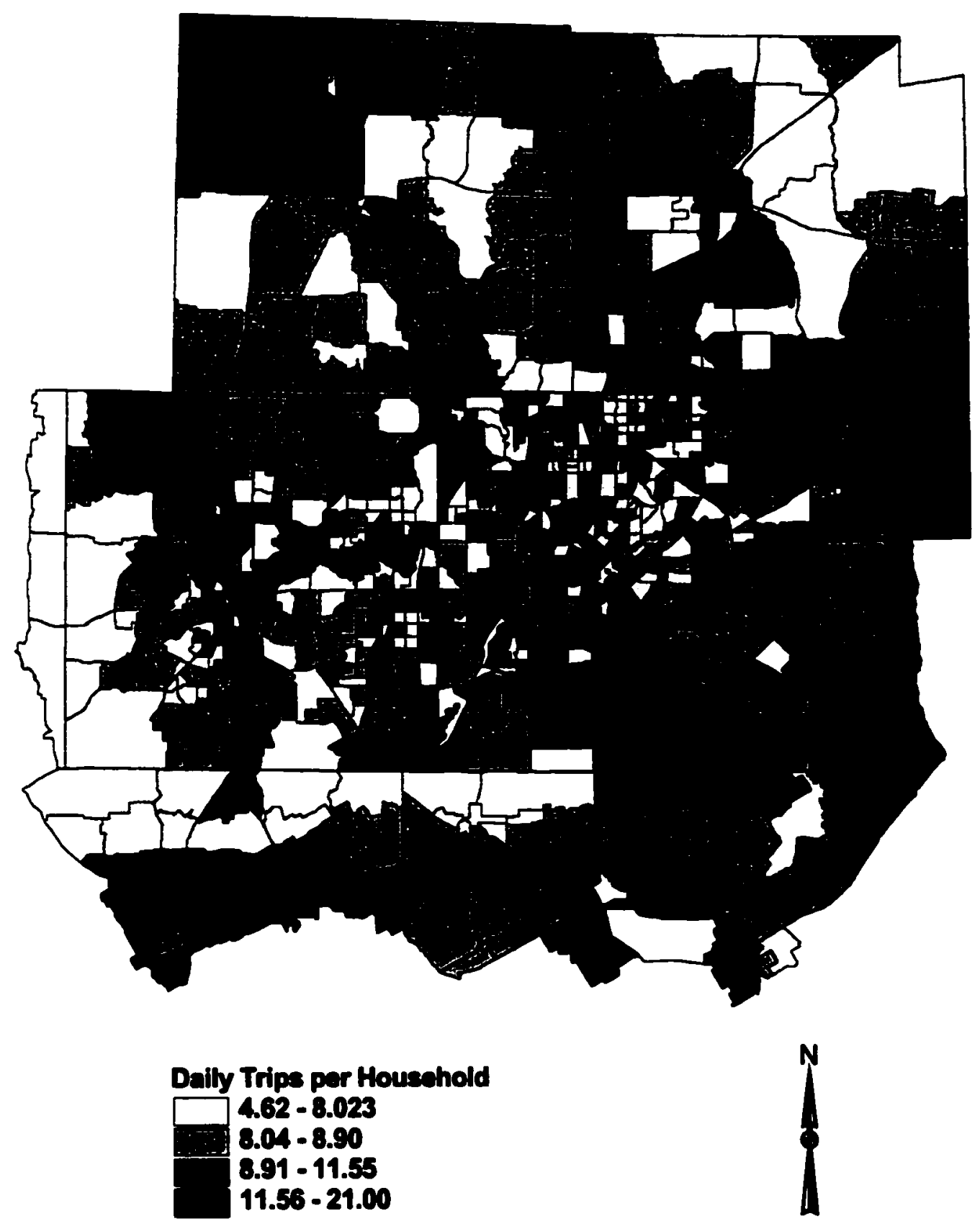

Figure 3.19. 1995 DFW TAP Zone Trip Productions per Household 


\section{Dallas-Fort Worth TAP Zones - 1984 Vehicle Miles of Travel}

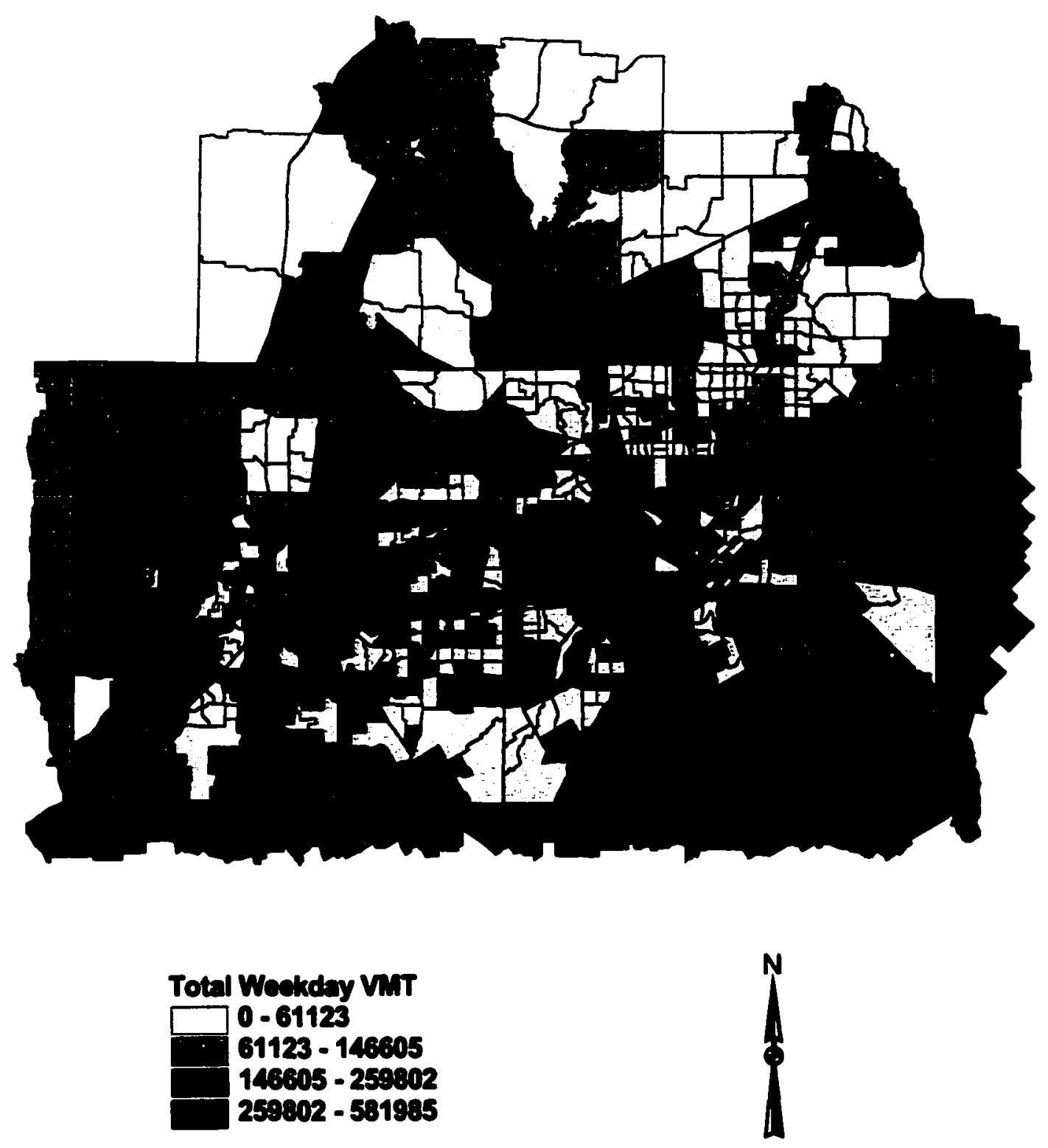

Figure 3.20. 1984 DFW Total Weekday VMT by Zone 


\section{Dallas-Fort Worth TAP Zones - 1995 Vehicle Miles of Travel}

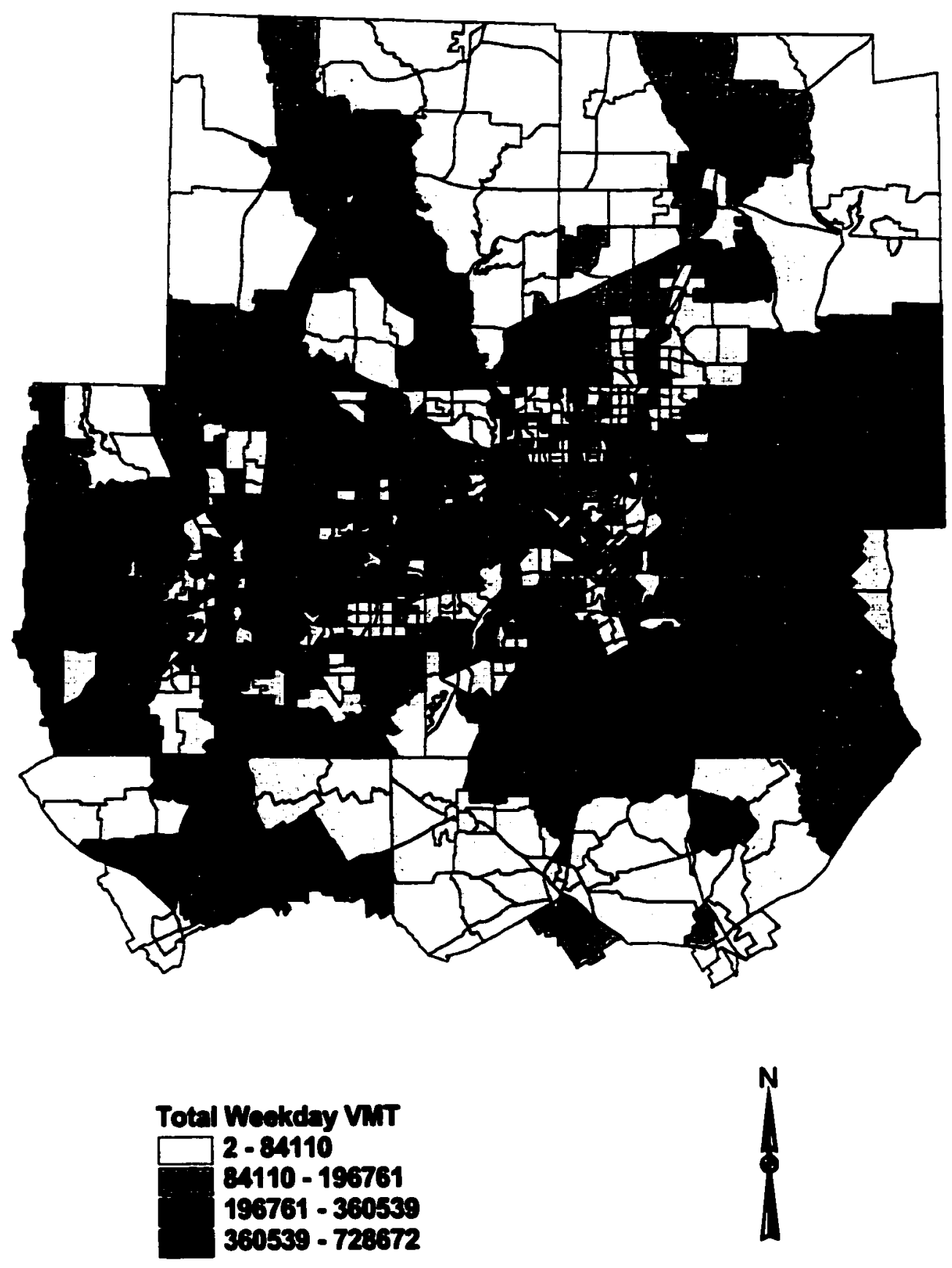

Figure 3.21. 1995 DFW Total Weekday VMT by Zone 


\section{Dallas-Fort Worth TAP Zones}

\section{Home-Based Work Trip Productions}

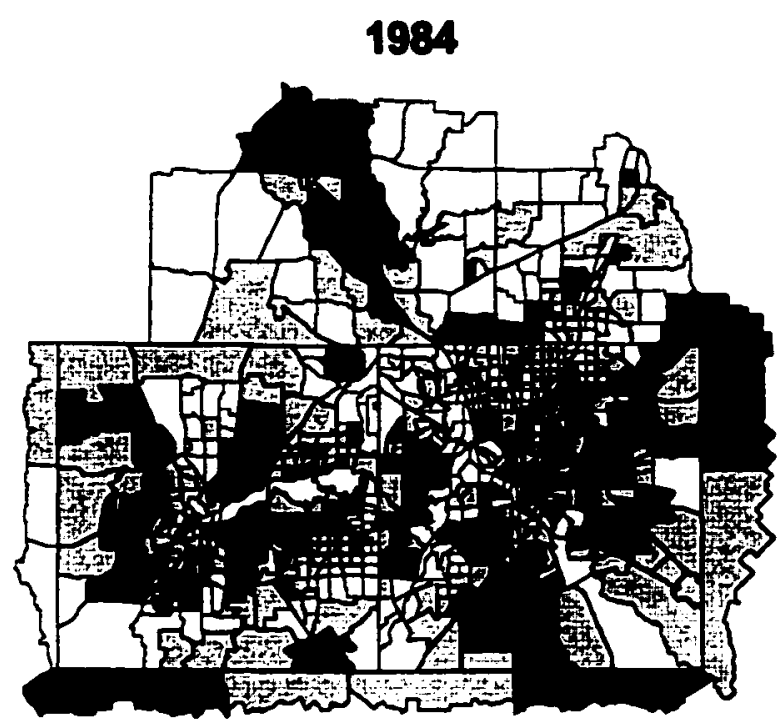

Number of HBW Trips Produced

0 - 2026

$2027-5166$

$5167-9712$

$9713-22296$

1995

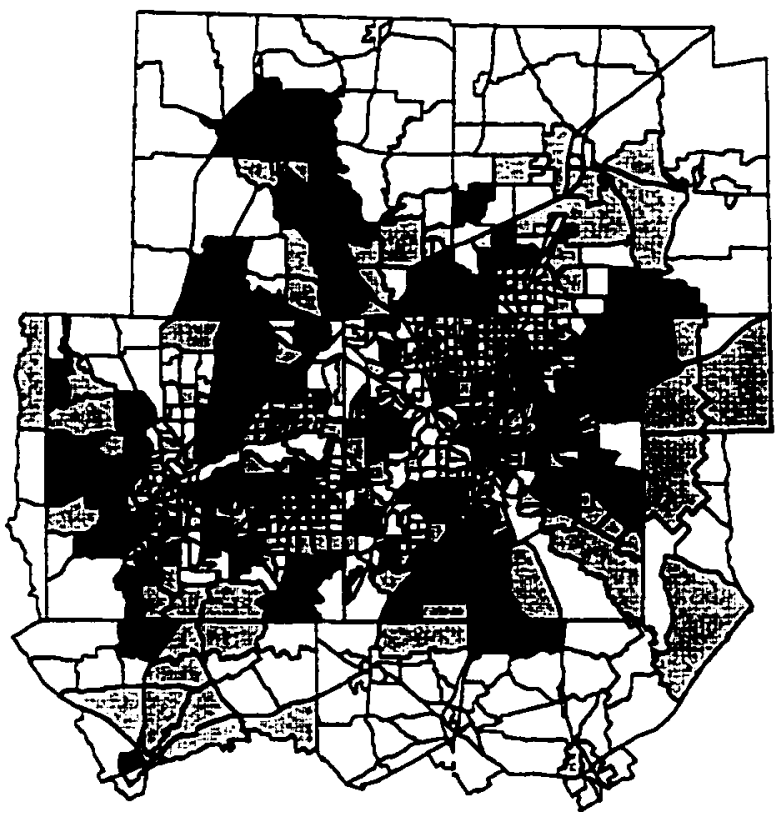

Number of HBW Trips Produced

$\square$ - 2472

$2473-6389$

$6390-12183$

$12184-32804$

Figure 3.22. 1984 and 1995 Home-Based Work Trips Produced by Zone 


\section{Dallas-Fort Worth TAP Zones}

\section{Home-Based Nonwork Trip Productions}

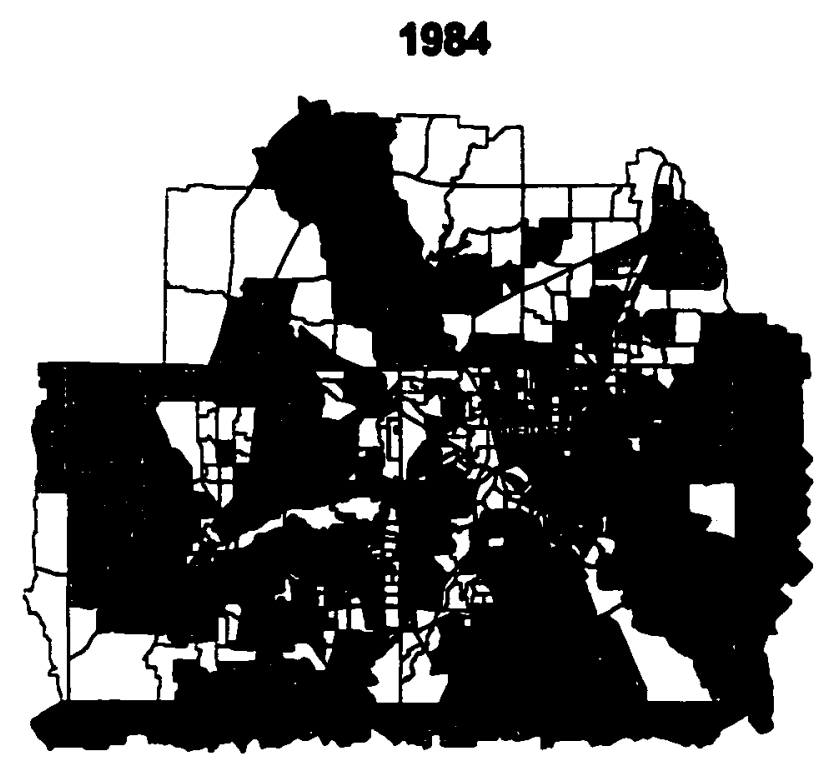

Number of HBNW Trips Produced

$\square$ - 3432

$3433-8874$

$8875-17248$

$17249-35886$

1995

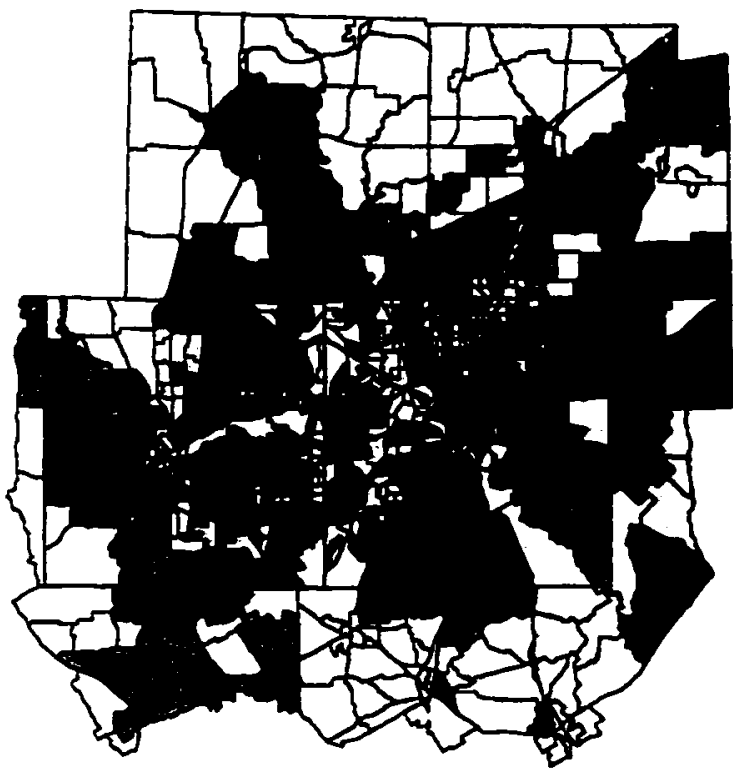

Number of HBNW Trips Produced

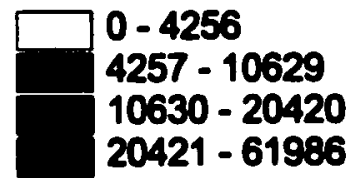

Figure 3.23. 1984 and 1995 Home-Based Non-Work Trips Produced by Zone 


\section{Dallas-Fort Worth TAP Zones}

\section{Nonhome-Based Trip Productions}

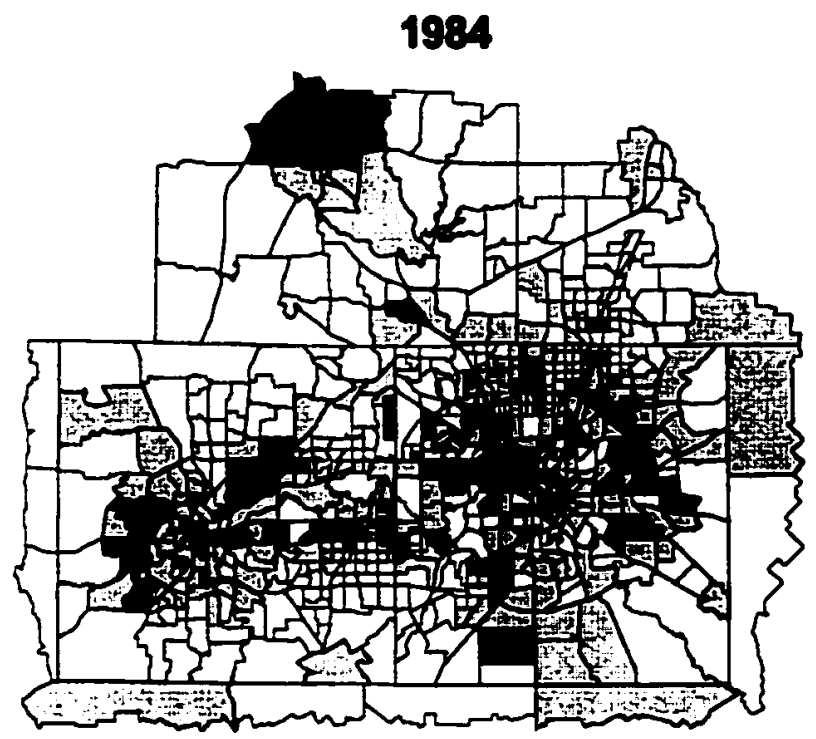

Number of NHB Trips Produced

0 - 2648

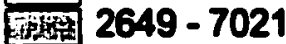

$7022-14797$

$14798-29011$

1995

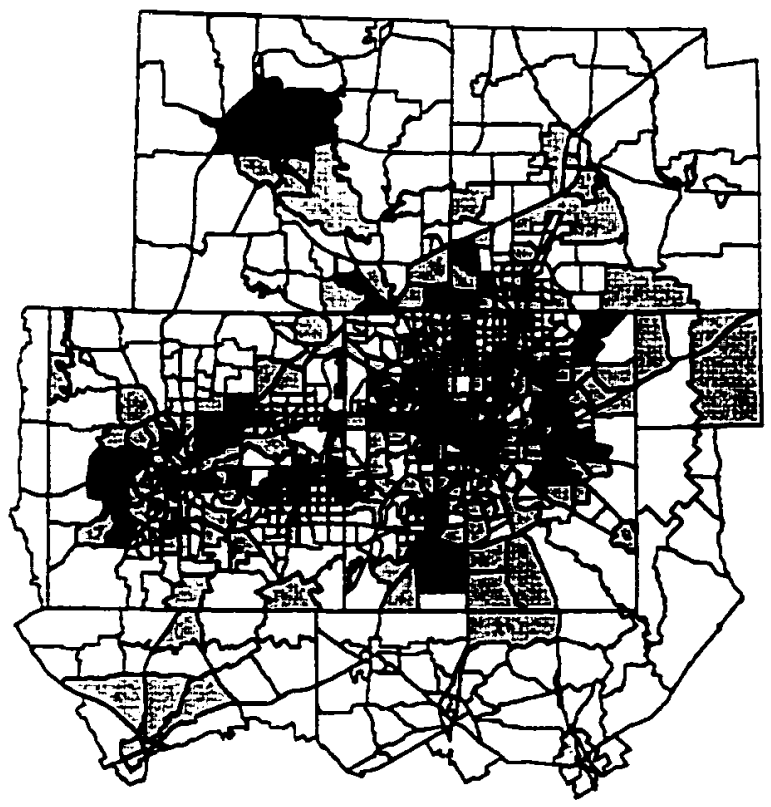

Number of NHB Trips Produced

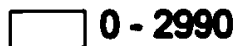

2991 - 7695

$7696-16600$

$16601-34790$

Figure 3.24. 1984 and 1995 Non-Home-Based Trips Produced by Zone 


\section{Dallas-Fort Worth TAP Zones Other Trip Productions}

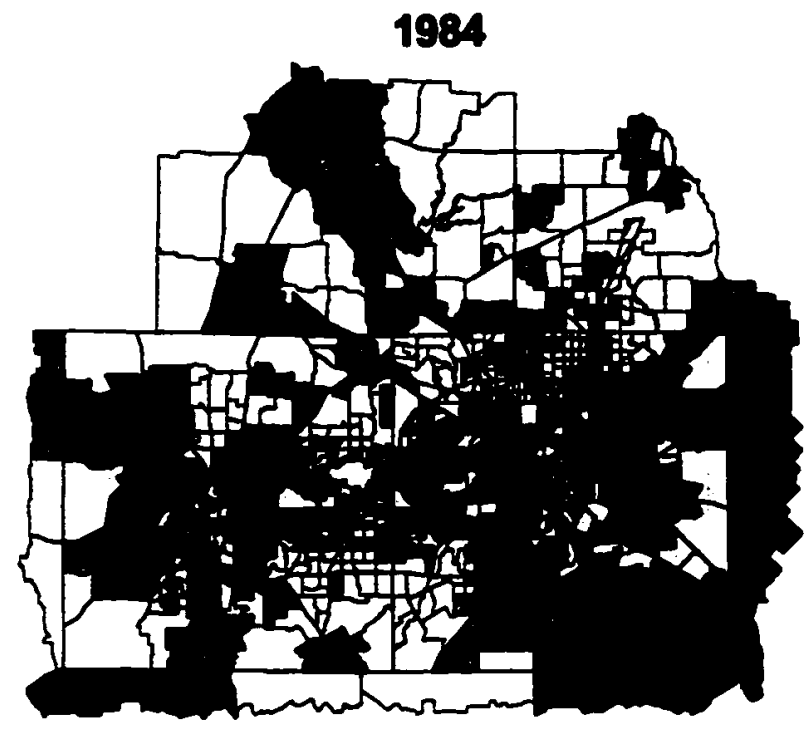

Number of Other Trips Produced

$0-1334$

$1335-3001$

$3002-5514$

$5515-11554$

1995

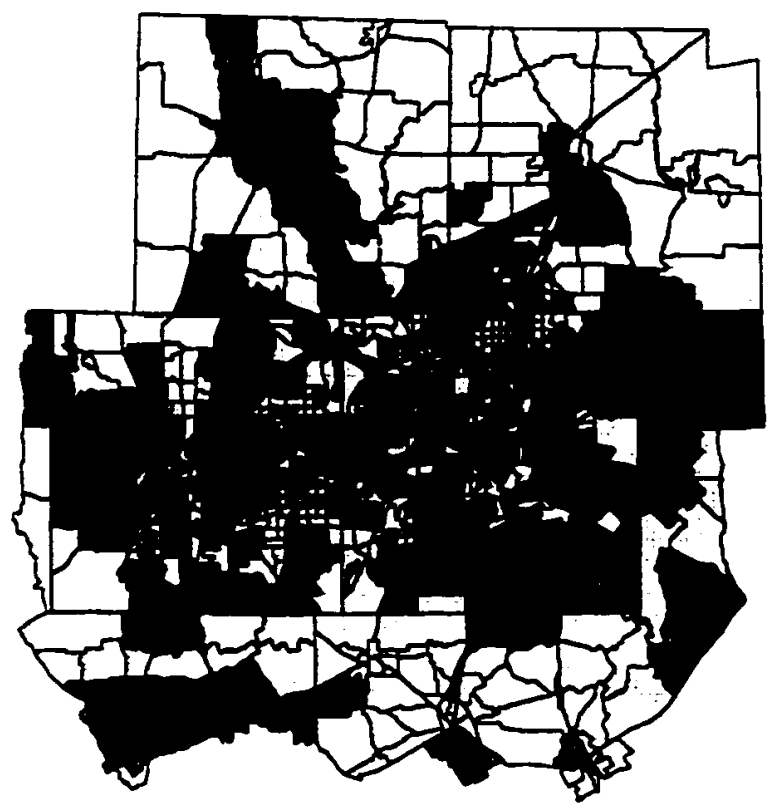

Number of Other Trips Produced

0-1397

$1398-3179$

$3180-6169$

$6170-18903$

Figure 3.25. 1984 and 1995 Other Trips Produced by Zone 


\section{Dallas-Fort Worth TAP Zones}

\section{Home-Based Work Trip Attractions}

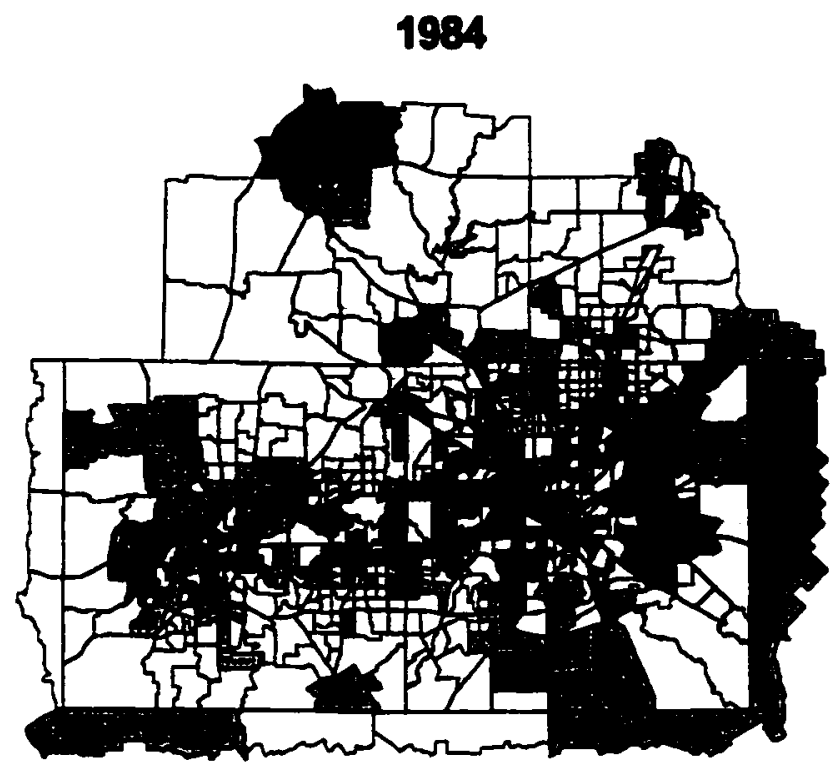

Number of HBW Trips Attracted

$0-2378$

$2379-6284$

$6285-12937$

12938 - 36956

1995

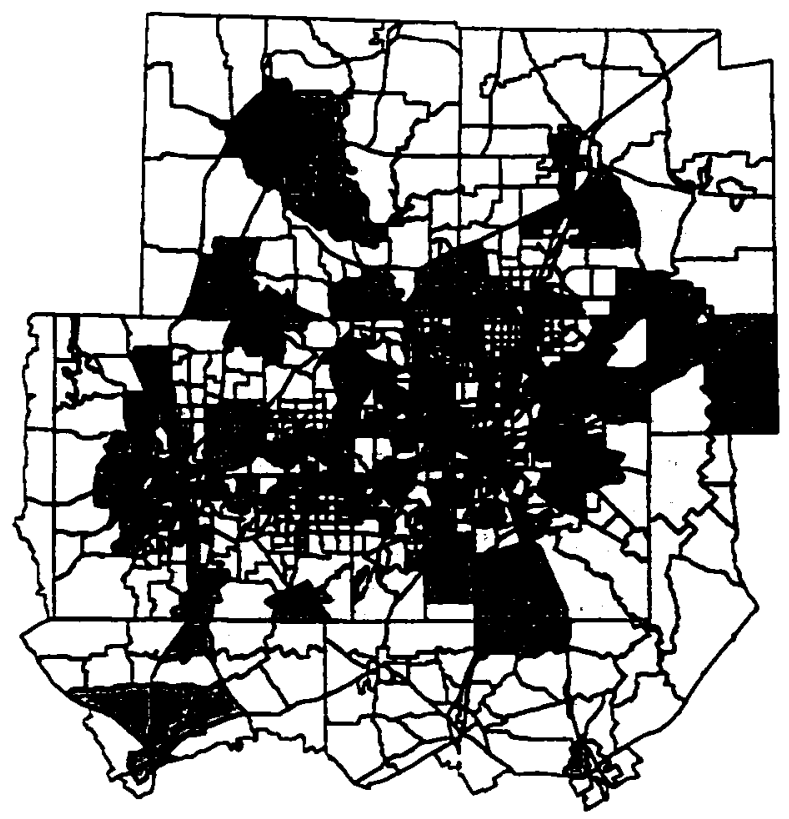

Number of HBW Trips Attracted

0 - 3034

$3035-9039$

$9040-17498$

$17499-39783$

Figure 3.26. 1984 and 1995 Home-Based Work Trips Attracted by Zone 


\section{Dallas-Fort Worth TAP Zones}

\section{Home-Based Nonwork Trip Attractions}

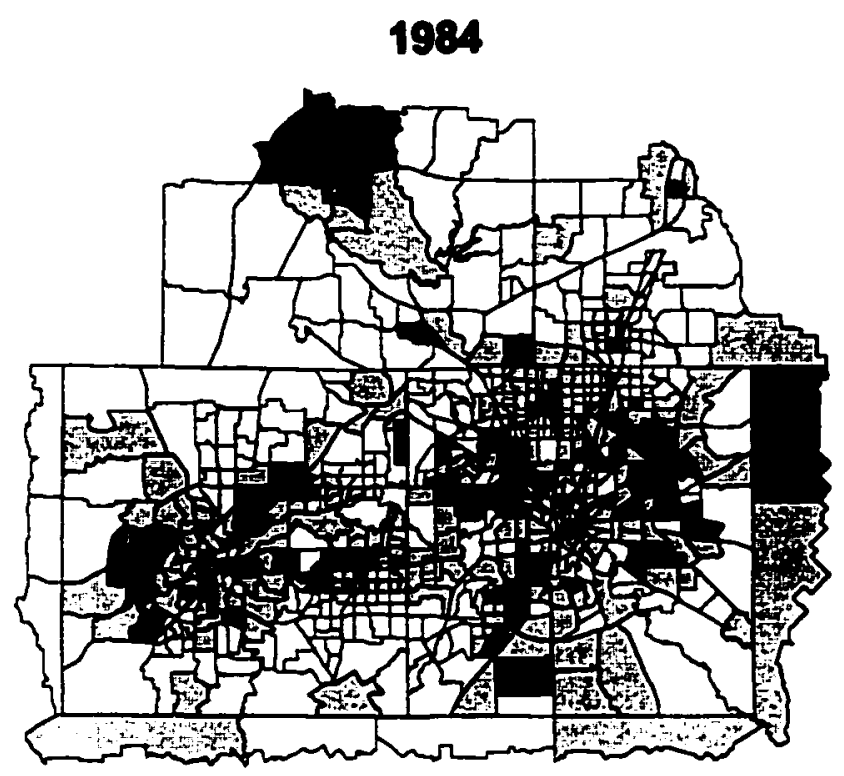

Number of HBNW Trips Altracted

$\square$ - 4323

$4324-11615$

$11616-25150$

$25151-66952$

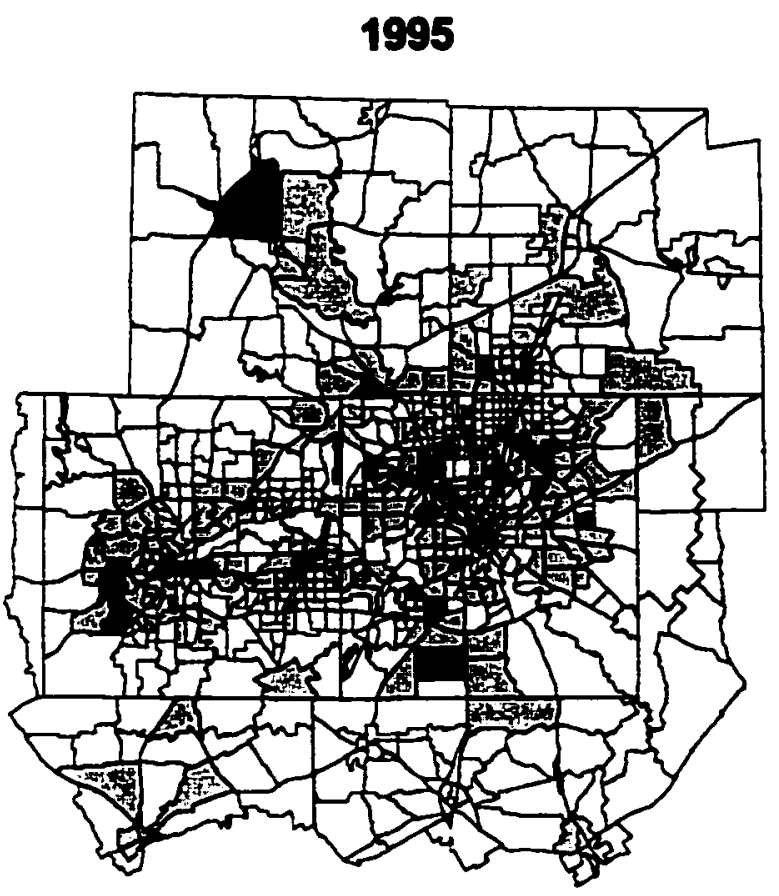

Number of HBNW Trips Attracted

0.7077

$7078-22509$

$22510-53679$

53680 - 157936

Figure 3.27. 1984 and 1995 Home-Base Non-Work Trips Attracted by Zone 


\section{Dallas-Fort Worth TAP Zones \\ Nonhome-Based Trip Attractions}

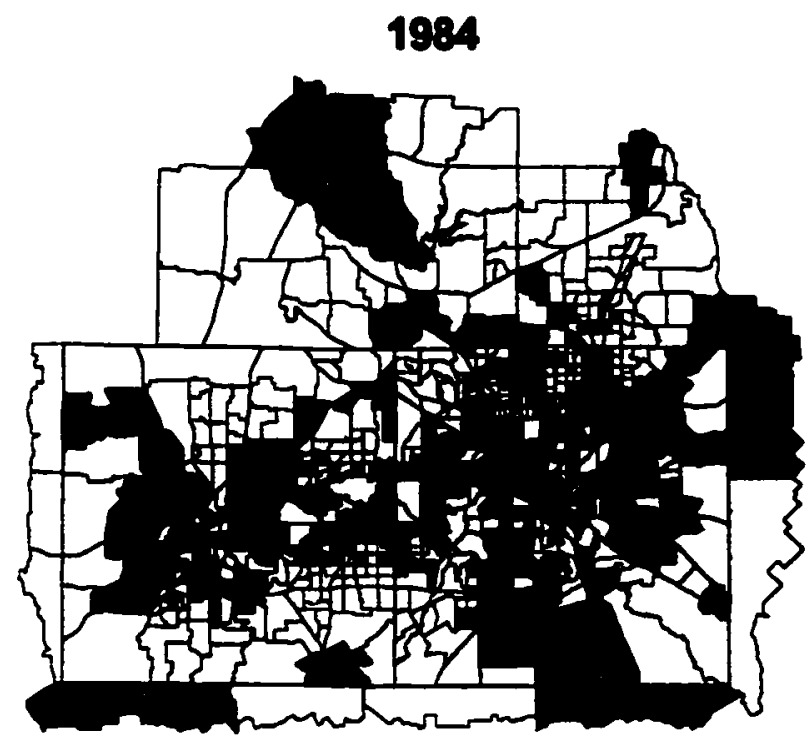

Number of NHB Trips Attracted

$0-2648$

$2649-7021$

$7022-14797$

$14798-29011$

1995

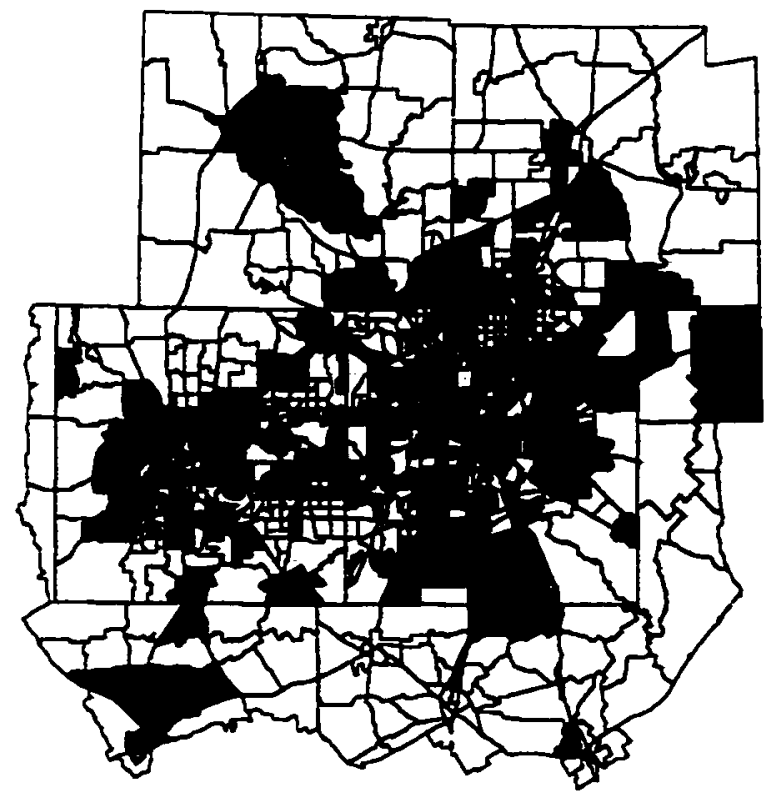

Number of NHB Trips Attracted

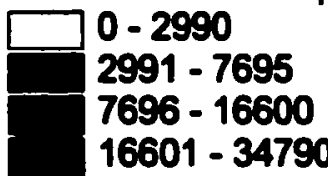

Figure 3.28. 1984 and 1995 Non-Home-Based Trips Attracted by Zone 


\section{Dallas-Fort Worth TAP Zones Other Trip Attractions}

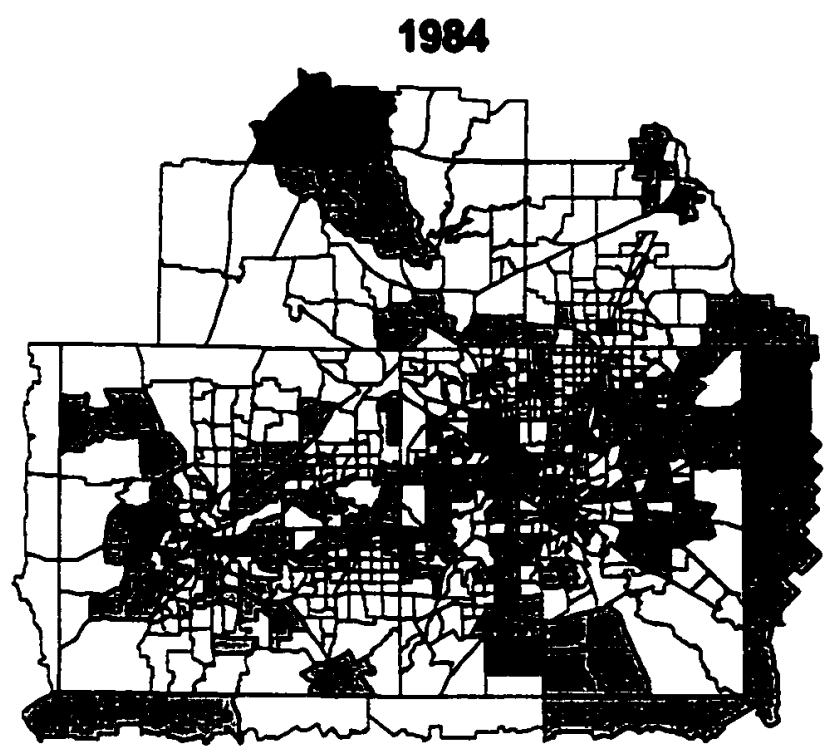

Number of Other Trips Attracted

$\square$ - 1779

$1780 \cdot 4505$

4506 - 9296

$9297-23124$

1995

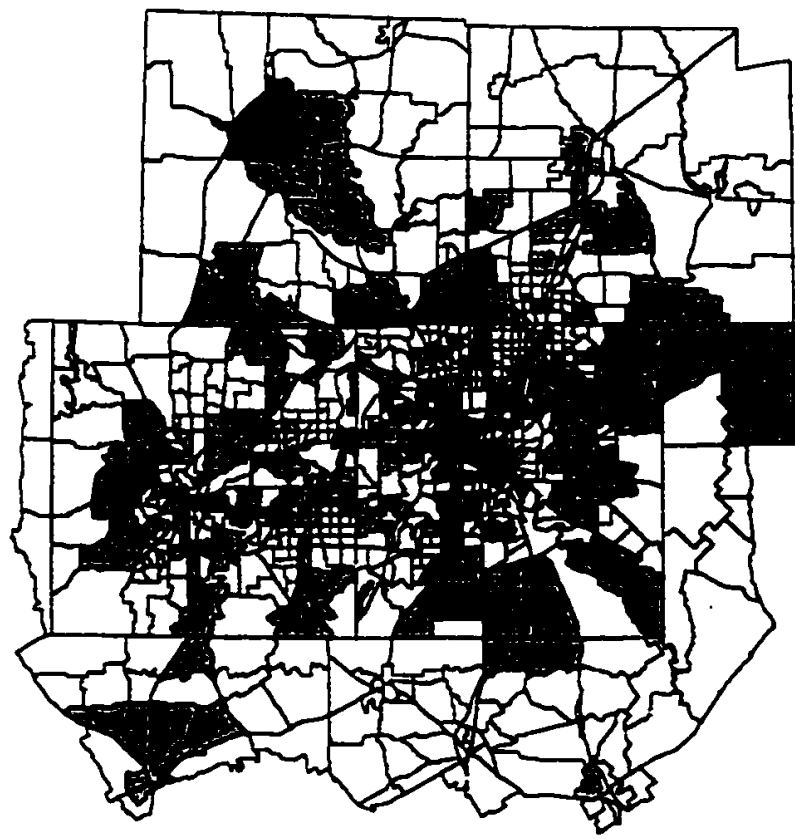

Number of Other Trips Attracted

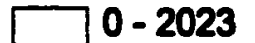

$2024-5731$

$5732-16059$

$16060-40593$

Figure 3.29. 1984 and 1995 Other Trips Attracted by Zone 
suburban zones. On the other hand, it is rather surprising that the total number of trips attracted to zones in the Dallas and Fort Worth central business districts is not higher, given that trip attractions are driven largely by employment distribution. This also seems to be the case for home-based work trip attractions (Figure 3.26). And again, we can see that Denton is a major activity and employment center that attracts a large number of trips for all purposes.

- Trip productions per household, shown in Figures 3.18 and 3.19, generally seem to be greatest in the urban residential and outer suburban zones east and southeast of Dallas as well as in the area surrounding the Fort Worth CBD. Although there appears to be an area of heavy trip-making in the high-income region north of Dallas (particularly noticeable in 1984), a strong geographic correlation between income (Figures 3.12 and 3.13) and trip making is not generally evident. In 1995, high per household trip rates can be seen in rural zones located both in the northwest and southwest corners of the survey area. (Note that the zones in Figures 3.18 and 3.19 with no color are zero-household zones).

- VMT is scattered evenly throughout the metropolitan area (Figures 3.20 and 3.21). There does, however, appear to be a concentration of zones in suburban residential areas that have relatively low VMT. These zones are primarily residential without the mixed-use development patterns that typically generate more travel demand. Again, the exceptions are in Denton and Richardson, where VMT is clearly high. 


\section{Method of Analysis}

The analytical approach used to determine the changes in travel demand caused by highway capacity additions was an analysis of covariance. The central purpose of an analysis of covariance, which combines linear regression techniques with analysis of variance, is to compensate for influences on the dependent variable that interfere with direct comparisons among a series of categories. In this study, travel demand measures used as dependent variables included total weekday vehicle-miles of travel in each TAP zone, trip productions per household in each zone, total trips produced by each zone, total trips attracted to each zone, and trip productions and attractions by purpose per zone (home-based work, home-based non-work, non-home-based, and other). The data were aggregated to the TAP zone level, and the four categories were comprised of zones inside and outside the study area both before and after highway capacity expansion. The method used to define the study areas and distinguish zones inside from those outside will be discussed shortly.

An analysis of variance (ANOVA) approach merely tells us whether the population means and variances of two groups of data differ. For example, ANOVA tells us whether average trip production in the DFW metropolitan area has changed significantly from 1984 to 1995 . However, we could probably assume as much without the need for analysis given the demographic and socioeconomic changes that have taken place over the 11 -year time period. In fact, a major criticism of the before-and-after case study approach is the failure to account for confounding variables such as increases in population, income, employment, and auto ownership that occur between the two time periods and which contribute substantially to traffic growth. Analysis of covariance is a 
more powerful analytical tool because it attempts to determine whether travel behavior would have differed between the two time periods, assuming that such things as income, population density, number of households, and employment were equal to a common value. In other words, it seeks to remove the influence of these confounding variables, called covariables or covariates, that bias direct comparisons between travel behavior before and after the addition of highway capacity. Thus, if we wish to say that highway capacity additions cause traffic growth, we should be able to state that the observed increase in traffic was not largely explained by demographic factors such as population and income growth. It should be noted, however, that demographic and socioeconomic factors could also be affected by highway capacity additions that improve the transportation system in a metropolitan area. For example, the improved accessibility to outer suburban areas provided by highway capacity additions can lead to land use changes as new residential and commercial developments are built in the new corridor. Population and economic growth will naturally follow in these new suburban centers. Analysis of covariance is based on the following underlying assumptions:

1. The $\mathbf{k}$ regressions between the response or dependent variable and the explanatory variables are linear ( $k=$ number of groups).

2. The $\mathrm{k}$ regression lines (or regression planes) are parallel.

3. The variances about each regression line (plane) are equal.

4. The observations are independent.

5. The errors are normally distributed.

6. The values of the covariate(s) cannot depend on the conditions defining the groups. 
Perhaps the most important of these assumptions underlying the analysis of covariance is that the regression coefficients for predicting the dependent variable from the covariates are the same for all the groups or categories. For a single covariate, this is the assumption that the regression lines for each group are parallel (i.e., they have equal slopes). Therefore, the key to an analysis of covariance is the feasibility of a particular statistical model, sometimes referred to simply as the parallel model, that provides the specific structure to statistically remove the influence of the covariate. If the assumption of parallel regression lines (or planes) is violated, then the analysis of covariance model cannot be justified. The individual response surfaces must be analyzed separately. This restriction turned out to be important in this study because in some cases the relationships between the dependent variable and one or more covariates were not the same for both groups (e.g., before vs. after capacity expansion). The implication is that there is an interaction between the dependent variable and the covariate, and the "non-parallel" behavior of the two groups must be understood to reach any conclusive results.

For each year (1984 and 1995), the DFW travel model data were divided into two groups: A sample representing zones inside the study area and a sample representing zones outside the study area. Zones inside the study area are assumed to consist of travelers whose behavior is affected by the presence of an improved highway system, whereas the group outside the study area, being located in zones where the network was largely unchanged, is considered to be a control group. Although the control group was certainly not completely immune to the effects of the highway changes from 1984 to 1995, it is assumed that it was less affected by them. The following four cases were analyzed: 
1. Inside the study area; Before vs. After capacity addition,

2. Outside the study area; Before vs. After capacity addition,

3. Before capacity addition; Inside vs. Outside the study area, and

4. After capacity addition; Inside vs. Outside the study area.

An important limitation of this before-and-after case study was the lack of familiarity with the Dallas-Fort Worth metropolitan area, thus making it difficult to identify specific geographic corridors in which significant road improvement projects had been completed between 1984 and 1995. In the absence of direct, first-hand knowledge of particular highway improvements, this study relied on the travel model data to distinguish zones inside the study area from those outside the study area. This study compared the capacities of freeways and principal arterials for the two years by joining the 1984 and 1995 link data files by link name code number. These unique link identification numbers did not change from one time period to the next. All freeway and principal arterial links that had undergone a capacity increase of more than 5 percent from 1984 to 1995 were identified. These links were then grouped by TAP zone number. Therefore, zones "inside the study area" are defined to be those which completed capacity additions of over 5 percent on at least one major highway facility between the two time periods. All other zones are referred to as being "outside the study area." The resulting data set, shown pictorially in Figure 3.30, consisted of 260 TAP zones inside the study area in 1995; using the structural equivalency table in Appendix A, these zones corresponded to 250 zones in 1984. Each zone was then coded as "Inside" or "Outside" in the 1984 and 1995 subarea zonal data files. 


\section{Dallas-Fort Worth TAP Zones \\ Inside vs. Outside Comparison}

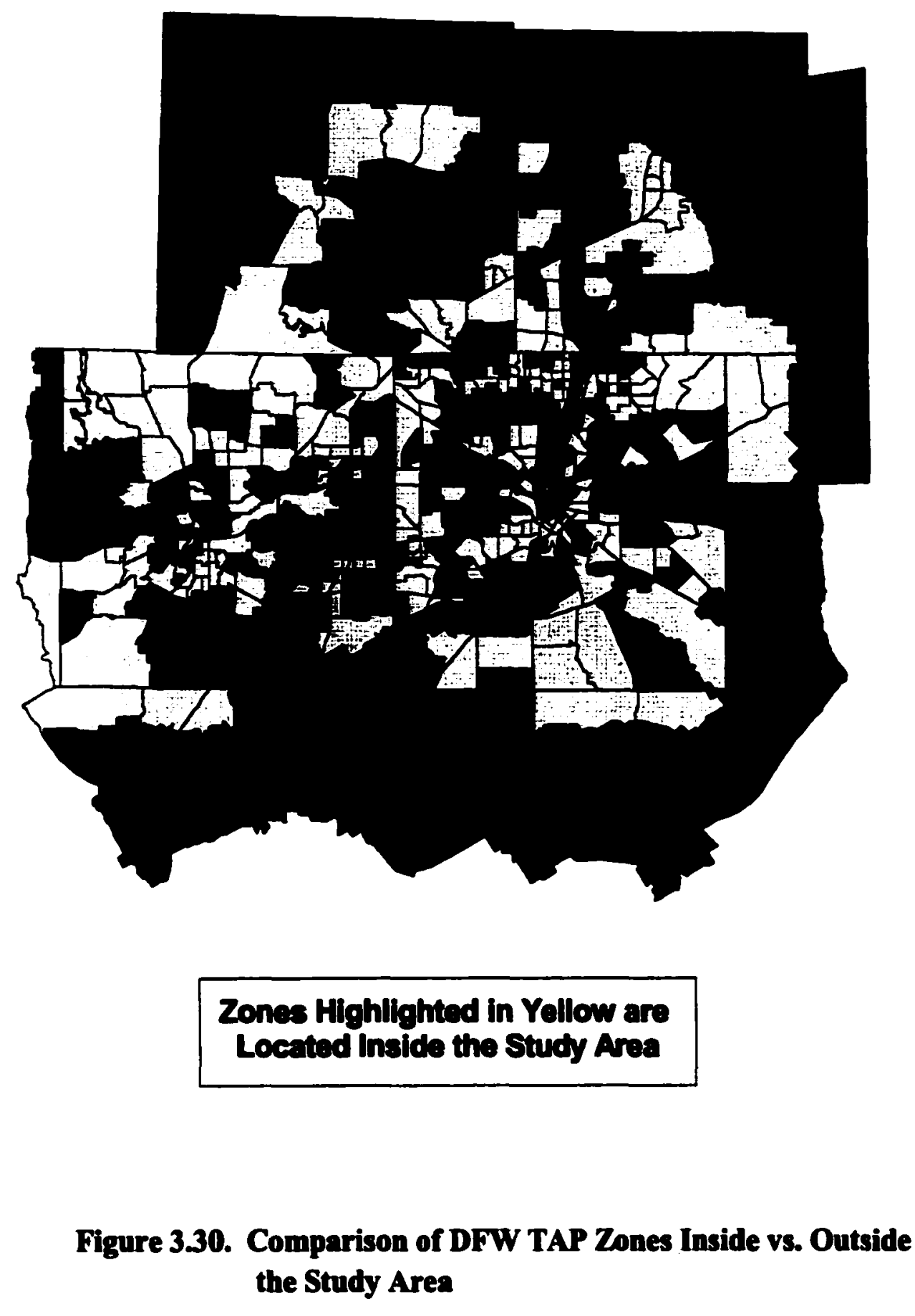




\section{$\underline{\text { Results }}$}

Four cases were compared to determine whether travel growth in the Dallas-Fort Worth metropolitan area from 1984 to 1995 could be attributed to highway capacity expansion. As mentioned previously, the comparisons consisted of:

1. Inside the study area; Before vs. After capacity addition,

2. Outside the study area; Before vs. After capacity addition,

3. Before capacity addition; Inside vs. Outside the study area, and

4. After capacity addition; Inside vs. Outside the study area.

For each case analyzed, the following travel demand measures by TAP zone were used as the dependent variables: Daily trip productions per household; total weekday VMT; total daily trips produced in the zone; total daily trips attracted to the zone; and daily trip productions and attractions by purpose. Median household income and population density were used as covariates in all cases. When analyzing differences in trip productions and VMT, the effects of the number of households in the zone were also controlled for in the model. When trip attractions were evaluated in the model, the number of employees rather than households in the zone was added as a covariate.

One of the critical assumptions underlying an analysis of covariance is that the relationships between the covariates and the response variable must be the same for each group being compared. This is the assumption of parallelism of regression lines, and it is necessary for statistically removing the influences of the covariates and thereby providing a direct comparison of the travel behavior between the groups being analyzed. As an example, consider a simple model in which we wish to compare the change in VMT before and after capacity additions in zones located inside the study area (i.e., before and 
after treatment in the treatment group) after adjusting for changes caused by one covariate, number of households. The assumption of parallelism requires that the relationship between the number of households and VMT be the same before and after capacity additions. Stated simply, the two lines on a graph of VMT vs. number of households that fit the data for the before and after groups must have equal slopes (though they may have different intercepts). Thus, the first step in an analysis of covariance is to test for the feasibility of this so-called parallel model. If the assumption of parallel regression lines is violated, the analysis of covariance model cannot be justified and interpretation of the results must involve the different rates of change relative to the covariates.

Figure 3.31 shows a partial sample of the output produced by JMP, the statistical analysis software package that was used to perform the analyses in this study. In this particular case, we are comparing the difference in total trips produced by all zones inside the study area between 1984 and 1995 (i.e., before vs. after highway expansion). On the top half of the figure, the test results for the validity of the assumption of parallelism are presented. Under the Effect Test, all the explanatory variables used in this model are shown. There is a categorical variable indicating whether the observation is before or after the capacity addition (Before/After). This is followed by the three covariates, median household income (MEDINC), number of households (HHOLDS), and population density (POPDEN). Then, the interaction terms, which are the cross-products of each covariate with the Before/After group variable, are added as explanatory variables. The null hypothesis being tested is that the interactions between the covariates and the group variable (Before/After in Figure 3.31) are insignificant; in other words, the 


\section{INSIDE STUDY AREA; BEFORE vs. AFTER CAPACITY ADDITION TOTAL TRIP PRODUCTIONS}

\section{Interaction Model (Test for Parallelism)}

\section{Summary of Fit}

\section{RSquare}

RSquare Adj

Root Mean Square Ertor

Mean of Response

Observations (or Sum Wgts)

\section{Effect Test}

Source

Before/After

MEDINC

HHOLDS

POPDEN

Before/After*MEDINC

Before/After"HHOLDS

Before/After* POPDEN
0.876652

0.874932

5603.654

20257.4

510

$\begin{array}{lll}\text { Nparm } & \text { DF } & \text { Sum of Squares } \\ 1 & 1 & 33132028.7 \\ 1 & 1 & 540801150 \\ 1 & 1 & 8.97374 \mathrm{e} 10 \\ 1 & 1 & 566181740 \\ 1 & 1 & 377753.677 \\ 1 & 1 & 7227792.78 \\ 1 & 1 & 3045796.8\end{array}$

Parallel Model

\section{Summary of Fit}

RSquare

RSquare Adj

Root Mean Square Error

Mean of Response

Observations (or Sum Wgts)

\section{Effect Test}

Source

Before/After

MEDINC

HHOLDS

POPDEN

Least Squares Means

\begin{tabular}{llll}
\hline Level & Least Sq Mean & Std Error & Mean \\
After & 20907.23064 & 348.8917646 & 22167.0 \\
Before & 19581.57214 & 355.8954238 & 18271.5
\end{tabular}

$\begin{aligned} & 0.876593 \\ & 0.875616\end{aligned}$
5588.33
20257.4
510

$\begin{array}{lllll}\text { Nparm } & \text { DF } & \text { Sum of Squares } & \text { F Ratio } & \text { Prob }>\text { F } \\ 1 & 1 & 218008873 & 6.9809 & 0.0085 \\ 1 & 1 & 583493324 & 18.6841 & <.0001 \\ 1 & 1 & 9.25376 e 10 & 2963.155 & <.0001 \\ 1 & 1 & 559739607 & 17.9235 & <.0001\end{array}$

Prob $>F$ 0.3048 $<.0001$ $<.0001$ $<.0001$ 0.9127 0.6316 0.7556

Figure 3.31. Analysis of Covariance Sample Output 
rate of change of the response (total trips produced) based on each covariate is the same both before and after the capacity expansion. Because the F Ratios on all three interaction terms are very low, with correspondingly high p-values (i.e., Prob $>F$ on Figure 3.31), we fail to reject the null hypothesis of no interaction and conclude that the assumption of parallelism is valid. We conclude that a reasonable model is one in which the regression planes describing the sample data within the Before and After groups have the same slope but different intercepts.

The next step is to fit the parallel model by simply removing the insignificant interaction terms. The hypothesis tested in this model is that there is no difference in group means (that is, the expected number of trips produced between the two time periods), after controlling for the variation explained by the covariates. Under the Effect Test, the F Ratio on the Before/After effect is 6.9809 with a p-value of 0.0085 . Thus, at the 0.05 significance level, we reject the null hypothesis and conclude that the number of trips produced inside the study area in 1984 vs. 1995 is significantly different, after accounting for the influence of income, number of households, and population density. The magnitude of this difference is given by the least squares means. Least squares, or adjusted, means represent the expected number of trips produced in each group (i.e., Before and After) after adjusting for common values of MEDINC, HHOLDS, and POPDEN. Thus, in this case there are 1325 more daily trips produced inside the study area after highway capacity is added, an increase of almost 7 percent.

Complete results using analysis of covariance for all four comparison groups and for every dependent travel demand variable are presented in Appendix $C$. These results are summarized in Tables 3.1 and 3.2. Adjusted mean values for all travel demand 
parameters (trips per household, VMT, total productions, total attractions, and productions/attractions by purpose) for each group comparison are given, along with the percent change and the p-value, or the measure of statistical significance. The p-value, also known as the observed significance level, is the smallest level of significance that would lead to rejection of the null hypothesis being tested. Typically, statisticians accept a 5 percent risk of being wrong. Thus, a p-value less than 0.05 will lead to rejection of the null hypothesis and to the conclusion that there is a significant difference in travel demand for the two groups being compared, inside vs. outside or before vs. after. But it should be emphasized that this establishes only statistical significance; "real world" or actual significance is a more subjective consideration that is open to interpretation by transportation engineers, urban planners, and other experts and depends to a large extent on the magnitude of the observed difference. Cases where the significance probability is less than 0.05 , highlighted in boldface type on Tables 3.1 and 3.2 , indicate a statistically significant difference in travel behavior between the two groups being compared. Asterisks indicate that there is a significant interaction between one or more covariates and the categorical group variable, so the underlying assumption of parallel regression planes is violated. In these cases, we cannot assume that the parallel model is valid, and an analysis of covariance model is not justified.

Comparison relationships of trip productions per household, total weekday VMT, total trip productions, and total trip attractions are shown schematically in Figures 3.32 through 3.35. Figure 3.32 shows that there was no statistically significant difference in the number of trips produced per household between the two time periods for zones either inside or outside the study area, after accounting for changes in median household 
Table 3.1. Comparison of Dallas-Fort Worth Travel Behavior Before vs. After Highway Capacity Additions

\begin{tabular}{|c|c|c|c|c|c|c|c|c|}
\hline \multirow{2}{*}{$\begin{array}{l}\text { Response } \\
\text { Variable }\end{array}$} & \multicolumn{4}{|c|}{ Inside the Study Area } & \multicolumn{4}{|c|}{ Outaide the Study Aren } \\
\hline & Before & After & $\%$ Change & p-Value & Before & After & $\%$ Change & p-Value \\
\hline $\begin{array}{l}\text { Total Trip Productions } \\
\text { per Household }\end{array}$ & 10.11 & 11.12 & 10.01 & 0.0935 & 11.51 & 11.56 & 0.41 & 0.9468 \\
\hline Total Weekday VMT & 121,226 & 163,761 & 35.09 & $<0.0001$ & 94,908 & 109,669 & 15.55 & 0.0043 \\
\hline Total Trip Productions & 19,582 & 20,907 & 6.77 & 0.0085 & 14,332 & 14,654 & 2.25 & 0.3098 \\
\hline Total Trip Attractions & 17,848 & 18,827 & 5.48 & 0.2216 & 14,677 & 15,468 & 5.39 & 0.2402 \\
\hline HBW Trip Productions & $*$ & * & * & * & $*$ & * & * & * \\
\hline HBNW Trip Productions & 8,648 & 8,810 & 1.87 & 0.2719 & $*$ & * & $*$ & * \\
\hline NHB Trip Productions & 3,912 & 4,983 & 27.38 & 0.0042 & 3,305 & 3,779 & 14.34 & 0.0527 \\
\hline Other Trip Productions & 2,168 & 2,450 & 13.01 & 0.0218 & 1,695 & 1,805 & 6.43 & 0.1876 \\
\hline HBW Trip Attractions & 4,007 & 4,040 & 0.82 & 0.2151 & 3,601 & 3,608 & 0.19 & 0.8464 \\
\hline HBNW Trip Attractions & 7,593 & 8,102 & 6.70 & 0.3177 & 6,093 & 6,541 & 7.35 & 0.3140 \\
\hline NHB Trip Attractions & 4,273 & 4,636 & 8.50 & 0.0488 & 3,428 & 3,679 & 7.35 & 0.0728 \\
\hline Other Trip Attractions & 1,975 & 2,049 & 3.75 & 0.5317 & 1,556 & 1,640 & 5.4 & 0.4551 \\
\hline
\end{tabular}

* There is a significant interaction between one or more covariates and the Before/After variable, so the parallel model is not valid; Hence, the analysis of covariance model is not justified. 
Table 3.2. Comparison of Dallas-Fort Worth Travel Behavior Inside vs. Outside the Study Area

\begin{tabular}{|c|c|c|c|c|c|c|c|c|}
\hline \multirow{2}{*}{$\begin{array}{c}\text { Response } \\
\text { Variable }\end{array}$} & \multicolumn{3}{|c|}{1984 - Before Capacity Additions } & \multicolumn{3}{c|}{1995 - After Capacity Additions } \\
\cline { 2 - 9 } & Inside & Outside & $\%$ Change & p-Value & Inside & Outside & \% Change & p-Value \\
\hline $\begin{array}{c}\text { Total Trip Productions } \\
\text { per Household }\end{array}$ & 9.95 & 11.85 & 19.02 & 0.0106 & 10.82 & 11.50 & 6.29 & 0.3789 \\
\hline Total Weekday VMT & 105,458 & 100,130 & 5.32 & 0.3707 & 147,033 & 119,247 & 23.30 & 0.0003 \\
\hline Total Trip Productions & 15,486 & 15,450 & 0.23 & 0.9263 & 17,825 & 16,789 & 6.17 & 0.0158 \\
\hline Total Trip Attractions & $*$ & $*$ & $*$ & $*$ & 18,400 & 16,258 & 13.18 & 0.0134 \\
\hline HBW Trip Productions & 3,635 & 3,627 & 0.22 & 0.8387 & 3,887 & 3,808 & 2.07 & 0.0263 \\
\hline HBNW Trip Productions & 6,480 & 6,374 & 1.66 & 0.2739 & 7,357 & 7,099 & 3.63 & 0.0194 \\
\hline NHB Trip Productions & 3,516 & 3,607 & 2.52 & 0.7551 & 4,432 & 3,936 & 12.60 & 0.1317 \\
\hline Other Trip Productions & 1,854 & 1,843 & 0.60 & 0.9111 & $*$ & $*$ & $*$ & $*$ \\
\hline HBW Trip Attractions & $*$ & $*$ & $*$ & $*$ & $*$ & $*$ & $*$ & $*$ \\
\hline HBNW Trip Attractions & $*$ & $*$ & $*$ & $*$ & 8,008 & 6,816 & 17.49 & $\mathbf{0 . 0 3 8 6}$ \\
\hline NHB Trip Attractions & $*$ & $*$ & $*$ & $*$ & $*$ & $*$ & $*$ & $*$ \\
\hline Other Trip Attractions & $*$ & $*$ & $*$ & $*$ & 2,040 & 1,711 & 19.23 & 0.0254 \\
\hline
\end{tabular}

* There is a significant interaction between one or more covariates and the Inside/Outside variable, so the parallel model is not valid; Hence, the analysis of covariance model is not justified. 


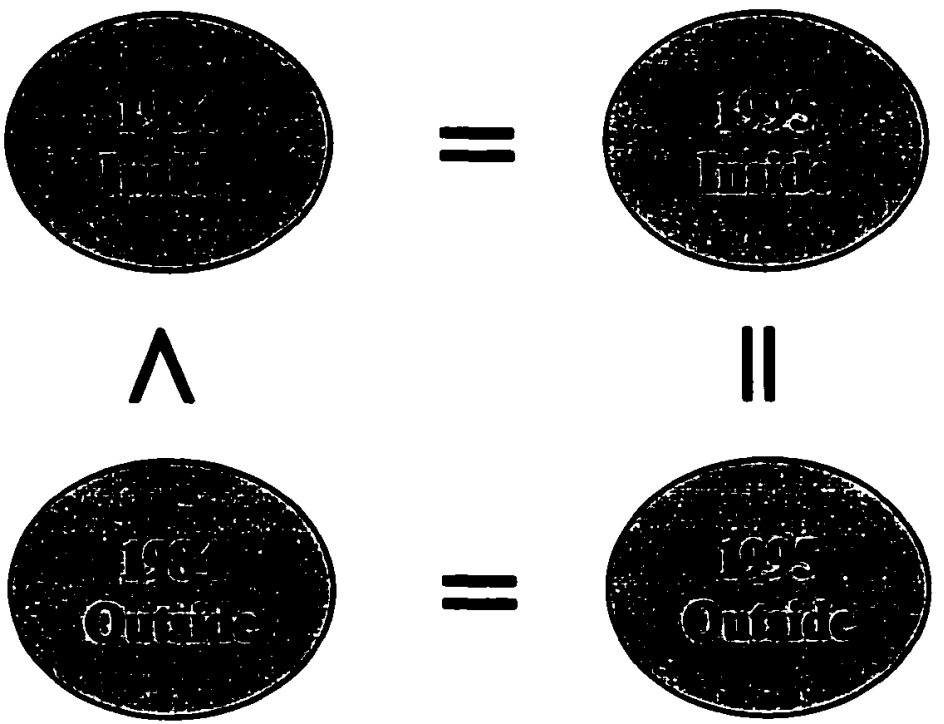

Figure 3.32. Schematic of Trip Productions per Household Comparisons

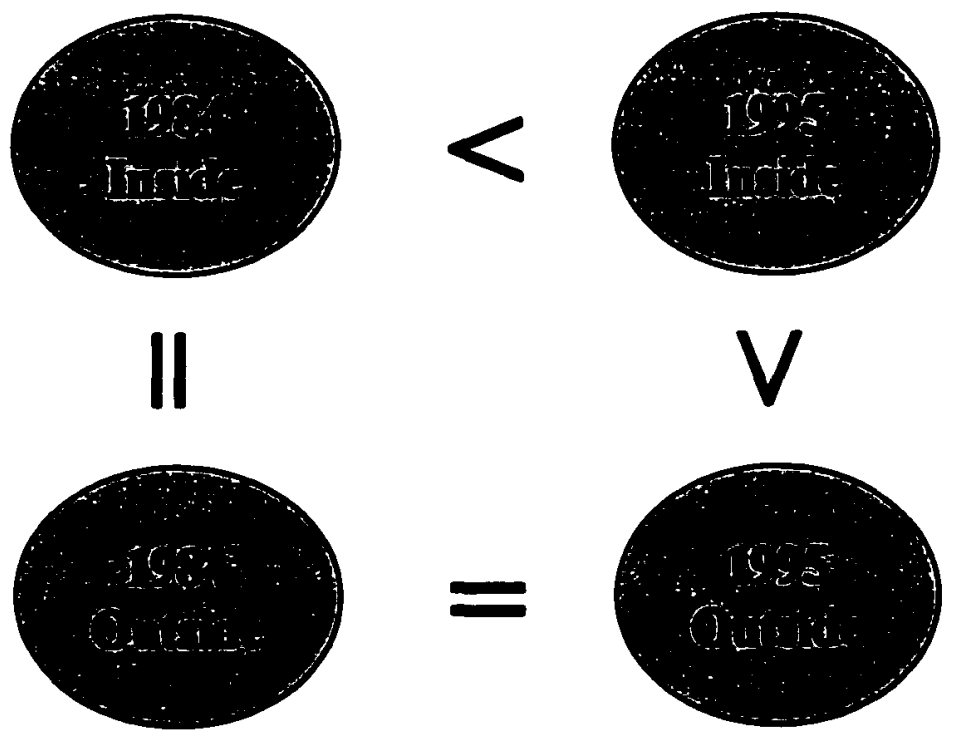

Figure 3.33. Schematic of Total Trip Production Comparisons 

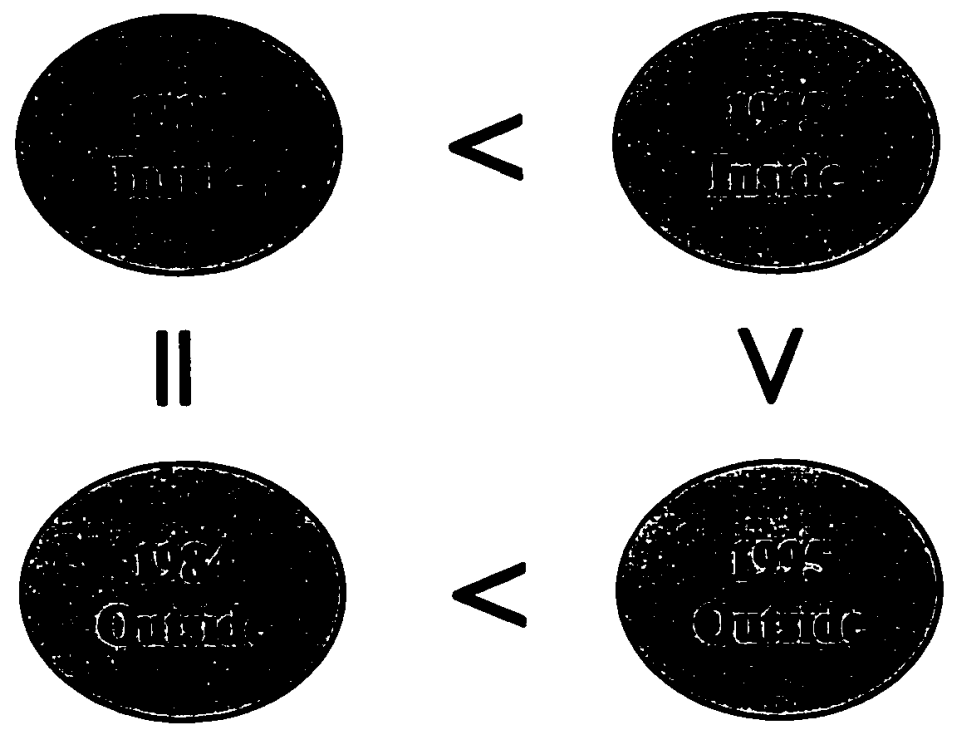

Figure 3.34. Schematic of Vehicle-Miles of Travel Comparisons

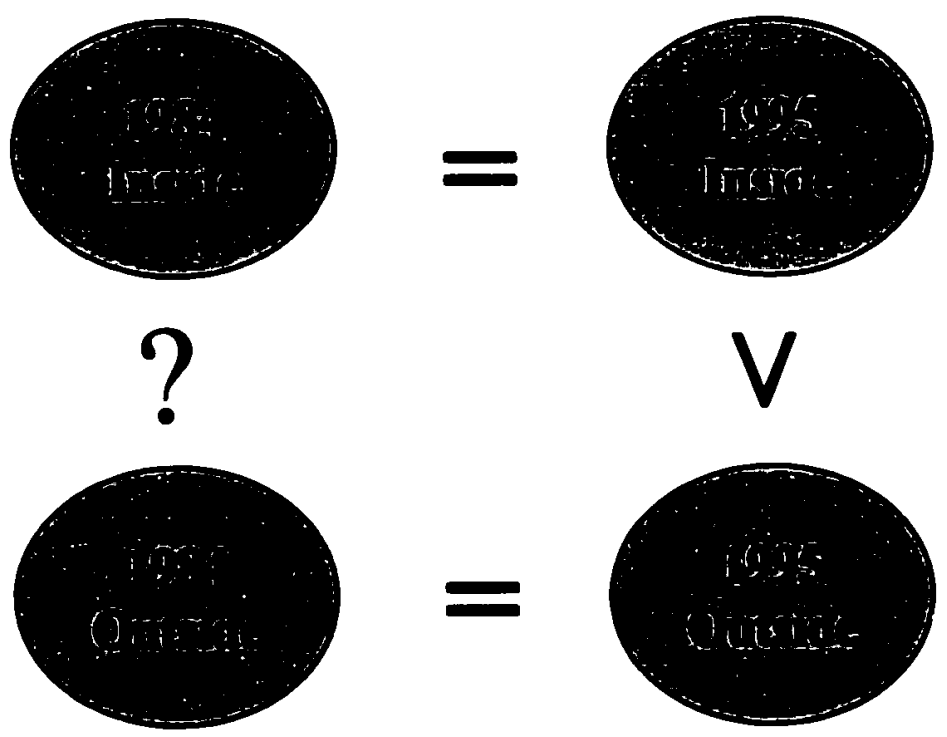

Figure 3.35. Schematic of Total Trip Attraction Comparisons 
income and population density. (From Table 3.2, note that after roadway capacity was added, one additional daily trip was produced by households inside the study area, but this change is statistically insignificant). In 1984, there were nearly two fewer daily trips per household produced inside the study area than outside the study area. Over the years, however, this difference disappeared. So we can see that prior to highway expansion, households outside the study area were making more trips than those inside. By 1995 , however, households inside the study area were making just as many daily trips as households outside the study area. Therefore, we can conclude that, after controlling for changes in income and population density, the data provide evidence that additional highway capacity generated a demand for more trips. The magnitude of this difference is 1.89 daily trips per household, an increase of 19 percent. This result must be interpreted with caution since it may be possible that other variables than those studied account for the change in travel behavior (e.g., different expectations or needs).

A similar conclusion is supported by the total trip productions schematic shown in Figure 3.33. There was no significant difference in total trip productions for zones inside the study area as opposed to those outside for 1984 . However, zones inside the study area produced approximately 6 percent more daily trips than zones outside after capacity additions had taken place. This suggests that additional highway capacity generated more trip productions, after taking into account median household income, number of households, and population density. Total trip productions inside the study area grew over time by nearly 7 percent. On the other hand, the fact that trip production rates did not change over time in the outside group indicates that the model may be temporally stable when there are no major transportation system changes. 
Figure 3.34 shows that total weekday VMT varied both temporally and spatially. VMT increased by 35.09 percent inside the study area as opposed to a 15.55 percent increase for the outside group from 1984 to 1995 . In 1984, there was no significant difference in VMT between the groups inside and outside the study area. Over time, VMT increased by over 23 percent in zones located inside the study area versus zones outside the area. This suggests once again that highway improvements generated additional VMT, after controlling for the influences of income, number of households, and population density. It should be noted that some of the VMT growth may have been generated by households located outside the study area. Nevertheless, the data appear to confirm the hypothesis that adding highway capacity increases VMT.

Figure 3.35 shows that there was no statistically significant difference in the number of trip attractions between the two time periods either inside or outside the study area, after taking into account changes in median household income, number of employees, and population density. After capacity was added, zones inside the study area attracted about 13 percent more trips than zones in the outside group. However, the overall results are inconclusive since we cannot compare total trip attractions inside and outside the study area before the capacity additions took place. In this case, the analysis showed a significant interaction between the Inside/Outside group variable and the total number of employees in the zone. This means that the relationship between total employment and trip attractions is not the same inside and outside the study area in 1984 (i.e., there is a differential effect of total employment on trip attraction for the two groups). Hence, an analysis of covariance cannot statistically remove the influence of total employment, and conclusive results cannot be obtained. 
Schematic diagrams are not presented for home-based work, home-based nonwork, non-home based, and other trip productions and attractions. The results are shown in Tables 3.1 and 3.2. The major difficulty encountered in analyzing travel behavior by trip purpose was that the assumption of parallel regression planes was not valid in many cases, and an analysis of covariance model provided no straightforward results. Nevertheless, the trip production and VMT results just presented appear to furnish credible evidence in support of the argument that adding highway capacity induces demand for travel. Again, I must caution that other variables than those included in the model may be at work, and it is always difficult to establish causation in a retrospective study. Perhaps the best that we can say is that a statistically significant difference in travel demand, as measured by number of trips produced and VMT, was observed in the Dallas-Fort Worth metropolitan area after accounting for changes in income, population density, and number of households.

The analysis of covariance methodology is similar to a statistical technique commonly used in econometric modeling called difference-in-differences (Meyer, 1995). This analytical technique can be applied when data are available for the time period before and after the treatment for a group that does not receive the treatment but experiences some or all of the other influences that affect the treatment group. In our DFW Before-and-After case study, data are available before and after significant highway capacity expansion for TAP zones "Inside" the study area that received the treatment (i.e., experienced capacity additions) as well as for a comparison group of TAP zones "Outside" the study area that did not receive the treatment.

Analysis of covariance makes four comparisons of two groups: a treatment group 
and a control group before treatment, a treatment and control group after treatment, before and after treatment for the treatment group, and before and after treatment for the control group. For each comparison that is made, a statistical test is done to determine whether the relationship between each covariate and the response variable is the same for the two groups being compared. This tests the validity of the parallel model which allows the influence of the covariates to be removed and a direct comparison between the groups to be made. Difference-in-differences, on the other hand, is perhaps a more direct analytical design in that it imposes the assumption of an equal relationship between the covariates and the response variable and compares the differences in the treatment and control groups before and after treatment in a single model. Thus, it assumes equal slopes but allows the intercept to vary in the model.

Using the difference-in-differences approach, the underlying model of the outcome variable is of the following form:

$$
Y_{i t}=\alpha+X_{i l} \beta+D_{\text {inside }} \gamma_{1}+D_{\text {affer }} \gamma_{2}+\left(D_{\text {inside }} \times D_{\text {affer }}\right) \gamma_{3}+\varepsilon
$$

where $Y_{i r}$ are the various measures of travel demand used in the study, $X_{i r}$ are the covariates, and $D_{\text {inside }}$ and $D_{\text {affer }}$ are dummy variables indicating whether the zone is inside the study area and after the capacity expansion, respectively $(1=$ inside and after, 0 otherwise). So, $D_{\text {inside }} \times D_{\text {after }}$ is a dummy variable indicating those zones in the experimental group after receiving the treatment. The parameter $\gamma_{1}$ captures any unobserved effects that are unique to the zone's location inside the study area (i.e., in the experimental or treatment group). If all travel zones experienced increases in travel demand due to uniform changes such as population and income growth that occur over time, this would be accounted for by $\gamma_{2}$. And finally, $\gamma_{3}$ captures the special effects of 
being inside zones that have undergone highway system improvements after the improvements have been made. The test for induced demand is $\mathrm{H}_{0}: \gamma_{3}=0$.

Applying the difference-in-differences technique to the DFW travel model data, it was found that highway capacity additions had a significant effect on VMT, after accounting for changes in number of households, income, and population density. The magnitude of the parameter $\gamma_{3}$ was found to be 23,145 , indicating that total weekday VMT in zones inside the treatment group after treatment (i.e., after additions to highway capacity) increased by approximately 20 percent. This result supports the hypothesis that increasing highway capacity in a particular metropolitan area can induce significant additional travel.

Both the analysis of covariance and difference-in-differences analytical techniques do not account for zone effects in the time periods before and after highway capacity additions. Travel behavior in the same groups of households is measured before and after treatment. And although the household groups are not static from 1984 to 1995 , the before and after measurement of travel demand used in the analyses presents a situation where the two responses form a pair of measurements coming from the same experimental unit, in this case the TAP zone. Because the measurements are paired, treating the Before and After results as independent discards potentially useful information. To test for independence, pairwise regressions of Before versus After responses were conducted (i.e., 1995 VMT was regressed on 1984 VMT, 1995 trip productions on 1984 trip productions, and so on). The R-squared values for these pairwise regressions ranged from 0.76 for VMT up to 0.9 for home-based work trip attractions. This indicates that the responses are highly associated and not independent 
for a given TAP zone. Hence, while it may not be incorrect to use analysis of covariance and difference-in-differences designs under these conditions, it must be noted that these techniques may not have as much statistical power to signal differences as a technique that takes into account correlation between the before and after measures.

I applied a third analytical design which involved estimating a model using the difference in travel demand between 1984 and 1995 as the response variable. This technique essentially differences out the zone effects and allows the impact of highway system improvements on various measures of travel demand to be determined after controlling for demographic and economic differences. Therefore, the following model was estimated:

$$
Y_{i t}-Y_{i t-1}=\alpha+\gamma D_{i}+\sum \beta\left(X_{i t}-X_{i t-1}\right)+\varepsilon
$$

Where $Y_{i t}-Y_{i t-l}$ is the difference in travel demand (e.g., VMT, number of trips produced) in zone $\mathrm{i}$ between 1984 and $1995, \sum\left(X_{i t}-X_{i r-l}\right)$ are the differences in the covariates (household income, population density, employment, and number of households) in zone $i$ between 1984 and 1995 , and $D_{i}$ is a dummy variable indicating whether or not the zone had experienced significant additions to highway capacity (i.e., whether the zone is "inside" or "outside" the study area). It is important to note that only the TAP zones common to both time periods were used in the analysis. Thus, the zones that were added in 1995 when the metropolitan travel survey area was expanded were not considered.

Results of the analysis are presented in Table 3.3. For each measure of travel demand, the coefficient of the Inside/Outside indicator variable along with its corresponding t-statistic and the model R-squared value are shown. A t-ratio of at least 
1.96 indicates a statistically significant effect of highway capacity additions on travel demand at a 5 percent significance level; these appear in boldface type in Table 3.3.

Table 3.3. Regression Analysis of Differences in Travel Behavior Between 1984 and 1995 in Dallas-Fort Worth

\begin{tabular}{|l|c|c|c|}
\hline \multicolumn{1}{|c|}{$\begin{array}{c}\text { Regponse Variable } \\
\text { Coeficient of }\end{array}$} & t-Ratio & R \\
\hline Difference in Trips Produced per Household & 46.1 & 0.57 & 0.0079 \\
\hline Difference in Total Weekday VMT & $24,257.6$ & 4.17 & 0.092 \\
\hline Difference in Total Trip Productions & $1,164.6$ & 3.68 & 0.679 \\
\hline Difference in Total Trip Attractions & 809.1 & 1.07 & 0.370 \\
\hline $\begin{array}{l}\text { Difference in Home-Based Work Trips } \\
\text { Produced }\end{array}$ & 185.9 & 3.06 & 0.818 \\
\hline $\begin{array}{l}\text { Difference in Home-Based Non-Work } \\
\text { Trips Produced }\end{array}$ & 430.3 & 3.44 & 0.814 \\
\hline $\begin{array}{l}\text { Difference in Non-Home Based Trips } \\
\text { Produced }\end{array}$ & 392.0 & 2.10 & 0.037 \\
\hline Difference in Other Trips Produced & 156.4 & 2.69 & 0.243 \\
\hline $\begin{array}{l}\text { Difference in Home-Based Work Trips } \\
\text { Attracted }\end{array}$ & 50.8 & 2.03 & 0.979 \\
\hline $\begin{array}{l}\text { Difference in Home-Based Non-Work } \\
\text { Trips Attracted }\end{array}$ & 396.5 & 0.74 & 0.139 \\
\hline $\begin{array}{l}\text { Difference in Non-Home Based Trips } \\
\text { Attracted }\end{array}$ & 243.0 & 1.91 & 0.555 \\
\hline Difference in Other Trips Attracted & 118.7 & 0.96 & 0.143 \\
\hline
\end{tabular}

The results in Table 3.3 suggest, for example, that we can conclude that highway improvements in the Dallas-Fort Worth metropolitan area had a significant effect on the difference in total weekday VMT between 1984 and 1995, after accounting for differences in median household income, number of households in the zone, and population density. Furthermore, the magnitude of the coefficient tells us that the 
temporal difference in total weekday VMT was over 24,000 miles higher in zones that had undergone capacity enhancements, an increase of slightly more than 20 percent over the average VMT for zones inside the study area in 1984. Similarly, the following statistically significant increases in other measures of travel demand can be attributed to roadway capacity additions: 6.4 percent in tctal trip productions, 4.2 percent in homebased work trips produced, 5.5 percent in home-based non-work trips produced, 10.0 percent in non-home based trips produced, and 7.4 percent in other trips produced. For trip attractions, only home-based work trips attracted were statistically significant; the difference between 1984 and 1995 , an increase of 1.4 percent, was relatively minor.

\section{Summary of Major Findings}

Many recent research studies have defined and quantified the phenomenon of induced travel demand. However, case studies using a before-and-after approach to examine changes in travel behavior that occur in response to highway system improvements have rarely appeared in the literature. With the study presented in this chapter, I have attempted to address this shortcoming and enhance the state of the art of induced travel research by using calibrated travel model data from the Dallas-Fort Worth metropolitan area to investigate differences in observed travel patterns between 1984 and 1995. Various statistical techniques were employed to estimate relationships between highway capacity and several measures of travel demand.

Analysis of covariance and difference-in-differences are very powerful beforeand-after research designs for comparing treatment and control groups for the time periods before and after the treatment. Both of these designs were applied to the DFW 
travel model data to determine the differences in travel behavior in travel zones that experienced increases in highway capacity versus zones that remained largely unchanged in the period before (1984) and after (1995) capacity was added. Results using the analysis of covariance modeling approach suggested that adding highway capacity generated about 6 percent additional demand for the number of trips made and also increased VMT demand by approximately 23 percent, after controlling for differences in income, number of households, and population density. Using the difference-indifferences design, VMT demand increased 20 percent; statistically significant relationships between capacity expansion and all other measures of travel demand were not found.

Because the before and after measures of travel demand are paired measurements and the responses are, therefore, not independent for a given zone, the analysis of covariance and difference-in-differences designs may not have as much statistical power to signal differences as a technique that takes into account correlation between the before and after measures. To difference out the zone effects in the before and after time periods, a model was fit using ordinary least squares linear regression to estimate the effect of highway capacity expansion on the difference in travel demand between 1984 and 1995. Results of this analysis showed that the total weekday VMT in TAP zones experiencing significant highway capacity additions increased approximately 20 percent from 1984 to 1995, after accounting for changes in income, population density, and number of households over this period. In addition, the total number of trips produced in these TAP zones increased by 6.4 percent. Trip productions by purpose were all significantly influenced by highway improvements with the magnitude of the effect 
ranging from 4.2 percent for home-based work trips to 10 percent for non-home based trips. This finding is very interesting because it suggests that highway capacity expansion will induce greater demand for discretionary travel such as non-home based trips than for home-to-work trips which will be made regardless of whether or not the local transportation network is improved.

The impact of capacity additions on the number of trips attracted to a zone was, for the most part, insignificant using all three analytical methods. Differences in trip attractions between the two time periods as well as between the zones inside and outside the study area were found to be influenced primarily by the total number of employees in the zone. When changes in employment are controlled for in the analysis, substantial absolute differences in trip attraction rates turned out to be statistically insignificant in most cases. This would seem to suggest that the change in employment in the zone was a more important determinant of trip attraction differences than changes in highway supply.

In summary, three statistical analysis approaches were used to investigate the effects of highway capacity expansion on travel behavior in a before-and-after case study of the Dallas-Fort Worth metropolitan area. All three research designs produced very similar results. After accounting for the effects of some demographic and socioeconomic factors that contribute to growth in travel demand, vehicle miles of travel were found to increase about 20 percent and total trips produced increased 6 to 7 percent in travel zones that had undergone additions to roadway capacity between 1984 and 1995 . These results support the hypothesis that expansion of highway capacity can generate additional demand for travel. 


\section{CHAPTER IV}

\section{CONCLUSIONS}

Two separate but complementary empirical approaches were taken to investigate the issue of induced growth in highway travel demand. Both approaches apply multivariate statistical techniques to measure and quantify the effects of highway system improvements on travel behavior after controlling for many of the socioeconomic and demographic factors that cause growth in motor vehicle travel. However, two different data sets are utilized. The first study used disaggregate, cross-sectional NPTS travel survey data. Disaggregate data are advantageous since they reflect individual decisions about where, when, and how to travel rather than average travel behavior aggregated to the travel zone, metropolitan area, or state level. Also, cross-sectional data describe the travel patterns of a wide variety of people who face different highway situations and transportation system attributes. On the other hand, the data did not capture region-specific effects that may be unique to a particular metropolitan area, nor did the study evaluate the long-term changes in travel demand induced by additional supply since the NPTS is not a longitudinal survey. The second study, therefore, complements the NPTS study by using travel data specific to the Dallas-Fort Worth metropolitan area from two time periods to measure temporal changes in travel demand. The same groups of households are surveyed in 1984 and 1995, although the groups are not necessarily static over the 11-year period. The drawback of this study, however, is that it uses data aggregated to the travel zone level. Therefore, two different but 
complementary analytical studies were conducted to examine the induced demand hypothesis by estimating relationships between highway capacity and travel behavior.

In the first study, household data from the 1995 Nationwide Personal Transportation Survey (NPTS) were used to estimate travel demand elasticities with respect to travel time. The time elasticity of travel demand measures the response of highway use to changes in capacity that reduce travel time resulting from investments that extend the highway network or widen its existing links. Travel time elasticities are a useful way of estimating induced travel demand because they consider the context of highway capacity additions, that is, pre-existing levels of congestion and bottlenecks on the highway network. For this reason, travel time as a measure of supply is preferred to lane miles. But it must be noted that travel time is also an imperfect metric because it is such a variable parameter. Travel time varies by time of day, day of week, season of the year, urban vs. suburban vs. rural area, etc. Nevertheless, the NPTS provided a very robust, disaggregate, cross-sectional data set for the analysis. Cross-sectional studies give insight into the long-term effects of changes in highway supply on travel demand since they assume that travel and land use adjustments have been made in response to the available levels of service of the transportation system. Statistically significant relationships were found between travel time and VMT; this supports the hypothesis that adding highway capacity to reduce travel times can induce additional VMT. Elasticities in the range of -0.3 to -0.5 were found. This indicates that, after controlling for the effects of changes in socioeconomic and demographic factors such as income, household size, population density, and employment, a 10 percent reduction in average household travel time will restlt in a 3 to 5 percent increase in annual household VMT. However, 
the statistical models developed in this study do not resolve the issue of causality (i.e., does additional capacity cause VMT growth, or does VMT demand increase in response to anticipated future highway improvements). The NPTS results suggest that higher travel speeds (i.e., shorter travel times) caused increased VMT. It may be, however, that more VMT causes higher speeds. In other words, short trips are typically made at low speeds on local roads, whereas longer trips are made on freeways at higher speeds. In recently completed work, Harry Cohen (2001) extended the NPTS analysis that was done in this study to investigate the possibility that households with higher annual VMT may make longer trips, which may involve higher average speeds. After calculating a normalized travel time rate based on household trip length and duration, he re-estimated the 15 models that were calibrated in this study. He concluded that average speed does increase significantly with trip length and, therefore, leads to an overestimate of travel time elasticities. Cohen's analysis based on normalized travel time rates implied travel time elasticities in the range of -0.1 to -0.4 , after controlling for differences in population density, household income, household size, and number of workers in the household.

The ordinary least squares modeling approach used to analyze the NPTS data raises two major issues that represent possible areas for further investigation. The first issue concerns errors of measurement in the explanatory variable INVSPEED. Because travel time exhibits spatial and temporal variation and also because the variable INVSPEED is determined from survey responses of trip length and duration, both of which are prone to reporting errors, this variable is subject to measurement error. In this case, the explanatory variable is correlated with the error term in the model, and the resulting OLS estimators are biased and inconsistent. A suggested remedy is the use of 
an instrumental or proxy variable that is correlated with travel speed but uncorrelated with the error term. This approach could also be used to address the problem of endogeneity that arises from the way in which the travel speed variable is constructed. Unfortunately, it is difficult in practice to find good instrumental variables, and, in fact, I was unable to find a suitable instrument in the NPTS database.

The second major study undertaken in this research was to conduct a before-andafter case study analysis using validated travel model data from the Dallas-Fort Worth metropolitan area. Using roadway link and volume data files, travel zones which had experienced significant highway capacity increases between 1984 and 1995 were identified. Using an analysis of covariance modeling approach, differences in travel behavior were analyzed between zones where capacity had been added and zones that remained mostly unchanged for both years. Results of the analysis suggested that adding highway capacity generated demand for more trip productions and also increased VMT demand, after controlling for differences in income, number of households, and population density. Looking at trip productions by purpose, it appears that the addition of capacity caused statistically significant differences in home-based work and home-based non-work trips of approximately 2 and 4 percent, respectively. However, analysis of covariance models did not give definitive results for trip productions by purpose because differential effects between covariates and the dependent variable were found in many cases. Thus, a direct comparison of travel behavior between the inside/outside group, the before/after group, or both was unreliable. A similar difficulty was encountered when attempting to quantify the differences in trip attraction rates before and after highway expansion. 
For this reason, the analysis of covariance approach was supplemented by two additional analytical designs. The difference-in-differences design, commonly used in econometric analyses, showed that VMT was the only measure of travel demand to be significantly influenced by highway capacity increases. Comparing travel behavior inside and outside the study area in 1984 and 1995, VMT growth of approximately 20 percent can be attributed to added capacity. And finally, estimating the relationship between capacity additions and the difference in travel demand from 1984 to 1995 using ordinary least squares regression, increases in VMT of 20 percent and in the number of trips produced of 6 to 7 percent were found.

For the most part, the modeling techniques used in the case study proved to be useful research designs for analyzing and comparing differences in travel behavior caused by highway improvements between two points in time. However, the before-andafter case study was subject to some important limitations that could possibly be addressed in future research. The analyses in this study were done at a very aggregate level (i.e., the TAP zone is the unit of observation). Using travel and demographic data for each traffic survey zone rather than doing the analysis at the TAP zone level might produce better results. In addition, bringing the network files into the GIS environment and overiaying them on the zone structures may be a helpful way of differentiating geographic corridors affected by highway improvements from areas used as a control group. A better understanding of the spatial characteristics and land use patterns in the Dallas-Fort Worth region would also improve the definition of the "inside" and "outside" groups. Finally, origin-destination survey data of household travel behavior, if available, would be a better data source than travel model output data for performing the analysis. 
The research presented in this dissertation adds to the growing body of knowledge on induced travel demand in two ways. First of all, my analysis is one of a select few in which travel time elasticities are estimated using disaggregate household-level travel survey data. This addresses a concern expressed by the transportation planning community that studies of induced demand have typically been done using aggregate data at the county, metropolitan, or state level. Disaggregate data is advantageous since individual travelers, not states, counties, or metropolitan areas, make decisions regarding their travel behavior (how, where, when, and why to travel). And secondly, an analytical methodology was adapted to a before-and-after case study to quantify changes in travel behavior that occur as a result of transportation investments made in a selected metropolitan area. Both empirical studies reached the conclusion that the hypothesis of induced travel cannot be rejected; that is, adding capacity to the transportation system can significantly increase the demand for additional travel. While it is not possible to strictly prove causality with the statistical techniques used in this research, these results strongly suggest that the induced demand phenomenon is real and should be considered by planners and public officials in the evaluation of transportation investment decisions.

Travel demand elasticities, such as those derived in this study using NPTS household travel survey data, are especially useful as inputs to the travel demand forecasting models used by transportation planners. One of the biggest factors behind efforts to improve transportation planning models is compliance with the environmental conformity requirements contained in the 1990 Clean Air Act Amendments. And that, in part, is why accounting for induced travel demand in proposed transportation improvement projects is so important. Traditional four-step models, which include trip 
generation, trip distribution, mode choice, and route assignment, are used for two purposes: (1) forecasting travel patterns (e.g., overall traffic volumes and the spatial distribution of trips) into the future, and (2) defining and setting transportation policy objectives. Using point elasticities that quantify induced demand in the four-step modeling process is an appropriate approach for checking the reasonableness of the model and for improving the accuracy of predicted future travel activity. However, caution must be exercised when attempting to use point elasticities in the public debate about new transportation investments. Many transportation and urban planners are uncomfortable with the notion of applying empirically-based point elasticities which have been derived from many varied data sources to specific transportation improvement projects in metropolitan areas.

Capacity improvements may also have important effects for land use development. The added capacity may permit increased speeds and lower travel times, enabling greater travel distances in a given amount of time. This, in turn, may open new areas for potential development in outlying regions that were previously beyond the limits of acceptable travel times. Individual decisions to locate in outlying areas farther away from employment and commercial centers have given rise to the phenomenon of urban sprawl. New outlying developments in sprawling regions may eventually generate longer trips to and from currently developed areas. Those longer trips produce more vehicle-miles of travel which, even if traveled at more efficient speeds, may produce more air polluting emissions than were reduced by the capacity additions that eased congestion and smoothed traffic flow. Urban sprawl and air quality are societal concerns that must be considered when weighing the costs and benefits of highway capacity 
additions as a potential transportation improvement strategy.

Previous research has clearly established a temporal component to the induced demand phenomenon. Lee et al. (1997) referred to the short-term effects of highway system improvements (e.g., route diversion and shifts in trip departure times) as induced traffic, while long-term effects such as land use changes were designated as induced travel. Induced demand, then, consists of both induced traffic and induced travel. The public perception of previous levels of congestion returning to a new/improved transportation facility is a fact. This does indeed happen after a period of time. However, this does not mean that society does not benefit at all from transportation system improvements. Induced demand should not necessarily be viewed as a negative problem to be solved, but rather a phenomenon that needs to be considered and accounted for in the transportation planning, investment decision, and policy-making processes. Future research should focus on system benefits that accrue at the regional level from capacity expansion. The issue of induced demand should not be addressed only with respect to highways. A system-wide perspective must be taken in which induced demand is considered in major investment decisions for all transportation modes, most notably public transit. Transportation professionals continue to debate the following controversial questions: Do we build roads and expand highway capacity to relieve traffic congestion? Or do we build roads to improve accessibility and serve regional growth? The prevailing opinion seems to suggest that land use, not congestion, is the predominant issue and that transportation investments are made to serve growth. 


\section{LIST OF REFERENCES}


1. Bonsall, P. Can Induced Traffic Be Measured by Surveys? Transportation, Volume 23, No. 1, February 1996.

2. Brand, D. Forecasting Models. Conference Proceedings, The Effects of Added Transportation Capacity, Bethesda, MD. 1991.

3. Burright, B. K. Cities and Travel. Garland Publishing, New York. 1984.

4. Cambridge Systematics, Inc. Draft Report of ITS Deployment Analysis System (IDAS) Progress Meeting. June 1998.

5. Cohen, H. S. Appendix B, Review of Empirical Studies of Induced Traffic. Expanding Metropolitan Highways: Implications for Air Quality and Energy Use. TRB Committee for Study of Impacts of Highway Capacity Improvements on Air Quality and Energy Consumption. TRB Special Report 245. 1995.

6. Cohen, H.S. The Induced Demand Effect: Evidence from National Data. Presented at the Eno Transportation Foundation Policy Forum: Working Together to Address Induced Demand. Washington, DC. February 22, 2001.

7. Coombe, D. Induced Traffic: What Do Transportation Models Tell Us? Transportation, Volume 23, No. 1, February 1996.

8. DeCorla-Souza, P. and H. S. Cohen. Accounting for Induced Travel in Evaluation of Metropolitan Highway Expansion. Transportation Research Board, $77^{\text {th }}$ Annual Meeting, Paper No. 980132, Washington, DC. 1998.

9. Domencich, T. A., G. Kraft, and J. P. Vallette. Estimation of Urban Passenger Travel Behavior: An Economic Demand Model. In Highway Research Record 238. Highway Research Board, National Research Council, Washington, DC. 1968.

10. Dowling, R. G. and S. B. Colman. Effects of Increased Highway Capacity: Results of a Household Travel Behavior Survey. Proceedings of Session No. 275 at the 1997 Annual Meeting of TRB. Transportation Research Board, Washington, DC. 1997.

11. Dunphy, R. T. Widening the Roads: Data Gaps and Philosophical Problems. Proceedings of Session No. 275 at the 1997 Annual Meeting of TRB. Transportation Research Board, Washington, DC. 1997.

12. Federal Highway Administration, United States Department of Transportation. 1995 NPTS User's Guide for the Public Use Data Files. Publication No. FHWAPL-98-002. 1997. 
13. Fulton, L.M., D.J. Meszler, R.B. Noland, and J.V. Thomas. A Statistical Analysis of Induced Travel Effects in the U.S. Mid-Atlantic Region. Transportation Research Board, $79^{\text {th }}$ Annual Meeting, Paper No. 001289, Washington, D.C. 2000.

14. Goodwin, P. B. Empirical Evidence on Induced Traffic: A Review and Synthesis. Transportation, Volume 23, No. 1, February 1996.

15. Handy, S. Travel Behavior Issues Related to Neo-Traditional Developments - A Review of the Research. Summary, Recommendations, and Compendium of Papers, Urban Design, Telecommuting, and Travel Forecasting Conference, Williamsburg, VA. 1996.

16. Hansen, M., D. Gillen, A. Dobbins, Y. Huang, and M. Puvathingal. The Air Quality Impacts of Urban Highway Capacity Expansion: Traffic Generation and Land-Use Impacts. UCB-ITS-RR-93-5. Institute of Transportation Studies, University of California, Berkeley. April 1993.

17. Hansen, M. and Y. Huang. Road Supply and Traffic in California Urban Areas. Transportation Research-A, Volume 31, No. 3, 1997.

18. Heanue, K. Highway Capacity and Induced Travel: Issues, Evidence and Implications. Proceedings of Session No. 275 at the 1997 Annual Meeting of TRB. Transportation Research Board, Washington, DC. 1997.

19. Hills, P. J. What Is Induced Traffic? Transportation, Volume 23, No. 1, February 1996.

20. Kiefer, M. and S. R. Mehndiratta. If We Build It, Will They Really Keep Coming? A Critical Analysis of the Induced Demand Hypothesis. Transportation Research Board, $77^{\text {th }}$ Annual Meeting, Paper No. 980937, Washington, DC. 1998.

21. Kitamura, R. The Effects of Added Transportation Capacity on Travel: A Review of Theoretical and Empirical Results. Conference Proceedings, The Effects of Added Transportation Capacity, Bethesda, MD. 1991.

22. Kroes, E., A. Daly, H. Gunn, and T. Van Der Hoorn. The Opening of the Amsterdam Ring Road: A Case Study on Short-Term Effects of Removing a Bottleneck. Transportation, Volume 23, No. 1, February 1996.

23. Lee, D. B., L. Klein, and G. Camus. Modeling Induced Highway Travel Versus Induced Demand. Proceedings of the Transportation Research Board 76th Annual Meeting, Washington, DC. 1997. 
24. Meyer, B.D. Natural and Quasi-Experiments in Economics. Journal of Business and Economic Statistics. Volume 13, No. 2, April 1995.

25. Miller, E. J. and A. Ibrahim. Urban Form and Vehicular Travel: Some Empirical Findings. Transportation Research Record, No. 1617. Transportation Research Board, National Research Council. 1998.

26. Noland, R. B. Relationships Between Highway Capacity and Induced Vehicle Travel. Transportation Research Board, $78^{\text {th }}$ Annual Meeting, Paper No. 991069, Washington, DC. 1999.

27. Noland, R.B. and W.A. Cowart. Analysis of Metropolitan Highway Capacity and the Growth in Vehicle Miles of Travel. Transportation Research Board, 79 Annual Meeting, Paper No. 001288, Washington, D.C. 2000.

28. Ruiter, E. R., W. R. Loudon, C. R. Kern, D. A. Bell, M. J. Rothenberg, and T. W. Austin. The Vehicle-Miles of Travel - Urban Highway Supply Relationship. National Cooperative Highway Research Program Research Results Digest 127. Transportation Research Board, National Research Council. 1980.

29. Standing Advisory Committee on Trunk Road Assessment (SACTRA). Trunk Roads and the Generation of Traffic. Department of Transport, London. 1994.

30. Smith, M. E. and G. E. Schoener. Testing for Significant Induced Trip Making and Travel in Providence, Rhode Island. Transportation Research Record, No. 673. Transportation Research Board, National Academy of Sciences. 1978.

31. Transportation Research Board. Committee for Study of Impacts of Highway Capacity Improvements on Air Quality and Energy Consumption. Expanding Metropolitan Highways: Implications for Air Quality and Energy Use. TRB Special Report 245. National Research Council. 1995.

32. A. M. Voorhees \& Associates, Inc. A System Sensitive Approach for Forecasting Urbanized Area Travel Demands. FH-11-7546. FHWA, U. S. Department of Transportation. December, 1971.

33. Zahavi, Y. Traffic Performance Evaluation of Road Networks by the AlphaRelationship. Traffic Engineering and Control. Volume 14, Nos. 5,6, 1972. 


\section{APPENDIX A}

1995 Nationwide Personal Transportation Survey Analysis

Regression Model Estimates of Travel Time Elasticities 


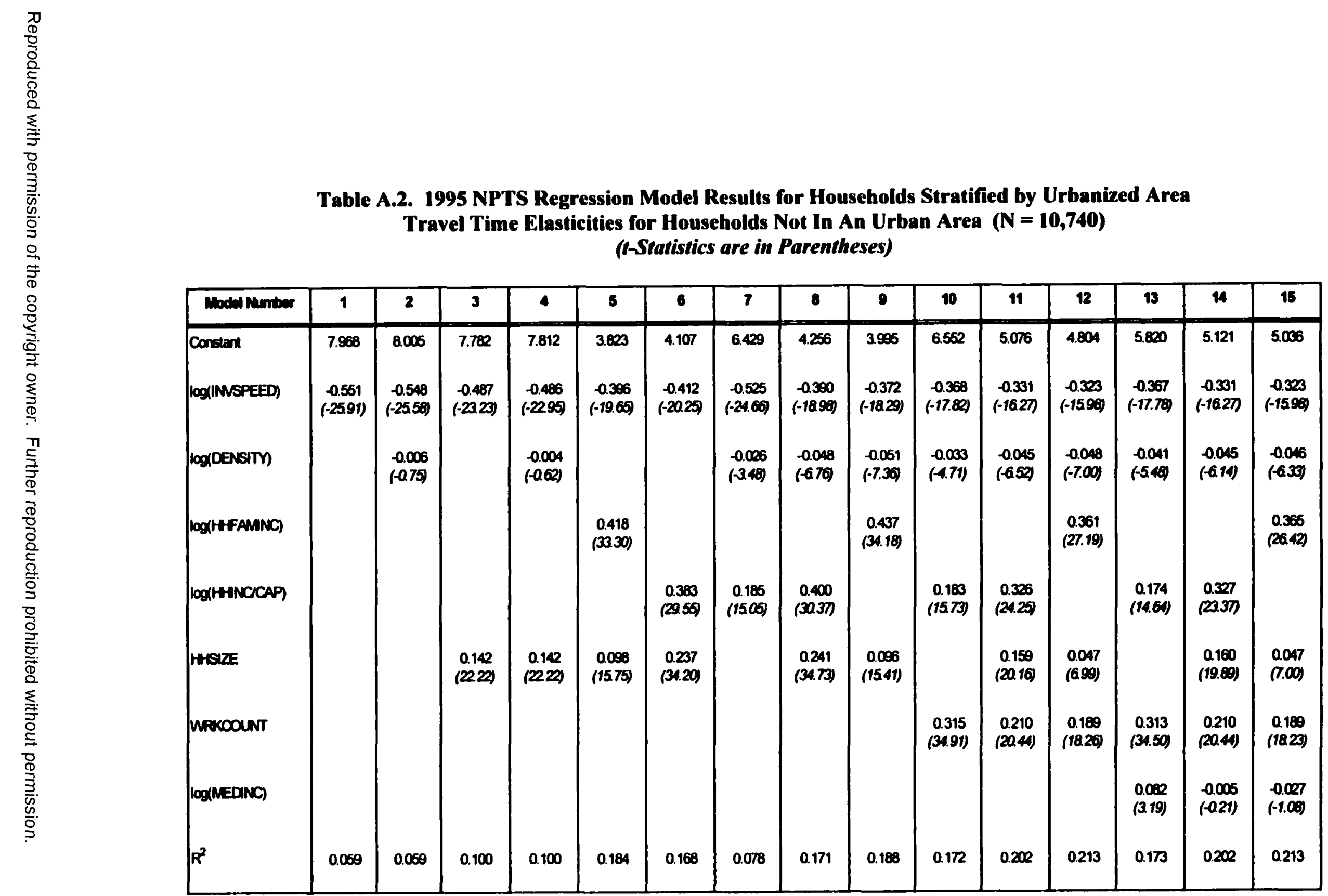


Table A.4. 1995 NPTS Regression Model Results for Households Stratified by Public Transportation Availability Travel Time Elasticities for Households With No Transit Available $(\mathbf{N}=9,553)$ (r-Statistics are in Parentheses)

\begin{tabular}{|c|c|c|c|c|c|c|c|c|c|c|c|c|c|c|c|}
\hline Model Number & 1 & 2 & 3 & 4 & 5 & 6 & 7 & 8 & 9 & 10 & 11 & 12 & 13 & 14 & 15 \\
\hline Constant & 7.789 & 7.901 & 7.587 & 7.660 & 3.519 & $37 \pi 3$ & 6.281 & 3.952 & 3.719 & 6.393 & 4.773 & 4.522 & 5.405 & 4.682 & 4.638 \\
\hline $\log ($ (IMSPEED) & $\begin{array}{r}-0.598 \\
(-27.69)\end{array}$ & $\begin{array}{r}-0.589 \\
(-2679)\end{array}$ & $\begin{array}{r}-0.524 \\
(-24.69)\end{array}$ & $\begin{array}{c}-0.517 \\
(-23.9)\end{array}$ & $\begin{array}{r}-0.429 \\
(-21.06)\end{array}$ & $\begin{array}{c}-0.444 \\
(-21.59)\end{array}$ & $\begin{array}{r}-0.560 \\
(-25.79)\end{array}$ & $\begin{array}{r}-0.413 \\
(-19.71)\end{array}$ & $\begin{array}{c}-0.397 \\
(-19.11)\end{array}$ & $\begin{array}{c}-0.401 \\
(-1899)\end{array}$ & $\begin{array}{r}-0.369 \\
(-17.269)\end{array}$ & $\begin{array}{r}-0.352 \\
(-17.004)\end{array}$ & $\begin{array}{c}-0.396 \\
(-1874)\end{array}$ & $\begin{array}{r}-0.359 \\
(-17.24)\end{array}$ & $\begin{array}{r}-0.362 \\
(-17.039)\end{array}$ \\
\hline logiDENSTM & & $\begin{array}{r}-0.014 \\
(-219)\end{array}$ & & $\begin{array}{r}-0.012 \\
(-1.809)\end{array}$ & & & $\begin{array}{r}-0.029 \\
(-1.46)\end{array}$ & $\begin{array}{r}-0.043 \\
(-7.10)\end{array}$ & $\begin{array}{l}-0.045 \\
(-7.50)\end{array}$ & $\begin{array}{l}-0.034 \\
(-522)\end{array}$ & $\begin{array}{l}-0.042 \\
(-7.003)\end{array}$ & $\begin{array}{l}-0.043 \\
(-7.339)\end{array}$ & $\begin{array}{l}-0.041 \\
(-6.54)\end{array}$ & $\begin{array}{r}-0.042 \\
1-6.924\end{array}$ & $\begin{array}{r}-0.012 \\
1-697)\end{array}$ \\
\hline logethaAmic) & & & & & $\begin{array}{r}0.431 \\
(3249\end{array}$ & & & & $\begin{array}{c}0.448 \\
(33.39)\end{array}$ & & & $\begin{array}{r}0.373 \\
(2660)\end{array}$ & & & $\begin{array}{r}0.375 \\
(25.50)\end{array}$ \\
\hline $\log (H+H N C C A P)$ & & & & & & $\begin{array}{c}0.308 \\
(29.03)\end{array}$ & $\begin{array}{c}0.187 \\
(14.31)\end{array}$ & $\begin{array}{r}0.415 \\
(29.90)\end{array}$ & & $\begin{array}{r}0.186 \\
(1509)\end{array}$ & $\begin{array}{c}0.341 \\
(24.01)\end{array}$ & & $\begin{array}{c}0.172 \\
(1349)\end{array}$ & $\begin{array}{r}0.330 \\
(2270)\end{array}$ & \\
\hline HaLEE & & & $\begin{array}{c}0.162 \\
(2343)\end{array}$ & $\begin{array}{c}0.162 \\
(23.49)\end{array}$ & $\begin{array}{r}0.115 \\
(17.18\end{array}$ & $\begin{array}{c}0.261 \\
(3503)\end{array}$ & & $\begin{array}{c}0.265 \\
(3551)\end{array}$ & $\begin{array}{c}0.113 \\
(1682)\end{array}$ & & $\begin{array}{r}0.179 \\
(20.87)\end{array}$ & $\begin{array}{l}0.081 \\
\text { (a.37) }\end{array}$ & & $\begin{array}{c}0.179 \\
(20.39)\end{array}$ & $\begin{array}{l}0.061 \\
\text { (8.36) }\end{array}$ \\
\hline UFucoONT & & & & & & & & & & $\begin{array}{c}0.332 \\
(34.30)\end{array}$ & $\begin{array}{r}0.210 \\
(1890)\end{array}$ & $\begin{array}{r}0.189 \\
(1680)\end{array}$ & $\begin{array}{r}0.328 \\
(3275)\end{array}$ & $\begin{array}{r}0.210 \\
(1890)\end{array}$ & $\begin{array}{r}0.169 \\
(16839)\end{array}$ \\
\hline $\log (N=D N C)$ & & & & & & & & & & & & & $\begin{array}{l}0.112 \\
(4.396)\end{array}$ & $\begin{array}{l}0.011 \\
(0.44)\end{array}$ & $\begin{array}{r}-0.014 \\
(-0.50)\end{array}$ \\
\hline$R^{2}$ & 0.074 & 0.074 & 0.124 & 0.124 & 0.211 & 0.196 & 0.094 & 0.199 & 0.216 & 0.198 & 0.228 & 0.238 & 0.194 & 0.228 & 0.238 \\
\hline
\end{tabular}




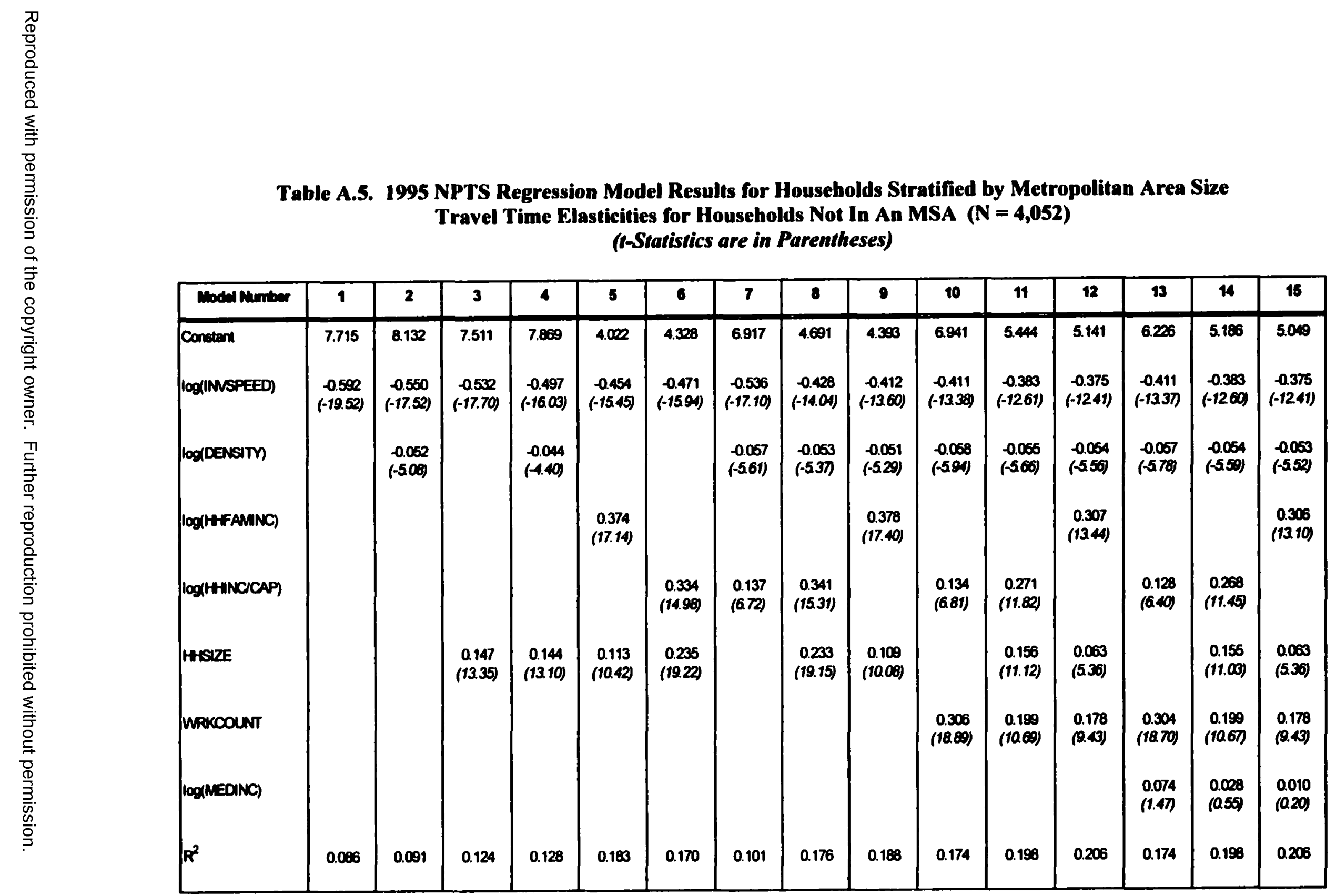




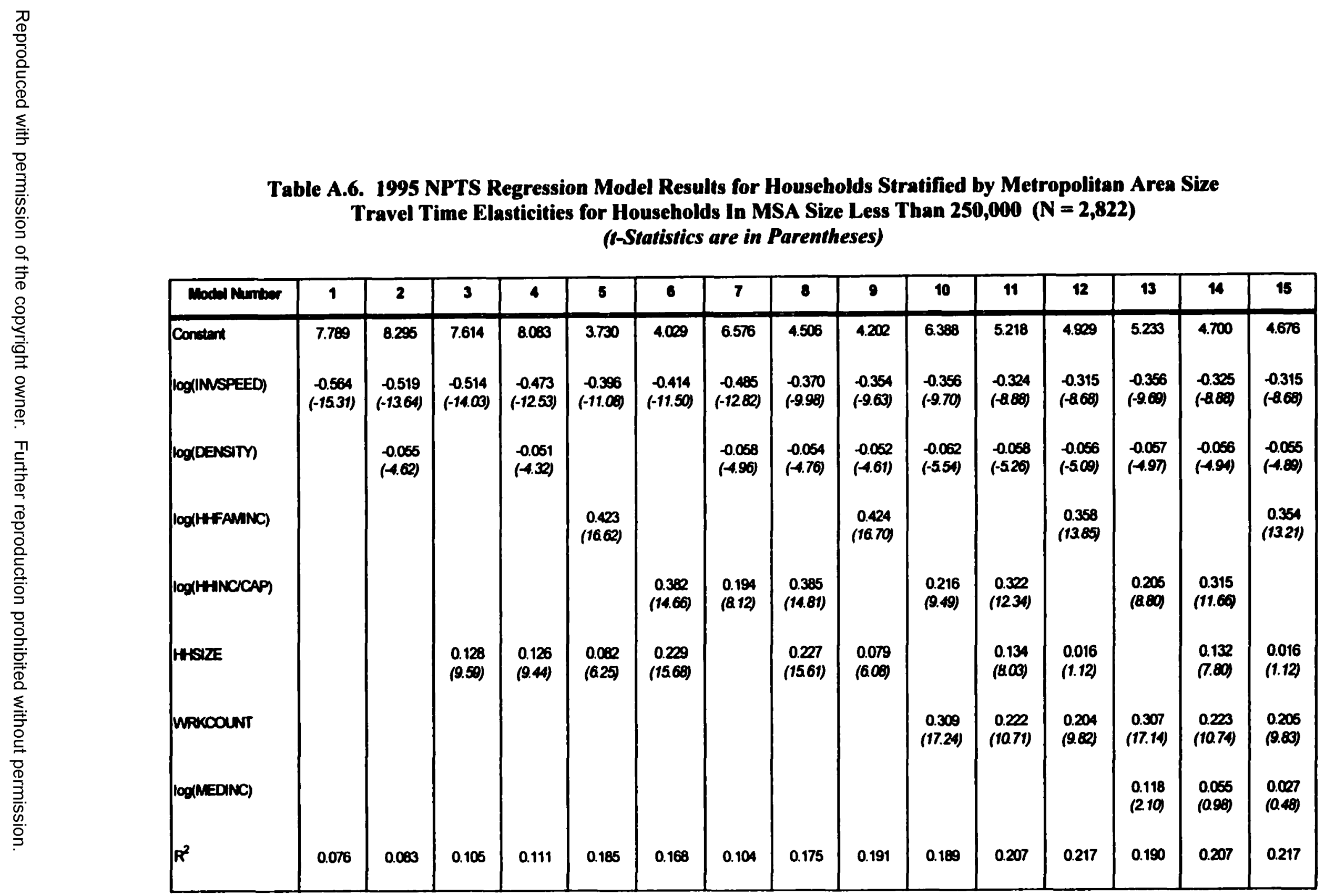




\begin{tabular}{|c|c|c|c|c|c|c|c|c|c|c|c|c|c|c|c|}
\hline \multicolumn{16}{|c|}{$\begin{array}{l}\text { Table A.7. } 1995 \text { NPTS Regression Model Results for Households Stratified by Metropolitan Area Size } \\
\text { Travel Time Elasticities for Households In MSA Size 250,000-499,999 }(\mathrm{N}=1,758) \\
\text { (T-Statistics are in Parentheses) }\end{array}$} \\
\hline Moded Munterer & 1 & 2 & 3 & 4 & 5 & 6 & 7 & 8 & ? & 10 & 11 & 12 & 13 & 14 & 15 \\
\hline Constant & 7.414 & 8.179 & 7.251 & 7.967 & 3.961 & 4.320 & 7.160 & 5.016 & 4.668 & 7.218 & 5.821 & 5.465 & 7.317 & 6.62 & 6.456 \\
\hline $\log ($ IMSPEED) & $\begin{array}{r}-0.675 \\
(-14.71)\end{array}$ & $\begin{array}{r}-0.000 \\
(-1266)\end{array}$ & $\begin{array}{r}-0.599 \\
(-1299)\end{array}$ & $\begin{array}{r}-0.521 \\
(-11.15)\end{array}$ & $\begin{array}{r}-0.508 \\
(-11.43)\end{array}$ & $\begin{array}{r}-0.525 \\
(-11.72)\end{array}$ & $\begin{array}{r}-0.588 \\
(-1241)\end{array}$ & $\begin{array}{l}-0.451 \\
(-9.79)\end{array}$ & $\begin{array}{l}-0.434 \\
(-9.49)\end{array}$ & $\begin{array}{r}-0.433 \\
(-9.34)\end{array}$ & $\begin{array}{l}-0.398 \\
(-868)\end{array}$ & $\begin{array}{r}-0.389 \\
(-0.54)\end{array}$ & $\begin{array}{r}-0.433 \\
(-9.32)\end{array}$ & $\begin{array}{r}-0.402 \\
(-876)\end{array}$ & $\begin{array}{l}-0.394 \\
(-864)\end{array}$ \\
\hline $\log$ DENSIM & & $\begin{array}{l}-0.076 \\
(-560)\end{array}$ & & $\begin{array}{l}-0.071 \\
(-536)\end{array}$ & & & $\begin{array}{l}-0.079 \\
-(-5.80)\end{array}$ & $\begin{array}{l}-0.076 \\
(-586)\end{array}$ & $\begin{array}{l}-0.076 \\
(-592)\end{array}$ & $\begin{array}{l}-0.088 \\
(-6.75)\end{array}$ & $\begin{array}{l}-0.083 \\
(-6,60)\end{array}$ & $\begin{array}{r}-0.008 \\
(-6.45)\end{array}$ & $\begin{array}{c}-0.088 \\
(-6.73)\end{array}$ & $\begin{array}{r}-0.084 \\
(-0.56)\end{array}$ & $\begin{array}{l}-0.004 \\
(-6.50)\end{array}$ \\
\hline $\log (H+F A M M C)$ & & & & & \begin{tabular}{|c|}
0.352 \\
$(111.08)$
\end{tabular} & & & & $\begin{array}{c}0.358 \\
(11.37\end{array}$ & & & $\begin{array}{l}0.289 \\
(887)\end{array}$ & & & $\begin{array}{l}0.308 \\
(9.06)\end{array}$ \\
\hline $\log (H+A N C C A P)$ & & & & & & $\begin{array}{l}0.308 \\
0.47\end{array}$ & $\begin{array}{l}0.113 \\
(3.74)\end{array}$ & $\begin{array}{l}0.315 \\
(9.7)\end{array}$ & & $\begin{array}{l}0.121 \\
(4.22)\end{array}$ & $\begin{array}{l}0.248 \\
(7.54)\end{array}$ & & $\begin{array}{l}0.122 \\
(4.14)\end{array}$ & $\begin{array}{l}0.254 \\
(7.67)\end{array}$ & \\
\hline HaSIZE & & & $\begin{array}{c}0.165 \\
(10.25)\end{array}$ & $\begin{array}{l}0.161 \\
(10.11)\end{array}$ & $\begin{array}{l}0.124 \\
(7.789)\end{array}$ & $\begin{array}{c}0.241 \\
(1368)\end{array}$ & & $\begin{array}{l}0.240 \\
(1370)\end{array}$ & $\begin{array}{l}0.120 \\
(7.58)\end{array}$ & & $\begin{array}{l}0.154 \\
7.52)\end{array}$ & $\begin{array}{l}0.065 \\
(374)\end{array}$ & & $\begin{array}{l}0.160 \\
0.689\end{array}$ & $\begin{array}{l}0.066 \\
(376)\end{array}$ \\
\hline Wrexcount & & & & & & & & & & $\begin{array}{c}0.312 \\
(1383)\end{array}$ & $\begin{array}{l}0.204 \\
0.74)\end{array}$ & $\begin{array}{l}0.185 \\
(697)\end{array}$ & $\begin{array}{c}0.312 \\
(1381)\end{array}$ & $\begin{array}{l}0.200 \\
(7.66)\end{array}$ & $\begin{array}{l}0.182 \\
(689)\end{array}$ \\
\hline log(MEDNC) & & & & & & & & & & & & & $\begin{array}{l}-0.011 \\
(-0.18)\end{array}$ & $\begin{array}{l}-0.093 \\
(-1.5)\end{array}$ & $\begin{array}{r}-0.114 \\
(-1.99)\end{array}$ \\
\hline$R^{2}$ & 0.109 & 0.124 & 0.159 & 0.172 & 0.214 & 0.199 & 0.131 & 0.214 & 0.228 & 0.216 & 0.240 & 0.249 & 0.215 & 0.240 & 0.250 \\
\hline
\end{tabular}




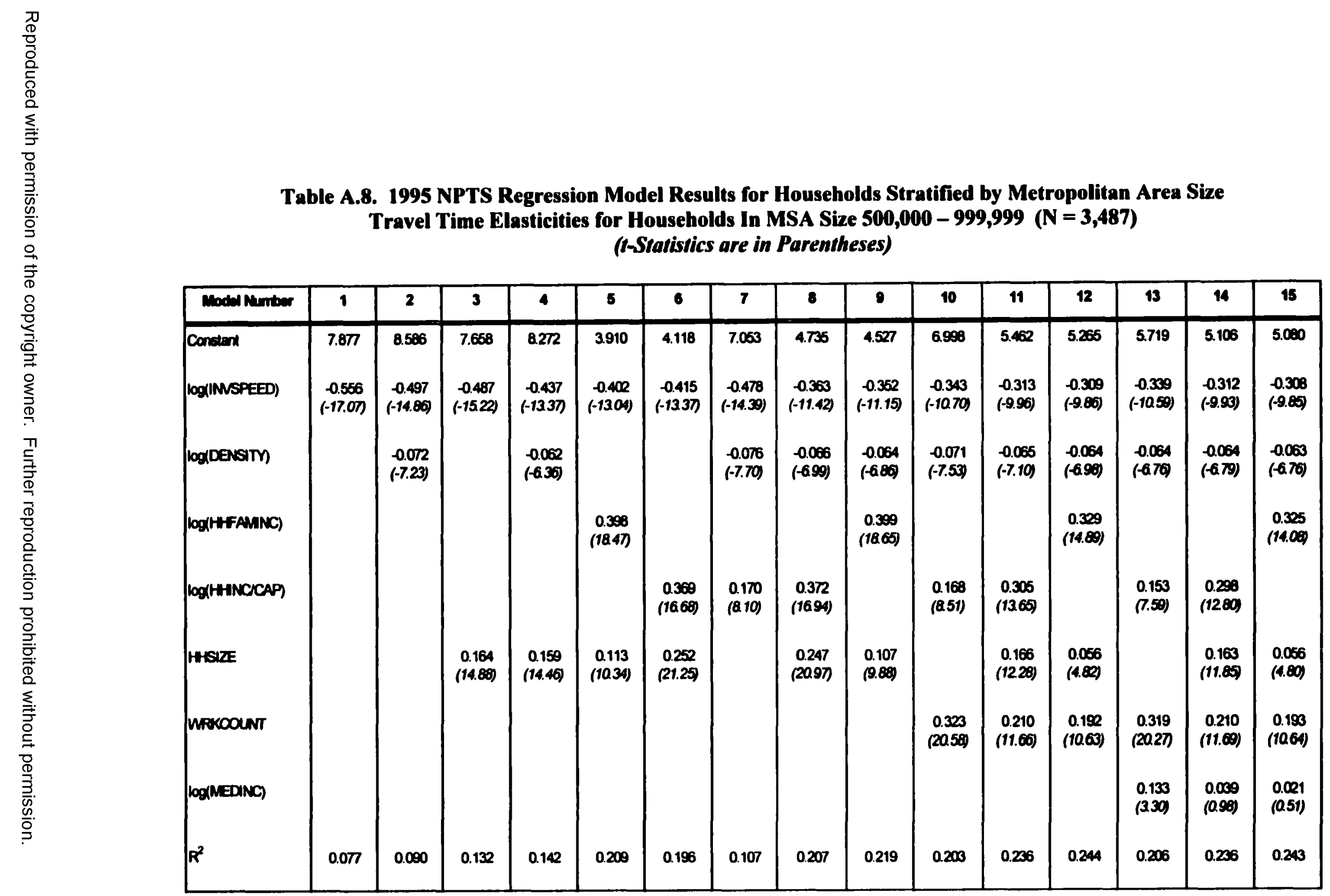




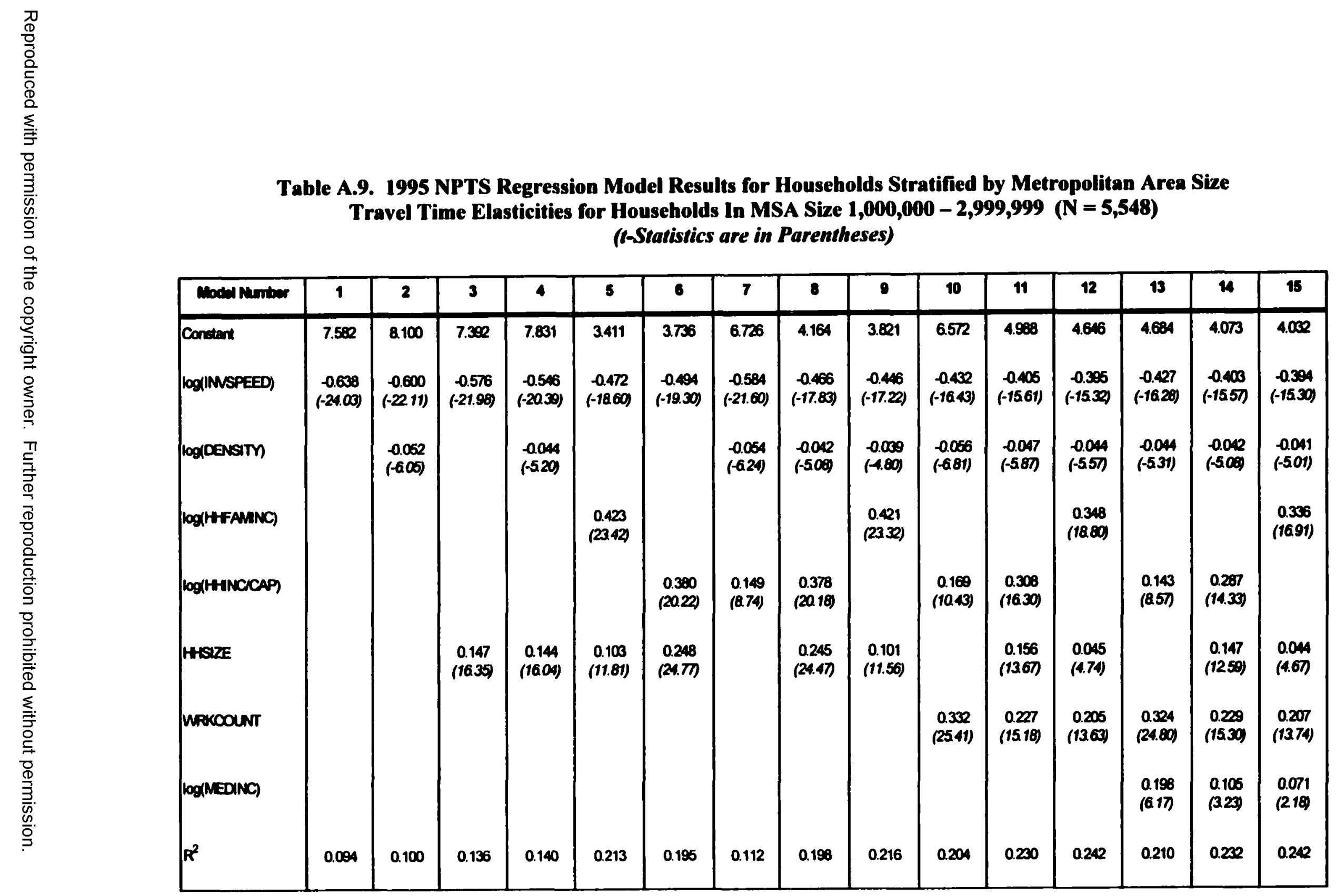




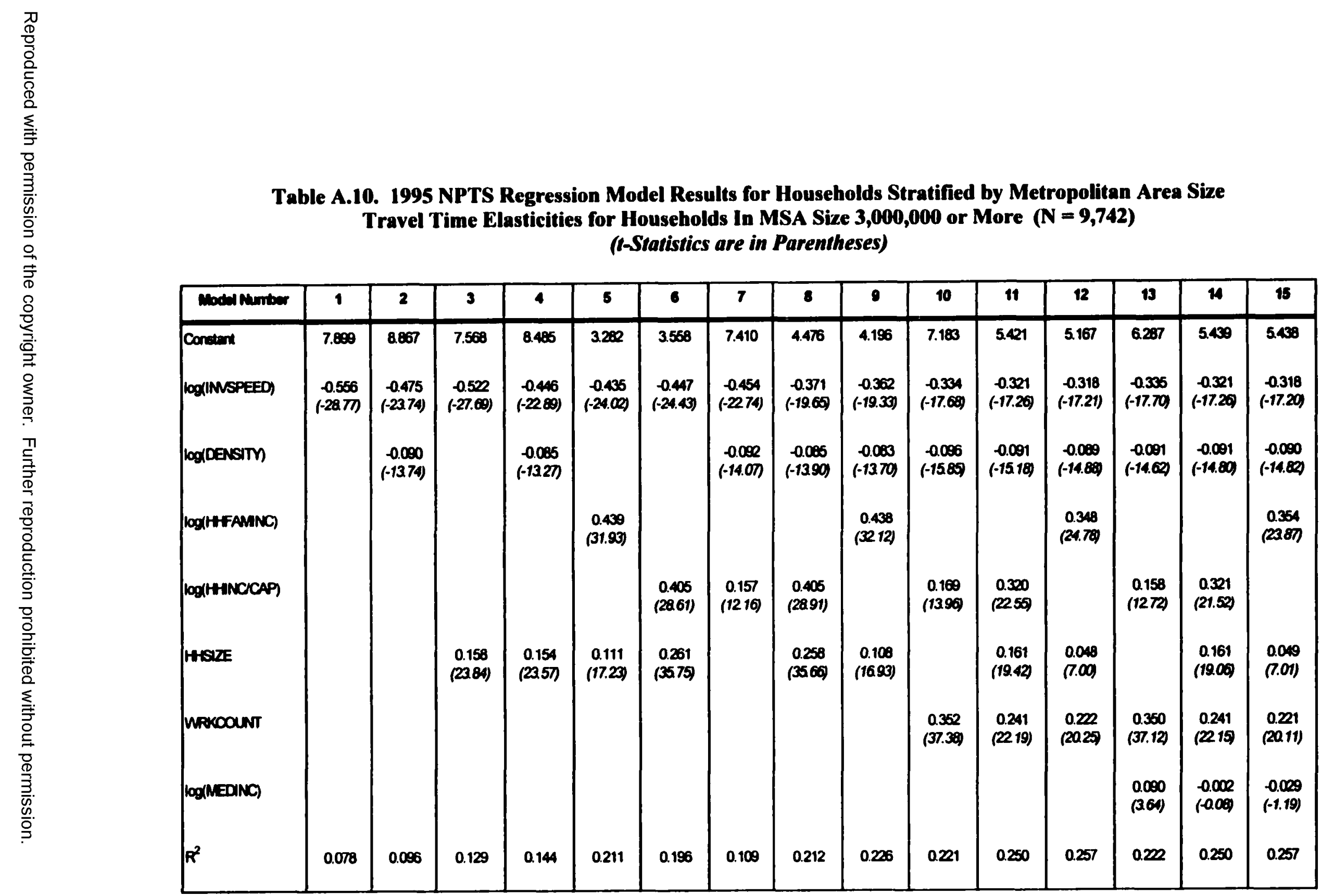




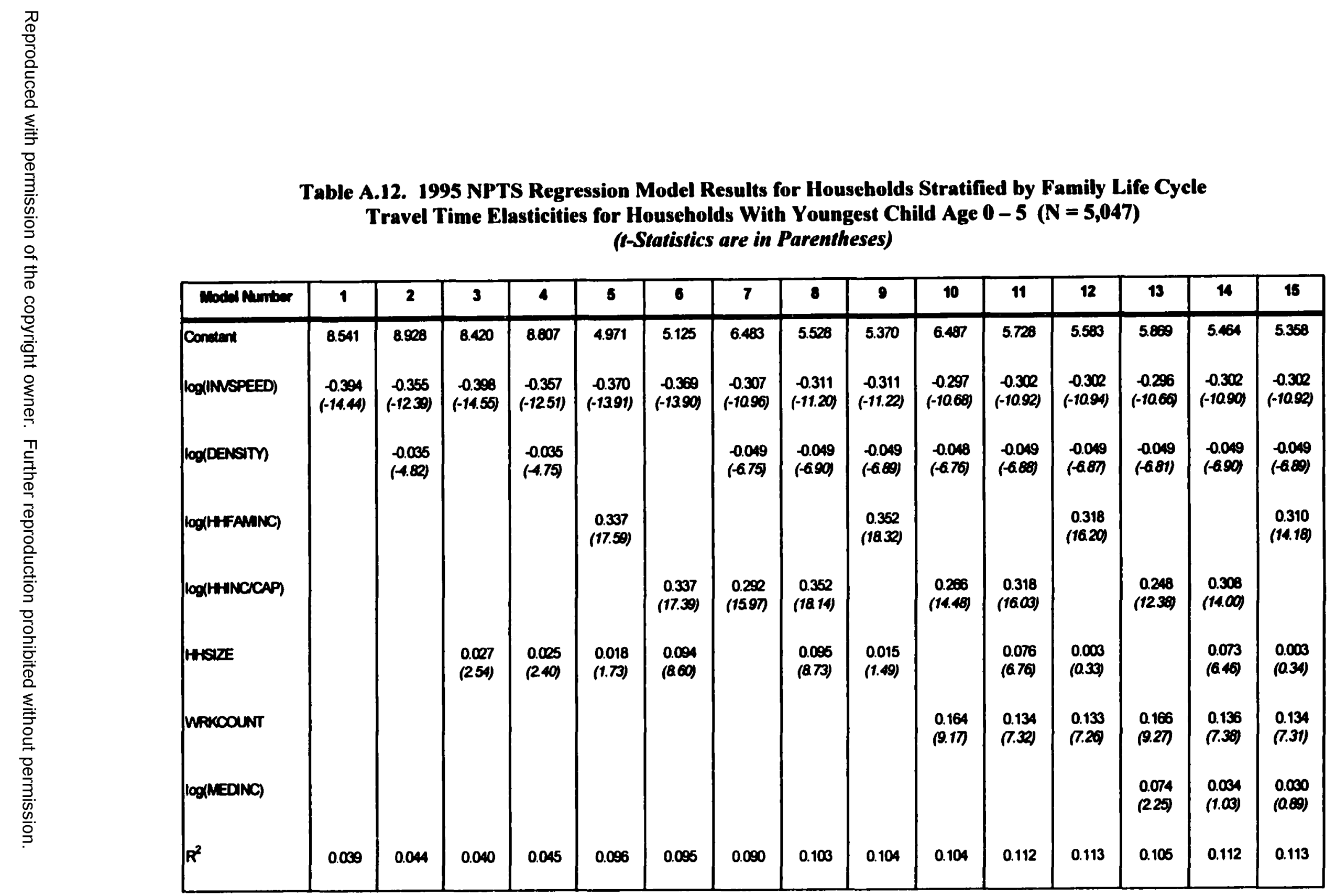




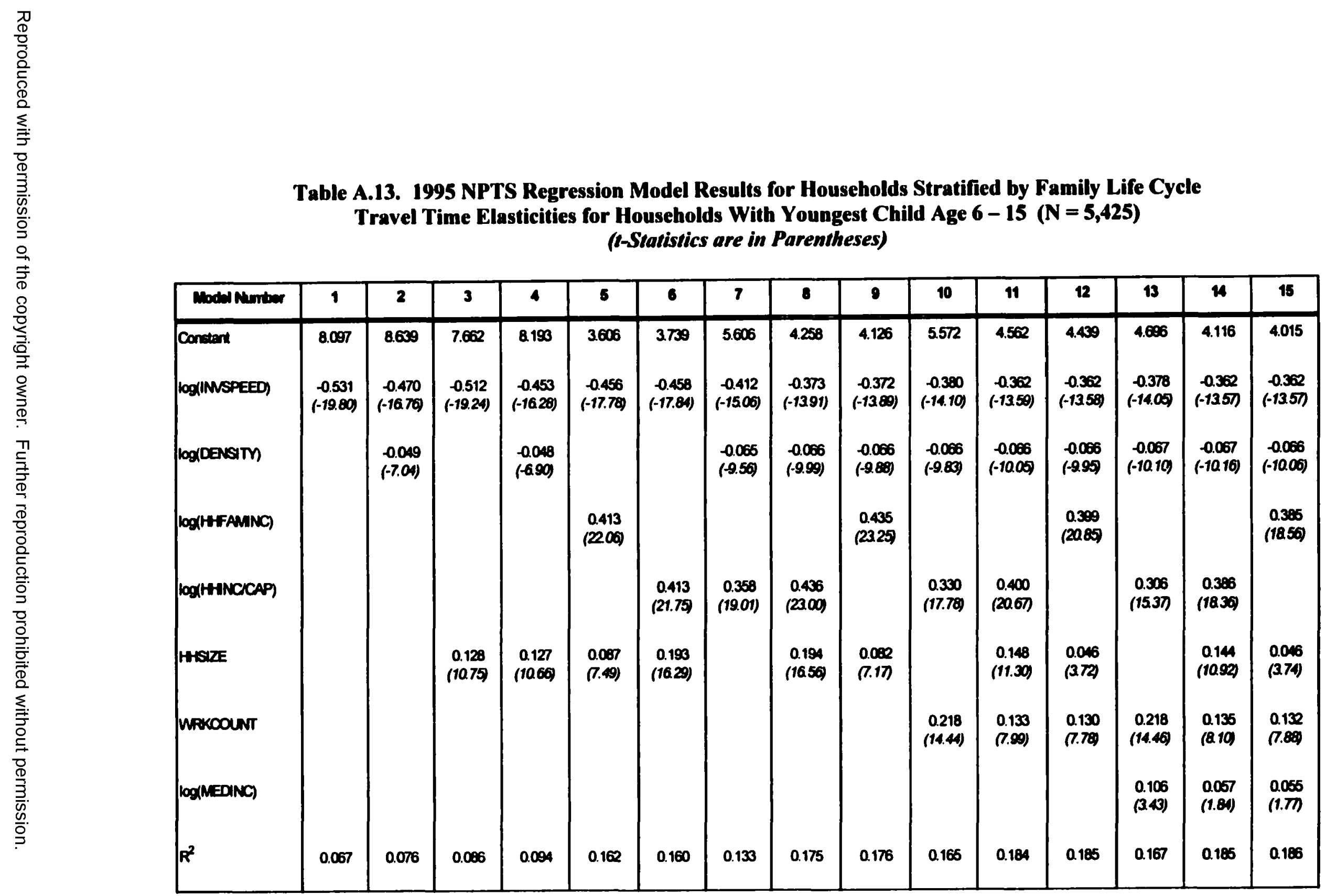


Table A.18. 1995 NPTS Regression Model Results for Travel Day-of-Week Analysis Travel Time Elasticities for Tuesday Trips, All Households $(\mathbf{N}=\mathbf{4 , 2 1 1})$

(1-Statistics are in Parentheses)

\begin{tabular}{|c|c|c|c|c|c|c|c|c|c|c|c|c|c|c|c|}
\hline Model Number & 1 & 2 & 3 & 4 & 5 & 6 & 7 & 8 & 9 & 10 & 11 & 12 & 13 & 14 & 15 \\
\hline Constent & 7.577 & 8.218 & 7.323 & 7.935 & 3.221 & 3.449 & 6.469 & 4.047 & 3.844 & 6.507 & 4.977 & 4.774 & 4.949 & 4.278 & 4.279 \\
\hline $\log ($ (IMSPEED) & $\begin{array}{r}-0.640 \\
(-20.71)\end{array}$ & $\begin{array}{c}-0.574 \\
(-17.86)\end{array}$ & $\begin{array}{r}-0.589 \\
(-19.40)\end{array}$ & $\begin{array}{c}-0.527 \\
(-16.70)\end{array}$ & $\begin{array}{c}-0.497 \\
(-17.04)\end{array}$ & $\begin{array}{r}-0.512 \\
(-17.43)\end{array}$ & $\begin{array}{c}-0.542 \\
(-16.99)\end{array}$ & $\begin{array}{c}-0.427 \\
(-1399)\end{array}$ & $\begin{array}{r}-0.412 \\
(-13.61)\end{array}$ & $\begin{array}{r}-0.396 \\
(-1299)\end{array}$ & $\begin{array}{r}-0.369 \\
(-1230)\end{array}$ & $\begin{array}{r}-0.363 \\
(-12.15)\end{array}$ & $\begin{array}{c}-0.391 \\
(-12.84)\end{array}$ & $\begin{array}{r}-0.368 \\
(-12.25)\end{array}$ & $\begin{array}{r}-0.362 \\
(-12.12)\end{array}$ \\
\hline $\log$ (DENSIIT) & & $\begin{array}{l}-0.060 \\
(-7.02)\end{array}$ & & $\begin{array}{l}-0.057 \\
(-6.84)\end{array}$ & & & $\begin{array}{r}-0.009 \\
(-8.15)\end{array}$ & $\begin{array}{r}-0.074 \\
(-9.31)\end{array}$ & $\begin{array}{r}-0.074 \\
(-9.38)\end{array}$ & $\begin{array}{r}-0.075 \\
(-9.48)\end{array}$ & $\begin{array}{r}-0.076 \\
(-9.83)\end{array}$ & $\begin{array}{r}-0.076 \\
(-9.82)\end{array}$ & $\begin{array}{r}-0.076 \\
(-9.59)\end{array}$ & $\begin{array}{r}-0.077 \\
(-9.87)\end{array}$ & $\begin{array}{r}-0.076 \\
(-9.86)\end{array}$ \\
\hline $\log ($ (HAFAMNC) & & & & & $\begin{array}{c}0.432 \\
(21.33)\end{array}$ & & & & $\begin{array}{c}0.451 \\
(22.37)\end{array}$ & & & $\begin{array}{c}0.363 \\
(17.39)\end{array}$ & & & $\begin{array}{c}0.350 \\
(15.73)\end{array}$ \\
\hline $\log ($ HHACACAP) & & & & & & $\begin{array}{c}0.400 \\
(19.13)\end{array}$ & $\begin{array}{r}0.199 \\
(10.17)\end{array}$ & $\begin{array}{c}0.421 \\
(20.21)\end{array}$ & & $\begin{array}{c}0.196 \\
(10.65)\end{array}$ & $\begin{array}{c}0.336 \\
(1586)\end{array}$ & & $\begin{array}{l}0.171 \\
(8.97)\end{array}$ & $\begin{array}{c}0.318 \\
(14.15)\end{array}$ & \\
\hline HHSIZE & & & $\begin{array}{c}0.154 \\
(14.78)\end{array}$ & $\begin{array}{r}0.153 \\
(14.69)\end{array}$ & $\begin{array}{c}0.104 \\
(10.23)\end{array}$ & $\begin{array}{c}0.254 \\
(22.51)\end{array}$ & & $\begin{array}{c}0.257 \\
(23.00)\end{array}$ & $\begin{array}{l}0.100 \\
(9.89)\end{array}$ & & $\begin{array}{c}0.161 \\
(12.63)\end{array}$ & $\begin{array}{l}0.042 \\
(3.84)\end{array}$ & & $\begin{array}{c}0.155 \\
(11.81)\end{array}$ & $\begin{array}{l}0.042 \\
(3.83)\end{array}$ \\
\hline WRKCOUNT & & & & & & & & & & $\begin{array}{c}0.357 \\
(24.16)\end{array}$ & $\begin{array}{c}0.246 \\
(14.49)\end{array}$ & $\begin{array}{r}0.225 \\
(13.17)\end{array}$ & $\begin{array}{c}0.352 \\
(23.86)\end{array}$ & $\begin{array}{c}0.248 \\
(14.61)\end{array}$ & $\begin{array}{c}0.227 \\
(1326)\end{array}$ \\
\hline $\log$ (MEDINC) & & & & & & & & & & & & & $\begin{array}{l}0.174 \\
(4.93)\end{array}$ & $\begin{array}{l}0.005 \\
(2.40)\end{array}$ & $\begin{array}{l}0.060 \\
(1.70)\end{array}$ \\
\hline$R^{2}$ & 0.092 & 0.102 & 0.137 & 0.146 & 0.221 & 0.206 & 0.124 & 0.222 & 0.237 & 0.230 & 0.258 & 0.267 & 0.235 & 0.259 & 0.267 \\
\hline
\end{tabular}




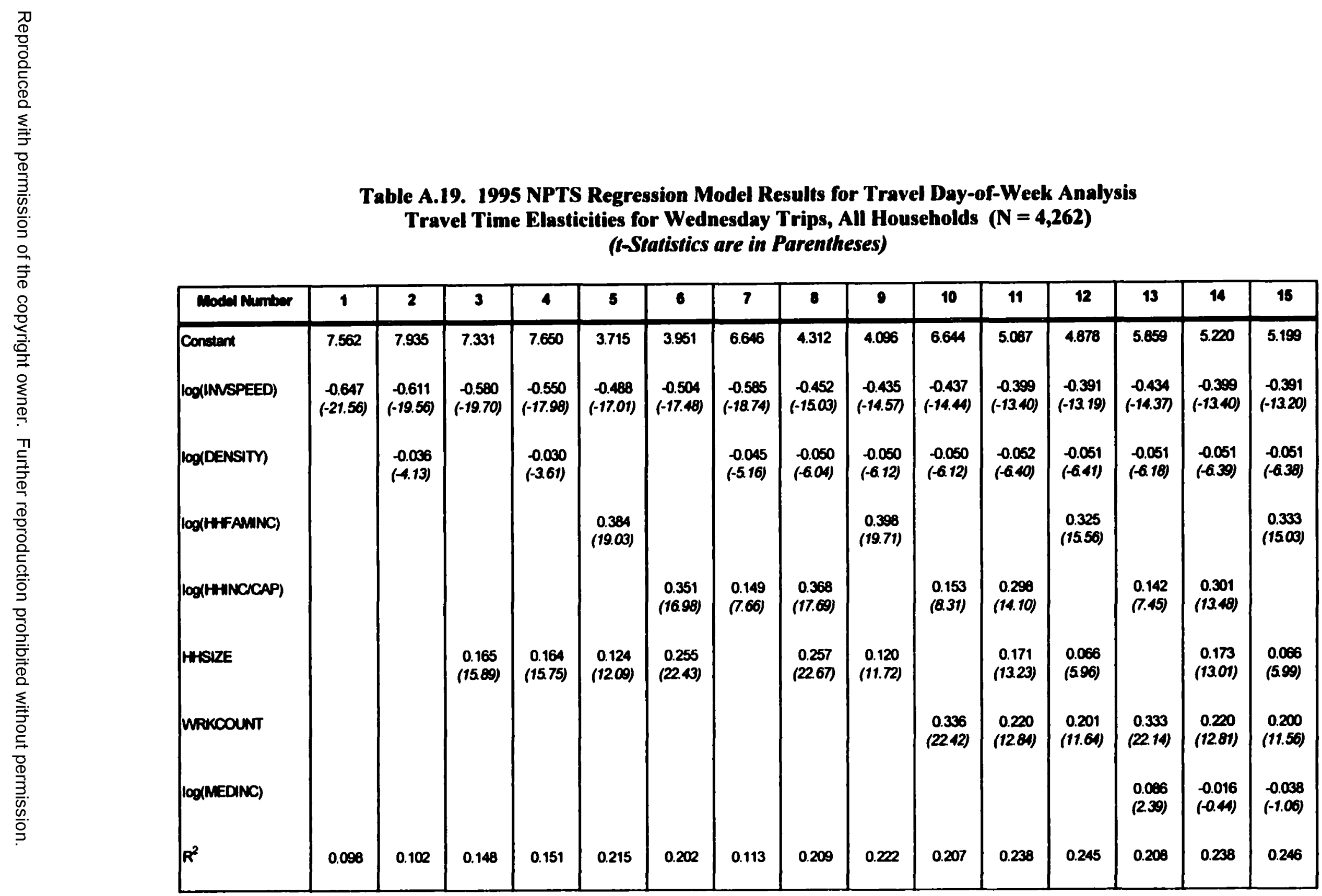


Table A.20. 1995 NPTS Regression Model Results for Travel Day-of-Week Analysis Travel Time Elasticities for Thursday Trips, All Households $(N=4,071)$

(1-Statistics are in Parentheses)

\begin{tabular}{|c|c|c|c|c|c|c|c|c|c|c|c|c|c|c|c|}
\hline Model Number & 1 & 2 & 3 & 4 & 5 & 6 & 7 & 8 & 9 & 10 & 11 & 12 & 13 & 14 & 15 \\
\hline Constant & 7.714 & 7.977 & 7.447 & 7.670 & 3.547 & 3.854 & 6.572 & 4.154 & 3.864 & 6.568 & 4.908 & 4.594 & 5.257 & 4.619 & 4.562 \\
\hline $\log ($ IMSPEED) & $\begin{array}{c}-0.598 \\
(-18.63)\end{array}$ & $\begin{array}{c}-0.572 \\
(-17.09)\end{array}$ & $\begin{array}{c}-0.546 \\
(-17.38)\end{array}$ & $\begin{array}{c}-0.524 \\
(-16.02)\end{array}$ & $\begin{array}{r}-0.460 \\
(-15.18)\end{array}$ & $\begin{array}{c}-0.475 \\
(-1551)\end{array}$ & $\begin{array}{c}-0.545 \\
(-16.34)\end{array}$ & $\begin{array}{r}-0.432 \\
(-13.53)\end{array}$ & $\begin{array}{c}-0.417 \\
(-13.18)\end{array}$ & $\begin{array}{r}-0.408 \\
(-12.02)\end{array}$ & $\begin{array}{c}-0.383 \\
(-12.06)\end{array}$ & $\begin{array}{r}-0.376 \\
(-11.93)\end{array}$ & $\begin{array}{c}-0.404 \\
(-12.50)\end{array}$ & $\begin{array}{r}-0.382 \\
(-12.04)\end{array}$ & $\begin{array}{r}-0.376 \\
(-11.92)\end{array}$ \\
\hline $\log ($ DENSIM & & $\begin{array}{l}-0.025 \\
(-2.78)\end{array}$ & & $\begin{array}{l}-0.021 \\
(-2.41)\end{array}$ & & & $\begin{array}{l}-0.033 \\
(-3.71)\end{array}$ & $\begin{array}{r}-0.038 \\
(-4.55)\end{array}$ & $\begin{array}{r}-0.039 \\
(-4.68)\end{array}$ & $\begin{array}{r}-0.041 \\
(-1.82)\end{array}$ & $\begin{array}{r}-0.042 \\
(-1.99)\end{array}$ & $\begin{array}{r}-0.042 \\
(-5.05)\end{array}$ & $\begin{array}{r}-0.042 \\
(-4.91)\end{array}$ & $\begin{array}{r}-0.042 \\
(-5.01)\end{array}$ & $\begin{array}{r}-0.012 \\
(-505)\end{array}$ \\
\hline $\log ($ HFAMINC) & & & & & $\begin{array}{c}0.410 \\
(19.84)\end{array}$ & & & & $\begin{array}{c}0.420 \\
(20.28)\end{array}$ & & & $\begin{array}{c}0.353 \\
(16.39)\end{array}$ & & & $\begin{array}{c}0.353 \\
(1522)\end{array}$ \\
\hline $\log ($ (H)HNCCAP) & & & & & & $\begin{array}{c}0.371 \\
(17.43)\end{array}$ & $\begin{array}{l}0.161 \\
(807)\end{array}$ & $\begin{array}{c}0.382 \\
(17.88)\end{array}$ & & $\begin{array}{l}0.165 \\
(8.69)\end{array}$ & $\begin{array}{c}0.316 \\
(14.42)\end{array}$ & & $\begin{array}{l}0.144 \\
(7.26)\end{array}$ & $\begin{array}{c}0.308 \\
(13.14)\end{array}$ & \\
\hline HSIZE & & & $\begin{array}{c}0.159 \\
(15.04)\end{array}$ & $\begin{array}{c}0.158 \\
\text { (14.98) }\end{array}$ & $\begin{array}{c}0.114 \\
(11.02)\end{array}$ & $\begin{array}{c}0.253 \\
(21.94)\end{array}$ & & $\begin{array}{c}0.254 \\
(2211)\end{array}$ & $\begin{array}{c}0.111 \\
(10.79)\end{array}$ & & $\begin{array}{r}0.175 \\
(13.07)\end{array}$ & $\begin{array}{l}0.003 \\
(557)\end{array}$ & & $\begin{array}{c}0.172 \\
(12.51)\end{array}$ & $\begin{array}{l}0.063 \\
(5.57)\end{array}$ \\
\hline WRKCOLNT & & & & & & & & & & $\begin{array}{c}0.321 \\
(20.97)\end{array}$ & $\begin{array}{c}0.198 \\
(11.18)\end{array}$ & $\begin{array}{l}0.176 \\
(9.89)\end{array}$ & $\begin{array}{c}0.317 \\
(20.64)\end{array}$ & $\begin{array}{r}0.199 \\
(11.22)\end{array}$ & $\begin{array}{l}0.177 \\
(9.87)\end{array}$ \\
\hline $\log ($ MEDINC) & & & & & & & & & & & & & $\begin{array}{l}0.146 \\
(3.84)\end{array}$ & $\begin{array}{l}0.035 \\
(0.92)\end{array}$ & $\begin{array}{l}0.004 \\
(0.10)\end{array}$ \\
\hline$R^{2}$ & 0.078 & 0.080 & 0.127 & 0.128 & 0.204 & 0.187 & 0.094 & 0.191 & 0.208 & 0.182 & 0.215 & 0.226 & 0.185 & 0.215 & 0.226 \\
\hline
\end{tabular}




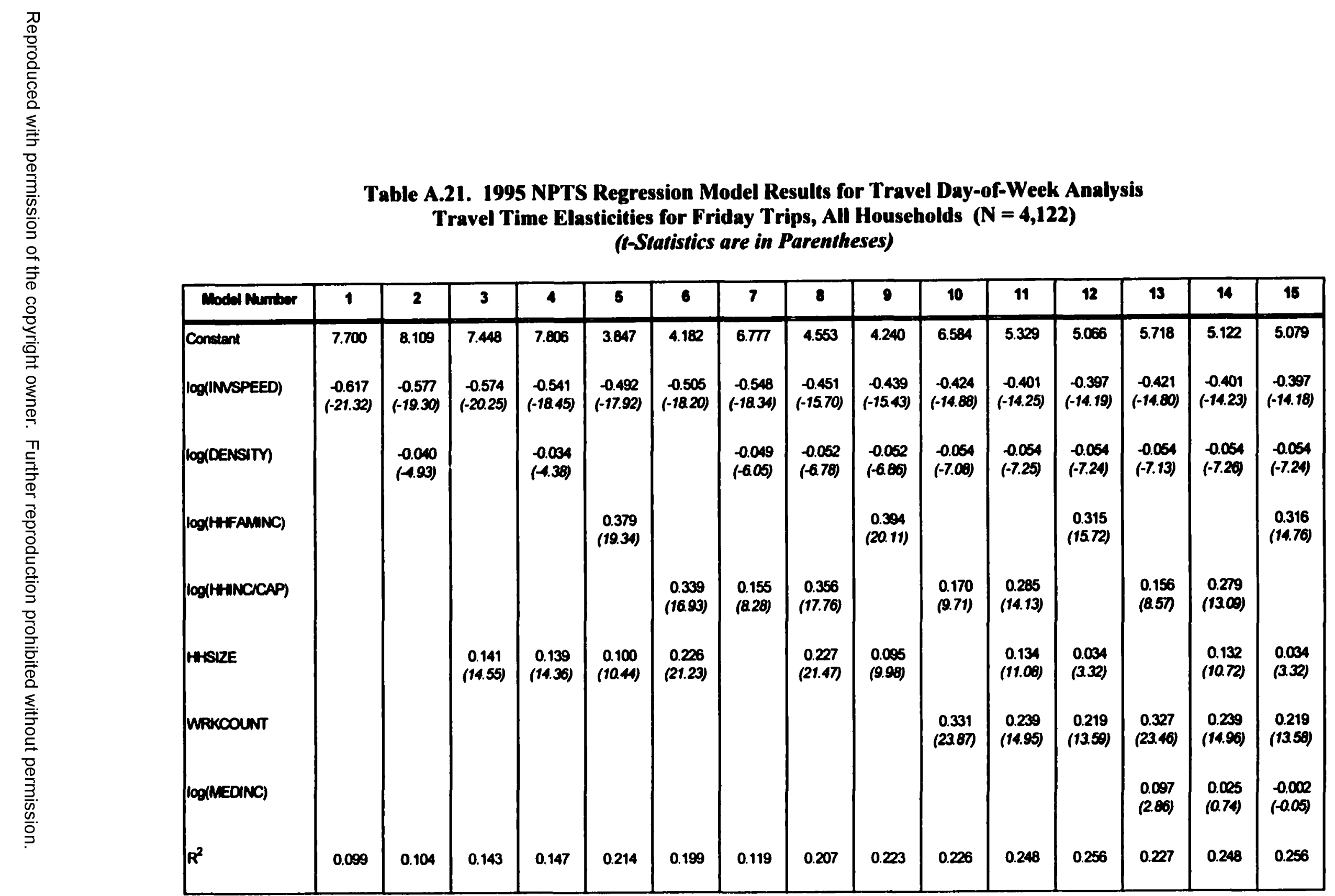


Table A.22. 1995 NPTS Regression Model Results for Travel Day-of-Week Analysis

Travel Time Elasticities for Saturday Trips, All Households $(\mathbf{N}=3,390)$

(t-Statistics are in Parentheses)

\begin{tabular}{|c|c|c|c|c|c|c|c|c|c|c|c|c|c|c|c|}
\hline Model Munters & 1 & 2 & 3 & 4 & 5 & 6 & 7 & 8 & 9 & 10 & 11 & 12 & 13 & 14 & 15 \\
\hline Constent & 7.853 & 8.336 & 7.663 & 8.115 & 3.844 & 4.130 & 6.714 & 4.559 & 4.296 & 6.722 & 5.442 & 5.183 & 5.528 & 4.900 & 4.897 \\
\hline $\log (M N S P E E D)$ & $\begin{array}{c}-0.552 \\
(-16.70)\end{array}$ & $\begin{array}{r}-0.510 \\
(-15.05)\end{array}$ & $\begin{array}{c}-0.494 \\
(-15.08)\end{array}$ & $\begin{array}{r}-0.456 \\
(-13.59)\end{array}$ & $\begin{array}{r}-0.444 \\
(-14.07)\end{array}$ & $\begin{array}{r}-0.455 \\
(-14.31)\end{array}$ & $\begin{array}{c}-0.502 \\
(-14.96)\end{array}$ & $\begin{array}{c}-0.402 \\
(-12.36)\end{array}$ & $\begin{array}{c}-0.391 \\
(-12.11)\end{array}$ & $\begin{array}{r}-0.370 \\
(-11.41)\end{array}$ & $\begin{array}{c}-0.347 \\
(-10.82)\end{array}$ & $\begin{array}{r}-0.343 \\
(-10.73)\end{array}$ & $\begin{array}{r}-0.370 \\
(-11.43)\end{array}$ & $\begin{array}{c}-0.348 \\
(-10.84)\end{array}$ & $\begin{array}{r}-0.343 \\
(-10.74)\end{array}$ \\
\hline $\log$ (DENSITY & & $\begin{array}{r}-0.048 \\
(-5.31)\end{array}$ & & $\begin{array}{r}-0.045 \\
(-5.04)\end{array}$ & & & $\begin{array}{l}-0.056 \\
(-6.23)\end{array}$ & $\begin{array}{l}-0.060 \\
(-6.94)\end{array}$ & $\begin{array}{r}-0.060 \\
(-7.02)\end{array}$ & $\begin{array}{r}-0.065 \\
(-7.61)\end{array}$ & $\begin{array}{r}-0.065 \\
(-7.69)\end{array}$ & $\begin{array}{l}-0.064 \\
(-7.69)\end{array}$ & $\begin{array}{l}-0.066 \\
(-7.80)\end{array}$ & $\begin{array}{r}-0.065 \\
(-7.76)\end{array}$ & $\begin{array}{l}-0.065 \\
(-7.73)\end{array}$ \\
\hline $\log ($ HWFAMNC) & & & & & $\begin{array}{c}0.390 \\
(17.23)\end{array}$ & & & & $\begin{array}{c}0.405 \\
(17.96)\end{array}$ & & & $\begin{array}{c}0.324 \\
(13.91)\end{array}$ & & & $\begin{array}{r}0.316 \\
(1269)\end{array}$ \\
\hline $\log (H+1 N C C A P)$ & & & & & & $\begin{array}{c}0.354 \\
(15.22)\end{array}$ & $\begin{array}{l}0.177 \\
(\mathbf{2} 21)\end{array}$ & $\begin{array}{c}0.372 \\
(1598)\end{array}$ & & $\begin{array}{l}0.178 \\
(8.72)\end{array}$ & $\begin{array}{c}0.293 \\
(1242)\end{array}$ & & $\begin{array}{l}0.157 \\
(7.38)\end{array}$ & $\begin{array}{r}0.279 \\
(11.10)\end{array}$ & \\
\hline HHSIZE & & & $\begin{array}{c}0.139 \\
(11.70)\end{array}$ & $\begin{array}{c}0.137 \\
(11.58)\end{array}$ & $\begin{array}{l}0.097 \\
(8.31)\end{array}$ & $\begin{array}{r}0.230 \\
(17.77)\end{array}$ & & $\begin{array}{c}0.232 \\
(18.05)\end{array}$ & $\begin{array}{r}0.092 \\
(8.00)\end{array}$ & & $\begin{array}{l}0.138 \\
(9.39)\end{array}$ & $\begin{array}{l}0.033 \\
(262)\end{array}$ & & $\begin{array}{l}0.133 \\
(8.87)\end{array}$ & $\begin{array}{l}0.033 \\
(2.02)\end{array}$ \\
\hline WRKCOUNT & & & & & & & & & & $\begin{array}{c}0.333 \\
(20.01)\end{array}$ & $\begin{array}{r}0.240 \\
(1257)\end{array}$ & $\begin{array}{c}0.222 \\
(11.54)\end{array}$ & $\begin{array}{c}0.328 \\
(19.65)\end{array}$ & $\begin{array}{c}0.241 \\
(12.61)\end{array}$ & $\begin{array}{r}0.223 \\
(11.57)\end{array}$ \\
\hline $\log ($ MEDINC) & & & & & & & & & & & & & $\begin{array}{l}0.134 \\
(3.42)\end{array}$ & $\begin{array}{l}0.062 \\
(1.58)\end{array}$ & $\begin{array}{l}0.035 \\
(0.89)\end{array}$ \\
\hline$R^{2}$ & 0.076 & 0.083 & 0.111 & 0.118 & 0.183 & 0.168 & 0.101 & 0.179 & 0.194 & 0.196 & 0.216 & 0.225 & 0.198 & 0.216 & 0.225 \\
\hline
\end{tabular}




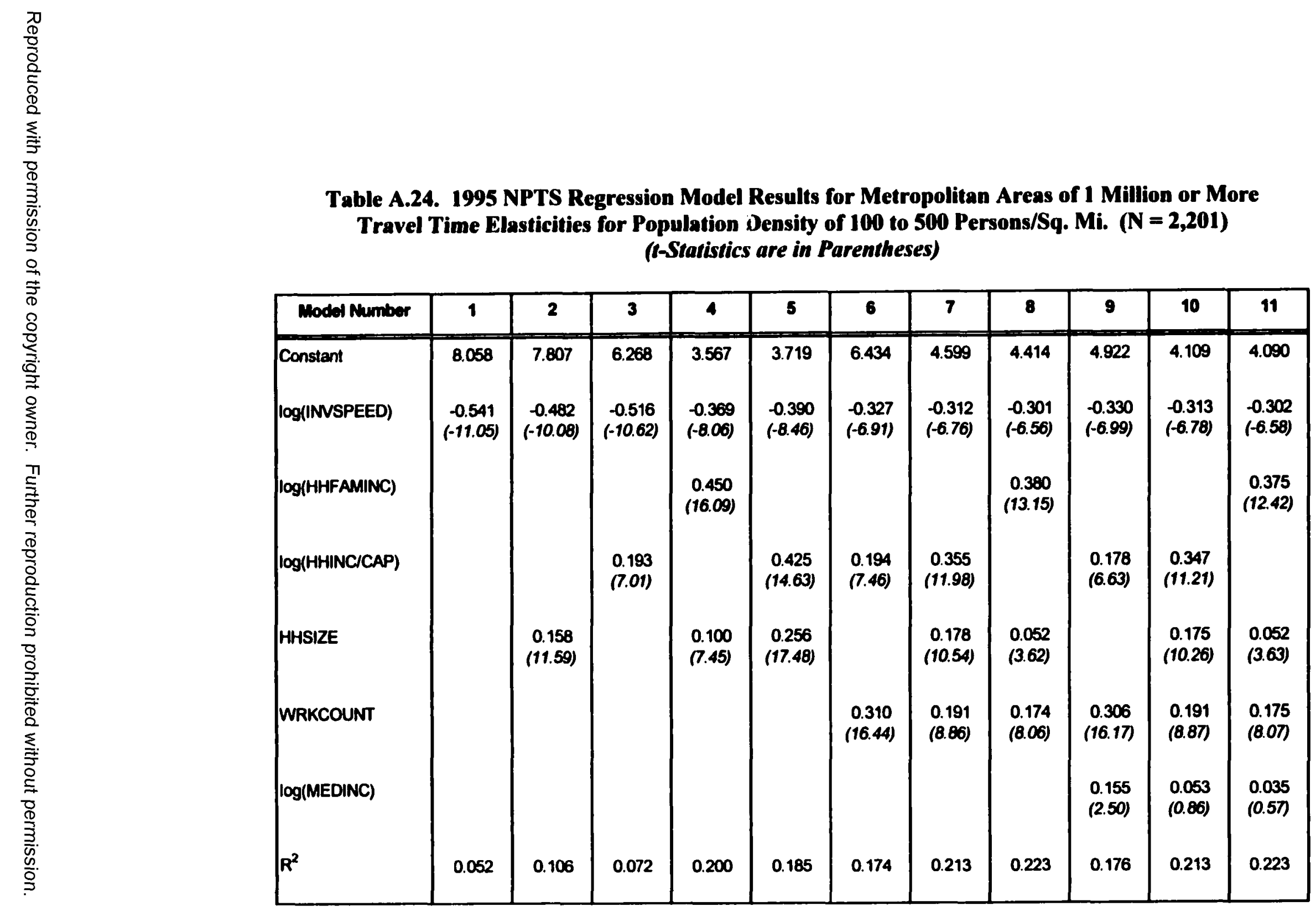




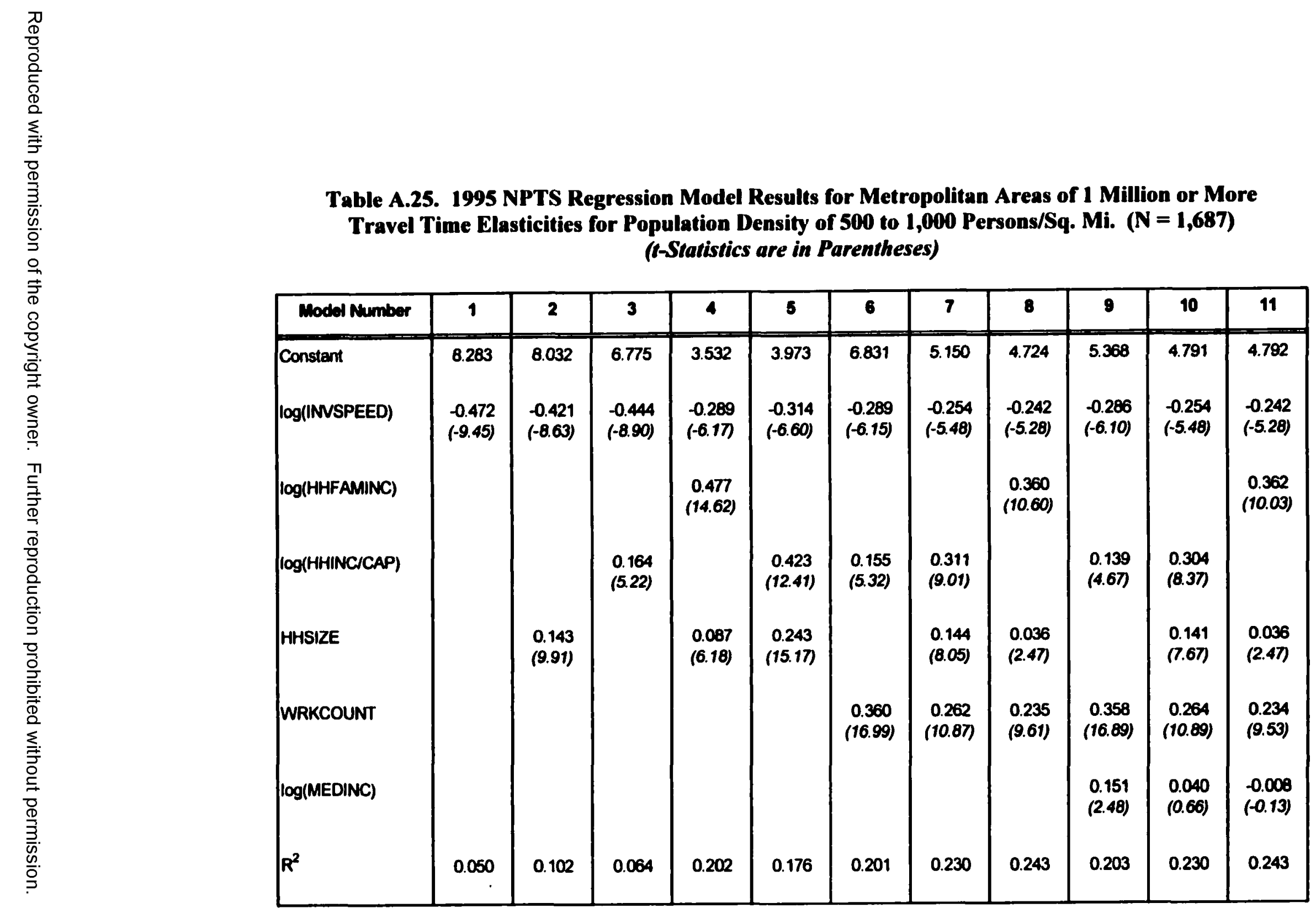




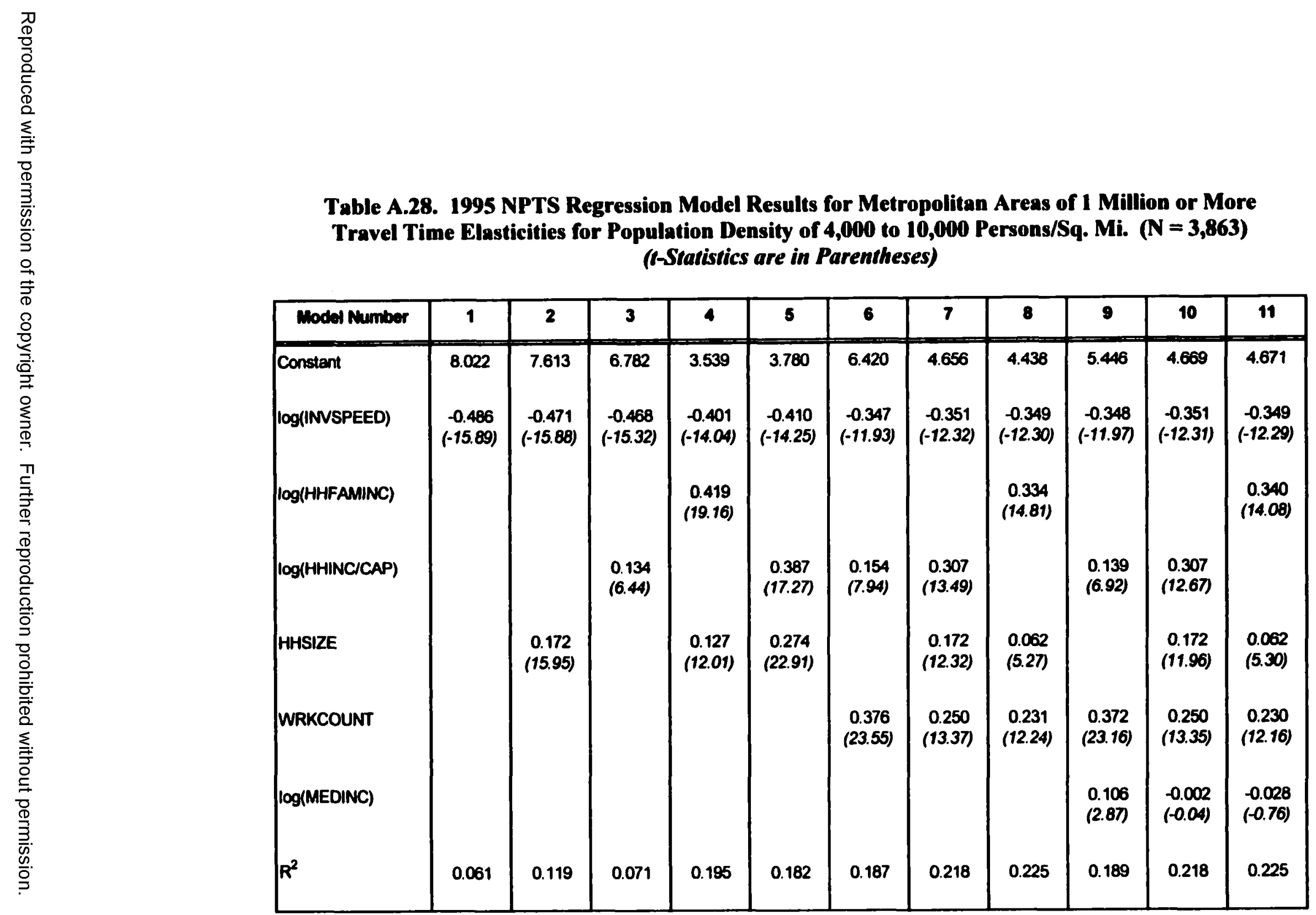


Table A.29. 1995 NPTS Regression Model Results for Metropolitan Areas of 1 Million or More Travel Time Elasticities for Population Density of 10,000 to 25,000 Persons/Sq. Mi. $(\mathbf{N}=1,192)$ (I-Statistics are in Parentheses)

\begin{tabular}{|c|c|c|c|c|c|c|c|c|c|c|c|}
\hline Model Number & 1 & 2 & 3 & 4 & 5 & 6 & 7 & 8 & 9 & 10 & 11 \\
\hline Constant & 7.818 & 7.638 & 6.665 & 4.133 & 4.520 & 6.295 & 5.382 & 4.998 & 6.860 & 6.202 & 6.086 \\
\hline $\log ($ (NVSPEED) & $\begin{array}{r}-0.516 \\
(-9.91)\end{array}$ & $\begin{array}{r}-0.494 \\
(-9.54)\end{array}$ & $\begin{array}{r}-0.510 \\
(-9.83)\end{array}$ & $\begin{array}{r}-0.454 \\
(-8.99)\end{array}$ & $\begin{array}{r}-0.458 \\
(-8.98)\end{array}$ & $\begin{array}{l}-0.424 \\
(-8.39)\end{array}$ & $\begin{array}{r}-0.418 \\
(-8.29)\end{array}$ & $\begin{array}{r}-0.418 \\
(-8.35)\end{array}$ & $\begin{array}{r}-0.420 \\
(-8.27)\end{array}$ & $\begin{array}{r}-0.411 \\
(-8.12)\end{array}$ & $\begin{array}{r}-0.410 \\
(-8.14)\end{array}$ \\
\hline $\log$ (HHFAMINC) & & & & $\begin{array}{l}0.350 \\
(8.58)\end{array}$ & & & & $\begin{array}{l}0.263 \\
(6.16)\end{array}$ & & & $\begin{array}{l}0.288 \\
(6.44)\end{array}$ \\
\hline $\log ($ HHINC/CAP) & & & $\begin{array}{l}0.120 \\
\text { (3.33) }\end{array}$ & & $\begin{array}{l}0.308 \\
(7.28)\end{array}$ & $\begin{array}{l}0.140 \\
(4.00)\end{array}$ & $\begin{array}{l}0.222 \\
(5.11)\end{array}$ & & $\begin{array}{l}0.147 \\
(4.10)\end{array}$ & $\begin{array}{l}0.239 \\
(5.30)\end{array}$ & \\
\hline HHSIZE & & $\begin{array}{l}0.092 \\
(4.76)\end{array}$ & & $\begin{array}{l}0.067 \\
(3.53)\end{array}$ & $\begin{array}{l}0.184 \\
(8.06)\end{array}$ & & $\begin{array}{l}0.085 \\
\text { (3.16) }\end{array}$ & $\begin{array}{l}0.007 \\
(0.32)\end{array}$ & & $\begin{array}{l}0.090 \\
(3.33)\end{array}$ & $\begin{array}{l}0.006 \\
(0.29)\end{array}$ \\
\hline WRKCOUNT & & & & & & $\begin{array}{c}0.299 \\
(10.04)\end{array}$ & $\begin{array}{l}0.237 \\
(6.64)\end{array}$ & $\begin{array}{l}0.215 \\
(5.98)\end{array}$ & $\begin{array}{c}0.301 \\
(10.08)\end{array}$ & $\begin{array}{l}0.236 \\
(6.62)\end{array}$ & $\begin{array}{l}0.212 \\
(5.90)\end{array}$ \\
\hline $\log ($ MEDINC) & & & & & & & & & $\begin{array}{r}-0.060 \\
(-0.90)\end{array}$ & $\begin{array}{r}-0.094 \\
(-1.40)\end{array}$ & $\begin{array}{l}-0.126 \\
(-1.87)\end{array}$ \\
\hline$R^{2}$ & 0.075 & 0.092 & 0.083 & 0.144 & 0.130 & 0.154 & 0.160 & 0.169 & 0.154 & 0.161 & 0.170 \\
\hline
\end{tabular}


Table A.30. 1995 NPTS Regression Model Results for Metropolitan Areas of 1 Million or More Travel Time Elasticities for Population Density Over 25,000 Persons/Sq. Mi. $(\mathbf{N}=396)$ (1-Statistics are in Parentheses)

\begin{tabular}{|c|c|c|c|c|c|c|c|c|c|c|c|}
\hline Model Number & 1 & 2 & 3 & 4 & 5 & 6 & 7 & 8 & 9 & 10 & 11 \\
\hline Constant & 8.600 & 8.367 & 8.336 & 6.633 & 6.917 & 7.786 & 7.889 & 7.695 & 8.727 & 8.750 & 8.654 \\
\hline $\log ($ INVSPEED) & $\begin{array}{l}-0.217 \\
(-2.42)\end{array}$ & $\begin{array}{l}-0.224 \\
(-2.51)\end{array}$ & $\begin{array}{r}-0.214 \\
(-2.39)\end{array}$ & $\begin{array}{l}-0.217 \\
(-2.44)\end{array}$ & $\begin{array}{r}-0.219 \\
(-2.45)\end{array}$ & $\begin{array}{r}-0.180 \\
(-2.07)\end{array}$ & $\begin{array}{r}-0.178 \\
(-2.05)\end{array}$ & $\begin{array}{r}-0.178 \\
(-2.04)\end{array}$ & $\begin{array}{r}-0.186 \\
(-2.13)\end{array}$ & $\begin{array}{r}-0.185 \\
(-2.11)\end{array}$ & $\begin{array}{r}-0.186 \\
(-2.12)\end{array}$ \\
\hline $\log$ (HHFAMINC) & & & & $\begin{array}{l}0.166 \\
(2.23)\end{array}$ & & & & $\begin{array}{l}0.056 \\
(0.74)\end{array}$ & & & $\begin{array}{l}0.086 \\
(1.04)\end{array}$ \\
\hline $\log (H H I N C / C A P)$ & & & $\begin{array}{l}0.028 \\
(0.45)\end{array}$ & & $\begin{array}{l}0.137 \\
(1.85)\end{array}$ & $\begin{array}{l}0.046 \\
(0.76)\end{array}$ & $\begin{array}{l}0.037 \\
(0.50)\end{array}$ & & $\begin{array}{l}0.066 \\
(1.02)\end{array}$ & $\begin{array}{l}0.063 \\
(0.78)\end{array}$ & \\
\hline HHSIZE & & $\begin{array}{l}0.076 \\
(1.98)\end{array}$ & & $\begin{array}{l}0.074 \\
(1.93)\end{array}$ & $\begin{array}{l}0.124 \\
(2.68)\end{array}$ & & $\begin{array}{r}-0.010 \\
(-0.19)\end{array}$ & $\begin{array}{r}-0.022 \\
(-0.50)\end{array}$ & & $\begin{array}{r}-0.003 \\
(-0.06)\end{array}$ & $\begin{array}{r}-0.024 \\
(-0.55)\end{array}$ \\
\hline WRKCOUNT & & & & & & $\begin{array}{l}0.305 \\
(5.38)\end{array}$ & $\begin{array}{l}0.312 \\
(4.62)\end{array}$ & $\begin{array}{l}0.306 \\
(4.48)\end{array}$ & $\begin{array}{l}0.304 \\
(5.36)\end{array}$ & $\begin{array}{l}0.307 \\
(4.51)\end{array}$ & $\begin{array}{l}0.298 \\
(4.34)\end{array}$ \\
\hline $\log$ (MEDINC) & & & & & & & & & $\begin{array}{r}-0.110 \\
(-0.88)\end{array}$ & $\begin{array}{r}-0.109 \\
(-0.86)\end{array}$ & $\begin{array}{r}-0.123 \\
(-0.96)\end{array}$ \\
\hline$R^{2}$ & 0.012 & 0.019 & 0.010 & 0.029 & 0.025 & 0.076 & 0.073 & 0.074 & 0.075 & 0.074 & 0.074 \\
\hline
\end{tabular}




\section{APPENDIX B}

Dallas-Fort Worth Transportation Analysis Process Zones

1984 - 1995 Structural Equivalency 
COMPARISON OF 1984 AND 1995 TRANSPORTATION ANALYSIS

PROCESS (TAP) ZONE STRUCTURES

Table B.1. 1984 TAP Zone Numbers Representing External Stations (Total = 59)

\begin{tabular}{|c|c|c|c|c|}
\hline 1 & 49 & 150 & 169 & 183 \\
2 & 50 & 151 & 170 & 184 \\
3 & 51 & 152 & 171 & 185 \\
4 & 52 & 153 & 172 & 186 \\
11 & 53 & 155 & 173 & 190 \\
12 & 54 & 156 & 174 & 191 \\
22 & 63 & 157 & 175 & 192 \\
23 & 64 & 158 & 178 & 193 \\
24 & 65 & 159 & 179 & 194 \\
46 & 147 & 160 & 180 & 299 \\
47 & 148 & 162 & 181 & 313 \\
48 & 149 & 168 & 182 & \\
\hline
\end{tabular}

Table B.2. 1995 TAP Zone Numbers Representing External Stations (Total = 61)

\begin{tabular}{|c|c|c|c|c|}
\hline 1 & 38 & 63 & 100 & 296 \\
2 & 39 & 64 & 101 & 297 \\
3 & 40 & 65 & 102 & 298 \\
6 & 46 & 66 & 136 & 299 \\
16 & 47 & 67 & 141 & 301 \\
19 & 48 & 75 & 146 & 302 \\
26 & 53 & 76 & 147 & 303 \\
27 & 54 & 77 & 148 & 306 \\
28 & 55 & 78 & 149 & 415 \\
29 & 56 & 79 & 150 & 430 \\
30 & 59 & 98 & 201 & 431 \\
31 & 60 & 99 & 202 & 434 \\
37 & & & & \\
\hline
\end{tabular}


Table B.3. 1995 TAP Zones Located Outside the 1984 Survey Area

\begin{tabular}{|c|c|c|c|}
\hline 4 & 45 & 91 & 123 \\
5 & 49 & 92 & 124 \\
7 & 50 & 93 & 125 \\
8 & 51 & 94 & 126 \\
9 & 52 & 95 & 127 \\
10 & 57 & 96 & 128 \\
11 & 58 & 97 & 129 \\
12 & 61 & 103 & 130 \\
13 & 62 & 104 & 131 \\
14 & 68 & 105 & 132 \\
15 & 69 & 106 & 133 \\
17 & 70 & 107 & 134 \\
18 & 71 & 108 & 135 \\
20 & 72 & 109 & 137 \\
21 & 73 & 110 & 138 \\
22 & 74 & 111 & 139 \\
23 & 80 & 112 & 140 \\
24 & 81 & 113 & 142 \\
25 & 82 & 114 & 143 \\
32 & 83 & 115 & 144 \\
33 & 84 & 116 & 145 \\
34 & 85 & 117 & 151 \\
35 & 86 & 118 & 152 \\
36 & 87 & 119 & 153 \\
41 & 88 & 120 & 154 \\
42 & 89 & 121 & 155 \\
43 & 90 & 122 & 156 \\
44 & & & \\
\hline
\end{tabular}


Table B.4. 1984 - 1995 TAP Zone Structural Equivalency (Zone-to-Zone Comparison)

\begin{tabular}{|c|c|}
\hline 1984 & mogs \\
\hline 5 & 157 \\
\hline 6 & 158 \\
\hline 7 & 159 \\
\hline 8 & 160 \\
\hline 9 & 161 \\
\hline 10 & 162 \\
\hline 13 & 163 \\
\hline 14 & 164 \\
\hline 15 & 165 \\
\hline 16 & 166 \\
\hline 17 & 167 \\
\hline 18 & 168 \\
\hline 19 & 169 \\
\hline 20 & 170 \\
\hline 21 & 171 \\
\hline 25 & 172 \\
\hline 26 & 173 \\
\hline 27 & 174 \\
\hline $28+29$ & $175+176$ \\
\hline 30 & 177 \\
\hline 31 & 178 \\
\hline $32+44+45$ & $\begin{array}{c}179+191 \\
+192\end{array}$ \\
\hline 33 & 180 \\
\hline 34 & 181 \\
\hline 35 & 182 \\
\hline 36 & 183 \\
\hline 37 & 184 \\
\hline 38 & 185 \\
\hline 39 & 186 \\
\hline 40 & 187 \\
\hline 41 & 188 \\
\hline 42 & 189 \\
\hline 43 & 190 \\
\hline 55 & 193 \\
\hline 56 & 194 \\
\hline 57 & 195 \\
\hline 58 & 196 \\
\hline 59 & 197 \\
\hline
\end{tabular}

\begin{tabular}{|c|c|}
\hline 1984 & 1995 \\
\hline 60 & 198 \\
\hline 61 & 199 \\
\hline 62 & 200 \\
\hline 66 & 203 \\
\hline 67 & 204 \\
\hline 68 & 205 \\
\hline 69 & 206 \\
\hline 70 & 207 \\
\hline 71 & 208 \\
\hline 72 & 209 \\
\hline $73+166$ & $210+290$ \\
\hline 74 & 211 \\
\hline 75 & 212 \\
\hline 76 & 213 \\
\hline 77 & 214 \\
\hline 78 & $\overline{215}$ \\
\hline 79 & 216 \\
\hline 80 & 217 \\
\hline 81 & 218 \\
\hline 82 & 219 \\
\hline 83 & 220 \\
\hline$\overline{84}$ & 221 \\
\hline 85 & 222 \\
\hline 86 & 223 \\
\hline 87 & 224 \\
\hline 88 & 225 \\
\hline 89 & 226 \\
\hline 90 & 227 \\
\hline 91 & 228 \\
\hline 92 & 229 \\
\hline$\overline{93}$ & 230 \\
\hline$\overline{94}$ & 231 \\
\hline$\overline{95}$ & 232 \\
\hline$\overline{96}$ & 233 \\
\hline 97 & 234 \\
\hline 98 & 235 \\
\hline 99 & 236 \\
\hline 100 & 237 \\
\hline 101 & 238 \\
\hline
\end{tabular}

\begin{tabular}{|c|c|}
\hline$+19 x^{2}$ & oloss \\
\hline 102 & 239 \\
\hline 103 & 240 \\
\hline $104+110$ & $241+247$ \\
\hline 105 & 242 \\
\hline 106 & 243 \\
\hline 107 & 244 \\
\hline 108 & 245 \\
\hline 109 & 246 \\
\hline 111 & 248 \\
\hline $112+113$ & $249+250$ \\
\hline+115 & +252 \\
\hline 114 & $25 !$ \\
\hline 116 & 253 \\
\hline 117 & 254 \\
\hline 118 & 255 \\
\hline 119 & 256 \\
\hline 120 & 257 \\
\hline 121 & 258 \\
\hline 122 & 259 \\
\hline 123 & 260 \\
\hline 124 & 261 \\
\hline 125 & 262 \\
\hline 126 & 263 \\
\hline 127 & 264 \\
\hline $\begin{array}{c}128+129 \\
+130+132 \\
+138\end{array}$ & $\begin{array}{c}265+267 \\
+273\end{array}$ \\
\hline 131 & 266 \\
\hline 133 & 268 \\
\hline 134 & 269 \\
\hline 135 & 270 \\
\hline 136 & 271 \\
\hline 137 & 272 \\
\hline 139 & 274 \\
\hline 140 & 275 \\
\hline 141 & 276 \\
\hline 142 & 277 \\
\hline 143 & 278 \\
\hline 144 & 279 \\
\hline
\end{tabular}


Table B.4. 1984 - 1995 TAP Zone Structural Equivalency (continued)

\begin{tabular}{|c|c|}
\hline 1984,4 & $f_{10}$ \\
\hline 145 & 280 \\
\hline 146 & 281 \\
\hline 154 & $282+283$ \\
\hline 161 & $\begin{array}{c}284+285 \\
+286\end{array}$ \\
\hline 163 & 287 \\
\hline 164 & 288 \\
\hline 165 & 289 \\
\hline 167 & 291 \\
\hline 176 & $292+293$ \\
\hline 177 & $294+295$ \\
\hline 187 & 300 \\
\hline 188 & 304 \\
\hline 189 & 305 \\
\hline 195 & $\begin{array}{c}307+308 \\
+309\end{array}$ \\
\hline 196 & $310+311$ \\
\hline 197 & 312 \\
\hline 198 & 313 \\
\hline 199 & 314 \\
\hline 200 & 315 \\
\hline 201 & 316 \\
\hline 202 & 317 \\
\hline 203 & 318 \\
\hline 204 & 319 \\
\hline 205 & 320 \\
\hline 206 & 321 \\
\hline 207 & 322 \\
\hline 208 & 323 \\
\hline 209 & 324 \\
\hline 210 & 325 \\
\hline 211 & 326 \\
\hline$\overline{212}$ & 327 \\
\hline 213 & 328 \\
\hline$\overline{214}$ & 329 \\
\hline 215 & 330 \\
\hline 216 & $3 \overline{31}$ \\
\hline 217 & 332 \\
\hline 218 & $\overline{333}$ \\
\hline
\end{tabular}

\begin{tabular}{|c|c|}
\hline s & $419 \%$ \\
\hline 219 & $\overline{334}$ \\
\hline $220+221$ & $335+336$ \\
\hline+382 & +503 \\
\hline 222 & 337 \\
\hline 223 & 338 \\
\hline 224 & 339 \\
\hline 225 & 340 \\
\hline 226 & 341 \\
\hline 227 & $\overline{342}$ \\
\hline 228 & 343 \\
\hline 229 & 344 \\
\hline 230 & $\overline{345}$ \\
\hline 231 & 346 \\
\hline 232 & 347 \\
\hline 233 & $\overline{348}$ \\
\hline 234 & $\overline{349}$ \\
\hline 235 & 350 \\
\hline 236 & 351 \\
\hline 237 & 352 \\
\hline 238 & 353 \\
\hline 239 & $\overline{354}$ \\
\hline 240 & 355 \\
\hline 241 & 356 \\
\hline$\overline{242}$ & 357 \\
\hline 243 & 358 \\
\hline 244 & 359 \\
\hline 245 & $\overline{360}$ \\
\hline 246 & 361 \\
\hline 247 & 362 \\
\hline 248 & 363 \\
\hline 249 & $\overline{364}$ \\
\hline 250 & 365 \\
\hline $251+255$ & $366+370$ \\
\hline 252 & 367 \\
\hline 253 & 368 \\
\hline$\overline{254}$ & 369 \\
\hline 256 & 371 \\
\hline $257+349$ & $372+470$ \\
\hline 258 & 373 \\
\hline
\end{tabular}

\begin{tabular}{|c|c|}
\hline 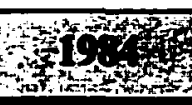 & 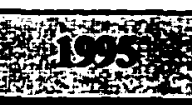 \\
\hline 259 & 374 \\
\hline 260 & 375 \\
\hline 261 & 376 \\
\hline 262 & 377 \\
\hline 263 & 378 \\
\hline $264+425$ & $379+546$ \\
\hline$+426+427$ & $+547+548$ \\
\hline+429 & +550 \\
\hline 265 & 380 \\
\hline 266 & 381 \\
\hline 267 & 382 \\
\hline 268 & 383 \\
\hline 269 & 384 \\
\hline 270 & 385 \\
\hline 271 & 386 \\
\hline 272 & 387 \\
\hline 273 & 388 \\
\hline 274 & 389 \\
\hline 275 & 390 \\
\hline 276 & 391 \\
\hline 277 & 392 \\
\hline 278 & 393 \\
\hline 279 & 394 \\
\hline 280 & 395 \\
\hline 281 & 396 \\
\hline 282 & 397 \\
\hline 283 & 398 \\
\hline 284 & 399 \\
\hline 285 & 400 \\
\hline 286 & 401 \\
\hline 287 & 402 \\
\hline 288 & 403 \\
\hline 289 & 404 \\
\hline 290 & 405 \\
\hline 291 & 406 \\
\hline 292 & 407 \\
\hline 293 & 408 \\
\hline 294 & 409 \\
\hline 295 & 410 \\
\hline
\end{tabular}


Table B.4. 1984 - 1995 TAP Zone Structural Equivalency (continued)

\begin{tabular}{|c|c|}
\hline 4,1984 & 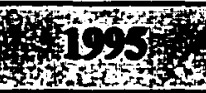 \\
\hline 296 & 411 \\
\hline 297 & 412 \\
\hline 298 & 413 \\
\hline 300 & 414 \\
\hline 301 & $416+417$ \\
\hline 302 & 418 \\
\hline 303 & 419 \\
\hline 304 & 420 \\
\hline 305 & 421 \\
\hline 306 & 422 \\
\hline 307 & 423 \\
\hline 308 & 424 \\
\hline 309 & 425 \\
\hline 310 & 426 \\
\hline 311 & 427 \\
\hline 312 & 428 \\
\hline 314 & 429 \\
\hline $315+316$ & $\begin{array}{c}432+433 \\
+435+436 \\
+437\end{array}$ \\
\hline 317 & 438 \\
\hline 318 & 439 \\
\hline 319 & 440 \\
\hline 320 & 441 \\
\hline 321 & 442 \\
\hline 322 & 443 \\
\hline 323 & 444 \\
\hline 324 & 445 \\
\hline $325+352$ & $446+473$ \\
\hline 326 & 447 \\
\hline 327 & 448 \\
\hline 328 & 449 \\
\hline 329 & 450 \\
\hline 330 & 451 \\
\hline 331 & 452 \\
\hline 332 & 453 \\
\hline 333 & 454 \\
\hline 334 & 455 \\
\hline 335 & 456 \\
\hline
\end{tabular}

\begin{tabular}{|c|c|}
\hline 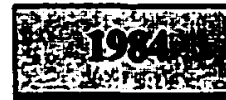 & 3 os \\
\hline 336 & 457 \\
\hline 337 & 458 \\
\hline 338 & 459 \\
\hline 339 & 460 \\
\hline 340 & 461 \\
\hline 341 & 462 \\
\hline 342 & 463 \\
\hline 343 & 464 \\
\hline $3 \overline{44}$ & 465 \\
\hline 345 & 466 \\
\hline 346 & 467 \\
\hline 347 & 468 \\
\hline $348+455$ & $469+576$ \\
\hline 350 & 471 \\
\hline 351 & 472 \\
\hline $353+354$ & $474+475$ \\
\hline 355 & 476 \\
\hline 356 & 477 \\
\hline 357 & 478 \\
\hline 358 & 479 \\
\hline 359 & 480 \\
\hline 360 & 481 \\
\hline 361 & 482 \\
\hline 362 & 483 \\
\hline 363 & 484 \\
\hline 364 & 485 \\
\hline 365 & 486 \\
\hline 366 & 487 \\
\hline 367 & 488 \\
\hline 368 & 489 \\
\hline 369 & 490 \\
\hline 370 & 491 \\
\hline 371 & 492 \\
\hline 372 & 493 \\
\hline 373 & 494 \\
\hline 374 & 495 \\
\hline $375+377$ & $496+498$ \\
\hline $376+422$ & $497+543$ \\
\hline 378 & 499 \\
\hline
\end{tabular}

\begin{tabular}{|c|c|}
\hline$x^{2} \mathrm{Sg} / \mathrm{s}$ & 4tos \\
\hline 379 & 500 \\
\hline 380 & 501 \\
\hline 381 & 502 \\
\hline 383 & 504 \\
\hline 384 & 505 \\
\hline$\overline{385}$ & 506 \\
\hline $386+387$ & $507+508$ \\
\hline 388 & 509 \\
\hline 389 & 510 \\
\hline 390 & 511 \\
\hline 391 & 512 \\
\hline 392 & 513 \\
\hline 393 & 514 \\
\hline 394 & 515 \\
\hline 395 & 516 \\
\hline 396 & 517 \\
\hline 397 & 518 \\
\hline 398 & 519 \\
\hline 399 & 520 \\
\hline 400 & 521 \\
\hline 401 & 522 \\
\hline $402+403$ & $523+524$ \\
\hline 404 & 525 \\
\hline 405 & 526 \\
\hline 406 & 527 \\
\hline 407 & 528 \\
\hline 408 & 529 \\
\hline 409 & 530 \\
\hline $410+415$ & $531+536$ \\
\hline$+416+417$ & $+537+538$ \\
\hline$+418+420$ & $+539+541$ \\
\hline+424 & +545 \\
\hline 411 & 532 \\
\hline 412 & 533 \\
\hline 413 & 534 \\
\hline 414 & 535 \\
\hline 419 & 540 \\
\hline 421 & 542 \\
\hline 423 & 544 \\
\hline
\end{tabular}


Table B.4. 1984 - 1995 TAP Zone Structural Equivalency (continued)

\begin{tabular}{|c|c|}
\hline mishors & 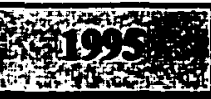 \\
\hline 428 & 549 \\
\hline 430 & 551 \\
\hline $431+435$ & $552+556$ \\
\hline$+436+437$ & $+557+558$ \\
\hline$+469+470$ & $+590+591$ \\
\hline+472 & +593 \\
\hline 432 & 553 \\
\hline 433 & 554 \\
\hline$\overline{434}$ & $\overline{555}$ \\
\hline 438 & 559 \\
\hline 439 & 560 \\
\hline 440 & 561 \\
\hline 441 & 562 \\
\hline 442 & 563 \\
\hline 443 & 564 \\
\hline 444 & 565 \\
\hline 445 & 566 \\
\hline 446 & 567 \\
\hline 447 & 568 \\
\hline 448 & 569 \\
\hline 449 & 570 \\
\hline 450 & 571 \\
\hline $451+452$ & $572+573$ \\
\hline 453 & 574 \\
\hline 454 & 575 \\
\hline $456+457$ & $577+578$ \\
\hline 458 & 579 \\
\hline $459+605$ & $580+724$ \\
\hline 460 & 581 \\
\hline 461 & 582 \\
\hline 462 & 583 \\
\hline 463 & 584 \\
\hline 464 & 585 \\
\hline 465 & 586 \\
\hline 466 & 587 \\
\hline 467 & 588 \\
\hline 468 & 589 \\
\hline 471 & 592 \\
\hline 473 & 594 \\
\hline
\end{tabular}

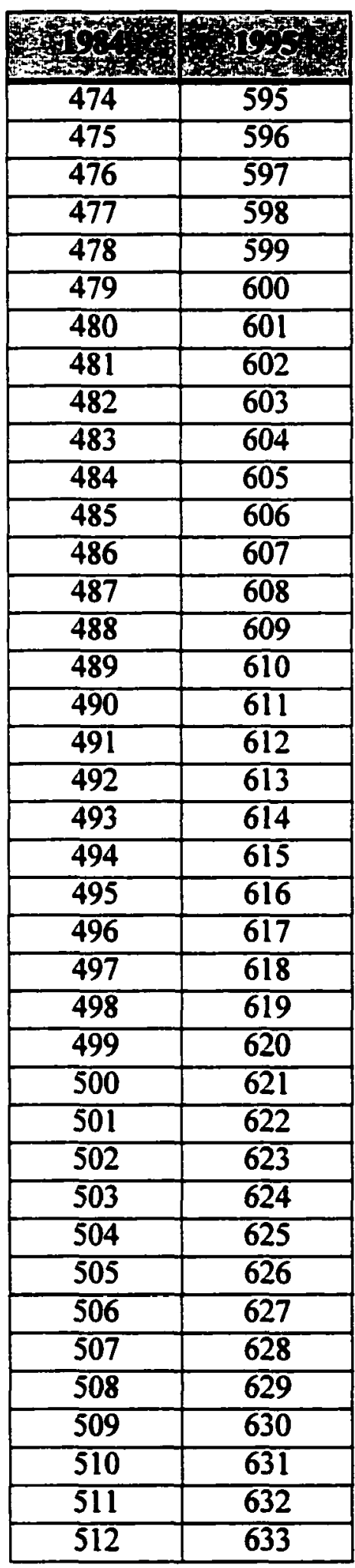

\begin{tabular}{|c|c|}
\hline 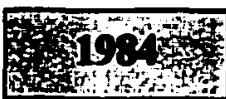 & 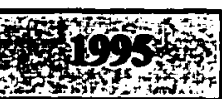 \\
\hline 513 & 634 \\
\hline 514 & 635 \\
\hline 515 & 636 \\
\hline 516 & 637 \\
\hline 517 & 638 \\
\hline 518 & 639 \\
\hline 519 & 640 \\
\hline 520 & 641 \\
\hline 521 & 642 \\
\hline 522 & $\overline{643}$ \\
\hline 523 & $\overline{644}$ \\
\hline 524 & $\overline{645}$ \\
\hline 525 & 646 \\
\hline 526 & 647 \\
\hline 527 & 648 \\
\hline 528 & $\overline{649}$ \\
\hline 529 & 650 \\
\hline 530 & 651 \\
\hline 531 & 652 \\
\hline 532 & 653 \\
\hline 533 & 654 \\
\hline$\overline{534}$ & 655 \\
\hline 535 & 656 \\
\hline$\overline{536}$ & 657 \\
\hline 537 & 658 \\
\hline 538 & 659 \\
\hline 539 & 660 \\
\hline 540 & 661 \\
\hline 541 & 662 \\
\hline 542 & 663 \\
\hline 543 & 664 \\
\hline 544 & 665 \\
\hline 545 & 666 \\
\hline 546 & 667 \\
\hline 547 & 668 \\
\hline 548 & 669 \\
\hline 549 & 670 \\
\hline 550 & 671 \\
\hline 551 & 672 \\
\hline
\end{tabular}


Table B.4. 1984 - 1995 TAP Zone Structural Equivalency (continued)

\begin{tabular}{|c|c|}
\hline (4) & $45 \sin$ \\
\hline 552 & 673 \\
\hline 553 & 674 \\
\hline 554 & 675 \\
\hline 555 & 676 \\
\hline 556 & 677 \\
\hline 557 & 678 \\
\hline 558 & 679 \\
\hline 559 & 680 \\
\hline 560 & 681 \\
\hline 561 & 682 \\
\hline 562 & $\overline{683}$ \\
\hline$\overline{563}$ & 684 \\
\hline 564 & 685 \\
\hline 565 & 686 \\
\hline 566 & 687 \\
\hline 567 & 688 \\
\hline $568+569$ & $689+690$ \\
\hline+582 & +703 \\
\hline 570 & 691 \\
\hline $571+572$ & $692+693$ \\
\hline+573 & +694 \\
\hline 574 & 695 \\
\hline $575+725$ & $696+844$ \\
\hline 576 & 697 \\
\hline 577 & 698 \\
\hline 578 & 699 \\
\hline 579 & 700 \\
\hline 580 & 701 \\
\hline 581 & 702 \\
\hline 583 & 704 \\
\hline 584 & 705 \\
\hline 585 & 706 \\
\hline $\begin{array}{c}586+587 \\
+588\end{array}$ & 707 \\
\hline 589 & 708 \\
\hline $590+595$ & $709+714$ \\
\hline$+722+723$ & $+841+842$ \\
\hline 591 & 710 \\
\hline 592 & 711 \\
\hline
\end{tabular}

\begin{tabular}{|c|c|}
\hline (3) & 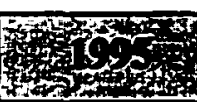 \\
\hline 593 & 712 \\
\hline 594 & 713 \\
\hline 596 & 715 \\
\hline 597 & 716 \\
\hline 598 & 717 \\
\hline 599 & 718 \\
\hline 600 & 719 \\
\hline 601 & 720 \\
\hline 602 & 721 \\
\hline 603 & 722 \\
\hline 604 & 723 \\
\hline 606 & 725 \\
\hline 607 & 726 \\
\hline 608 & 727 \\
\hline 609 & 728 \\
\hline 610 & 729 \\
\hline 611 & 730 \\
\hline 612 & 731 \\
\hline 613 & 732 \\
\hline 614 & 733 \\
\hline 615 & 734 \\
\hline 616 & 735 \\
\hline 617 & 736 \\
\hline 618 & 737 \\
\hline 619 & 738 \\
\hline 620 & 739 \\
\hline 621 & 740 \\
\hline 622 & 741 \\
\hline 623 & 742 \\
\hline 624 & 743 \\
\hline 625 & 744 \\
\hline 626 & 745 \\
\hline 627 & 746 \\
\hline $628+629$ & $747+748$ \\
\hline 630 & 749 \\
\hline 631 & 750 \\
\hline 632 & 751 \\
\hline 633 & 752 \\
\hline 634 & $\overline{753}$ \\
\hline
\end{tabular}

\begin{tabular}{|c|c|}
\hline (1) & Hossty \\
\hline 635 & 754 \\
\hline 636 & 755 \\
\hline 637 & 756 \\
\hline$\overline{638}$ & 757 \\
\hline 639 & 758 \\
\hline 640 & 759 \\
\hline 641 & 760 \\
\hline 642 & 761 \\
\hline 643 & 762 \\
\hline 644 & $\overline{763}$ \\
\hline$\overline{645}$ & 764 \\
\hline 646 & 765 \\
\hline 647 & 766 \\
\hline $648+651$ & $767+770$ \\
\hline 649 & 768 \\
\hline 650 & 769 \\
\hline 652 & 771 \\
\hline $653+654$ & $772+773$ \\
\hline 655 & 774 \\
\hline 656 & $\overline{775}$ \\
\hline 657 & 776 \\
\hline 658 & 777 \\
\hline 659 & 778 \\
\hline 660 & 779 \\
\hline 661 & 780 \\
\hline 662 & 781 \\
\hline 663 & 782 \\
\hline 664 & 783 \\
\hline 665 & 784 \\
\hline 666 & 785 \\
\hline 667 & 786 \\
\hline 668 & 787 \\
\hline 669 & 788 \\
\hline 670 & 789 \\
\hline 671 & $\overline{790}$ \\
\hline 672 & 791 \\
\hline 673 & $\overline{792}$ \\
\hline$\overline{674}$ & $\overline{793}$ \\
\hline 675 & $\overline{794}$ \\
\hline
\end{tabular}


Table B.4. 1984 - 1995 TAP Zone Structural Equivalency (concluded)

\begin{tabular}{|c|c|}
\hline 1994 & $4190<$ \\
\hline 676 & 795 \\
\hline 677 & 796 \\
\hline 678 & 797 \\
\hline 679 & 798 \\
\hline 680 & 799 \\
\hline 681 & 800 \\
\hline 682 & 801 \\
\hline 683 & 802 \\
\hline 684 & 803 \\
\hline 685 & $\overline{804}$ \\
\hline 686 & 805 \\
\hline 687 & 806 \\
\hline 688 & 807 \\
\hline 689 & 808 \\
\hline 690 & 809 \\
\hline 691 & 810 \\
\hline 692 & 811 \\
\hline 693 & 812 \\
\hline 694 & 813 \\
\hline 695 & $\overline{814}$ \\
\hline 696 & 815 \\
\hline 697 & 816 \\
\hline 698 & 817 \\
\hline 699 & 818 \\
\hline 700 & 819 \\
\hline 701 & 820 \\
\hline 702 & 821 \\
\hline$\overline{703}$ & 822 \\
\hline$\overline{704}$ & 823 \\
\hline 705 & 824 \\
\hline 706 & 825 \\
\hline $707+708$ & $826+827$ \\
\hline$+709+710$ & $+828+829$ \\
\hline+711 & +830 \\
\hline 712 & 831 \\
\hline 713 & 832 \\
\hline 714 & 833 \\
\hline$\overline{715}$ & $\overline{834}$ \\
\hline 716 & 835 \\
\hline
\end{tabular}

\begin{tabular}{|c|c|}
\hline $\operatorname{los}_{\mathrm{p}}$ & 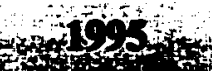 \\
\hline $\begin{array}{c}717+720 \\
+721\end{array}$ & $\begin{array}{c}836+839 \\
+840\end{array}$ \\
\hline 718 & 837 \\
\hline 719 & 838 \\
\hline 724 & 843 \\
\hline 726 & 845 \\
\hline 727 & 846 \\
\hline 728 & 847 \\
\hline 729 & 848 \\
\hline 730 & 849 \\
\hline 731 & 850 \\
\hline 732 & 851 \\
\hline 733 & 852 \\
\hline 734 & 853 \\
\hline 735 & 854 \\
\hline 736 & 855 \\
\hline 737 & 856 \\
\hline 738 & 857 \\
\hline 739 & 858 \\
\hline 740 & 859 \\
\hline 741 & 80 \\
\hline 742 & 861 \\
\hline 743 & 862 \\
\hline 744 & 833 \\
\hline 745 & 884 \\
\hline 746 & 865 \\
\hline 747 & 866 \\
\hline 748 & 867 \\
\hline 749 & 868 \\
\hline 750 & 869 \\
\hline 751 & 870 \\
\hline 752 & 871 \\
\hline 753 & 872 \\
\hline 754 & 873 \\
\hline 755 & 874 \\
\hline 756 & 875 \\
\hline 757 & 876 \\
\hline 758 & 877 \\
\hline 759 & 878 \\
\hline
\end{tabular}

\begin{tabular}{|c|c|}
\hline $\sin ^{2}$ & 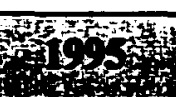 \\
\hline 760 & 879 \\
\hline 761 & 880 \\
\hline$\overline{762}$ & 881 \\
\hline 763 & 882 \\
\hline 764 & 883 \\
\hline 765 & $\overline{884}$ \\
\hline 766 & 885 \\
\hline 767 & 886 \\
\hline 768 & 887 \\
\hline 769 & $\overline{888}$ \\
\hline$\overline{770}$ & 889 \\
\hline 771 & 890 \\
\hline$\overline{772}$ & 891 \\
\hline$\overline{773}$ & 892 \\
\hline 774 & 893 \\
\hline 775 & 894 \\
\hline 776 & 895 \\
\hline 777 & 896 \\
\hline 778 & 897 \\
\hline 779 & 898 \\
\hline 780 & 899 \\
\hline 781 & 900 \\
\hline 782 & 901 \\
\hline$\overline{783}$ & 902 \\
\hline$\overline{784}$ & 903 \\
\hline 785 & 904 \\
\hline 786 & $\overline{905}$ \\
\hline 787 & 906 \\
\hline 788 & 907 \\
\hline 789 & 908 \\
\hline 790 & $\overline{909}$ \\
\hline$\overline{791}$ & 910 \\
\hline $792+793$ & $911+912$ \\
\hline 794 & 913 \\
\hline$\overline{795}$ & $\overline{914}$ \\
\hline 796 & 915 \\
\hline 797 & 916 \\
\hline 798 & 917 \\
\hline$\overline{799}$ & 918 \\
\hline 800 & 919 \\
\hline
\end{tabular}




\section{APPENDIX C}

Before-and-After Case Study Analysis

Analysis of Covariance Model Results 


\section{INSIDE STUDY AREA; BEFORE vs. AFTER CAPACITY ADDITION TOTAL TRIP PRODUCTIONS PER HOUSEHOLD}

\section{Interaction Model (Test for Parallelism)}

Summary of Fit

\begin{tabular}{ll}
\hline RSquare & 0.097366 \\
RSquare Adj & 0.087224 \\
Root Mean Square Error & 6.311342 \\
Mean of Response & 10.63796 \\
Observations (or Sum Wgts) & 451
\end{tabular}

\section{Efreet Test}

Source

Before/After

MEDINC

POPDEN

Before/After*MEDINC

Before/After*POPDEN

$\begin{array}{lll}\text { Nparm } & \text { DF } & \text { Sum of Squares } \\ 1 & 1 & \mathbf{9 7 . 5 4 3 7} \\ 1 & 1 & \mathbf{4 2 5 . 6 9 1 7} \\ 1 & 1 & 1451.7793 \\ 1 & 1 & 44.8474 \\ 1 & 1 & \mathbf{9 . 8 5 9 1}\end{array}$

F Ratio
2.4488
10.6869
36.4466
1.1259
0.2475

Prob $>F$

0.1183

0.0012

$<.0001$

0.2892

0.6191

\section{Parallel Model}

\section{Summary of Fit}

\section{Rsquare}

RSquare Adj

0.0949

0.088826

6.305803

Root Mean Square Error

10.63796

Mean of Response

451

\section{Efrect Test}

Source

Before/After

MEDINC

POPDEN

$\begin{array}{lll}\text { Nparm } & \text { DF } & \text { Sum of Squares } \\ 1 & 1 & 112.3491 \\ 1 & 1 & 632.1572 \\ 1 & 1 & 1494.2949\end{array}$

F Ratio

Prob $>F$

\section{Least Squares Means}

Level Least Sq Mean

After

11.12514499

Std Error

Before

10.11259896

0.4149361534

10.9006

0.4311029009

10.3547

\section{Figure C.1}




\title{
OUTSIDE STUDY AREA; BEFORE vs. AFTER CAPACITY ADDITION TOTAL TRIP PRODUCTIONS PER HOUSEHOLD
}

\author{
Interaction Model (Test for Parallelism)
}

\begin{tabular}{ll} 
Summary of Fit & \\
\hline Rsquare & 0.04716 \\
RSquare Adj & 0.041936 \\
Root Mean Square Error & 10.47468 \\
Mean of Response & 11.53882 \\
Observations (or Sum Wgts) & 918
\end{tabular}

\section{Efrect Test}

Source

Before/After

MEDINC

POPDEN

Before/After*MEDINC

Before/After* POPDEN

$\begin{array}{lll}\text { Nparm } & \text { DF } & \text { Sum of Squares } \\ 1 & 1 & 370.6159 \\ 1 & 1 & 2602.5044 \\ 1 & 1 & 2661.2665 \\ 1 & 1 & 320.4749 \\ 1 & 1 & 138.1472\end{array}$

$\begin{array}{ll}\text { F Ratio } & \text { Prob>F } \\ 3.3779 & 0.0664 \\ 23.7198 & <.0001 \\ 24.2553 & <.0001 \\ 2.9209 & 0.0878 \\ 1.2591 & 0.2621\end{array}$

Parallel Model

\section{Summary of Fit}

RSquare

RSquare Adj

Root Mean Square Error

Mean of Response

Observations (or Sum Wgts)

\section{Effect Test}

Source

Before/After

MEDINC

POPDEN
0.043083
0.039942
10.48557
11.53882
918

$\begin{array}{lll}\text { Nparm } & \text { DF } & \text { Sum of Squares } \\ 1 & 1 & 0.4900 \\ 1 & 1 & 2319.9486 \\ 1 & 1 & 2478.8949\end{array}$

$\begin{array}{ll}\text { F Ratio } & \text { Prob>F } \\ 0.0045 & 0.9468 \\ 21.1006 & <.0001 \\ 22.5462 & <.0001\end{array}$

Least Squares Means

$\begin{array}{llll}\text { Level } & \text { Least Sq Mean } & \text { Std Error } & \text { Mean } \\ \text { After } & 11.55948493 & 0.4642847914 & 11.4661 \\ \text { Before } & 11.51230390 & 0.5268716366 & 11.6321\end{array}$

Figure C.2 


\title{
BEFORE CAPACITY ADDITION; INSIDE vS. OUTSIDE STUDY AREA TOTAL TRIP PRODUCTIONS PER HOUSEHOLD
}

\author{
Interaction Model (Test for Parallelism)
}

\section{Summary of Fit}

Rsquare

0.077461

0.069936

RSquare Adj

8.681255

11.18431

Observations (or Sum Wgts)

619

\section{Effect Test}

\section{Source}

Inside/Outside

MEDINC

POPDEN

Inside/Outside*MEDINC

Inside/Outside* POPDEN

$\begin{array}{lll}\text { Nparm } & \text { DF } & \text { Sum of Squares } \\ 1 & 1 & 454.1863 \\ 1 & 1 & 912.9946 \\ 1 & 1 & 1866.3021 \\ 1 & 1 & 276.2067 \\ 1 & 1 & 8.9819\end{array}$

$\begin{array}{ll}\text { F Ratio } & \text { Prob }>\text { F } \\ 6.0266 & 0.0144 \\ 12.1144 & 0.0005 \\ 24.7638 & <.0001 \\ 3.6650 & 0.0560 \\ 0.1192 & 0.7300\end{array}$

\section{Parallel Model}

\section{Summary of Fit}

RSquare

0.071945

0.067418

8.693001

RSquare Adj

11.18431

Mean of Response

619

Observations (or Sum Wgts)

\section{Effect Test}

Source

Inside/Outside

MEDINC

POPDEN

$\begin{array}{lll}\text { Nparm } & \text { DF } & \text { Sum of Squares } \\ 1 & 1 & 496.9885 \\ 1 & 1 & 1411.0795 \\ 1 & 1 & 2392.2562\end{array}$

$\begin{array}{ll}\text { F Ratio } & \text { Prob>F } \\ 6.5767 & 0.0106 \\ 18.6729 & <.0001 \\ 31.6569 & <.0001\end{array}$

Least Squares Means

\begin{tabular}{llll}
\hline Level & Least Sq Mean & Std Error & Mean \\
Inside & 9.95468542 & 0.5932784640 & 10.3547 \\
Outside & 11.84805663 & 0.4348219066 & 11.6321
\end{tabular}

Figure C.3 


\title{
AFTER CAPACITY ADDITION; INSIDE vs. OUTSIDE STUDY AREA TOTAL TRIP PRODUCTIONS PER HOUSEHOLD
}

\author{
Interaction Model (Test for Parallelism)
}

\begin{tabular}{|ll} 
Summary of Fit & \\
\hline Rsquare & 0.043135 \\
RSquare Adj & 0.036704 \\
Root Mean Square Error & 9.809409 \\
Mean of Response & 11.2897 \\
Observations (or Sum Wgts) & 750
\end{tabular}

\section{Efrect Test}

Source

Inside/Outside

MEDINC

POPDEN

Inside/Outside* MEDINC

Inside/Outside* POPDEN

$\begin{array}{lll}\text { Nparm } & \text { DF } & \text { Sum of Squares } \\ 1 & 1 & 13.6732 \\ 1 & 1 & 1460.6244 \\ 1 & 1 & 1711.6768 \\ 1 & 1 & 10.4595 \\ 1 & 1 & 98.7818\end{array}$

F Ratio

Prob $>$ F

$0.1421 \quad 0.7063$

$15.1793 \quad 0.0001$

$17.7884 \quad<.0001$

$\begin{array}{ll}0.1087 & 0.7417\end{array}$

$\begin{array}{ll}1.0266 & 0.3113\end{array}$

\section{Parallel Model}

\section{Summary of Fit}

Rsquare

RSquare Adj

0.041768

0.037914

9.803247

Root Mean Square Error

11.2897

Mean of Response

750

Observations (or Sum Wgts)

Efrect Test

Source

Inside/Outside

MEDINC

POPDEN

DF Sum of Squares

F Ratio

Prob $>F$

$\begin{array}{lll}\text { Nparm } & \text { DF } & \text { Sum of Squares } \\ 1 & 1 & 74.4950 \\ 1 & 1 & 1596.9616 \\ 1 & 1 & 1728.7326\end{array}$

0.7752

0.3789

16.6171

$<.0001$

17.9882

$<.0001$

\section{Least Squares Means}

\begin{tabular}{ll}
\hline Level & Least Sq Mean \\
Inside & 10.82085619 \\
Outside & 11.50231094
\end{tabular}

Std Error

Figure C.4 


\section{INSIDE STUDY AREA; BEFORE vs. AFTER CAPACITY ADDITION TOTAL WEEKDAY VMT}

\section{Interaction Model (Test for Parallelism)}

\section{Summary of Fit}

Rsquare

0.281707

RSquare Adj

0.271691

Root Mean Square Error

97733.17

Mean of Response

142910.5

Observations (or Sum Wgts)

510

\section{Effect Test}

Source

Before/After

MEDINC

HHOLDS

POPDEN

Before/After MEDINC

Before/After*HHOLDS

Before/After*POPDEN

$\begin{array}{lll}\text { Nparm } & \text { DF } & \text { Sum of Squares } \\ 1 & 1 & 6089095465 \\ 1 & 1 & 1.52673 \mathrm{e} 11 \\ 1 & 1 & 1.42483 \mathrm{e} 12 \\ 1 & 1 & 6.09671 \mathrm{e} 11 \\ 1 & 1 & 1.99437 \mathrm{e} 10 \\ 1 & 1 & 181130896 \\ 1 & 1 & 843541054\end{array}$

F Ratio

Prob $>F$

$\begin{array}{ll}0.6375 & 0.4250\end{array}$

$15.9838<<.0001$

$149.1692<.0001$

$63.8280<.0001$

$2.0880 \quad 0.1491$

$0.0190 \quad 0.8905$

$0.0883 \quad 0.7665$

\section{Parallel Model}

\section{Summary of Fit}

Rsquare

0.278438

RSquare Adj

0.272722

97663.96

Root Mean Square Error

142910.5

Observations (or Sum Wgts)

510

\section{Efrect Test}

Source

Before/After

MEDINC

HHOLDS

POPDEN

$\begin{array}{lll}\text { Nparm } & \text { DF } & \text { Sum of Squares } \\ 1 & 1 & 2.24436 \mathrm{ell} \\ 1 & 1 & 1.32878 \mathrm{e} 11 \\ 1 & 1 & 1.48658 \mathrm{e} 12 \\ 1 & 1 & 6.21365 \mathrm{e} 11\end{array}$

F Ratio

Prob $>F$

$23.5301<.0001$

$13.9311 \quad 0.0002$

$155.8546<<.0001$

$65.1445<.0001$

Least Squares Means

\begin{tabular}{llll}
\hline Level & Least Sq Mean & Std Error & Mean \\
After & 163760.7372 & 6097.376588 & 165759 \\
Before & 121226.2688 & 6219.775430 & 119148
\end{tabular}

Figure C.5 


\section{OUTSIDE STUDY AREA; BEFORE vs. AFTER CAPACITY ADDITION TOTAL WEEKDAY VMT}

\section{Interaction Model (Test for Parallelism)}

\section{Summary of Fit}

Rsquare

RSquare Adj

Root Mean Square Error

Mean of Response

Observations (or Sum Wgts)

Efrect Test

Source

Before/After

MEDINC

HHOLDS

POPDEN

Before/After"MEDNC

Before/After*HHOLDS

Before/After"POPDEN
0.303424

0.298913

83639.91

103013.8

1089

$\begin{array}{lll}\text { Nparm } & \text { DF } & \text { Sum of Squares } \\ 1 & 1 & 1650043531 \\ 1 & 1 & 8.95658 \mathrm{e} 10 \\ 1 & 1 & 2.95496 \mathrm{e} 12 \\ 1 & 1 & 6.24359 \mathrm{e} 11 \\ 1 & 1 & 2000377478 \\ 1 & 1 & 1828173325 \\ 1 & 1 & 35768442\end{array}$

F Ratio

Prob $>$ F

0.2359

0.6273

$12.8031 \quad 0.0004$

$422.4006<.0001$

$89.2499<.0001$

$0.2859 \quad 0.5929$

0.2613

0.0051

0.6093

0.9430

\section{Parallel Model}

\section{Summary of Fit}

Rsquare

RSquare Adj

Root Mean Square Error

Mean of Response

Observations (or Sum Wgts)

0.302912
0.30034
83554.78
103013.8
1089

\section{Efrect Test}

Source

Before/After

MEDINC

HHOLDS

POPDEN

$\begin{array}{lll}\text { Nparm } & \text { DF } & \text { Sum of Squares } \\ 1 & 1 & 5.70777 \mathrm{e} 10 \\ 1 & 1 & 9.14081 \mathrm{e} 10 \\ 1 & 1 & 3.14585 \mathrm{e} 12 \\ 1 & 1 & 6.40416 \mathrm{el} 11\end{array}$

$\begin{array}{ll}\text { F Ratio } & \text { Prob }>\text { F } \\ 8.1757 & 0.0043 \\ 13.0931 & 0.0003 \\ 450.6039 & <.0001 \\ 91.7317 & <.0001\end{array}$

Least Squares Means

\begin{tabular}{llll}
\hline Level & Least Sq Mean & Std Error & Mean \\
After & 109669.0704 & 3439.239850 & 111105 \\
Before & 94908.2952 & 3800.902116 & 93159
\end{tabular}

Figure C.6 


\section{BEFORE CAPACITY ADDITION; INSIDE vs. OUTSIDE STUDY AREA TOTAL WEEKDAY VMT}

\section{Interaction Model (Test for Parallelism)}

\begin{tabular}{ll} 
Summary of Fit & \\
\hline RSquare & 0.325664 \\
RSquare Adj & 0.319224 \\
Root Mean Square Error & 74287.86 \\
Mean of Response & 101927.5 \\
Observations (or Sum Wgts) & 741
\end{tabular}

\section{Effect Test}

Source

Inside/Outside

MEDINC

HHOLDS

POPDEN

Inside/Outside*MEDINC

Inside/Outside*HHOLDS

Inside/Outside*POPDEN

$\begin{array}{lll}\text { Nparm } & \text { DF } & \text { Sum of Squares } \\ 1 & 1 & 7.60596 \mathrm{e} 10 \\ 1 & 1 & 1.55316 \mathrm{e} 11 \\ 1 & 1 & 1.64373 \mathrm{e} 12 \\ 1 & 1 & 5.27117 \mathrm{ell} \\ 1 & 1 & 2.57467 \mathrm{e} 10 \\ 1 & 1 & 1.48757 \mathrm{e} 10 \\ 1 & 1 & 1.73138 \mathrm{e} 10\end{array}$

F Ratio

13.7822

Prob $>F$

28.1436

297.8481

95.5149

4.6654

2.6955

3.1373

\section{Parallel Model}

\section{Summary of Fit}

RSquare

RSquare Adj

Root Mean Square Error

0.309306

0.305552

75030.11

Mean of Response

101927.5

Observations (or Sum Wgts)

741

\section{Effect Test}

Source

Inside/Outside

MEDINC

HHOLDS

POPDEN

$\begin{array}{lll}\text { Nparm } & \text { DF } & \text { Sum of Squares } \\ 1 & 1 & 4516163169 \\ 1 & 1 & 1.19769 \mathrm{el} 1 \\ 1 & 1 & 1.67884 \mathrm{e} 12 \\ 1 & 1 & 4.91507 \mathrm{el} 1\end{array}$

$\begin{array}{ll}\text { F Ratio } & \text { Prob>F } \\ 0.8022 & 0.3707 \\ 21.2753 & <.0001 \\ 298.2204 & <.0001 \\ 87.3089 & <.0001\end{array}$

\section{Least Squares Means}

\begin{tabular}{llll}
\hline Level & Least Sq Mean & Std Error & Mean \\
Inside & 105457.9676 & 4809.807491 & 119148 \\
Outside & 100129.8928 & 3409.568351 & 93159
\end{tabular}

\section{Figure C.7}




\section{AFTER CAPACITY ADDITION; INSIDE vs. OUTSIDE STUDY AREA TOTAL WEEKDAY VMT}

\section{Interaction Model (Test for Parallelism)}

\begin{tabular}{ll} 
Summary of Fit & \\
\hline RSquare & 0.296931 \\
RSquare Adj & 0.291141 \\
Root Mean Square Error & $\mathbf{9 8 8 8 8 . 3 7}$ \\
Mean of Response & 127666.9 \\
Observations (or Sum Wgts) & $\mathbf{8 5 8}$
\end{tabular}

\section{Effect Test}

Source

Inside/Outside

MEDINC

HHOLDS

POPDEN

Inside/Outside "MEDINC

Inside/Outside*HHOLDS

Inside/Outside* POPDEN

$\begin{array}{lll}\text { Nparm } & \text { DF } & \text { Sum of Squares } \\ 1 & 1 & 1.37061 \mathrm{ell} \\ 1 & 1 & 8.55206 \mathrm{e} 10 \\ 1 & 1 & 2.65315 \mathrm{e} 12 \\ 1 & 1 & 6.6314 \mathrm{e}+11 \\ 1 & 1 & 3470337380 \\ 1 & 1 & 3.1287 \mathrm{e}+10 \\ 1 & 1 & 3.33244 \mathrm{e} 10\end{array}$

F Ratio

14.0160

Prob $>F$

8.7454

0.0002

271.3132

0.0032

67.8133

$<.0001$

0.3549

$<.0001$

3.1994

0.5515

3.4078

0.0740

0.0652

\section{Parallel Model}

\section{Summary of Fit}

Rsquare

RSquare Adj

Root Mean Square Error

Mean of Response

Observations (or Sum Wgts)

0.286309

0.282963

99457.21

127666.9

858

\section{Efrect Test}

Source

Inside/Outside

MEDINC

HHOLDS

POPDEN

$\begin{array}{lll}\text { Nparm } & \text { DF } & \text { Sum of Squares } \\ 1 & 1 & 1.33542 \mathrm{ell} \\ 1 & 1 & 8.48906 \mathrm{e} 10 \\ 1 & 1 & 2.82024 \mathrm{e} 12 \\ 1 & 1 & 6.17284 \mathrm{el}\end{array}$

$\begin{array}{ll}\text { F Ratio } & \text { Prob }>\text { F } \\ 13.5003 & 0.0003 \\ 8.5820 & 0.0035 \\ 285.1111 & <.0001 \\ 62.4040 & <.0001\end{array}$

\section{Least Squares Means}

\begin{tabular}{llll}
\hline Level & Least Sq Mean & Std Error & Mean \\
Inside & 147033.0267 & 6269.730811 & 165759 \\
Outside & 119246.7888 & 4096.386259 & 111105
\end{tabular}

Figure C.8 


\section{INSIDE STUDY AREA; BEFORE vs. AFTER CAPACITY ADDITION TOTAL TRIP PRODUCTIONS}

\section{Interaction Model (Test for Parallelism)}

\section{Summary of Fit}

Rsquare

RSquare Adj

Root Mean Square Error

Mean of Response

Observations (or Sum Wgts)

\section{Effect Test}

Source

Before/After

MEDINC

HHOLDS

POPDEN

Before/After"MEDINC

Before/After*HHOLDS

Before/After* POPDEN

$\begin{array}{lll}\text { Nparm } & \text { DF } & \text { Sum of Squares } \\ 1 & 1 & 33132028.7 \\ 1 & 1 & 540801150 \\ 1 & 1 & 8.97374 \mathrm{e} 10 \\ 1 & 1 & 566181740 \\ 1 & 1 & 377753.677 \\ 1 & 1 & 7227792.78 \\ 1 & 1 & 3045796.8\end{array}$

\section{Parallel Model}

\section{Summary of Fit}

RSquare

RSquare Adj

Root Mean Square Error

Mean of Response

Observations (or Sum Wgts)

\section{Effect Test}

Source

Before/After

MEDINC

HHOLDS

POPDEN

Least Squares Means

\begin{tabular}{ll}
\hline Level & Least Sq Mean \\
After & 20907.23064 \\
Before & 19581.57214
\end{tabular}

0.876652

0.874932

5603.654

20257.4

510

$\begin{array}{ll}\text { F Ratio } & \text { Prob>F } \\ 1.0551 & 0.3048 \\ 17.2225 & <.0001 \\ 2857.795 & <.0001 \\ 18.0307 & <.0001 \\ 0.0120 & 0.9127 \\ 0.2302 & 0.6316 \\ 0.0970 & 0.7556\end{array}$

0.876593

0.875616

5588.33

20257.4

510

$\begin{array}{lll}\text { Nparm } & \text { DF } & \text { Sum of Squares } \\ 1 & 1 & 218008873 \\ 1 & 1 & 583493324 \\ 1 & 1 & 9.25376 \mathrm{e} 10 \\ 1 & 1 & 559739607\end{array}$

F Ratio

6.9809

18.6841

2963.155

17.9235
Prob>F

0.0085

$<.0001$

$<.0001$

$<.0001$

Figure C.9 


\section{OUTSIDE STUDY AREA; BEFORE vs. AFTER CAPACITY ADDITION TOTAL TRIP PRODUCTIONS}

\section{Interaction Model (Test for Parallelism)}

\section{Summary of Fit}

RSquare

RSquare Adj

Root Mean Square Error

Mean of Response

Observations (or Sum Wgts)

\section{Effect Test}

Source

Before/After

MEDINC

HHOLDS

POPDEN

Before/After*MEDINC

Before/After"HHOLDS

Before/After*POPDEN
0.859682

0.858773

5121.203

14509

1089

$\begin{array}{lll}\text { Nparm } & \text { DF } & \text { Sum of Squares } \\ 1 & 1 & 265063.906 \\ 1 & 1 & 630578680 \\ 1 & 1 & 1.28531 \mathrm{e} 11 \\ 1 & 1 & 229945493 \\ 1 & 1 & 12552.7066 \\ 1 & 1 & 43112932.3 \\ 1 & 1 & 85493492.6\end{array}$

$\begin{array}{ll}\text { F Ratio } & \text { Prob>F } \\ 0.0101 & 0.9199 \\ 24.0434 & <.0001 \\ 4900.772 & 0.0000 \\ 8.7676 & 0.0031 \\ 0.0005 & 0.9825 \\ 1.6439 & 0.2001 \\ 3.2598 & 0.0713\end{array}$

\section{Parallel Model}

\section{Summary of Fit}

RSquare

0.859233

0.858713

5122.293

Root Mean Square Error

14509

Mean of Response

1089

\section{Efrect Test}

Source

Before/After

MEDINC

HHOLDS

POPDEN

$\begin{array}{lll}\text { Nparm } & \text { DF } & \text { Sum of Squares } \\ 1 & 1 & 27086083.5 \\ 1 & 1 & 704026712 \\ 1 & 1 & 1.34346 \mathrm{e} 11 \\ 1 & 1 & 198823858\end{array}$

F Ratio

1.0323

26.8324

5120.305

7.5777

Prob $>F$

0.3098

$<.0001$

0.0000

0.0060

\section{Least Squares Means}

\begin{tabular}{llll}
\hline Level & Least Sq Mean & Std Error & Mean \\
After & 14653.98092 & 210.8412491 & 14900.8 \\
Before & 14332.43057 & 233.0128123 & 14031.9
\end{tabular}

Figure C.10 


\section{BEFORE CAPACITY ADDITION; INSIDE vs. OUTSIDE STUDY AREA TOTAL TRIP PRODUCTIONS}

\section{Interaction Model (Test for Parallelism)}

\section{Summary of Fit}

\section{Rsquare}

RSquare Adj

Root Mean Square Error

Mean of Response

\section{Efrect Test}

Source

Inside/Outside

MEDINC

HHOLDS

POPDEN

Inside/Outside*MEDINC

Inside/Outside *HHOLDS

Inside/Outside* POPDEN
Observations (or Sum Wgts)

0.873652

0.872446

4850.717

15462.24

741

$\begin{array}{lllll}\text { Nparm } & \text { DF } & \text { Sum of Squares } & \text { F Ratio } & \text { Prob }>\text { F } \\ 1 & 1 & 61620892.9 & 2.6189 & 0.1060 \\ 1 & 1 & 441325936 & 18.7563 & <.0001 \\ 1 & 1 & 9.08724 e 10 & 3862.068 & <.0001 \\ 1 & 1 & 560778041 & 23.8330 & <.0001 \\ 1 & 1 & 15024878.4 & 0.6386 & 0.4245 \\ 1 & 1 & 18877923.8 & 0.8023 & 0.3707 \\ 1 & 1 & 29754034 & 1.2645 & 0.2612\end{array}$

\section{Parallel Model}

\section{Summary of Fit}

RSquare

RSquare Adj

Root Mean Square Error

Mean of Response

Observations (or Sum Wgts)

\section{Effect Test}

\section{Source}

Inside/Outside

MEDINC

HHOLDS

POPDEN

Least Squares Means

\begin{tabular}{ll}
\hline Level & Least Sq Mean \\
Inside & 15485.83650 \\
Outside & 15450.22378
\end{tabular}

\subsection{5 \\ 0.872093 \\ 4857.415 \\ 15462.24 \\ 741}

$\begin{array}{lllll}\text { Nparm } & \text { DF } & \text { Sum of Squares } & \text { F Ratio } & \text { Prob }>\text { F } \\ 1 & 1 & 201761.966 & 0.0086 & 0.9263 \\ 1 & 1 & 425902414 & 18.0509 & <.0001 \\ 1 & 1 & 9.31475 \mathrm{e} 10 & 3947.853 & <.0001 \\ 1 & 1 & 501949865 & 21.2740 & <.0001\end{array}$

\section{Figure C.11}




\section{AFTER CAPACITY ADDITION; INSIDE vs. OUTSIDE STUDY AREA TOTAL TRIP PRODUCTIONS}

\section{Interaction Model (Test for Parallelism)}

\section{Summary of Fit}

RSquare

0.868134

RSquare Adj

0.867048

Root Mean Square Error

5622.147

Mean of Response

17102.63

Observations (or Sum Wgts)

858

\section{Efrect Test}

Source

Inside/Outside

MEDINC

HHOLDS

POPDEN

Inside/Outside *MEDINC

Inside/Outside*HHOLDS

Inside/Outside*POPDEN

$\begin{array}{lll}\text { Nparm } & \text { DF } & \text { Sum of Squares } \\ 1 & 1 & 239877299 \\ 1 & 1 & 751196132 \\ 1 & 1 & 1.28817 \mathrm{e} 11 \\ 1 & 1 & 254546108 \\ 1 & 1 & 20008489.3 \\ 1 & 1 & 3314230.35 \\ 1 & 1 & 125145932\end{array}$

F Ratio

Prob $>F$

7.5890

0.0060

23.7656

$<.0001$

$4075.376 \quad 0.0000$

$8.0531 \quad 0.0047$

$0.6330 \quad 0.4265$

$0.1049 \quad 0.7462$

$3.9592 \quad 0.0469$

\section{Parallel Model}

\section{Summary of Fit}

Rsquare

RSquare Adj

Root Mean Square Error

0.866485

5634.041

17102.63

Mean of Response

858

\section{Effect Test}

Source

Inside/Outside

MEDINC

HHOLDS

POPDEN

$\begin{array}{lll}\text { Nparm } & \text { DF } & \text { Sum of Squares } \\ 1 & 1 & 185716446 \\ 1 & 1 & 768186532 \\ 1 & 1 & 1.34087 \mathrm{e} 11 \\ 1 & 1 & 126829059\end{array}$

$\begin{array}{ll}\text { F Ratio } & \text { Prob }>\text { F } \\ 5.8507 & 0.0158 \\ 24.2006 & <.0001 \\ 4224.211 & 0.0000 \\ 3.9956 & 0.0459\end{array}$

Least Squares Means

\begin{tabular}{llll}
\hline Level & Least Sq Mean & Sid Error & Mean \\
Inside & 17824.83659 & 355.1669918 & 22167.0 \\
Outside & 16788.62958 & 232.0516189 & 14900.8
\end{tabular}

Figure C.12 


\section{INSIDE STUDY AREA; BEFORE vs. AFTER CAPACITY ADDITION TOTAL TRIP ATTRACTIONS}

\section{Interaction Model (Test for Parallelism)}

\section{Summary of Fit}

Rsquare

RSquare Adj

Root Mean Square Error

Mean of Response

Observations (or Sum Wgts)

\section{Effect Test}

Source

Before/After

MEDINC

TOTEMP

POPDEN

Before/After"MEDINC

Before/After"TOTEMP

Before/After ${ }^{*}$ POPDEN
0.76186

0.758539

8886.004

18346.94

510

$\begin{array}{lll}\text { Nparm } & \text { DF } & \text { Sum of Squares } \\ 1 & 1 & 186727259 \\ 1 & 1 & 1006529193 \\ 1 & 1 & 1.13221 \text { l1 } \\ 1 & 1 & 3655208498 \\ 1 & 1 & 130380041 \\ 1 & 1 & 6814573.94 \\ 1 & 1 & 9094062.59\end{array}$

Parallel Model

\section{Summary of Fit}

Rsquare

RSquare Adj

Root Mean Square Error

Mean of Response

Observations (or Sum Wgis)

\section{Effect Test}

Source

Before/After

MEDINC

TOTEMP

POPDEN
0.761018

0.759125

8875.22

18346.94

510

$\begin{array}{lll}\text { Nparm } & \text { DF } & \text { Sum of Squares } \\ \text { I } & 1 & 117986856 \\ 1 & 1 & 883944504 \\ 1 & 1 & 1.16876 \mathrm{ell} \\ 1 & 1 & 3664484964\end{array}$

F Ratio

2.3648

12.7472

1433.878

46.2913

1.6512

0.0863

0.1152
Prob $>F$

0.1247

0.0004

$<.0001$

$<.0001$

0.1994

0.7691

0.7345

\section{Least Squares Means}

\begin{tabular}{ll}
\hline Level & Least Sq Mean \\
After & 18827.13267 \\
Before & 17847.53803
\end{tabular}

F Ratio

Prob>F

$1.4979 \quad 0.2216$

$\begin{array}{ll}11.2219 & 0.0009\end{array}$

$1483.774<<.0001$

$46.5216<.0001$

Std Error

555.3305836

566.5277785
Mean

20137.8

16484.5

Figure C.13 


\section{OUTSIDE STUDY AREA; BEFORE v3. AFTER CAPACITY ADDITION TOTAL TRIP ATTRACTIONS}

\section{Interaction Model (Test for Parallelism)}

\begin{tabular}{ll} 
Summary of Fit & \\
\hline RSquare & 0.673149 \\
RSquare Adj & 0.671033 \\
Root Mean Square Error & 10889.34 \\
Mean of Response & 15111.2 \\
Observations (or Sum Wgts) & 1089
\end{tabular}

\section{Effect Test}

Source

Before/After

MEDINC

TOTEMP

POPDEN

Before/After"MEDINC

Before/After"TOTEMP

Before/After*POPDEN

$\begin{array}{lll}\text { Nparm } & \text { DF } & \text { Sum of Squares } \\ 1 & 1 & 122960277 \\ 1 & 1 & 213063339 \\ 1 & 1 & 2.32092 e 11 \\ 1 & 1 & \mathbf{4 8 1 2 9 2 8 0 5 5} \\ 1 & 1 & 98406142.8 \\ 1 & 1 & 92390856.5 \\ 1 & 1 & 9181927.16\end{array}$

\section{F Ratio}

Prob $>F$

1.0370

0.3088

1.7968

0.1804

1957.299

$<.0001$

40.5888

$<.0001$

0.8299

0.3625

0.7792

0.3776

0.0774

0.7809

\section{Parallel Model}

\section{Summary of Fit}

Rsquare

RSquare Adj

Root Mean Square Error

Mean of Response

Observations (or Sum Wgts)

$$
\begin{aligned}
& 0.672427 \\
& 0.671218 \\
& 10886.27 \\
& 15111.2 \\
& 1089
\end{aligned}
$$

\section{Effect Test}

Source

Before/After

MEDINC

TOTEMP

POPDEN

$\begin{array}{lll}\text { Nparm } & \text { DF } & \text { Sum of Squares } \\ 1 & 1 & 163665973 \\ 1 & 1 & 141754027 \\ 1 & 1 & 2.38212 \mathrm{el} \\ 1 & 1 & 4963447287\end{array}$

$\begin{array}{ll}\text { F Ratio } & \text { Prob }>\text { F } \\ 1.3810 & 0.2402 \\ 1.1961 & 0.2743 \\ 2010.044 & <.0001 \\ 41.8818 & <.0001\end{array}$

Least Squares Means

\begin{tabular}{llll}
\hline Level & Least Sq Mean & Std Error & Mean \\
After & 15467.58823 & 448.1015810 & 15501.9 \\
Before & 14677.14916 & 495.2243674 & 14635.3
\end{tabular}

Figure C.14 


\title{
BEFORE CAPACITY ADDITION; INSIDE vs. OUTSIDE STUDY AREA TOTAL TRIP ATTRACTIONS
}

\section{Interaction Model (Test for Parallelism)}

\author{
Summary of Fit \\ RSquare \\ 0.751143 \\ RSquare Adj \\ 0.748766 \\ Root Mean Square Error \\ 8534.938 \\ Mean of Response \\ 15259.21 \\ Observations (or Sum Wgts) \\ 741
}

Effect Test

Source

Inside/Outside

MEDINC

TOTEMP

POPDEN

Inside/Outside*MEDINC

Inside/Outside*TOTEMP

Inside/Outside* POPDEN

$\begin{array}{lllll}\text { Nparm } & \text { DF } & \text { Sum of Squares } & \text { F Ratio } & \text { Prob }>\text { F } \\ 1 & 1 & 221409552 & 3.0395 & 0.0817 \\ 1 & 1 & 928920699 & 12.7520 & 0.0004 \\ 1 & 1 & 1.23243 e 11 & 1691.854 & <.0001 \\ 1 & 1 & 4074387902 & 55.9322 & <.0001 \\ 1 & 1 & 198344714 & 2.7228 & 0.0994 \\ 1 & 1 & 648577565 & 8.9035 & 0.0029 \\ 1 & 1 & 100571985 & 1.3806 & 0.2404\end{array}$

There is a significant interaction between the variables Inside/Outside and TOTEMP; thus, we reject the null hypothesis of no interaction and we cannot assume that the parallel model holds. This means that the relationship between the total number of employees in the TAP zone and the total number of trips attracted to that zone is not the same for the two groups, i.e., inside and outside the study area. It says that - because the slopes of the two lines are different - there is a differential effect of total employment on trip attraction inside versus outside the study area.

\section{Figure C.15}




\section{AFTER CAPACITY ADDITION; INSIDE vs. OUTSIDE STUDY AREA TOTAL TRIP ATTRACTIONS}

\section{Interaction Model (Test for Parallelism)}

\begin{tabular}{|ll} 
Summary of Fit & \\
\hline Rsquare & 0.669881 \\
RSquare Adj & 0.667162 \\
Root Mean Square Ertor & 11602.51 \\
Mean of Response & 16906.72 \\
Observations (or Sum Wgts) & $\mathbf{8 5 8}$
\end{tabular}

\section{Effect Test}

Source

Inside/Outside

MEDINC

TOTEMP

POPDEN

Inside/Outside*MEDINC

Inside/Outside"TOTEMP

Inside/Outside* POPDEN

$\begin{array}{lllll}\text { Nparm } & \text { DF } & \text { Sum of Squares } & \text { F Ratio } & \text { Prob>F } \\ 1 & 1 & 64674232.8 & 0.4804 & 0.4884 \\ 1 & 1 & 282559349 & 2.0990 & 0.1478 \\ 1 & 1 & 1.77659 \mathrm{e} 11 & 1319.721 & <.0001 \\ 1 & 1 & 3721354322 & 27.6437 & <.0001 \\ 1 & 1 & 154933288 & 1.1509 & 0.2837 \\ 1 & 1 & 358611299 & 2.6639 & 0.1030 \\ 1 & 1 & 84899574.7 & 0.6307 & 0.4273\end{array}$

\section{Parallel Model}

\section{Summary of Fit}

RSquare

0.668439

0.666884

11607.36

16906.72

Root Mean Square Error

858

Observations (or Sum Wgts)

\section{Efrect Test}

Source

Inside/Outside

MEDINC

TOTEMP

POPDEN

$\begin{array}{lllll}\text { Nparm } & \text { DF } & \text { Sum of Squares } & \text { F Ratio } & \text { Prob }>\text { F } \\ 1 & 1 & 826744735 & 6.1363 & 0.0134 \\ 1 & 1 & 146053487 & 1.0840 & 0.2981 \\ 1 & 1 & 2.08833 \mathrm{ell} & 1549.999 & <.0001 \\ 1 & 1 & 3868679669 & 28.7142 & <.0001\end{array}$

Least Squares Means

\begin{tabular}{llll}
\hline Level & Least Sq Mean & Std Error & Mean \\
Inside & 18399.91851 & 721.3762628 & 20137.8 \\
Outside & 16257.50198 & 475.0957613 & 15501.9
\end{tabular}

Figure C.16 


\title{
INSIDE STUDY AREA; BEFORE vs. AFTER CAPACITY ADDITION HOME-BASED WORK TRIP PRODUCTIONS
}

\author{
Interaction Model (Test for Parallelism)
}

\section{Summary of Fit}

Rsquare

0.982241

RSquare Adj

0.981993

Root Mean Square Error

586.5698

Mean of Response

4757.229

Observations (or Sum Wgts)

510

\section{Efrect Test}

Source

Before/After

MEDINC

HHOLDS

POPDEN

Before/After $*$ MEDINC

Before/After*HHOLDS

Before/After*POPDEN

$\begin{array}{lll}\text { Nparm } & \text { DF } & \text { Sum of Squares } \\ 1 & 1 & 1326810.05 \\ 1 & 1 & 18695573.7 \\ 1 & 1 & 7278073987 \\ 1 & 1 & 11769337.8 \\ 1 & 1 & 6032429.35 \\ 1 & 1 & 498709.388 \\ 1 & 1 & 591414.433\end{array}$

F Ratio

1.7189
Prob $>$ F

0.0501

$<.0001$

0.0000

$<.0001$

$<.0001$

0.2292

0.1904

There is a significant interaction between the variables Before/After and MEDINC; thus, we rejeet the null hypothesis of no interaction and we cannot assume that the parallel model holds. This means that the relationship between the median income in the TAP zone and the number of home-based work trips produced in that zone is not the same for the two groups, i.e., before and after the capacity expansion. It says that - because the slopes of the two lines are different - there is a differential effect of median income on home-based work trip production before versus after the capacity expansion.

\section{Figure C.17}




\title{
OUTSIDE STUDY AREA; BEFORE vs. AFTER CAPACITY ADDITION HOME-BASED WORK TRIP PRODUCTIONS
}

\author{
Interaction Model (Test for Parallelism)
}

\section{Summary of Fit}

Rsquare

RSquare Adj

Root Mean Square Error

Mean of Response

Observations (or Sum Wgts)

\section{Effect Test}

Source

Before/After

MEDNC

HHOLDS

POPDEN

Before/After"MEDINC

Before/After ${ }^{*}$ HHOLDS

Before/After POPDEN

\author{
0.986256 \\ 0.986167 \\ 425.7097 \\ 3261.311 \\ 1089
}

$\begin{array}{lllll}\text { Nparm } & \text { DF } & \text { Sum of Squares } & \text { F Ratio } & \text { Prob }>\text { F } \\ 1 & \text { I } & 1811443.71 & 9.9953 & 0.0016 \\ 1 & 1 & 21940853.2 & 121.0672 & <.0001 \\ 1 & 1 & 1.02176 \mathrm{e} 10 & 56379.68 & 0.0000 \\ 1 & 1 & 14683993.5 & 81.0246 & <.0001 \\ 1 & 1 & 7708746.01 & 42.5360 & <.0001 \\ 1 & 1 & 5847219.48 & 32.2643 & <.0001 \\ 1 & 1 & 1694814.66 & 9.3518 & 0.0023\end{array}$

There is a significant interaction between the variables Before/After and MEDINC, HHOLDS, andPOPDEN; thus, we reject the null hypothesis of no interaction and we cannot assume that the parallel model holds. This means that the relationships between the median income, the number of households, and the population density in the TAP zone and the number of home-based work trips produced in that zone are not the same for the two groups, i.e., before and after the capacity expansion. It says that - because the slopes of the two lines are different - there is a differential effect of median income as well as of the number of households and the population density on homebased work trip production before versus after the capacity expansion.

Figure C.18 


\section{BEFORE CAPACITY ADDITION; INSIDE vs. OUTSIDE STUDY AREA HOME-BASED WORK TRIP PRODUCTIONS}

\section{Interaction Model (Test for Parallelism)}

\section{Summary of Fit \\ RSquare \\ RSquare Adj \\ Root Mean Square Error \\ Mean of Response \\ Observations (or Sum Wgts) \\ Effect Test \\ Source \\ Inside/Outside \\ MEDINC \\ HHOLDS \\ POPDEN \\ Inside/Outside* MEDINC \\ Inside/Outside*HHOLDS \\ Inside/Outside*POPDEN}

0.982193

0.982023

500.9908

3629.843

741

$\begin{array}{lll}\text { Nparm } & \text { DF } & \text { Sum of Squares } \\ 1 & 1 & 13614.5761 \\ 1 & 1 & 36815696.2 \\ 1 & 1 & 7331390653 \\ 1 & 1 & 18593944.9 \\ 1 & 1 & 1000835.94 \\ 1 & 1 & 1144740.64 \\ 1 & 1 & 229320.819\end{array}$

\section{Summary of Fit}

Rsquare

RSquare Adj

Root Mean Square Error

Mean of Response

Observations (or Sum Wgts)

\section{Efreet Test}

Source

Inside/Outside

MEDNC

HHOLDS

POPDEN

\section{Least Squares Means}

\begin{tabular}{ll}
\hline Level & Least Sq Mean \\
Inside & 3635.238061 \\
Outside & 3627.096710
\end{tabular}

$\begin{array}{lll}\text { Nparm } & \text { DF } & \text { Sum of Squares } \\ 1 & 1 & 10544.4026 \\ 1 & 1 & 39077429.5 \\ 1 & 1 & 7540177416 \\ 1 & 1 & 19631640.3\end{array}$

Parallel Model

0.981886

0.981787

504.2638

3629.843

741

$\begin{array}{ll}\text { F Ratio } & \text { Prob>F } \\ 0.0542 & 0.8159 \\ 146.6809 & <.0001 \\ 29209.68 & 0.0000 \\ 74.0819 & <.0001 \\ 3.9875 & 0.0462 \\ 4.5609 & 0.0330 \\ 0.9137 & 0.3395\end{array}$

F Ratio

Prob $>F$

$\begin{array}{ll}0.0415 & 0.8387\end{array}$

$153.6776<<.0001$

$29652.82 \quad 0.0000$

$77.2042<.0001$

Figure C.19 


\section{AFTER CAPACITY ADDITION; INSIDE vs. OUTSIDE STUDY AREA HOME-BASED WORK TRIP PRODUCTIONS}

\section{Interaction Model (Test for Parallelism)}

\begin{tabular}{ll} 
Summary of Fit & \\
\hline Rsquare & 0.987185 \\
RSquare Adj & 0.98708 \\
Root Mean Square Error & 466.087 \\
Mean of Response & 3832.216 \\
Observations (or Sum Wgts) & 858
\end{tabular}

\begin{tabular}{llllll} 
Effect Test & & & & & \\
\hline Source & Nparm & DF & Sum of Squares & F Ratio & Prob>F \\
Inside/Outside & 1 & 1 & 51971.1241 & 0.2392 & 0.6249 \\
MEDINC & 1 & 1 & 4796429.51 & 22.0792 & $<.0001$ \\
HHOLDS & 1 & 1 & $1.02914 e 10$ & 47374.08 & 0.0000 \\
POPDEN & 1 & 1 & 7061485.02 & 32.5059 & $<.0001$ \\
Inside/Outside*MEDINC & 1 & 1 & 193567.272 & 0.8910 & 0.3455 \\
Inside/Outside*HHOLDS & 1 & 1 & 102268.162 & 0.4708 & 0.4928 \\
Inside/Outside* POPDEN & 1 & 1 & 383076.236 & 1.7634 & 0.1846
\end{tabular}

\section{Parallel Model}

\section{Summary of Fit}

\begin{tabular}{ll}
\hline Rsquare & 0.987142 \\
RSquare Adj & 0.987082 \\
Root Mean Square Error & 466.0406 \\
Mean of Response & 3832.216 \\
Observations (or Sum Wgts) & 858
\end{tabular}

Efreet Test

Source

Inside/Outside

MEDINC

HHOLDS

POPDEN

$\begin{array}{lll}\text { Nparm } & \text { DF } & \text { Sum of Squares } \\ 1 & 1 & 1075357.29 \\ 1 & 1 & 5169709.97 \\ 1 & 1 & 1.07386 \mathrm{e} 10 \\ 1 & 1 & 7384286.79\end{array}$

$\begin{array}{ll}\text { F Ratio } & \text { Prob }>\text { F } \\ 4.9511 & 0.0263 \\ 23.8023 & <.0001 \\ 49442.27 & 0.0000 \\ 33.9986 & <.0001\end{array}$

Least Squares Means

\begin{tabular}{llll}
\hline Level & Least Sq Mean & Std Error & Mean \\
Inside & 3887.171178 & 29.37895463 & 5097.73 \\
Outside & 3808.321896 & 19.19501007 & 3281.99
\end{tabular}

Figure C.20 


\title{
INSIDE STUDY AREA; BEFORE vs. AFTER CAPACITY ADDITION HOME-BASED NONWORK TRIP PRODUCTIONS
}

\author{
Interaction Model (Test for Parallelism)
}

\section{Summary of Fit}

RSquare

RSquare Adj

Root Mean Square Error

Mean of Response

Observations (or Sum Wgts)

\section{Efrect Test}

Source

Before/After

MEDINC

HHOLDS

POPDEN

Before/After*MEDINC

Before/After"HHOLDS

Before/After"POPDEN
0.959453

0.958887

1628.89

8730.655

510

$\begin{array}{lll}\text { Nparm } & \text { DF } & \text { Sum of Squares } \\ 1 & 1 & 271259.678 \\ 1 & 1 & 55873309.6 \\ 1 & 1 & 2.38913 \mathrm{e} 10 \\ 1 & 1 & 71500404.1 \\ 1 & 1 & 4227331.41 \\ 1 & 1 & 10962197.6 \\ 1 & 1 & 422382.711\end{array}$

\section{Summary of Fit}

Rsquare

RSquare Adj

Root Mean Square Error

Mean of Response

Observations (or Sum Wgts)

\section{Efrect Test}

Source

Before/After

MEDINC

HHOLDS

POPDEN

\section{Least Squares Means}

\begin{tabular}{llll}
\hline Level & Least Sq Mean & Std Error & Mean \\
After & $\mathbf{8 8 0 9 . 8 5 0 5 9 9}$ & 102.1347093 & 9597.51 \\
Before & $\mathbf{8 6 4 8 . 2 9 1 3 7 7}$ & 104.1849632 & $\mathbf{7 8 2 9 . 1 3}$
\end{tabular}

Parallel Model

\subsection{7 \\ 0.958531 \\ 1635.93 \\ 8730.655 \\ 510}

$\begin{array}{ll}\text { F Ratio } & \text { Prob>F } \\ 0.1022 & 0.7493 \\ 21.0582 & <.0001 \\ 9004.425 & 0.0000 \\ 26.9479 & <.0001 \\ 1.5932 & 0.2074 \\ 4.1316 & 0.0426 \\ 0.1592 & 0.6901\end{array}$

$\begin{array}{lllll}\text { Nparm } & \text { DF } & \text { Sum of Squares } & \text { F Ratio } & \text { Prob }>\text { F } \\ 1 & 1 & 3237981.45 & 1.2099 & 0.2719 \\ 1 & 1 & 52736595.5 & 19.7053 & <.0001 \\ 1 & 1 & 2.4903410 & 9305.295 & 0.0000 \\ 1 & 1 & 75009190.7 & 28.0276 & <.0001\end{array}$

Figure C.21 


\section{OUTSIDE STUDY AREA; BEFORE vS. AFTER CAPACITY ADDITION HOME-BASED NONWORK TRIP PRODUCTIONS}

\section{Interaction Model (Test for Parallelism)}

\section{Summary of Fit}

RSquare

RSquare Adj

Root Mean Square Error

Mean of Response

Observations (or Sum Wgts)

Erfect Test

Source

Before/After

MEDINC

HHOLDS

POPDEN

Before/After MEDNC

Before/After"HHOLDS

Before/After*POPDEN
0.967205

0.966993

1195.874

5927.555

1089

$\begin{array}{lll}\text { Nparm } & \text { DF } & \text { Sum of Squares } \\ \text { I } & 1 & 1168369.1 \\ \text { I } & 1 & 77215358.4 \\ 1 & 1 & 3.30252 \mathrm{e} 10 \\ 1 & 1 & 76727638.1 \\ 1 & 1 & 10024154.5 \\ 1 & 1 & 1577936.26 \\ 1 & 1 & 2492771.32\end{array}$

F Ratio

0.8170

53.9924

23092.67

53.6514

7.0093

1.1034

1.7431
Prob $>$ F

0.3663

$<.0001$

0.0000

$<.0001$

0.0082

0.2938

0.1870

There is a significant interaction between the variables Before/After and MEDINC; thus, we reject the null hypothesis of no interaction and we cannot assume that the parallel model holds. This means that the relationship between the median income in the TAP zone and the number of home-based nonwork trips produced in that zone is not the same for the two groups, i.e., before and after the capacity expansion. It says that - because the slopes of the two lines are different - there is a differential effect of median income on home-based nonwork trip production before versus after the capacity expansion.

Figure C.22 


\section{BEFORE CAPACITY ADDITION; INSIDE vs. OUTSIDE STUDY AREA HOME-BASED NONWORK TRIP PRODUCTIONS}

\section{Interaction Model (Test for Parallelism)}

\section{Summary of Fit}

RSquare

0.965447

0.965117

Root Mean Square Error

1225.707

Mean of Response

6409.665

Observations (or Sum Wgts)

741

\section{Effect Test}

Source

Inside/Outside

MEDINC

HHOLDS

POPDEN

Inside/Outside*MEDINC

Inside/Outside *HHOLDS

Inside/Outside*POPDEN

$\begin{array}{lll}\text { Nparm } & \text { DF } & \text { Sum of Squares } \\ 1 & 1 & \mathbf{8 3 3 4 7 8 . 4 4 2} \\ 1 & 1 & 81491057.3 \\ 1 & 1 & 2.24773 \mathrm{e} 10 \\ 1 & 1 & 81964097.5 \\ 1 & 1 & 825575.853 \\ 1 & 1 & 1542240.73 \\ 1 & 1 & 1780268.78\end{array}$

F Ratio

Prob $>F$

0.5548

0.4566

$54.2421<.0001$

$14961.34 \quad 0.0000$

$54.5569<.0001$

$\begin{array}{ll}0.5495 & 0.4588\end{array}$

1.0265

0.3113

1.1850

0.2767

\section{Parallel Model}

\section{Summary of Fit}

Rsquare

0.965228

0.965039

RSquare Adj

1227.08

Root Mean Square Error

6409.665

Observations (or Sum Wgts)

741

\section{Effect Test}

Source

Inside/Outside

MEDINC

HHOLDS

POPDEN

$\begin{array}{lll}\text { Nparm } & \text { DF } & \text { Sum of Squares } \\ 1 & 1 & 1805316.96 \\ 1 & 1 & 92016114.1 \\ 1 & 1 & 2.30757 \mathrm{e} 10 \\ 1 & 1 & 83922151.7\end{array}$

$\begin{array}{ll}\text { F Ratio } & \text { Prob }>\text { F } \\ 1.1990 & 0.2739 \\ 61.1108 & <.0001 \\ 15325.29 & 0.0000 \\ 55.7354 & <.0001\end{array}$

Least Squares Means

\begin{tabular}{llll}
\hline Level & Least Sq Mean & Std Error & Mean \\
Inside & 6480.252447 & 78.66199030 & 7829.13 \\
Outside & 6373.724823 & 55.76178113 & 5686.92
\end{tabular}

Figure C.23 


\section{AFTER CAPACITY ADDITION; INSIDE vs. OUTSIDE STUDY AREA HOME-BASED NONWORK TRIP PRODUCTIONS}

\section{Interaction Model (Test for Parallelism)}

\section{Summary of Fit}

Rsquare

RSquare Adj

Root Mean Square Error

Mean of Response

Observations (or Sum Wgts)

Efrect Test

Source

Inside/Outside

MEDINC

HHOLDS

POPDEN

Inside/Outside MEDINC

Inside/Outside" POPDEN

Inside/Outside*HHOLDS
0.964897

0.964608

1445.754

7177.365

858

$\begin{array}{lll}\text { Nparm } & \text { DF } & \text { Sum of Squares } \\ 1 & 1 & 624394.464 \\ 1 & 1 & 40879256.7 \\ 1 & 1 & 3.56179 \mathrm{e} 10 \\ 1 & 1 & 59241107.5 \\ 1 & 1 & 1529534.36 \\ 1 & 1 & 3654689.55 \\ 1 & 1 & 1381439.37\end{array}$

\section{Parallel Model}

\section{Summary of Fit}

Rsquare

RSquare Adj

Root Mean Square Error

Mean of Response

Observations (or Sum Wgts)

Efrect Test

Source

Inside/Outside

MEDINC

HHOLDS

POPDEN

Least Squares Means

\begin{tabular}{ll}
\hline Level & Least Sq Mean \\
Inside & 7356.789077 \\
Outside & 7099.354247
\end{tabular}

0.964785

0.96462

1445.517

7177.365

858

$\begin{array}{lll}\text { Nparm } & \text { DF } & \text { Sum of Squares } \\ 1 & 1 & 11462831.7 \\ 1 & 1 & 44542154 \\ 1 & 1 & 3.71317 \mathrm{e} 10 \\ 1 & 1 & 61384523.4\end{array}$

F Ratio

Prob $>F$

$5.4859 \quad 0.0194$

$21.3169<.0001$

$17770.44 \quad 0.0000$

$29.3773<<.0001$
Prob $>F$

0.5848

$<.0001$

0.0000

$<.0001$

0.3926

0.1864

0.4165

\section{Figure C.24}




\section{INSIDE STUDY AREA; BEFORE vs. AFTER CAPACITY ADDITION NONHOME-BASED TRIP PRODUCTIONS}

\section{Interaction Model (Test for Parallelism)}

\section{Summary of Fit}

\begin{tabular}{ll}
\hline RSquare & 0.186192 \\
RSquare Adj & 0.174844 \\
Root Mean Square Error & 4156.33 \\
Mean of Response & 4457.859 \\
Observations (or Sum Wgts) & 510
\end{tabular}

\section{Effect Test}

Source

Before/After

MEDINC

HHOLDS

POPDEN

Before/After*MEDINC

Before/After*HHOLDS

Before/After*POPDEN

$\begin{array}{lll}\text { Nparm } & \text { DF } & \text { Sum of Squares } \\ 1 & 1 & 13905617.6 \\ 1 & 1 & 688220274 \\ 1 & 1 & 1205654164 \\ 1 & 1 & 21674710.7 \\ 1 & 1 & 10028469.3 \\ 1 & 1 & 12952142.2 \\ 1 & 1 & 25331.7938\end{array}$

F Ratio

Prob $>\mathbf{F}$

$0.8050 \quad 0.3700$

$39.8389<.0001$

$69.7915<.0001$

$\begin{array}{ll}1.2547 & 0.2632\end{array}$

$0.5805 \quad 0.4465$

$0.7498 \quad 0.3870$

$\begin{array}{ll}0.0015 & 0.9695\end{array}$

\section{Parallel Model}

\section{Summary of Fit}

Rsquare

0.184037

RSquare Adj

Root Mean Square Error

0.177574

4149.45

4457.859

Mean of Response

510

\section{Efreet Test}

Source

Before/After

MEDINC

HHOLDS

POPDEN

$\begin{array}{lll}\text { Nparm } & \text { DF } & \text { Sum of Squares } \\ 1 & 1 & 142468178 \\ 1 & 1 & 702422162 \\ 1 & 1 & 1203693829 \\ 1 & 1 & 20070829.3\end{array}$

F Ratio

Prob $>F$

$8.2744 \quad 0.0042$

$40.7960<.0001$

$69.9093<.0001$

$\begin{array}{ll}1.1657 & 0.2808\end{array}$

\section{Least Squares Means}

\begin{tabular}{llll}
\hline Level & Least Sq Mean & Std Error & Mean \\
After & 4983.178108 & 259.0593367 & 4970.78 \\
Before & 3911.526768 & 264.2596983 & 3924.42
\end{tabular}

Figure C.25 


\title{
OUTSIDE STUDY AREA; BEFORE vs. AFTER CAPACITY ADDITION NONHOME-BASED TRIP PRODUCTIONS
}

\author{
Interaction Model (Test for Parallelism)
}

\begin{tabular}{ll} 
Summary of Fit & \\
\hline RSquare & 0.17362 \\
RSquare Adj & 0.168269 \\
Root Mean Square Error & 3958.093 \\
Mean of Response & 3565.364 \\
Observations (or Sum Wgts) & 1089
\end{tabular}

\section{Efrect Test}

Source

Before/After

MEDINC

HHOLDS

POPDEN

Before/After"MEDINC

Before/After* HHOLDS

Before/After*POPDEN

$\begin{array}{lll}\text { Nparm } & \text { DF } & \text { Sum of Squares } \\ 1 & 1 & 844905.81 \\ 1 & 1 & 775511606 \\ 1 & 1 & 2115268741 \\ 1 & 1 & 1413494.33 \\ 1 & 1 & 17205995 \\ 1 & 1 & 17604597.7 \\ 1 & 1 & 25601117.5\end{array}$

$\begin{array}{ll}\text { F Ratio } & \text { Prob }>\text { F } \\ 0.0539 & 0.8164 \\ 49.5013 & <.0001 \\ 135.0186 & <.0001 \\ 0.0902 & 0.7640 \\ 1.0983 & 0.2949 \\ 1.1237 & 0.2894 \\ 1.6341 & 0.2014\end{array}$

\section{Parallel Model}

\section{Summary of Fit}

Rsquare

RSquare Adj

Root Mean Square Error

Mean of Response

Observations (or Sum Wgts)

0.171236

0.168178

3958.311

3565.364

1089

\section{Efrect Test}

Source

Before/After

MEDINC

HHOLDS

POPDEN

$\begin{array}{lll}\text { Nparm } & \text { DF } & \text { Sum of Squares } \\ 1 & 1 & 58917322.7 \\ 1 & 1 & 785806611 \\ 1 & 1 & 2137066494 \\ 1 & 1 & 3079262.37\end{array}$

$\begin{array}{ll}\text { F Ratio } & \text { Prob }>\text { F } \\ 3.7603 & 0.0527 \\ 50.1529 & <.0001 \\ 136.3949 & <.0001 \\ 0.1965 & 0.6576\end{array}$

\section{Least Squares Means}

\begin{tabular}{llll}
\hline Level & Least Sq Mean & Std Error & Mean \\
After & 3779.184949 & 162.9299909 & 3702.08 \\
Before & 3304.945826 & 180.0633204 & 3398.85
\end{tabular}

Figure C.26 


\section{BEFORE CAPACITY ADDITION; INSIDE vs. OUTSIDE STUDY AREA NONHOME-BASED TRIP PRODUCTIONS}

\section{Interaction Model (Test for Parallelism)}

\section{Summary of Fit}

RSquare

RSquare Adj

Root Mean Square Error

Mean of Response

Observations (or Sum Wgts)

\section{Effect Test}

Source

Inside/Outside

MEDINC

HHOLDS

POPDEN

Inside/Outside*MEDINC

Inside/Outside* HHOLDS

Inside/Outside* POPDEN
0.205363

0.197774

3649.476

3576.167

741

$\begin{array}{lll}\text { Nparm } & \text { DF } & \text { Sum of Squares } \\ 1 & 1 & 23829389.3 \\ 1 & 1 & 685954163 \\ 1 & 1 & 1588310277 \\ 1 & 1 & 17567922.4 \\ 1 & 1 & 19884577.7 \\ 1 & 1 & 4771970.3 \\ 1 & 1 & 1693171.34\end{array}$

Parallel Model

\section{Summary of Fit}

RSquare

0.202438

0.198103

3648.727

3576.167

741

Observations (or Sum Wgts)

Efrect Test

Source

Inside/Outside

MEDINC

HHOLDS

POPDEN

Least Squares Means

$\begin{array}{ll}\text { Level } & \text { Least Sq Mean } \\ \text { Inside } & 3516.352081 \\ \text { Outside } & 3606.623177\end{array}$

$\begin{array}{lll}\text { Nparm } & \text { DF } & \text { Sum of Squares } \\ 1 & 1 & 1296362.36 \\ 1 & 1 & 699628339 \\ 1 & 1 & 1624715212 \\ 1 & 1 & 11119618.4\end{array}$

Std Error

Mean

233.9017357

3924.42

165.8078742
F Ratio

Prob $>$ F

1.7892

51.5032

0.1814

1.3190

0.2511

1.4930

0.2221

0.3583

0.5496

0.1271

0.7215

\section{Figure C.27}




\section{AFTER CAPACITY ADDITION; INSIDE vs. OUTSIDE STUDY AREA NONHOME-BASED TRIP PRODUCTIONS}

\section{Interaction Model (Test for Parallelism)}

\begin{tabular}{ll} 
Summary of Fit & \\
\hline Rsquare & 0.167687 \\
RSquare Adj & 0.160832 \\
Root Mean Square Error & 4317.542 \\
Mean of Response & 4086.537 \\
Observations (or Sum Wgts) & 858
\end{tabular}

\begin{tabular}{llllll} 
Effect Test & & & & & \\
\hline Source & Nparm & DF & Sum of Squares & F Ratio & Prob $>$ F \\
Inside/Outside & 1 & 1 & 117072000 & 6.2803 & 0.0124 \\
MEDINC & 1 & 1 & 735080068 & 39.4332 & $<.0001$ \\
HHOLDS & 1 & 1 & 1611061746 & 86.4249 & $<.0001$ \\
POPDEN & 1 & 1 & 62639.6931 & 0.0034 & 0.9538 \\
Inside/Outside*MEDINC & 1 & 1 & 28831342.7 & 1.5466 & 0.2140 \\
Inside/Outside*HHOLDS & 1 & 1 & 7297875.5 & 0.3915 & 0.5317 \\
Inside/Outside*POPDEN & 1 & 1 & 27926669.5 & 1.4981 & 0.2213
\end{tabular}

\section{Parallel Model}

\section{Summary of Fit}

\begin{tabular}{ll}
\hline Rsquare & 0.162701 \\
RSquare Adj & 0.158775 \\
Root Mean Square Error & 4322.832 \\
Mean of Response & 4086.537 \\
Observations (or Sum Wgts) & 858
\end{tabular}

\section{Effect Test}

Source

Inside/Outside

MEDINC

HHOLDS

POPDEN

$\begin{array}{lll}\text { Nparm } & \text { DF } & \text { Sum of Squares } \\ 1 & 1 & 42536015.1 \\ 1 & 1 & 748221155 \\ 1 & 1 & 1660327918 \\ 1 & 1 & 11099228.6\end{array}$

$\begin{array}{ll}\text { F Ratio } & \text { Prob }>\text { F } \\ 2.2763 & 0.1317 \\ 40.0399 & <.0001 \\ 88.8499 & <.0001 \\ 0.5940 & 0.4411\end{array}$

\section{Least Squares Means}

\begin{tabular}{llll}
\hline Level & Least Sq Mean & Std Error & Mean \\
Inside & 4432.169057 & 272.5090998 & 4970.78 \\
Outside & 3936.262617 & 178.0463254 & 3702.08
\end{tabular}

Figure C.28 


\section{INSIDE STUDY AREA; BEFORE vs. AFTER CAPACITY ADDITION OTHER TRIP PRODUCTIONS}

\section{Interaction Model (Test for Parallelism)}

\section{Summary of Fit}

Rsquare

0.42879

RSquare Adj

0.420825

Root Mean Square Error

1364.183

Mean of Response

2311.655

Observations (or Sum Wgts)

510

Efrect Test

Source

Before/After

MEDINC

HHOLDS

POPDEN

Before/After MEDINC

Before/After"HHOLDS

Before/After" POPDEN

$\begin{array}{lll}\text { Nparm } & \text { DF } & \text { Sum of Squares } \\ 1 & 1 & 125543 \\ 1 & 1 & 77789965 \\ 1 & 1 & 622992693 \\ 1 & 1 & 52599120 \\ 1 & 1 & 3841556 \\ 1 & 1 & 2870566 \\ 1 & 1 & 27928\end{array}$

F Ratio

Prob $>F$

$0.0675 \quad 0.7952$

$41.8002<.0001$

$334.7632<<.0001$

$28.2640<.0001$

$2.0642 \quad 0.1514$

$1.5425 \quad 0.2148$

$\begin{array}{ll}0.0150 & 0.9025\end{array}$

\section{Parallel Model}

\section{Summary of Fit}

Rsquare

0.424907

0.420352

1364.739

RSquare Adj

Root Mean Square Error

2311.655

Mean of Response

510

Observations (or Sum Wgts)

Efrect Test

Source

Before/After

MEDINC

HHOLDS

POPDEN

$\begin{array}{lll}\text { Nparm } & \text { DF } & \text { Sum of Squares } \\ 1 & 1 & 9865875 \\ 1 & 1 & 75009991 \\ 1 & 1 & 630200488 \\ 1 & 1 & 51776111\end{array}$

$\begin{array}{ll}\text { F Ratio } & \text { Prob }>\text { F } \\ 5.2971 & 0.0218 \\ 40.2735 & <.0001 \\ 338.3602 & <.0001 \\ 27.7991 & <.0001\end{array}$

Least Squares Means

\begin{tabular}{llll}
\hline Level & Least Sq Mean & Std Error & Mean \\
After & 2449.894423 & 85.20369235 & 2500.94 \\
Before & 2167.885800 & $\mathbf{8 6 . 9 1 4 0 7 2 7 3}$ & 2114.80
\end{tabular}

Figure C.29 


\section{OUTSIDE STUDY AREA; BEFORE vs. AFTER CAPACITY ADDITION OTHER TRIP PRODUCTIONS}

\section{Interaction Model (Test for Parallelism)}

\section{Summary of Fit}

RSquare

0.377491

RSquare Adj

0.37346

1328.819

1754.773

Mean of Response

1089

Observations (or Sum Wgts)

\section{Effect Test}

Source

Before/After

MEDINC

HHOLDS

POPDEN

Before/After"MEDINC

Before/After"HHOLDS

Before/After *POPDEN

$\begin{array}{lll}\text { Nparm } & \text { DF } & \text { Sum of Squares } \\ 1 & 1 & 985610 \\ 1 & 1 & 115232715 \\ 1 & 1 & 882678439 \\ 1 & 1 & 14148560 \\ 1 & 1 & 3635067 \\ 1 & 1 & 1460031 \\ 1 & 1 & 1705147\end{array}$

F Ratio

Prob $>F$

\section{Parallel Model}

\section{Summary of Fit}

Rsquare

0.375535

RSquare Adj

0.37323

1329.063

1754.773

Mean of Response

1089

Observations (or Sum Wgts)

\section{Effect Test}

Source

Before/After

MEDINC

HHOLDS

POPDEN

$\begin{array}{lll}\text { Nparm } & \text { DF } & \text { Sum of Squares } \\ 1 & 1 & 3070980 \\ 1 & 1 & 114451040 \\ 1 & 1 & 911753486 \\ 1 & 1 & 13478677\end{array}$

F Ratio

Prob $>F$

$1.7385 \quad 0.1876$

$64.7931<<.0001$

$516.1626<.0001$

7.6306

0.0058

\section{Least Squares Means}

\begin{tabular}{llll}
\hline Level & Least Sq Mean & Std Error & Mean \\
After & 1803.589840 & 54.70620871 & 1791.55 \\
Before & 1695.318281 & 60.45898324 & 1709.99
\end{tabular}

Figure C.30 


\section{BEFORE CAPACITY ADDITION; INSIDE vs. OUTSIDE STUDY AREA OTHER TRIP PRODUCTIONS}

\section{Interaction Model (Test for Parallelism)}

\section{Summary of Fit}

Rsquare

0.418861

RSquare Adj

0.413311

Root Mean Square Error

1263.737

Mean of Response

1846.563

Observations (or Surn Wgts)

741

\section{Efrect Test}

Source

Inside/Outside

MEDINC

HHOLDS

POPDEN

Inside/Outside*MEDINC

Inside/Outside *HHOLDS

Inside/Outside* POPDEN

$\begin{array}{lll}\text { Nparm } & \text { DF } & \text { Sum of Squares } \\ 1 & 1 & 4717989 \\ 1 & 1 & 98245087 \\ 1 & 1 & 678549362 \\ 1 & 1 & 37501781 \\ 1 & 1 & 1758305 \\ 1 & 1 & 22924 \\ 1 & 1 & 5477308\end{array}$

F Ratio

Prob $>F$

2.95420 .0861

$61.5173<.0001$

$424.8816<.0001$

$23.4822<.0001$

$1.1010 \quad 0.2944$

$\begin{array}{ll}0.0144 & 0.9047\end{array}$

$3.4297 \quad 0.0644$

\section{Parallel Model}

\section{Summary of Fit}

RSquare

RSquare Adj

Root Mean Square Error

Mean of Response

Observations (or Sum Wgts)

0.414424

0.411241

1265.964

1846.563

741

\section{Effeet Test}

Source

Inside/Outside

MEDINC

HHOLDS

POPDEN

$\begin{array}{lll}\text { Nparm } & \text { DF } & \text { Sum of Squares } \\ 1 & 1 & 20009 \\ 1 & 1 & 100613179 \\ 1 & 1 & 683929920 \\ 1 & 1 & 30008093\end{array}$

$\begin{array}{ll}\text { F Ratio } & \text { Prob }>\text { F } \\ 0.0125 & 0.9111 \\ 62.7786 & <.0001 \\ 426.7451 & <.0001 \\ 18.7239 & <.0001\end{array}$

\section{Least Squares Means}

\begin{tabular}{llll}
\hline Level & Least Sq Mean & Std Error & Mean \\
Inside & 1853.993910 & 81.15468795 & 2114.80 \\
Outside & 1842.779068 & 57.52880049 & 1709.99
\end{tabular}

\section{Figure C.31}




\title{
AFTER CAPACITY ADDITION; INSIDE vs. OUTSIDE STUDY AREA OTHER TRIP PRODUCTIONS
}

\author{
Interaction Model (Test for Parallelism)
}

Summary of Fit

\begin{tabular}{ll}
\hline Rsquare & 0.399497 \\
RSquare Adj & 0.394552 \\
Root Mean Square Error & 1402.679 \\
Mean of Response & 2006.514 \\
Observations (or Sum Wgts) & $\mathbf{8 5 8}$
\end{tabular}

\section{Efrect Test}

\section{Source}

Inside/Outside

MEDINC

HHOLDS

POPDEN

Inside/Outside* MEDINC

Inside/Outside*HHOLDS

Inside/Outside* POPDEN

$\begin{array}{lllll}\text { Nparm } & \text { DF } & \text { Sum of Squares } & \text { F Ratio } & \text { Prob }>\text { F } \\ 1 & 1 & 13321282 & 6.7706 & 0.0094 \\ 1 & 1 & 78843060 & 40.0726 & <.0001 \\ 1 & 1 & 817891044 & 415.6990 & <.0001 \\ 1 & 1 & 28623056 & 14.5479 & 0.0001 \\ 1 & 1 & 608882 & 0.3095 & 0.5782 \\ 1 & 1 & 377223 & 0.1917 & 0.6616 \\ 1 & 1 & 11367953 & 5.7778 & 0.0164\end{array}$

There is a significant interaction between the variables Inside/Outside and POPDEN; thus, we rejeet the null hypothesis of no interaction and we cannot assume that the parallel model holds. This means that the relationship between the population density in the TAP zone and the number of "other" trips produced in that zone is not the same for the two groups, i.e., inside and outside the study area. It says that - because the slopes of the two lines are different - there is a differential effeet of population density on "other" trip production inside versus outside the study area.

\section{Figure C.32}




\title{
INSIDE STUDY AREA; BEFORE vs. AFTER CAPACITY ADDITION HOME-BASED WORK TRIP ATTRACTIONS
}

\author{
Interaction Model (Test for Parallelism)
}

\section{Summary of Fit}

Rsquare

RSquare Adj

Root Mean Square Error

Mean of Response

Observations (or Sum Wgts)

\section{Effect Test}

Source

Before/After

MEDINC

TOTEMP

POPDEN

Before/After"MEDINC

Before/After TOTEMP

Before/After *POPDEN
0.995711

0.995651

300.1516

4023.882

510

$\begin{array}{lll}\text { Nparm } & \text { DF } & \text { Sum of Squares } \\ 1 & 1 & 23453.7632 \\ 1 & 1 & 89839.1189 \\ 1 & 1 & 9072763073 \\ 1 & 1 & 18459.4965 \\ 1 & 1 & 1427.85296 \\ 1 & 1 & 41276.0866 \\ 1 & 1 & 33007.3399\end{array}$

\section{Parallel Model}

\section{Summary of Fit}

Rsquare

RSquare Adj

Root Mean Square Error

Mean of Response

Observations (or Sum Wgts)

\section{Efreet Test}

Source

Before/After

MEDINC

TOTEMP

POPDEN

\section{Least Squares Means}

\begin{tabular}{ll}
\hline Level & Least Sq Mean \\
After & 4040.318268 \\
Before & 4006.789001
\end{tabular}

0.995702

0.995668

299.5561

4023.882

510

$\begin{array}{lll}\text { Nparm } & \text { DF } & \text { Sum of Squares } \\ 1 & 1 & 138225.752 \\ 1 & 1 & 102219.987 \\ 1 & 1 & 9439357754 \\ 1 & 1 & 20106.8085\end{array}$

F Ratio

Prob $>F$

1.5404

0.2151

1.1391

$\begin{array}{ll}105192.8 & 0.0000\end{array}$

0.2241

0.6362

\section{Figure C.33}




\section{OUTSIDE STUDY AREA; BEFORE vs. AFTER CAPACITY ADDITION HOME-BASED WORK TRIP ATTRACTIONS}

\section{Interaction Model (Test for Parallelism)}

\section{Summary of Fit}

RSquare Adj

Root Mean Square Error

Mean of Response

Observations (or Sum Wgts)

\section{Efrect Test}

Source

Before/After

MEDINC

TOTEMP

POPDEN

Before/After*MEDINC

Before/After ${ }^{*}$ TOTEMP

Before/After $*$ POPDEN
Rsquare

0.989427

0.989359

522.4017

3604.723

1089

$\begin{array}{lll}\text { Nparm } & \text { DF } & \text { Sum of Squares } \\ \text { I } & 1 & 2696.98752 \\ \text { I } & 1 & 6014233.49 \\ \text { I } & 1 & 2.46733 \mathrm{e} 10 \\ \text { I } & 1 & 445135.089 \\ 1 & 1 & 31729.9873 \\ 1 & 1 & 7753.57637 \\ 1 & 1 & 125039.691\end{array}$

\section{Parallel Model}

\section{Summary of Fit}

RSquare

RSquare Adj

Root Mean Square Error

Mean of Response

Observations (or Sum Wgts)

Effect Test

Source

Before/After

MEDINC

TOTEMP

POPDEN

\section{Least Squares Means}

\begin{tabular}{ll}
\hline Level & Least Sq Mean \\
After & 3607.538488 \\
Before & 3601.293246
\end{tabular}

0.989421

0.989382

521.8246

3604.723

1089

$\begin{array}{lll}\text { Nparm } & \text { DF } & \text { Sum of Squares } \\ \text { I } & \text { I } & 10216.9229 \\ \text { I } & 1 & 6419223.26 \\ \text { I } & 1 & 2.52589 \mathrm{el} 0 \\ \text { I } & 1 & 517790.095\end{array}$

Std Error
Prob>F

0.9208

$<.0001$

0.0000

0.2018

0.7332

0.8662

0.4986

\section{Figure C.34}




\title{
BEFORE CAPACITY ADDITION; INSIDE vs. OUTSIDE STUDY AREA HOME-BASED WORK TRIP ATTRACTIONS
}

\author{
Interaction Model (Test for Parallelism)
}

\begin{tabular}{ll} 
Summary of Fit & \\
\hline Rsquare & 0.989892 \\
RSquare Adj & 0.989796 \\
Root Mean Square Error & 478.3337 \\
Mean of Response & 3629.845 \\
Observations (or Sum Wgts) & 741
\end{tabular}

\section{Effect Test}

Source Inside/Outside MEDINC

TOTEMP POPDEN

Inside/Outside*MEDINC Inside/Outside*TOTEMP Inside/Outside* POPDEN

$\begin{array}{lllll}\text { Nparm } & \text { DF } & \text { Sum of Squares } & \text { F Ratio } & \text { Prob>F } \\ 1 & 1 & 229433.072 & 1.0028 & 0.3170 \\ 1 & 1 & 1029844.22 & 4.5010 & 0.0342 \\ 1 & 1 & 1.14407 e 10 & 50002.19 & 0.0000 \\ 1 & 1 & 8072.92895 & 0.0353 & 0.8511 \\ 1 & 1 & 553925.636 & 2.4210 & 0.1202 \\ 1 & 1 & 2017084.87 & 8.8158 & 0.0031 \\ 1 & 1 & 20494.477 & 0.0896 & 0.7648\end{array}$

There is a significant interaction between the variables Inside/Outside and TOTEMP; thus, we rejeet the null hypothesis of no interaction and we cannot assume that the parallel model holds. This means that the relationship between the total number of employees in the TAP zone and the number of home-based work trips attracted to that zone is not the same for the two groups, i.e., inside and outside the study area. It says that - because the slopes of the two lines are different - there is a differential effect of total employment on home-based work trip attraction inside versus outside the study area.

Figure C.35 


\title{
AFTER CAPACITY ADDITION; INSIDE vs. OUTSIDE STUDY AREA HOME-BASED WORK TRIP ATTRACTIONS
}

\author{
Interaction Model (Test for Parallelism)
}

\begin{tabular}{ll} 
Summary of Fit & \\
\hline RSquare & 0.992122 \\
RSquare Adj & 0.992057 \\
Root Mean Square Error & 450.5183 \\
Mean of Response & 3832.177 \\
Observations (or Sum Wgts) & 858
\end{tabular}

\section{Effect Test}

Source

Inside/Outside

MEDNNC

TOTEMP

POPDEN

Inside/Outside* MEDINC

Inside/Outside*TOTEMP

Inside/Outside*POPDEN

$\begin{array}{lll}\text { Nparm } & \text { DF } & \text { Sum of Squares } \\ 1 & 1 & 152096.43 \\ 1 & 1 & 1699923.69 \\ 1 & 1 & 1.61969 \mathrm{e} 10 \\ 1 & 1 & 351050.806 \\ 1 & 1 & 668390.286 \\ 1 & 1 & 1814729.46 \\ 1 & 1 & 41752.233\end{array}$

F Ratio

Prob $>\mathbf{F}$

$0.7494 \quad 0.3869$

$8.3754 \quad 0.0039$

$79800.78 \quad 0.0000$

$1.7296 \quad 0.1888$

$3.2931 \quad 0.0699$

$8.9410 \quad 0.0029$

$0.2057 \quad 0.6503$

There is a significant interaction between the variables Inside/Outside and TOTEMP; thus, we reject the null hypothesis of no interaction and we cannot assume that the parallel model holds. This means that the relationship between the total number of employees in the TAP zone and the number of home-based work trips attracted to that zone is not the same for the two groups, i.e., inside and outside the study area. It says that - because the slopes of the two lines are different - there is a differential effeet of total employment on home-based work trip attraction inside versus outside the study area.

Figure C.36 


\section{INSIDE STUDY AREA; BEFORE vs. AFTER CAPACITY ADDITION HOME-BASED NONWORK TRIP ATTRACTIONS}

\section{Interaction Model (Test for Parallelism)}

\section{Summary of Fit}

Rsquare

RSquare Adj

Root Mean Square Error

Mean of Response

Observations (or Sum Wgts)

\section{Effect Test}

Source

Before/After

MEDINC

TOTEMP

POPDEN

Before/After"MEDINC

Before/After TOTEMP

Before/After*POPDEN
0.528375

0.521799

5645.642

7852.371

510

$\begin{array}{lll}\text { Nparm } & \text { DF } & \text { Sum of Squares } \\ 1 & 1 & 72158281.7 \\ 1 & 1 & 331480627 \\ 1 & 1 & 1.55934 \mathrm{e} 10 \\ 1 & 1 & 1415304335 \\ 1 & 1 & 50903500.7 \\ 1 & 1 & 3792708.27 \\ 1 & 1 & 6635809.38\end{array}$

Parallel Model

\section{Summary of Fit}

RSquare

0.526688

0.522939

5638.909

7852.371

510

$\begin{array}{lll}\text { Nparm } & \text { DF } & \text { Sum of Squares } \\ 1 & 1 & 31810793.4 \\ 1 & 1 & 284815818 \\ 1 & 1 & 1.60081 \mathrm{e} 10 \\ 1 & 1 & 1417607367\end{array}$

F Ratio

1.0004

8.9572

503.4422

44.5826

\section{Effect Test}

Source

Before/After

TOTEMP

POPDEN
Prob $>F$

0.1330

0.0013

$<.0001$

$<.0001$

0.2069

0.7303

0.6484

Least Squares Means

\begin{tabular}{llll}
\hline Level & Least Sq Mean & Std Error & Mean \\
After & 8101.707553 & 352.8316755 & 8651.90 \\
Before & 7593.060144 & 359.9458614 & 7020.86
\end{tabular}

Figure C.37 


\section{OUTSIDE STUDY AREA; BEFORE vs. AFTER CAPACITY ADDITION HOME-BASED NONWORK TRIP ATTRACTIONS}

\section{Interaction Model (Test for Parallelism)}

\section{Summary of Fit}

RSquare

RSquare Adj

Root Mean Square Error

Mean of Response

Observations (or Sum Wgts)

\section{Effect Test}

Source

Before/After

MEDINC

TOTEMP

POPDEN

Before/After" MEDINC

Before/After TOTEMP

Before/After *POPDEN
0.373181
0.369122
7205.699
6338.902
1089

$\begin{array}{lll}\text { Nparm } & \text { DF } & \text { Sum of Squares } \\ 1 & 1 & 63191805.1 \\ 1 & 1 & 55763529.9 \\ 1 & 1 & 2.79236 \mathrm{e} 10 \\ 1 & 1 & 1870812437 \\ 1 & 1 & 48256990.1 \\ 1 & 1 & 21342325.2 \\ 1 & 1 & 7608971.48\end{array}$

Parallel Model

\section{Summary of Fit}

RSquare

RSquare Adj

Root Mean Square Error

Mean of Response

Observations (or Sum Wgts)

Efrect Test

Source

Before/After

MEDINC

TOTEMP

POPDEN
0.371969

0.369652

7202.672

6338.902

1089

$\begin{array}{lll}\text { Nparm } & \text { DF } & \text { Sum of Squares } \\ 1 & 1 & 52639518.1 \\ 1 & 1 & 29607943.9 \\ 1 & 1 & 2.863 e+10 \\ 1 & 1 & 1920753584\end{array}$

F Ratio

1.2171

1.0740

537.7978

36.0311

0.9294

0.4110

0.1465
Prob $>F$

0.2702

0.3003

$<.0001$

$<.0001$

0.3352

0.5216

0.7019

\section{Least Squares Means}

\begin{tabular}{ll}
\hline Level & Least Sq Mean \\
After & 6541.016845 \\
Before & 6092.741195
\end{tabular}

F Ratio

Prob $>F$

1.0147

0.3140

0.5707

0.4501

$551.8674<<.0001$

37.0241

$<.0001$

\section{Figure C.38}




\title{
BEFORE CAPACITY ADDITION; INSIDE vs. OUTSIDE STUDY AREA HOME-BASED NONWORK TRIP ATTRACTIONS
}

\author{
Interaction Model (Test for Parallelism)
}

\section{Summary of Fit}

RSquare

0.495676

RSquare Adj

0.49086

Root Mean Square Error

5412.286

Mean of Response

6409.661

Observations (or Sum Wgts)

741

\section{Effect Test}

Source

Inside/Outside

MEDINC

TOTEMP

POPDEN

Inside/Outside"MEDINC

Inside/Outside*TOTEMP

Inside/Outside* POPDEN

$\begin{array}{lll}\text { Nparm } & \text { DF } & \text { Sum of Squares } \\ 1 & 1 & 77206210.1 \\ 1 & 1 & 320640213 \\ 1 & 1 & 1.59859 \mathrm{e} 10 \\ 1 & 1 & 1638756852 \\ 1 & 1 & 68349874.2 \\ 1 & 1 & 206966242 \\ 1 & 1 & 39587822\end{array}$

F Ratio

2.6357

Prob $>F$

10.9460

545.7259

55.9439

2.3333

7.0654

1.3515
0.1049

0.0010

$<.0001$

$<.0001$

0.1271

0.0080

0.2454

There is a significant interaction between the variables Inside/Outside and TOTEMP; thus, we rejeet the null hypothesis of no interaction and we cannot assume that the parallel model holds. This means that the relationship between the total number of employees in the TAP zone and the number of home-based nonwork trips attracted to that zone is not the same for the two groups, i.e., inside and outside the study area. It says that - because the slopes of the two lines are different - there is a differential effect of total employment on home-based nonwork trip attraction inside versus outside the study area.

Figure C.39 


\section{AFTER CAPACITY ADDITION; INSIDE vs. OUTSIDE STUDY AREA HOME-BASED NONWORK TRIP ATTRACTIONS}

\section{Interaction Model (Test for Parallelism)}

\section{Summary of Fit}

RSquare

RSquare Adj

Root Mean Square Error

Mean of Response

Observations (or Sum Wgts)

\section{Effect Test}

Source

Inside/Outside

MEDINC

TOTEMP

POPDEN

Inside/Outside*MEDINC

Inside/Outside*TOTEMP

Inside/Outside*POPDEN
0.378112

0.372991

7719.839

7177.406

858

$\begin{array}{lll}\text { Nparm } & \text { DF } & \text { Sum of Squares } \\ 1 & 1 & 28130225.8 \\ 1 & 1 & 67543706.7 \\ 1 & 1 & 2.29288 e 10 \\ 1 & 1 & 1385615639 \\ 1 & 1 & 59795221.1 \\ 1 & 1 & 115290019 \\ 1 & 1 & 31516961.1\end{array}$

\section{Summary of Fit}

\section{Rsquare}

RSquare Adj

Root Mean Square Error

Mean of Response

Observations (or Sum Wgts)

\section{Efrect Test}

Source

Inside/Outside

MEDINC

TOTEMP

POPDEN

\section{Least Squares Means}

\begin{tabular}{ll}
\hline Level & Least Sq Mean \\
Inside & 8007.987716 \\
Outside & 6816.282933
\end{tabular}

Outside

6816.282933
Parallel Model

0.376006

0.37308

7719.287

7177.406

858

F Ratio

0.4720

1.1334

384.7374

23.2502

1.0033

1.9345

0.5288

Prob $>F$

0.4922

0.2874

$<.0001$

$<.0001$

0.3168

0.1646

0.4673

$\begin{array}{ll}\text { F Ratio } & \text { Prob>F } \\ 4.2929 & 0.0386 \\ 0.4305 & 0.5119 \\ 441.2311 & <.0001 \\ 24.2331 & <.0001\end{array}$

Figure C.40 


\section{INSIDE STUDY AREA; BEFORE vs. AFTER CAPACITY ADDITION NONHOME-BASED TRIP ATTRACTIONS}

\section{Interaction Model (Test for Parallelism)}

\begin{tabular}{ll} 
Summary of Fit & \\
\hline Rsquare & 0.804076 \\
RSquare Adj & 0.801344 \\
Root Mean Square Error & 2039.353 \\
Mean of Response & 4457.859 \\
Observations (or Sum Wgts) & 510
\end{tabular}

\section{Effect Test}

Source

Before/After

MEDINC

TOTEMP

POPDEN

Before/After"MEDINC

Before/After"TOTEMP

Before/After*POPDEN

$\begin{array}{lll}\text { Nparm } & \text { DF } & \text { Sum of Squares } \\ 1 & 1 & 7003233.73 \\ 1 & 1 & 50270137 \\ 1 & 1 & 7500101846 \\ 1 & 1 & 293286699 \\ 1 & 1 & 5433047.5 \\ 1 & 1 & 1429232.18 \\ 1 & 1 & 492.38604\end{array}$

$\begin{array}{ll}\text { F Ratio } & \text { Prob>F } \\ 1.6839 & 0.1950 \\ 12.0872 & 0.0006 \\ 1803.359 & <.0001 \\ 70.5192 & <.0001 \\ 1.3063 & 0.2536 \\ 0.3437 & 0.5580 \\ 0.0001 & 0.9913\end{array}$

\section{Parallel Model}

\section{Summary of Fit}

\begin{tabular}{ll}
\hline RSquare & 0.803164 \\
RSquare Adj & 0.801605 \\
Root Mean Square Error & 2038.016 \\
Mean of Response & 4457.859 \\
Observations (or Sum Wgts) & 510
\end{tabular}

\section{Efrect Test}

Source

Before/After

MEDINC

TOTEMP

POPDEN

$\begin{array}{lll}\text { Nparm } & \text { DF } & \text { Sum of Squares } \\ 1 & 1 & 16202139.3 \\ 1 & 1 & 45561042.3 \\ 1 & 1 & 7801229396 \\ 1 & 1 & 294146314\end{array}$

$\begin{array}{ll}\text { F Ratio } & \text { Prob }>\text { F } \\ \mathbf{3 . 9 0 0 8} & 0.0488 \\ 10.9693 & 0.0010 \\ 1878.226 & <.0001 \\ 70.8187 & <.0001\end{array}$

Least Squares Means

\begin{tabular}{llll}
\hline Level & Least Sq Mean & Std Error & Mean \\
After & 4635.803746 & 127.5205132 & 4970.78 \\
Before & 4272.796104 & 130.0917241 & 3924.42
\end{tabular}

Figure C.41 


\section{OUTSIDE STUDY AREA; BEFORE vS. AFTER CAPACITY ADDITION NONHOME-BASED TRIP ATTRACTIONS}

\section{Interaction Model (Test for Parallelism)}

\section{Summary of Fit}

RSquare

RSquare Adj

Root Mean Square Ertor

Mean of Response

Observations (or Sum Wgts)

\section{Errect Test}

Source

Before/After

MEDINC

TOTEMP

POPDEN

Before/After"MEDINC

Before/After*TOTEMP

Before/After" POPDEN
0.730503

0.728758

2260.336

3565.364

1089

$\begin{array}{lll}\text { Nparm } & \text { DF } & \text { Sum of Squares } \\ 1 & 1 & 1216454.07 \\ 1 & 1 & 50743752.1 \\ 1 & 1 & 1.31421 \text { el } \\ 1 & 1 & 357223609 \\ 1 & 1 & 1836411.83 \\ 1 & 1 & 17917137.5 \\ 1 & 1 & 724146.23\end{array}$

Parallel Model

\section{Summary of Fit}

RSquare

RSquare Adj

Root Mean Square Error

Mean of Response

Observations (or Sum Wgts)

\section{Effect Test}

Source

Before/After

MEDINC

TOTEMP

POPDEN

\section{Least Squares Means}

\begin{tabular}{ll}
\hline Level & Least Sq Mean \\
After & 3678.555328 \\
Before & 3427.504916
\end{tabular}

Std Error

93.1272575

102.9206081
0.729249

0.72825

2262.453

3565.364

1089

$\begin{array}{lll}\text { Nparm } & \text { DF } & \text { Sum of Squares } \\ 1 & 1 & 16509863.5 \\ 1 & 1 & 49404863 \\ 1 & 1 & 1.35728 \mathrm{e} 10 \\ 1 & 1 & 374383420\end{array}$

F Ratio

Prob $>F$

3.2254

9.6519

0.0728

0.0019

$2651.606<.0001$

73.1404
Prob $>F$

0.6257

0.0017

$<.0001$

$<.0001$

0.5489

0.0614

0.7066
Mean

3702.08

3398.85

Figure C.42 


\section{BEFORE CAPACITY ADDITION; INSIDE vs. OUTSIDE STUDY AREA NONHOME-BASED TRIP ATTRACTIONS}

\section{Interaction Model (Test for Parallelism)}

\begin{tabular}{|ll} 
Summary or Fit & \\
\hline Rsquare & 0.756919 \\
RSquare Adj & 0.754598 \\
Root Mean Square Error & 2018.466 \\
Mean of Response & 3576.167 \\
Observations (or Sum Wgts) & 741
\end{tabular}

\section{Efrect Test}

Source

Inside/Outside

MEDINC

TOTEMP

POPDEN

Inside/Outside*MEDINC

Inside/Outside* TOTEMP

Inside/Outside* POPDEN

$\begin{array}{lllll}\text { Nparm } & \text { DF } & \text { Sum of Squares } & \text { F Ratio } & \text { Prob>F } \\ 1 & 1 & 11458156.9 & 2.8124 & 0.0940 \\ 1 & 1 & 59292566.6 & 14.5532 & 0.0001 \\ 1 & 1 & 7307882559 & 1793.696 & <.0001 \\ 1 & 1 & 277453078 & 68.1000 & <.0001 \\ 1 & 1 & 4122445.44 & 1.0118 & 0.3148 \\ 1 & 1 & 87424574.8 & 21.4581 & <.0001 \\ 1 & 1 & 10529668.2 & 2.5845 & 0.1083\end{array}$

There is a significant interaction between the variables Inside/Outside and TOTEMP; thus, we rejeet the aull hypothesis of no interaction and we cannot assume that the parallel model holds. This means that the relationship between the total number of employees in the TAP zone and the number of nonhome-based trips attracted to that zone is not the same for the two groups, i.e., inside and outside the study area. It says that - because the slopes of the two lines are different - there is a differential effect of total employment on nonhome-based trip attraction inside versus outside the study area.

Figure C.43 


\section{AFTER CAPACITY ADDITION; INSIDE vs. OUTSIDE STUDY AREA NONHOME-BASED TRIP ATTRACTIONS}

\section{Interaction Model (Test for Parallelism)}

\section{Summary of Fit}

\begin{tabular}{ll}
\hline RSquare & 0.757089 \\
RSquare Adj & 0.755089 \\
Root Mean Square Error & 2332.472 \\
Mean of Response & 4086.537 \\
Observations (or Sum Wgts) & 858
\end{tabular}

\section{Erreet Test}

\section{Source}

Inside/Outside

MEDINC

TOTEMP

POPDEN

Inside/Outside*MEDINC

Inside/Outside*TOTEMP

Inside/Outside* POPDEN

$\begin{array}{lll}\text { Nparm } & \text { DF } & \text { Sum of Squares } \\ 1 & 1 & 1710633.93 \\ 1 & 1 & 37436778.1 \\ 1 & 1 & 1.13643 \mathrm{e} 10 \\ 1 & 1 & 330858475 \\ 1 & 1 & 544717.197 \\ 1 & 1 & \mathbf{8 4 9 5 9 3 1 5 . 8} \\ 1 & 1 & 7682220.55\end{array}$

$\begin{array}{ll}\text { F Ratio } & \text { Prob>F } \\ 0.3144 & 0.5751 \\ 6.8812 & 0.0089 \\ 2088.868 & <.0001 \\ 60.8148 & <.0001 \\ 0.1001 & 0.7518 \\ 15.6163 & <.0001 \\ 1.4121 & 0.2350\end{array}$

There is a significant interaction between the variables Inside/Outside and TOTEMP; thus, we rejeet the null hypothesis of no interaction and we cannot assume that the parallel model holds. This means that the relationship between the total number of employees in the TAP zone and the number of nonhome-based trips attracted to that zone is not the same for the two groups, i.e., inside and outside the study area. It says that - because the slopes of the two lines are different - there is a differential effect of total employment on nonhome-based trip attraction inside versus outside the study area.

Figure C.44 


\section{INSIDE STUDY AREA; BEFORE vs. AFTER CAPACITY ADDITION OTHER TRIP ATTRACTIONS}

\section{Interaction Model (Test for Parallelism)}

\section{Summary of Fit}

Rsquare

RSquare Adj

Root Mean Square Error

Mean of Response

Observations (or Sum Wgts)

\section{Efrect Test}

Source

Before/After

MEDINC

TOTEMP

POPDEN

Before/After*MEDINC

Before/After TOTEMP

Before/After" POPDEN
0.519539

0.512839

1317.631

2012.827

510

$\begin{array}{lll}\text { Nparm } & \text { DF } & \text { Sum of Squares } \\ 1 & 1 & 5620250 \\ 1 & 1 & 45277058 \\ 1 & 1 & 885353109 \\ 1 & 1 & 34199572 \\ 1 & 1 & 3667464 \\ 1 & 1 & 4250427 \\ 1 & 1 & 78479\end{array}$

\section{Parallel Model}

\section{Summary of Fit}

RSquare

RSquare Adj

Root Mean Square Error

Mean of Response

Observations (or Sum Wgts)

\section{Efrect Test}

Source

Before/After

MEDINC

TOTEMP

POPDEN
0.516226

0.512394

1318.233

2012.827

510
F Ratio

3.2372

26.0790

509.9518

19.6985

2.1124

2.4482

0.0452
Prob $>F$

0.0726

$<.0001$

$<.0001$

$<.0001$

0.1467

0.1183

0.8317

\section{Least Squares Means}

\begin{tabular}{llll}
\hline Level & Least Sq Mean & Std Error & Mean \\
After & 2049.303099 & 82.48303416 & 2190.30 \\
Before & 1974.892777 & 84.14614913 & 1828.26
\end{tabular}

$\begin{array}{ll}\text { F Ratio } & \text { Prob>F } \\ 0.3918 & 0.5317 \\ 23.7520 & <.0001 \\ 513.3527 & <.0001 \\ 19.8622 & <.0001\end{array}$

Figure C.45 


\section{OUTSIDE STUDY AREA; BEFORE vs. AFTER CAPACITY ADDITION OTHER TRIP ATTRACTIONS}

\section{Interaction Model (Test for Parallelism)}

\section{Summary of Fit}

Rsquare

RSquare Adj

Root Mean Square Error

Mean of Response

Observations (or Sum Wgts)

\section{Effect Test}

Source

Before/After

MEDINC

TOTEMP

POPDEN

Before/After"MEDINC

Before/After *TOTEMP

Before/After*POPDEN
0.365915

0.361809

1839.196

1602.213

1089

$\begin{array}{lll}\text { Nparm } & \text { DF } & \text { Sum of Squares } \\ 1 & 1 & 3938462.04 \\ 1 & 1 & 6042351.95 \\ 1 & 1 & 1843831959 \\ 1 & 1 & 62239553.2 \\ 1 & 1 & 3226507.95 \\ 1 & 1 & 718139.677 \\ 1 & 1 & 591501.544\end{array}$

F Ratio

Prob $>F$

1.1643

0.2808

1.7863

0.1817

545.0866

18.3997

$<.0001$

0.9538

$<.0001$

0.2123

0.3290

0.1749

0.6451

0.6759

\section{Parallel Model}

\section{Summary of Fit}

Rsquare

0.364834

RSquare Adj

Root Mean Square Error

0.36249

1838.213

1602.213

Mean of Response

1089

\section{Efrect Test}

Source

Before/After

MEDINC

TOTEMP

POPDEN

$\begin{array}{lll}\text { Nparm } & \text { DF } & \text { Sum of Squares } \\ 1 & 1 & 1886718.43 \\ 1 & 1 & 3878895.26 \\ 1 & 1 & 1886425848 \\ 1 & 1 & 63934747.2\end{array}$

F Ratio

Prob $>F$

$0.5584 \quad 0.4551$

$\begin{array}{ll}1.1479 & 0.2842\end{array}$

$558.2746<<.0001$

$18.9210<.0001$

\section{Least Squares Means}

\begin{tabular}{llll}
\hline Level & Least Sq Mean & Std Error & Mean \\
After & 1640.477567 & 75.66467976 & 1645.51 \\
Before & 1555.609806 & 83.62164909 & 1549.48
\end{tabular}

Figure C.46 


\section{BEFORE CAPACITY ADDITION; INSIDE vs. OUTSIDE STUDY AREA OTHER TRIP ATTRACTIONS}

\section{Interaction Model (Test for Parallelism)}

\begin{tabular}{ll} 
Summary of Fit & \\
\hline Rsquare & 0.519294 \\
RSquare Adj & 0.514704 \\
Root Mean Square Error & 1288.277 \\
Mean of Response & 1643.533 \\
Observations (or Sum Wgts) & 741
\end{tabular}

\section{Efrect Test}

Source

Inside/Outside

MEDINC

TOTEMP

POPDEN

Inside/Outside*MEDINC

Inside/Outside*TOTEMP

Inside/Outside*POPDEN

$\begin{array}{lllll}\text { Nparm } & \text { DF } & \text { Sum of Squares } & \text { F Ratio } & \text { Prob }>\text { F } \\ 1 & 1 & 4969105.17 & 2.9941 & 0.0840 \\ 1 & 1 & 34649902.5 & 20.8778 & <.0001 \\ 1 & 1 & 1035420935 & 623.8767 & <.0001 \\ 1 & 1 & 45999552 & 27.7163 & <.0001 \\ 1 & 1 & 9250419.03 & 5.5737 & 0.0185 \\ 1 & 1 & 9928768.57 & 5.9824 & 0.0147 \\ 1 & 1 & 121500.44 & 0.0732 & 0.7868\end{array}$

There is a significant interaction between the variables Inside/Outside and TOTEMP as well as MEDINC; thus, we rejeet the null hypothesis of no interaction and we cannot assume that the parallel model holds. This means that the relationships between the total number of employees and between the median household income in the TAP zone and the number of "other" trips attracted to that zone are not the same for the two groups, i.e., inside and outside the study area. It says that because the slopes of the two lines are different - there is a differential effect of total employment as well as of median income on "other" trip attraction inside versus outside the study area. 


\title{
AFTER CAPACITY ADDITION; INSIDE vs. OUTSIDE STUDY AREA OTHER TRIP ATTRACTIONS
}

\author{
Interaction Model (Test for Parallelism)
}

\section{Summary of Fit}

Rsquare

RSquare Adj

Root Mean Square Error

Mean of Response

Observations (or Sum Wgts)

\section{Efrect Test}

Source

Inside/Outside

MEDINC

TOTEMP

POPDEN

Inside/Outside*MEDNC

Inside/Outside* TOTEMP

Inside/Outside* POPDEN
0.35034

0.34499

1973.845

1810.599

858

$\begin{array}{lll}\text { Nparm } & \text { DF } & \text { Sum of Squares } \\ 1 & 1 & 1082282.65 \\ 1 & 1 & 14260101.8 \\ 1 & 1 & 1310618351 \\ 1 & 1 & 38217440.8 \\ 1 & 1 & 9978536.41 \\ 1 & 1 & 108568.461 \\ 1 & 1 & 389480.961\end{array}$

\section{Parallel Model}

\section{Summary of Fit}

RSquare

RSquare Adj

Root Mean Square Error

Mean of Response

Observations (or Sum Wgts)

0.34824

0.345183

1973.554

1810.599

858

\section{Efrect Test}

Source

Inside/Outside

MEDINC

TOTEMP

POPDEN

\section{Least Squares Means}

\begin{tabular}{llll}
\hline Level & Least Sq Mean & Std Error & Mean \\
Inside & 2040.025889 & 122.6527732 & 2190.30 \\
Outside & 1710.848276 & 80.7786666 & 1645.51
\end{tabular}

$\begin{array}{ll}\text { F Ratio } & \text { Prob>F } \\ 0.2778 & 0.5983 \\ 3.6601 & 0.0561 \\ 336.3956 & <.0001 \\ 9.8092 & 0.0018 \\ 2.5612 & 0.1099 \\ 0.0279 & 0.8675 \\ 0.1000 & 0.7519\end{array}$

F Ratio Prob $>$ F

$5.0110 \quad 0.0254$

$1.8233 \quad 0.1773$

$407.8531<.0001$

$10.6928 \quad 0.0011$

\section{Figure C.48}

